\title{
Lifestyle and Embodied Energy: a Proposed Hybrid Analysis Method for Housing
}

\author{
By
}

Adele Louise Leah

A thesis submitted to the Victoria University of Wellington in fulfilment of the requirements for the degree of Doctor of Philosophy in Architecture

Victoria University of Wellington

2015 
Page $\mathbf{2}$ of $\mathbf{3 3 2}$ 


\begin{abstract}
This thesis set out to form a bridge between the disciplines of architectural history, social and women's history, building technology and environmental assessment, by investigating changes to existing houses over time and linking these with changes in lifestyle and technology. The primary aim of this research is to establish a Hybrid Analysis Method for Housing (HAMH) as a vehicle for the investigation of the relationship between the environmental impact of the building materials in a house and the lifestyle of its inhabitants, both immediately after construction and in the present day.
\end{abstract}

The method is developed using existing research techniques through the study of typical, working class, family houses in New Zealand (Tarikaka Settlement, Wellington) before being applied to a comparable sample of houses in England (Silver End, Witham). Although different in terms of layout, style, building materials and methods of construction, the two groups of case study houses have commonality in the people for whom they were originally designed, the period in which they were constructed and in their conception and planning.

The HAMH incorporates both qualitative and quantitative analysis. The former relates to oral interviews with people who lived around the time the case study houses were first constructed, complemented by oral interviews covering the same questions with the present inhabitants of the case study houses. The quantitative part of the research is an investigation of the embodied energy of building materials invested in the case study houses since their construction.

The research findings highlight a change in the purpose and function of housing which has taken place since the case study houses were constructed, when the house was very much a place of production and the adjacent public spaces were places for social interaction. Present day houses appear to be for eating and sleeping, relaxing, and engaging with technology, with the adjacent public spaces being dominated by the car. 
The results of the comparative study show that although the Tarikaka Settlement case study houses as constructed had much lower levels of embodied energy than the Silver End houses, the alterations and improvements made to them, combined with the necessary maintenance means that the cumulative embodied energy of these houses in 2012 is higher than the Silver End houses. The analysis of embodied energy highlights the importance of occupancy levels in the environmental impact of houses.

This thesis suggests that the real value of the HAMH is its use as a vehicle for comparison and as such, it needs to be applied to other groups of houses, constructed in different time periods and in other locations. This should enable meaningful comparison between houses designed differently, using varied methods of construction and materials that are inhabited by different people with differing lifestyles, with the overall aim being to see how lifestyle and the environmental impact of building materials relate to each other. This thesis argues that unless the impact of household behaviour is understood, many efforts to produce more sustainable housing may be less effective than envisaged. 


\section{Acknowledgements}

I would like to thank my supervisor, Professor Brenda Vale, for her unwavering support and encouragement throughout the duration of my study. I have learned so much from her logical way of thinking and attention to detail, whilst her passion and professionalism continue to inspire me.

I would also like to thank my supervisor, Nigel Isaacs, who has been a constant source of encouragement. I have particularly appreciated his technical advice and assistance with data handling. I could not imagine a more positive supervisor.

My husband, Ben, has been a source of strength and I am grateful for his continuous love and support. I would also like to thank my daughters Chara and Danielle for being a wonderful distraction, their laughter and smiles have brought me much joy through the tough times.

I would like to acknowledge the financial assistance received from my University of Victoria Doctoral Scholarship and I am grateful for the support of many members of the Faculty of Architecture and Design, in particular Kevin Cook and Eric Camplin for their technical help and advice.

Finally, and most importantly, I would like to thank the many people who have volunteered to participate in this research, including Christine Elston, Judith Fage and Catherine Leah, who gave generously of their time to carry out interviews in England on my behalf. I would like to thank the 29 elderly interviewees for allowing me to record their memories which have provided a wonderful and rich source of data as well as personal challenge and inspiration. I am particularly grateful to the 23 people who welcomed me into their homes, allowing me to survey and measure their houses and share details of their lifestyle. This research would not have been possible had they not been willing to participate and for their kindness and openness I am truly thankful. 
Page 6 of $\mathbf{3 3 2}$ 


\section{Table of Contents}

$\begin{array}{ll}\text { Abstract } & 3\end{array}$

$\begin{array}{ll}\text { Acknowledgements } & 5\end{array}$

$\begin{array}{ll}\text { Table of Contents } & 7\end{array}$

$\begin{array}{ll}\text { List of Figures } & 15\end{array}$

Chapter 1 - A Proposed Hybrid Analysis Method for Housing (HAMH) 25

$\begin{array}{lll}1.1 & \text { Introduction } & 25\end{array}$

$\begin{array}{ll}1.2 & \text { The Gap in Knowledge } \\ \end{array}$

1.2.1 The History of Housing 27

$\begin{array}{lll}\text { 1.2.2 Inhabiting Houses } & 27\end{array}$

$\begin{array}{ll}\text { 1.2.3 The Design of Houses } & 28\end{array}$

$\begin{array}{lll}\text { 1.2.4 Operating Energy } & 28\end{array}$

$\begin{array}{ll}\text { 1.2.5 Embodied Energy } & 29\end{array}$

1.2.6 Life Cycle Analysis (LCA) and Ecological Footprint (EF) 30

$\begin{array}{lll}\text { 1.2.7 Evaluating Housing Performance } & 31\end{array}$

$\begin{array}{lll}\text { 1.2.8 Summary } & 33\end{array}$

$\begin{array}{lll}1.3 & \text { Research Aims } & 33\end{array}$

$\begin{array}{lll}1.4 & \text { Research Phases } & 34\end{array}$

$\begin{array}{lll}1.5 & \text { Research Scope and Definitions } & 35\end{array}$

1.6 Lifestyle and Embodied Energy: Research Questions 36 
$\begin{array}{lll}\text { 1.7.1 New Zealand } & 37\end{array}$

$\begin{array}{lll}\text { 1.7.2 England } 38 & 38\end{array}$

1.7.3 Case Study Houses in New Zealand 39

1.7.4 Case Study Houses in England $\quad 40$

1.7.5 Case Study Houses Compared 41

$\begin{array}{lll}1.8 & \text { Summary } & 42\end{array}$

Chapter 2 - Research Methods $\quad 43$

$\begin{array}{lll}2.1 & \text { Introduction } & 43\end{array}$

2.2 Qualitative Data Collection 43

$\begin{array}{lll}\text { 2.2.1 Recorded Oral Interviews } & 43\end{array}$

2.2.2 Recorded Oral Interview Guides 44

$\begin{array}{lll}2.2 .3 & \text { Interview Analysis }\end{array}$

2.2.4 Recruitment of Volunteers 49

2.3 Quantitative Data Collection 54

2.3.1 Embodied Energy Analysis 54

2.4 Comparative Data Analysis $\quad 55$

$\begin{array}{lll}2.4 .1 & \text { Time Use } & 55\end{array}$

2.4.2 Space Use 55

$\begin{array}{lll}2.4 .3 & \text { Energy Use } & 56\end{array}$ 
3.2.1 House

3.2.2 Outdoor Space

3.2.3 Sense of Community

3.3.1 House

3.3.2 Outdoor Space 
4.2.1 House

$\begin{array}{lll}\text { 4.2.2 Outdoor Space } & 136\end{array}$

4.2.3 Sense of Community 143

$\begin{array}{lll}4.3 & \text { Space Use } & 144\end{array}$

$\begin{array}{lll}\text { 4.3.1 House } & 144\end{array}$

$\begin{array}{lll}\text { 4.3.2 } & \text { Outdoor Space } & 161\end{array}$

$\begin{array}{lll}4.4 & \text { Energy Use } & 166\end{array}$

$\begin{array}{lll}\text { 4.4.1 House } & 166\end{array}$

$\begin{array}{lll}\text { 4.4.2 Outdoor Space } & 176\end{array}$

$\begin{array}{lll}\text { 4.4.3 Embodied Energy Analysis } & 177\end{array}$

$\begin{array}{lll}4.5 & \text { Summary } & 189\end{array}$

Chapter 5 - Comparative Study: The Original Houses 193

5.1 Time Use 193

$\begin{array}{lll}\text { 5.1.1 House } & 193\end{array}$

$\begin{array}{lll}\text { 5.1.2 Outdoor Space } & 197\end{array}$

$\begin{array}{lll}5.2 & \text { Space Use } & 200\end{array}$

5.2.1 House 200

$\begin{array}{lll}\text { 5.2.2 Outdoor Space } & 203\end{array}$

$\begin{array}{lll} & \text { Energy Use } & 205\end{array}$

$\begin{array}{lll}\text { 5.3.1 House and Outdoor Space } & 205\end{array}$ 
7.4 Research Aim Evaluation

7.5 Lifestyle and Embodied Energy

7.6 Limitations of the $\mathrm{HAMH}$

273

7.6.1 Improving the HAMH

7.7 Further Research

7.7.1 Household Energy Use

7.7.2 Longitudinal Comparisons

Appendix A: Recorded Oral Interview Guide for use with Present Day Inhabitants of the Case Study Houses

Appendix B: Recorded Oral Interview Guide for use with 1930s and 1940s Housing and Lifestyle Interviewees

Appendix D: Notes from a Recorded Oral Interview with a Present Day Inhabitant of a Case Study House

Appendix E: Notes from a Recorded Oral Interview with a 1930s and 1940s Housing and Lifestyle Interviewee 299

Appendix F: Original Floor Plan of a Tarikaka Settlement House 307

Appendix G: Present Day Floor Plan of a Tarikaka Settlement House 
Appendix J: Results of the Embodied Energy Analysis for the Tarikaka Settlement House 
Page 14 of $\mathbf{3 3 2}$ 


\section{List of Figures}

Figure 1: Tarikaka Street, 2013

Figure 2: Silver Street, 2013

Figure 3: Topics for discussion in the recorded oral interview

Figure 4: Notes from a recorded oral interview

Figure 5: Section of a completed spreadsheet

Figure 6: Example of bar charts containing data from the completed spreadsheet 48

Figure 7: Part of a schedule of materials and quantities 57

Figure 8: Tarikaka Settlement, c.1980 (Unknown, 1986)..... 62

Figure 9: Tarikaka Settlement houses, 2013 63

Figure 10: Plan of Housing Scheme for Railway Department, Ngaio, A.B. 1089, c.1927 (Architectural Branch, 1927) 64

Figure 11: Recreation Reserve, 2013 66

Figure 12: Planting at junction of Tarikaka Street and Bombay Street, 2012 69

Figure 13: Persons per household engaged in full-time paid employment (NZ TS) 71

Figure 14: Person responsible for household work (NZ TS) 71

Figure 15: Person responsible for food preparation (NZ TS) 74

Figure 16: Frequency of eating out (NZ TS) 74

Figure 17: Person responsible for garden maintenance (NZ TS) 78

Figure 18: Percentage of consumed vegetables grown at home (NZ TS) 78

Figure 19: Number of different types of fruit grown at home (NZ TS) 78

Figure 20: Percentage of interviewees keeping chickens at home (NZ TS) 79 
Figure 21: Number of interviewees composting household waste (NZ TS) .....

Figure 22: Original Floor Plan, Standard House, Plan A.B.1123, Factory Cut.....

Figure 23: Typical Front Elevation, Standard House, Plan A.B.1123, Factory Cut

Figure 24: Original floor plan of the TS house redrawn to include the wash house and toilet 84

Figure 25: Number of persons per dwelling (NZ TS)

Figure 26: Number of adults per household (NZ TS)

Figure 27: Home ownership (NZ TS)

Figure 28: Number of persons per dwelling from 1925 to 2012 86

Figure 29: Current floor plan of a TS case study house 87

Figure 30: Alterations undertaken by the TS interviewees 94

Figure 31: Number of cars per household (NZ TS) 96

Figure 32: Use of public transportation (NZ TS) 96

Figure 33: Number of households where bicycles are used regularly (NZ TS)

Figure 34: Households with a mains water supply (NZ TS)

Figure 35: Households with a mains electricity supply (NZ TS)

Figure 36: Households with a mains gas supply (NZ TS)

Figure 37: Original floor plan of a TS house showing mechanical and electrical layout

Figure 38: Present day floor plan of a TS house showing mechanical and electrical layout. 99

Figure 39: Primary method of space heating (NZ TS). 100

Figure 40: Fuel type in the primary method of space heating (NZ TS). 100

Figure 41: Primary method of water heating (NZ TS) 103

Figure 42: Fuel used in the primary method of water heating (NZ TS) 103 
Figure 44: Assumptions behind the TS EEA

Figure 45: Embodied Energy (GJ) in the Building Elements of the TS House in 1928

Figure 46: Embodied Energy (GJ) in the Building Elements of the TS House in 1928, expressed as \%.... 109

Figure 47: Embodied Energy (GJ) in the Building Materials of the TS House in 1928, expressed as \% ... 109

Figure 48: Embodied Energy (GJ) in the Building Elements of the TS House in 2012

Figure 49: Embodied Energy (GJ) in the Building Elements of the TS House in 2012, expressed as \%.... 112

Figure 50: Embodied Energy (GJ) in the Building Materials of the TS House in 2012, expressed as \% ... 112

Figure 51: Embodied Energy (GJ) in the Building Elements of the TS House in 1928 and 2012 113

Figure 52: Embodied Energy (GJ) in the Building Elements of the TS House in 1928 and 2012 expressed as $\%$ of the total

Figure 53: Increase in the Embodied Energy (GJ) of the TS House for each of the stages

Figure 54: Increase in Embodied Energy (GJ) of the TS House from 1928 to 2012

Figure 55: Total Embodied Energy (GJ) of the 1928, 1960 and 2012 TS Snap Shot Houses

Figure 56: Embodied Energy (GJ/m²) of the 1928, 1960 and 2012 TS Snap Shot Houses

Figure 57: Embodied Energy (GJ/person) of the 1928, 1960 and 2012 TS Snap Shot Houses.....

Figure 58: Number of adults per household (ENG SE).

Figure 59: Persons per household engaged in full-time paid employment (ENG SE).....

Figure 60: Person responsible for household work (ENG SE)

Figure 61: Person responsible for food preparation (ENG SE)

Figure 62: Frequency of eating out (ENG SE)

Figure 63: Person responsible for garden maintenance (ENG SE)..... 
Figure 64: Percentage of consumed vegetables grown at home (ENG SE)

Figure 65: Number of different types of fruit grown at home (ENG SE).....

Figure 66: Percentage of interviewees keeping chickens at home (ENG SE)

Figure 67: Number of interviewees composting household waste (ENG SE)

Figure 68: Number of interviewees burning household waste (ENG SE).....

Figure 69: Balance between work, family and recreation time (ENG SE) 141

Figure 70: Original Ground Floor Plan of a Tait House 145

Figure 71: Original First Floor Plan of a Tait house 145

Figure 72: Original Front Elevation of a Tait house 146

Figure 73: Numbers 17 and 19 Silver Street, 2013. 146

Figure 74: Original Ground Floor Plan of a Stuart House 147

Figure 75: Original First Floor Plan of a Stuart house

Figure 76: Original Front Elevation of a Stuart house

Figure 77: Numbers 54 and 56 Silver Street, 2013

Figure 78: Original Ground Floor Plan of a Miller House

Figure 79: Original First Floor Plan of a Miller house..... 150

Figure 80: Original Front Elevation of a Miller house 150

Figure 81: Numbers 22/24/26/28 Broadway, 2013 151

Figure 82: Number of persons per dwelling (ENG SE) 153

Figure 83: Number of adults per household (ENG SE) 153

Figure 84: Home ownership (ENG SE) 153

Figure 85: Number of persons per dwelling from 1911 to 2012 153 
Figure 87: Reasons for choosing to buy or rent the house (all answers) (ENG SE)

Figure 88: Current floor plans of an SE Stuart case study house

Figure 89: Alterations undertaken by the SE interviewees

Figure 90: Alterations planned by the SE interviewees

Figure 91: Number of cars per household (ENG SE)

Figure 92: Use of public transportation (ENG SE)

Figure 93: Number of households where bicycles are used regularly (ENG SE) 165

Figure 94: Households with a mains water supply (ENG SE)

Figure 95: Households with a mains electricity supply (ENG SE)

Figure 96: Households with a mains gas supply (ENG SE)

Figure 97: Original floor plans of a SE Stuart house showing electrical layout.

Figure 98: Present day floor plans of a SE Stuart house showing electrical layout

Figure 99: Primary method of space heating (ENG SE)

Figure 100: Fuel type in the primary method of space heating (ENG SE)

Figure 101: Primary method of water heating (ENG SE)

Figure 102: Fuel used in the primary method of water heating (ENG SE) 175

Figure 103: The Three Stages of the SE EEA

Figure 104: Assumptions behind the SE EEA

Figure 105: Embodied Energy (GJ) in the Building Elements of the SE House in 1928

Figure 106: Embodied Energy (GJ) in the Building Elements of the SE House in 1928, expressed as \%.. 182

Figure 107: Embodied Energy (GJ) in the Building Materials of the SE House in 1928, expressed as \% . 182 
Figure 108: Embodied Energy (GJ) in the Building Elements of the SE House in 2012

Figure 109: Embodied Energy (GJ) in the Building Elements of the SE House in 2012, expressed as \% .. 185

Figure 110: Embodied Energy (GJ) in the Building Materials of the SE House in 2012, expressed as \%.. 185

Figure 111: Embodied Energy (GJ) in the Building Elements of the SE House in 1928 and 2012 186

Figure 112: Increase in the Embodied Energy (GJ) of the SE House for each of the stages 186

Figure 113: Increase in Embodied Energy (GJ) of the SE House from 1928 to 2012 187

Figure 114: Total Embodied Energy (GJ) of the 1928, 1969 and 2012 SE Snap Shot Houses 188

Figure 115: Embodied Energy (GJ/m²) of the 1928, 1969 and 2012 SE Snap Shot Houses 189

Figure 116: Embodied Energy (GJ/person) of the 1928, 1969 and 2012 SE Snap Shot Houses 189

Figure 117: Persons per household engaged in full-time paid employment (NZ ENG) 194

Figure 118: Number of adults per household (NZ ENG) 194

Figure 119: Person responsible for household work (NZ ENG) 194

Figure 120: Person responsible for food preparation (NZ ENG) 196

Figure 121: Frequency of eating out (NZ ENG) 196

Figure 122: Person responsible for garden maintenance (NZ ENG)

Figure 123: Percentage of consumed vegetables grown at home (NZ ENG)

Figure 124: Number of different types of fruit grown at home (NZ ENG) 197

Figure 125: Number of interviewees keeping chickens at home (NZ ENG) 198

Figure 126: Number of interviewees composting household waste (NZ ENG) 198

Figure 127: Number of interviewees burning household waste (NZ ENG) 198

Figure 128: Number of persons per dwelling (NZ ENG) 200

Figure 129: Number of adults per household (NZ ENG) 200 
Figure 130: Home ownership (NZ ENG)

Figure 131: Number of children per dwelling (NZ ENG)

Figure 132: Number of cars per household (NZ ENG)

Figure 133: Use of public transportation (NZ ENG)

Figure 134: Number of households where bicycles were used regularly (NZ ENG) 205

Figure 135: Households with a mains water supply (NZ ENG) 206

Figure 136: Households with a mains electricity supply (NZ ENG) 206

Figure 137: Households with a mains gas supply (NZ ENG)..... 206

Figure 138: Primary method of space heating (NZ ENG) 207

Figure 139: Fuel type in the primary method of space heating (NZ ENG) 207

Figure 140: Primary method of water heating (NZ ENG) 208

Figure 141: Fuel used in the primary method of water heating (NZ ENG) 208

Figure 142: Mode of transportation to and from work (NZ ENG) 208

Figure 143: Embodied Energy (GJ) in the Building Elements of the TS House and the SE House in 1928210

Figure 144: Embodied Energy (GJ) in the Building Elements of the TS House and the SE House in 1928 expressed as \%

Figure 145: Embodied Energy (GJ) in the Building Materials of the TS House and SE House in 1928 expressed as \%

Figure 146: Embodied Energy (GJ) of the 1928 TS House and SE House plus 50 Years Maintenance..... 214

Figure 147: Embodied Energy $\left(\mathrm{GJ} / \mathrm{m}^{2}\right.$ ) of the 1928 TS House and SE House plus 50 Years Maintenance215

Figure 148: Embodied Energy (GJ/person) of the 1928 TS House and SE House plus 50 Years Maintenance

Figure 149: Age of interviewees (TS SE) 
Figure 150: Number of persons per household (TS SE)

Figure 151: Number of years at this address (TS SE)

Figure 152: Persons per household engaged in full-time paid employment (TS SE)

Figure 153: Home ownership (TS SE)

Figure 154: Reasons for choosing to buy or rent the house (first answer) (TS SE)

Figure 155: Reasons for choosing to buy or rent the house (all answers) (TS SE)

Figure 156: Birth zone of interviewees (TS SE)

Figure 157: Number of adults per household (TS SE)

Figure 158: Balance between work, family and recreation time (TS SE) 220

Figure 159: Person responsible for household work (TS SE).

Figure 160: Person responsible for food preparation (TS SE)

Figure 161: Frequency of eating out (TS SE)

Figure 162: Households with a dishwasher (TS SE).

Figure 163: Households with a tumble dryer (TS SE) ......

Figure 164: Frequency of use of a tumble dryer (TS SE)

Figure 165: Percentage of consumed vegetables grown at home (TS SE)

Figure 166: Number of different types of fruit grown at home (TS SE) 225

Figure 167: Person responsible for garden maintenance (TS SE) 225

Figure 168: Percentage of interviewees keeping chickens at home (TS SE) 225

Figure 169: Number of interviewees composting household waste (TS SE) 225

Figure 170: Households with an electric lawnmower (TS SE) 225

Figure 171: Number of persons per household (TS SE) 
Figure 173: Use of public transportation (TS SE)

Figure 174: Number of households where bicycles are used regularly (TS SE)

Figure 175: Fuel used in the primary method of space heating (TS SE)

Figure 176: Primary method of space heating (TS SE)

Figure 177: Fuel used in the primary method of water heating (TS SE)

Figure 178: Primary method of water heating (TS SE)

Figure 179: Households with timer controlled space heating (TS SE)

Figure 180: Households with temperature controlled space heating (TS SE)

Figure 181: Household fuel cost (GBP per annum) (TS SE)

Figure 182: Fuel type for oven (TS SE) 235

Figure 183: Fuel type for hob (TS SE). 235

Figure 184: Alterations undertaken by the TS and SE interviewees

Figure 185: Increase in Embodied Energy (GJ) of the TS House from 1928 to 2012

Figure 186: Increase in Embodied Energy (GJ) of the SE House from 1928 to 2012 240

Figure 187: Embodied Energy (GJ) of the Building Materials invested in the TS House and SE House from construction in 1928 to 2012

Figure 188: Cumulative Embodied Energy (GJ) of the TS House and SE House in 2012

Figure 189: Embodied Energy (GJ) in the Building Elements of the TS House and the SE House in 2012244

Figure 190: Embodied Energy (GJ) in the Building Elements of the TS House and the SE House in 2012 expressed as \%

Figure 191: Embodied Energy (GJ) in the Building Materials of the TS House and the SE House in 2012 expressed as \% 
Figure 192: Embodied Energy (GJ) of the 1928, 1960/1969 and 2012 TS and SE Snap Shot Houses highlighting the 50 Years Maintenance

Figure 193: Embodied Energy (GJ) of the 1928, 1960/1969 and 2012 Snap Shot Houses 248

Figure 194: Embodied Energy (GJ/m²) of the 1928, 1960/1969 and 2012 Snap Shot Houses 249

Figure 195: Embodied Energy (GJ/person) of the 1928, 1960/1969 and 2012 Snap Shot Houses 250

Figure 196: Best thing about the house and place where you live (first answer) (TS and SE) 251

Figure 197: Best thing about the house and place where you live (all answers) (TS SE) 251

Figure 198: Worst thing about the house and place where you live (first answer) (TS and SE) ..... 253

Figure 199: Worst thing about the house and place where you live (all answers) (TS SE) 253

Figure 200: Historic fuels used for UK electricity (http://euanmearns.com/uk-electricity-generationstatistics-1920-2012/). 266 


\section{Chapter 1 - A Proposed Hybrid Analysis Method for Housing (HAMH)}

\subsection{Introduction}

In New Zealand (NZ) 45\% of the current housing stock was constructed before 1960 (Page \& Ryan, 2010). Over half (57\%) of English dwellings were constructed before 1964 and one in five (21\%) were built before 1919 (Department of Communities and Local Government, 2010). Three quarters of these older English dwellings have been subject to at least some major alterations since they were built and $43 \%$ have had extensions.

Today, many people in these two countries are living in housing designed and constructed over 50 years ago. In this period there has been significant social and technological change which has affected the way that people live in and use these houses, yet there appears to be a lack of research which seeks to identify and analyse patterns of house alteration and thereby establish and quantify the link between the physical shell of a house as constructed and the lifestyle of its inhabitants, both past and present.

Embodied energy is the total amount of energy used to produce a final product from raw materials (Cleveland \& Morris, 2009). The New Zealand Building Code and the UK Building Regulations have traditionally focussed on operational energy, with no current legislation for embodied energy (Department of Building and Housing (DBH), 2011; HM Government, 2010). In 2007, the NZ Minister for Building and Construction announced the release of a discussion document on the performance requirements of the NZ Building Code which included a proposal to require the embodied energy of building components to be taken into account when designing buildings (Ministry of Business Innovation and Employment (MBIE), 2007), although this proposal was not adopted. In recent years, governments in both New Zealand and England have introduced grants to help the public make their houses more 'sustainable' (EECA, 2014) and in line with this, guides aiming to help people increase the energy efficiency of their houses are becoming more commonplace in both New Zealand (EECA, 2009) and England (Energy 
Saving Trust, 2011). Research in England suggests that the tightening of the Building Regulation requirements for operating energy may have the unintended consequence of causing an increase in embodied energy (Institution of Civil Engineers (ICE), 2014).

Because of these publications, householders appear to be aware of the need to reduce operating energy through actions such as the installation of insulation, or improving and/or replacing existing forms of heating. The subject of embodied energy, however, including material selection, maintenance, and the embodied energy implications of house alterations appears to be of far less importance and significance. However, a recent study found that the initial energy embodied in a low-energy one family Swedish home accounted for more than $40 \%$ of the whole-life energy requirements over a 50 year life span (Thormark, 2006), thus showing the embodied energy of building materials in a house is important and should be considered.

The subject of 'sustainable' housing is extremely popular. Books which contain case studies of individually designed 'sustainable' or 'green' homes continue to be published (Bradbury \& Powers, 2011; Koones, 2014; Uffelen, 2012). Contemporary and professional magazines and journals in both New Zealand and England illustrate similar content. 'Greener' living is a term also becoming increasingly popular and the subject of recent publications (Crocombe, 2007). Alongside this, 'eco-refurbishment' or 'greening your home' is also an area of growing interest (Smith, 2004). However, recent research suggests that the behaviour of users has the greatest impact on overall energy use whether the house is conventional (Gram-Hanssen, 2010) or zero-carbon (Stevenson \& Rijal, 2010) and whilst a great deal has been written on the subject of the 'eco' house, 'green' house, 'natural' house and 'sustainable' house (Chiras, 2000; Mobbs, 2010; Roaf, Fuentes, \& Thomas, 2001; Stang \& Hawthorne, 2005), there is a lack of published information on establishing and quantifying the direct link between the physical shell of a house as constructed and the lifestyle of its inhabitants, both past and present. 


\subsection{The Gap in Knowledge}

\subsubsection{The History of Housing}

The history of housing has been the focus of considerable research, and there are many pictorial and written histories of the development of housing in both New Zealand (G. Ferguson, 1994; Humphris \& Mew, 2009; Salmond, 1986) and England (Jackson, 1973; P. Lewis, 2011; Muthesius, 1982). These types of publication typically contain historical information presented in chronological or typological order, while the lifestyle of the household is not usually explored. The latter appears to be a separate subject of research in New Zealand (B. Brookes, 2000; Schrader, 2005) and in England (Burnett, 1980; Jeremiah, 2000; Ravetz \& Turkington, 1995). However, publications in this field often do not explore the way that houses have been adapted over time, nor do they investigate the way these same houses are being used today. A recent study which examined the original designs of late $19^{\text {th }}$ century villas in Wellington, New Zealand also involved recording alterations which had taken place between 1890 and 2010, but did not record changes to the occupants' lifestyle or changes in their environmental impact (Mackay, 2011).

\subsubsection{Inhabiting Houses}

Research into the experiences of women in the home is another area of interest (J. Lewis, 1986). Researchers have published relevant information in this area both in New Zealand (May, 1992; Toynbee, 1995) and England (Beddoe, 1989; Pennington \& Westover, 1989; Roberts, 1984). Mrs. Beeton's book of household management gives an insight into a woman's role in the home in mid nineteenth century England (Humble, 2000). Labour saving in the home, electricity and the history and design of household domestic appliances is also a subject which has received attention (Forty, 1986), and in New Zealand, Jean Marie O'Donnell has carried out research on the impact of new technology in the lives of women (B Brookes, Macdonald, \& Tennant, 1992).

The way in which people live in houses is a subject which has received less attention. A report published by the Advertising Service Guild in 1943 summarised attitudes 
towards housing during wartime in England (Mass Observation, 1943). One 1970s study examined attitudes towards housing from two different cultures (Thorne \& Canter, 1970). During the late 1990s the interaction between lifestyles and dwellings and the meaning of home in NZ was explored (Perkins \& Thorns, 1999). This research examined the changing nature of the home and the activities taking place within it, but did not seek to track or measure the implications of these changes and relate them to the design of the house.

\subsubsection{The Design of Houses}

The design of houses has been the focus of research in New Zealand and England (Gunn, 1932; Rosenfeld, 1956). Design studies tend to focus on the plan and style of the house, and less on how it might be lived in, with one exception being the British publication, "Space in the Home" (Ministry of Housing and Local Government, 1963).

Research which examines the motivations of home-owners who alter their houses is uncommon. One such ongoing project relevant to this research examines why and how New Zealand home-owners alter their houses (McCarthy \& Dudding, 2008). However, it does not include a detailed study of the houses, nor does it seek to record details of the lifestyle of the home-owners.

\subsubsection{Operating Energy}

Household energy consumption is an area of recent research interest both in New Zealand (Isaacs et al., 2010; Thomas, 2009) and in England (Department of Energy \& Climate Change, 2013; Henretty, 2013).

The New Zealand Household Energy End-use Study (HEEP) monitored energy consumption and end-uses in a sample of four hundred houses located throughout the different climatic regions in NZ (Isaacs et al., 2010). HEEP was a long-term study with the objective of measuring and modelling the way energy is used in New Zealand households. HEEP monitoring activities included a detailed occupant survey and detailed house energy examination. The monitoring covered all fuel types (electricity, natural gas, LPG, solid fuel, solar water heaters) as well as temperatures in at least 
three locations. HEEP was limited to the houses studied, it was a study of operational energy and it did not record humidity levels. It was aimed at the big picture rather than the small details. One finding from the HEEP study was that operational energy is widely variable depending upon the comfort requirements of the inhabitants. HEEP also showed that in order to look at operational energy a large sample size is needed.

In the UK, a recent report published by the BRE Trust discusses changes to the housing stock over the past ninety years, with a focus upon energy use and carbon dioxide $\left(\mathrm{CO}_{2}\right)$ emissions (Utley \& Shorrock, 2012). It draws data from a number of sources including census records and presents information regarding the presence of basic amenities, the uptake of household electrical appliances and central heating and energy efficiency measures in UK houses.

\subsubsection{Embodied Energy}

As previously mentioned (section 1.1) the importance of operating energy is recognised whilst embodied energy has been given less attention. The Institution of Civil Engineers (ICE) in the UK produced a recent report focussing on embodied energy and carbon in construction (Institution of Civil Engineers (ICE), 2014) and there has been research to establish embodied energy coefficients and identify the embodied energy of specific building materials (A Alcorn, 2003; Construction Industry Research and Information Association (CIRIA), 1995; Hammond \& Jones, 2008; West, Atkinson, \& Howard, 1994).

One NZ study modelled a typical NZ house and measured and compared the embodied energy of the various building components (A Alcorn, 2010), however there has been little investigation of the embodied energy of an existing house immediately after construction. There is also a lack of research comparing the environmental impact, in terms of the embodied energy of its building materials, of a house constructed a century ago with that same house today. 


\subsubsection{Life Cycle Analysis (LCA) and Ecological Footprint (EF)}

LCA is a quantitative assessment of resource use (raw materials and energy) and waste discharges for every step of the life of products, service activities, and technologies, and thereby provides a way to evaluate and quantify the environmental impacts of a wide range of products and activities (Mithraratne, Vale, \& Vale, 2007, p. 23). LCA has been used to try and establish best practice in the design and construction of buildings. Mithraratne, Vale \& Vale describe the development of a New Zealand Life Cycle Analysis Model which considers costs, embodied and operating energy use, environmental impact and global warming potential (Mithraratne et al., 2007, p. ix). It considers the full lifespan of the building, including items such as finishes, furniture and appliances, and highlights the importance of material selection, systems specification and the behaviour of the inhabitants on the building's impact on the environment.

Wackenagel \& Rees developed the ecological footprint (EF) as a measure of each person's impact on the environment (Wackernagel \& Rees, 1996). The calculation and comparison of household EF has since become a topic of interest (Field, 2011; Lawton, 2013; B. Vale \& Vale, 2013; WWF Cymru \& Stockholm Environment Institute, 2005). Vale \& Vale compare the EF of three sustainable housing developments with the UK average. They suggest that low household EF within a sustainable housing development comes more from a shared ideal about living sustainably, than from the design of the houses (B. Vale \& Vale, 2013).

Comparing the environmental impact of housing and lifestyle, past and present, is a subject which has received little attention. A recent example of such research uses EF methodologies to estimate the ecological footprint of Wellingtonians in 1956 and 2006 (Field, 2011). Investigations were also conducted to understand and compare lifestyle and quality of life during the 1950s and 2006. Three research methods were used. The first was EF calculations based on the methodology of Wackernagel and Rees (Wackernagel \& Rees, 1996) the second was a questionnaire about housing and lifestyle for people who had lived in Wellington in the 1950s, and the third was focus group discussions of the same issues, to ensure a level of consensus about what life 
was like (Field, 2011, p. iii). This research demonstrates that it is possible to compare the environmental impact and quality of life of a specified group of people, past and present.

\subsubsection{Evaluating Housing Performance}

Post-occupancy evaluation (POE) has been used as a tool to evaluate building performance since the 1980s (Preiser, Rabinowitz, \& White, 1988). It includes aspects of building performance with the focus on how the occupants perceive the building in terms of comfort, health and other satisfaction measures (Federal Facilities Council, 2001). Stevenson and Leaman suggest reasons for the relatively few publications about residential POE compared with other sectors. These include the difficulty of gaining access to people's private homes, and the challenge of securing a representative benchmark sample (Stevenson \& Leaman, 2010). The Commission for Architecture and the Built Environment (CABE) acknowledge that there is a problem caused by the lack of post-occupancy research conducted by anyone in the housing sector (Commission for Architecture and the Built Environment, 2005, p. 28). One example of such research undertaken by CABE explores the views of residents on what it's like to live in new private housing. Independent researchers conducted in-depth, face-to-face interviews with a random sample of residents from eleven housing developments located in the north and south of Britain. Residents were asked to give their views on the places where they lived and focus groups were also implemented at each development (Commission for Architecture and the Built Environment, 2005).

In 1985, the National Housing Commission of New Zealand supported a pilot study which involved examining fifteen Housing Corporation New Zealand three bedroom single household detached house designs from between 1950 to 1980 (Tippett \& Runeson, 1985, p. 1). Four sets of indices were developed for the measurement of certain quality attributes. Accommodation indices included spatial arrangement and storage provision. Psychological comfort indices included lighting and power and thermal performance. The durability of the internal and external materials was also considered, as well as aesthetics. An attempt was made to measure quality in relation to the performance of a particular room in terms of its shape, size, location of 
window(s), and the flexibility of the arrangement. The assessment was undertaken on the design documentation of the houses before construction. Measurements of location and site planning were not made and occupants were not involved in the study. This pilot study was an attempt to assess housing quality by the development and testing of a quantified method to measure the effect of design on specific aspects of quality in low-cost public housing by generating quality profiles for each of the fifteen house designs.

In 1984, the Royal Australian Institute of Architects (RAIA) published the report, "Housing Issues 4: Evaluating Housing Standards and Performance" (Judd \& Bycroft, 1989). This publication arose from the RAIA 1989 National Housing Conference held in Canberra in the same year. One paper described a POE undertaken on married quarters accommodation associated with the Australian Defence Forces Academy (ADFA) (Evans, 1989). The methods used for the POE were aimed at providing an assessment of the estate, and in particular the houses, in terms of four criteria; cost-inuse, technical performance, user satisfaction, and fitness for purpose. The POE included interviews with tenants and also questionnaires which focussed on the three best and worst aspects of the houses and general satisfaction with them as well as their external appearance, standard of workmanship, living conditions in summer and winter and their layout. This POE highlights the value of carrying out interviews with tenants and hence considers not just the design of the houses, but the thoughts and feelings of those living inside them.

Vale and Vale (B. Vale \& Vale, 2010) suggest that as houses in developed countries have become more energy efficient due to building regulation requirements, the reduction in resource consumption has been counter balanced by the desire for larger houses and amenity. This suggests a measure of household performance is also required in $\mathrm{POE}$, rather than building performance alone, if energy is to be properly assessed. 


\subsubsection{Summary}

There is little published information which bridges the disciplines of architectural history, social and women's history, building technology and environmental assessment, by investigating the way in which houses are used and the embodied energy of the building materials in a house through the course of its life. As such, the relationship between the environmental impact of a house and the lifestyle of its inhabitants remains relatively unexplored and is thus the focus of this research.

\subsection{Research Aims}

The primary aim of this research is to establish and evaluate a Hybrid Analysis Method for Housing $(\mathrm{HAMH})$ as a vehicle for the investigation of the relationship between the environmental impact of the building materials in a house and the lifestyle of its inhabitants, both immediately after construction and in the present day. The HAMH will incorporate qualitative analysis of the comfort, adaptability and practicality in use of a house, and quantitative analysis of the environmental impact of the building materials in a house. For the purpose of this research, hybrid is defined as, "Derived from heterogeneous or incongruous sources; having a mixed character; composed of two diverse elements." (Oxford English Dictionary).

The environmental impact of alterations carried out to the house and its immediate outdoor space(s) will be measured and considered together with changes in lifestyle, to investigate to what extent a link exists between the energy invested in the building materials of a house and lifestyle.

The focus of this research is the use of houses (past and present), the patterns of alteration and maintenance, and the effect on the embodied energy of the building materials. Operating energy will not be considered due to the need for a large sample size and the problem of analysing a small sample of households with potentially varying comfort requirements. 


\subsection{Research Phases}

The HAMH will be developed through the study of a group of houses (hereafter referred to as the TS case study houses) before being applied to a second group of case study houses (SE houses). The research has both qualitative and quantitative components. The former relate to oral interviews with people who lived around the time the selected case study houses were first constructed, complemented by oral interviews covering the same questions with the present inhabitants of the case study houses. The quantitative part of the research is an investigation of the embodied energy of the case study houses. This whole process is conducted in four phases.

\section{Phase 1 - Method Development}

Phase 1 (chapter 3) is the development of a Hybrid Analysis Method for Housing (HAMH) using existing research methods through the study of a group of case study houses in NZ (TS houses). As well as investigating the houses past and present for how they were originally built and have since changed, oral interviews will be conducted. The results will then be tracked to examine the influence of lifestyle on the environmental impact of the building materials in a house then and now.

\section{Phase 2 - Method Application}

Phase 2 (chapter 4) will involve application of the method to a second group of case study houses (SE houses) to explore what can be learned through repetition of the $\mathrm{HAMH}$. This will be done by analysis of a comparable sample of houses as well as oral interviews with people living at the time the houses were constructed.

\section{Phase 3 - Comparative Study}

Phase 3 (chapters 5 and 6 ) is the comparison of findings from the investigation of the two groups of case study houses to explore what can be learned through application of the HAMH. 


\section{Phase 4 - Reflection and Conclusions}

Phase 4 (chapter 7) reflects on the HAMH and its use in establishing a link between lifestyle and the environmental impact of the building materials in a house.

\subsection{Research Scope and Definitions}

It was decided to develop the HAMH through the study of typical, working class, family houses. Methods of transportation to and from the house and storage areas for the various modes of private transportation would be identified and recorded, together with the proximity of the houses to public transportation. However, the environmental impact of transportation to and from the house, past and present, is not calculated or analysed, being considered outside the scope of this research. Further definitions are given below.

\section{The House}

For the purpose of this research, the house shall be defined as, "A building for human habitation; esp. a building that is the ordinary dwelling-place of a family." (Oxford English Dictionary).

\section{Outdoor Space}

The research will include all outdoor space associated with the house which could be the garden, yard, garaging or outhouse. It will also consider remote household space such as an allotment garden (which may be relevant to the case study houses in England).

\section{The 'Typical' House}

The research will focus on common or 'typical' house types which were mass produced by government departments, private organisations or developers. Unique, individually designed houses will not be considered. 


\section{The Working Class House}

The research will focus on houses designed for the working class. For the purpose of this research, the working class will be defined as, "The grade or grades of society comprising those who are employed to work for wages in manual or industrial occupations." (Oxford English Dictionary).

\section{The Family House}

The research will focus on houses which were originally designed to be inhabited by the nuclear family unit of typically a father, mother and children. Houses specifically designed for single person occupancy will not be considered.

The purpose of the research is to measure, not to model. The research does not seek to investigate what can be done to improve the energy efficiency of a house, but seeks to record alterations which have been made by the owners of the case study houses. The research is interested in the houses as they were constructed and as they exist today.

\subsection{Lifestyle and Embodied Energy: Research Questions}

This research will search for and analyse the relationship between the environmental impact of the building materials in a house and the lifestyle of its inhabitants. For the purpose of this study, lifestyle is defined as changes in time use, space use and energy use. These three sets of changes are then related to the measured and calculated embodied energy in the building materials in the house.

Three key questions form the focus of this research.

Since the case study houses were constructed:

- How has time use changed in the house and outdoor space?

- How has space use changed in the house and outdoor space?

- How has energy use changed in the house and outdoor space? 
Within these main questions are embedded other questions that will be addressed. For example, how does the number of occupants in a house make a difference to its environmental impact? What are the energy implications of alterations to the fabric of the house? These will be addressed when the results are compared.

\subsection{Selection of the Case Study Houses}

The proposed research involves the study of two groups of case study houses constructed during the late 1920s. The first group (used for the development of the method) are located in New Zealand and the second group (used for the application of the method) are in England. There is evidence that early in the twentieth century housing policy in NZ was at least in part influenced in part by UK housing policy (W. Ferguson, 1919; Watkins, 1919). Because New Zealand was once a British Dominion there are also similarities in the provision of houses and the lifestyles of the inhabitants. However, there are very different building traditions, with the majority of NZ houses being of wood construction compared to masonry construction in the UK. Both countries have governments with some commitment to conserving energy and reducing carbon dioxide $\left(\mathrm{CO}_{2}\right)$ emissions, again making conditions comparable. Examples of this are set out below.

\subsubsection{New Zealand}

As the selected houses are located in Wellington, that city will be used as the focus for consideration of NZ policies and activities. For example, the New Zealand government has recently dedicated millions of dollars to upgrading Wellington City Council's social housing over the next 20 years. The Housing Upgrade Project (HUP) is one of the largest redevelopment projects of its type in New Zealand, with the aim, "...to provide better housing. Installing insulation and double glazing, and improving ventilation and heating will allow tenants to enjoy, safer, warmer, drier homes." (Wellington City Council, 2014a).

For the wider city, one of the four goals of 'Toward 2040: A Smart Green Wellington', is the development of Wellington as an eco-city which involves a proactive response to environmental challenges (Wellington City Council, 2014b). 
For the individual house owner, there is information on making housing more sustainable on the Ministry for the Environment's website (Ministry for the Environment, 2013). Government funding is currently available to help Wellington homes become more sustainable. The Home Energy Saver Programme and the EnergyWise Home Grants are two ways the public can access funding (EECA, 2014).

Wellington City Council's other 'green' activities include household recycling collection for residents, recognising that recycling reduces the amount of waste going into landfill. The Council also offers grants to schools and not-for-profit organisations to encourage them to recycle. The Greater Wellington Regional Council promote composting as a way for the average household to reduce the rubbish it sends to landfill by $45 \%$. Similar information is communicated through numerous other council websites highlighting waste recycling as a clear area of interest for local government in New Zealand.

\subsubsection{England}

"Almost half of the UK's carbon dioxide emissions come from energy we use every day - much of it at home. By making more efficient use of energy and reducing waste we can all help prevent climate change - and save money on bills." (Planning Portal, 2014a)

In England, parts of the current Building Regulations, the Code for Sustainable Homes and the Energy Performance Certificate (EPC) for Construction, all aim to help reduce carbon emissions and protect the natural environment (Planning Portal, 2014b). The Code for Sustainable Homes was launched in 2006 as part of a package of measures in a move towards zero carbon development and is the national standard for the design and construction of new dwellings (Department for Communitites and Local Government, 2014).

The 'Grand Designs' Great British Refurb (GBR) campaign, with partners WWF, UK Green Building Council, Energy Savings Trust and Grand Designs Magazine, was launched in April 2009 and is an ongoing campaign which puts pressure on the government and business to help people to undertake full energy refurbishments of 
their homes (Grand Designs, 2014). The British government, like the New Zealand government, is currently offering grants to offset the cost of energy efficiency measures and the installation of renewable energy technologies in the home.

The British government is interested in reducing carbon dioxide emissions and conserving energy. The construction of dwellings which are less harmful to the natural environment and the refurbishment of existing dwellings are steps towards this goal.

The recycling of household waste is another area of concern for the British government. Councils in England are aiming to increase recycling rates to $50 \%$ by 2020. Over the past five years, fortnightly bin collections have been introduced in many areas, to include kerbside collections of garden waste and some households have as many as seven bins for the sorting of different types of waste. Home owners are being encouraged to change their habits and consider the natural environment.

\subsubsection{Case Study Houses in New Zealand}

Railway workers' houses which form the Tarikaka Settlement in Wellington, New Zealand were selected for the development of the HAMH (Figure 1). These 67 standard design houses were built in 1928-29 by the Department of Railways and rented to their workers. This group of houses were selected as they met the criteria described previously, being carefully designed and constructed on mass by the Department of Railways for railway workers and their families. The houses are timber framed, single storey, detached family dwellings, typical of houses being constructed in New Zealand during this period. Today they are mostly privately owned, the area has experienced gentrification and has Heritage Status. 


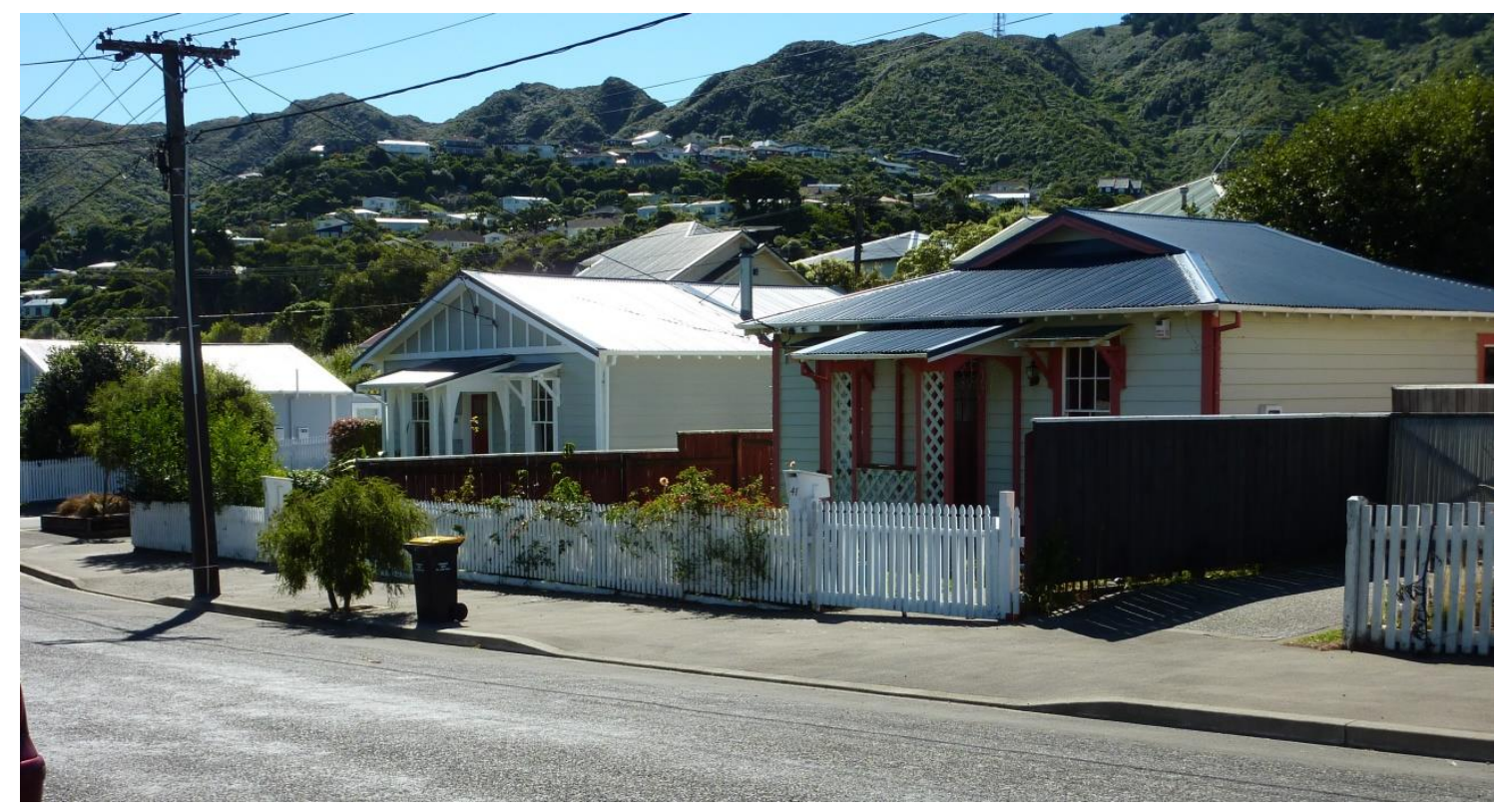

Figure 1: Tarikaka Street, 2013

\subsubsection{Case Study Houses in England}

For the application of the HAMH a comparable group of houses were sought in

England. It was considered important that the English houses were originally designed and constructed for inhabitants of a similar type, number and work situation and commissioned by a similar type of organisation as the case study houses in New Zealand. After careful consideration, a group of houses located in Silver End, Witham, England were selected as the second group of case study houses (Figure 2).

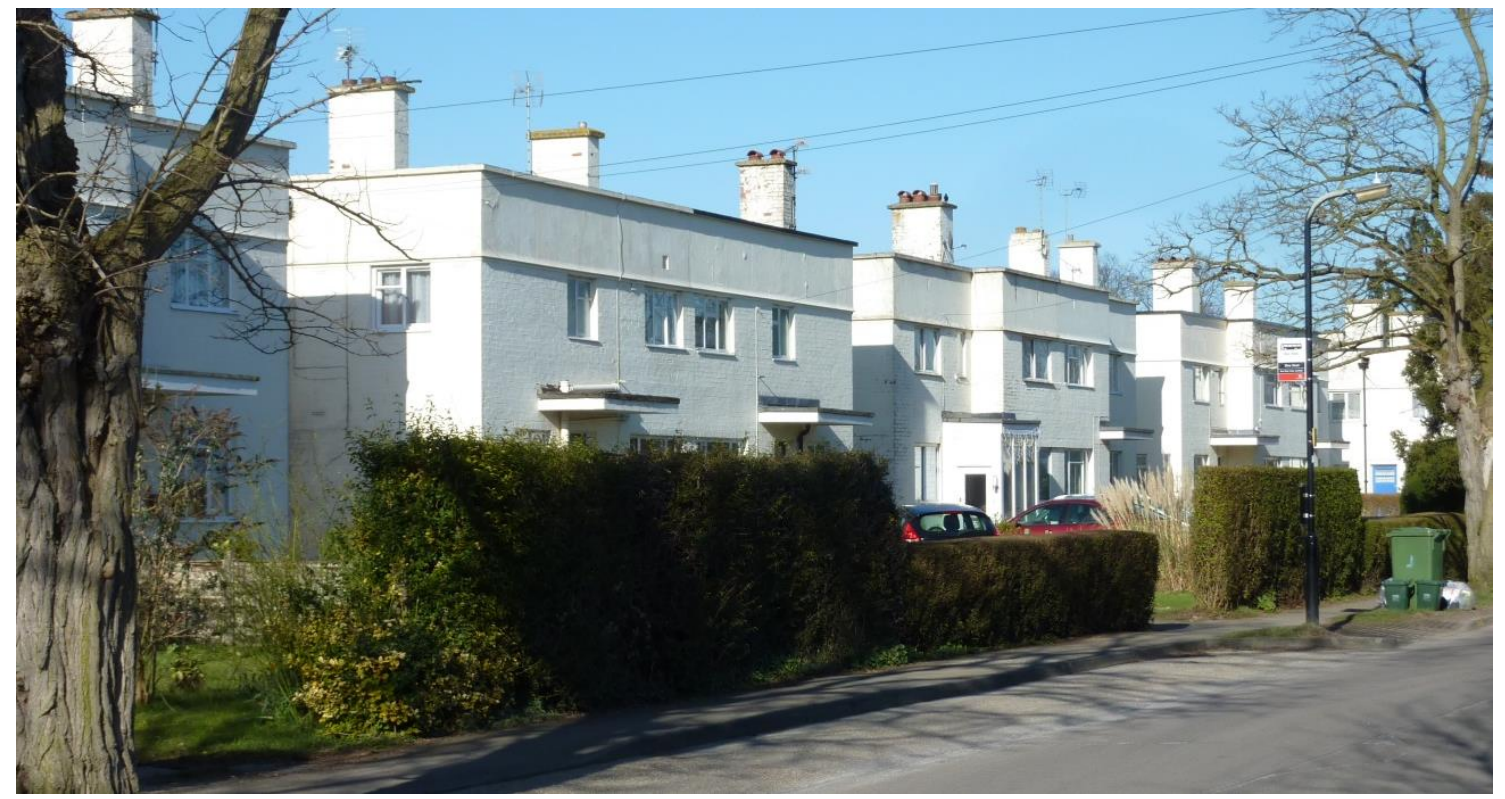

Figure 2: Silver Street, 2013 
These houses were built in 1928-29 by Francis Henry Crittall for rental to workers at his metal-window manufactory. Silver End has also been designated a Conservation Area. Constructed at the same time as the Tarikaka Settlement houses, these two-storey, semi-detached and terraced properties, of masonry construction, are typical of houses being constructed in England during this period, apart from many having flat roofs. However, this was not considered a legitimate reason for discounting them. Today some are privately owned, with the remainder maintained and managed by a local housing association.

\subsubsection{Case Study Houses Compared}

The two groups of case study houses were built in the late 1920s and it was important that both be affordable at the time. Research indicates that both groups of case study houses were designed to improve living conditions for workers and their families. Gordon Coates, NZ Minister of Railways from 1923 to 1928, wanted to, "see every railway settlement a garden suburb", so many railway worker settlements in New Zealand had their own roads, drainage systems, parks and recreation facilities (Coates, 1923, p. v), (Unknown, [New Zealand Building Progress], 1920, p. 79). Light, air and space were of great importance to Francis Henry Crittall, being considered a priority in the design of the houses at Silver End (Crittall, 1934, pp. 129-130).

This research is interested in three bedroom family homes so that embodied energy calculations are comparable in that they relate to the provision of a three bedroomed house. Choosing houses constructed at the same time in these two different countries was thought valuable in terms of comparing houses built of different materials and in different styles.

Both groups of case study houses were constructed before WWII, so this war had no impact on the materials from which the houses were constructed. During WWII the white render from the SE houses was removed back to brick, so that the houses could not be seen from the air, but this has not been considered in the embodied energy calculations. For the purpose of this thesis, therefore, any impact that WWII had on the building materials of the house has been ignored. Questions about WWII did not 
form part of the oral interview guide, but occasionally WWII was mentioned by an interviewee and quotations which include reference to WWII have been included for interest.

\subsection{Summary}

This research seeks to form a bridge between the disciplines of architectural history, social and women's history, building technology and environmental assessment. The proposed HAMH will provide a vehicle to investigate whether a link exists between the building materials in a house and lifestyle (defined as changes in time use, space use and energy use) and what form this link might take. Both qualitative and quantitative analysis will play a role in this research. Qualitative analysis will be used to explore the comfort, adaptability and practicality in use of a house, while quantitative analysis will examine the impact of building materials in a house on the natural environment, both immediately after construction and present day.

The method will be developed through the study of typical, working class, family houses in New Zealand (the Tarikaka Settlement in Wellington) before being applied to a sample of houses in England (Silver End in Witham). Although different in terms of layout, style, building materials and methods of construction, the two groups of case study houses have commonality in the people groups for which they were originally designed, the period in which they were constructed and in their conception and planning.

An analysis of operating energy will not form part of this thesis, but could form an area for future research. Chapter 2 outlines the research methods, the data for analysis and the method of recruitment of volunteers. 


\section{Chapter 2 - Research Methods}

\subsection{Introduction}

Development and application of the HAMH was envisaged to involve both investigative research (recorded oral interviews and house surveys, corresponding to qualitative and quantitative data collection) and data drawn from a wide variety of published information (building construction drawings, schedules, bills of quantities, photographs, planning and building regulations documentation, housing policy documentation, and journal and newspaper articles).

\subsection{Qualitative Data Collection}

Recorded oral interviews were undertaken with both present inhabitants of the two sets of case study houses and a selection of elderly people in their 70s and 80s in New Zealand and in England, who were willing to share memories of their housing and lifestyle during the 1930s and 1940s.

\subsubsection{Recorded Oral Interviews}

Recorded oral interviews were selected as one of the primary methods of data collection, as it was considered that they would facilitate the collection of a large amount of data in a comparatively short space of time. It was also thought that both the present day inhabitants of the case study houses and the elderly volunteers would be more willing to agree to an oral interview, rather than complete a detailed and lengthy questionnaire, as it is much quicker to speak an answer than to write one down. The recorded oral interview would enable the interviewer to request further information, whilst at the same time allowing the interviewee to share what was important to them. It was considered that a survey by questionnaire would not facilitate the collection of data of the required depth or breadth.

Recorded oral interviews were sought with present day inhabitants of the case study houses. An oral interview guide was carefully constructed and is included in Appendix A. 
In addition to the information obtained through these interviews, information regarding how the houses were originally used was needed to create a baseline. This was obtained from recorded oral interviews with elderly people in their 70s and 80s, who were willing to share memories of their housing and lifestyle during the 1930 s and 1940s. A second oral interview guide was constructed specifically for this type of interview and can be found in Appendix B. Ethics approval was obtained from Victoria University of Wellington for this work (Ethics Approval No. 19031). A copy of this approval is provided in Appendix C.

\subsubsection{Recorded Oral Interview Guides}

In both cases, the recorded oral interview guide listed over 50 questions and was distributed to volunteers prior to the interview. This was considered to give the participants time to consider their responses, perhaps encouraging more information to be shared. The only disadvantage of distributing the guide prior to the interview might be that the interview is less 'honest' and more contrived.

Topics for discussion were originally based on the standard questionnaire for establishing an individual's Ecological Footprint, developed as part of the New Zealand Ecological Footprint study (Field, 2011). It included questions on family, housing, education and work, food, transportation, recreation, significant moments and quality of life (Figure 3).

\section{FAMILY}

HOUSING

EDUCATION AND WORK

\section{FOOD}

\section{TRANSPORTATION}

RECREATION

SIGNIFICANT MOMENTS

QUALITY OF LIFE

Figure 3: Topics for discussion in the recorded oral interview

Each category contained a number of questions arranged thematically and interviewees were encouraged to disclose as much, or as little, information as they liked. Specific questions were asked about alterations undertaken to the house and 
garden as well as future plans, including maintenance. Many of the questions were open-ended, enabling interviewees to best describe in their own words the changes that they had observed or participated in. For the purposes of analysis, in a number of cases, the interviewee's first response to a question was considered separately, as well as part of the full range of their answers. Space and water heating, fuel costs and levels of thermal comfort were discussed and interviewees were invited to share any concerns about the cost of fuel, or heating the house in winter. Household waste and household appliances were also topics for discussion. Interviewees were asked to state the best and worst things about the house and its location. The role of the interviewer was to ensure that all topics were discussed, whilst allowing space for the interviewees to reflect and share their thoughts, feelings and opinions.

Both guides followed the same pattern. In the second guide for use with the elderly interviewees, questions were altered to suit the time period being discussed and rephrased in consideration of the fact that the interviewees were recounting the past rather than describing the present. Examples of questions from each of these guides are given below:

\section{Recorded Oral Interview Guide - Present Day Inhabitants}

Question 9: How often and by what means is the house heated?

Question 16: What do you consider are the best and worst things about the house and place where you live?

Question 40: How do you and your family spend time on the weekends? Please could you describe a typical Saturday and Sunday.

\section{Recorded Oral Interview Guide - Housing and Lifestyle 1930s and 1940s}

Question 13: Do you recall what types of waste were generated in the house and garden? How was waste disposed of?

Question 17: Did your family make any alterations or improvements to the house whilst you lived there? If so, please describe these. 
Question 39: What forms of private transport did you have at home? How often were these used and for what purposes? Car, bicycle, etc.

\subsubsection{Interview Analysis}

It was acknowledged that transcribing the recorded oral interviews would take a considerable amount of time and might be an unnecessary step. The information shared in the recorded oral interviews was not for analysis by an oral historian who would be interested in the order and the manner in which memories were shared, but for the purpose of gaining insight into the common issues and attitudes towards housing during the 1930s and 1940s, and verifying these against the relevant literature.

It was thus considered necessary that answers to questions be extracted for presentation in a format that would allow ease of analysis and comparison, but it was also important to extract relevant and interesting quotations that would highlight answers and opinions that were common, as well as unusual. In order to meet these requirements, a unique style of note-taking was developed which is similar to that used in the abstracting of oral history (Dudding, 2008) where the content of the interview is summarised by the abstractor in small sections, referencing the time code on the recording for each section, and names, dates, places and events are highlighted.

Notes from the recorded oral interviews were first put in an MS Word document in table format. Topics were colour coded for ease of identification, and knowing where questions were answered in a different order. Figure 4 is an example of notes from a recorded oral interview. Notes of an entire interview with a present day inhabitant of a case study house are contained in Appendix $D$, and notes of an entire interview with a 1930s and 1940s housing and lifestyle interviewee are contained in Appendix E. Notes from each of the recorded oral interviews undertaken for the purposes of this research are located on the accompanying CD-ROM. Note that the interviewee's names and addresses have been blanked out for the purposes of confidentiality. 
0:10:51 ELECTRICITY SUPPLY, ELECTRIC LIGHTS. WOOD BURNER lit mainly in the WINTER. WATER HEATED via. a WET BACK.

INVERCARGILL ... same kind of LIVING ROOM, but with a COAL RANGE and

0:11:19 no open fire. COAL RANGE was used for HEATING and COOKING and had a WET BACK. "It was all very simple... uncomplicated."

$0: 12: 02$ Explains that he won't be able to answer any questions about his parents' financial concerns. Details. WALLACETOWN GARDEN, "...very light on decorative stuff and heavy on a

0:12:35 vegetable garden, 'cause my father was a good gardener, and the same in Invercargill...very light on a flower garden and all the emphasis went on the vegetable garden ..." WASTE ... no recollection. LAVATORY ... a long drop, and a NIGHT SOIL bloke.

Spent WEEKENDS in the GARDEN with his FATHER. "...roles were clearly

$0: 13: 30$ defined, my father did all the outside work and the heavy work... and my mother was the king in the house and she did the housework and the cooking and the washing, and all that sort of stuff."

Recalls that his father didn't have lots to do other than spending time in

0:14:09 the garden. Mentions that they had no CAR, no transport to get away on the weekends.

No ALTERATIONS were made to the WALLACETOWN house. Spent very little time away from the home during the first six years of his life.

FATHER worked at a CONDENSED MILK FACTORY during this period. Details. Later, when they moved to INVERCARGILL, he went back to being

Figure 4: Notes from a recorded oral interview

Data extracted from the notes of each recorded oral interview was later compiled into an MS Excel spreadsheet. Figure 5 contains a section of a completed spreadsheet. The spreadsheet facilitated the identification of common and less common answers to questions and enabled patterns to be identified. The completed spreadsheet was analysed and information was extracted in graphical form. The completed spreadsheets for each group of recorded oral interviews undertaken for the purposes of this research can be found on the accompanying CD-ROM.

Figure 6 contains an example of data from a spreadsheet being represented in bar chart format. In these charts, TS refers to responses given by the current inhabitants of the Tarikaka Settlement houses, while NZ refers to responses given by the elderly interviewees from New Zealand. 


\begin{tabular}{|c|c|c|c|c|c|}
\hline 2 & $\begin{array}{l}\text { Who lived with you? Were there any } \\
\text { members of your immediate family that } \\
\text { did not live with you? Did you have any } \\
\text { relatives living nearby? Where did they } \\
\text { live? In the same street, same suburb, same } \\
\text { town, etc. }\end{array}$ & $\begin{array}{c}\text { Mother and mother's friend } \\
\text { (Aunty Dora). Family in England. } \\
\text { Father had drowned at sea just } \\
\text { before he was born. }\end{array}$ & $\begin{array}{l}\text { Mother, father and an older } \\
\text { brother. Relatives in the south } \\
\text { Island, but none living nearby. }\end{array}$ & $\begin{array}{c}\text { Mother and father, no siblings. } \\
\text { Aunts, uncles and cousins lived } \\
\text { locally. Grandparent's lived in } \\
\text { Rangiora, regarded as being, "... } \\
\text { in the country." }\end{array}$ & $\begin{array}{l}\text { Mother and father, no siblings. } \\
\text { Aunts, uncles and grandparents } \\
\text { lived in Wellington. }\end{array}$ \\
\hline 3 & $\begin{array}{l}\text { Did anyone else live with you, other than } \\
\text { the members of your immediate family } \\
\text { described previously? Lodger, friend, etc. } \\
\text { Did you have any pets? Dog, cat, bird, } \\
\text { goldfish etc. }\end{array}$ & $\begin{array}{c}\text { A cousin from England came to } \\
\text { live with them during the war } \\
\text { and they had a boarder staying } \\
\text { with them from time to time. } \\
\text { Pets ... a dog, pigeons, guinea } \\
\text { pigs and rabbits. }\end{array}$ & $\begin{array}{c}\text { A cousin lodged with them. No } \\
\text { pets. }\end{array}$ & $\begin{array}{l}\text { No one else ever lived with } \\
\text { them. Pets... Mother cats that } \\
\text { had kittens regularly. }\end{array}$ & $\begin{array}{l}\text { No one else ever lived with } \\
\text { them. Pets ... Horses, dogs, cats } \\
\text { and silkworms. }\end{array}$ \\
\hline \multicolumn{6}{|c|}{ HOUSING } \\
\hline 4 & $\begin{array}{l}\text { What type of house did you live in and } \\
\text { where was it located? }\end{array}$ & $\begin{array}{c}\text { House was located in Auckland. } \\
\text { Single storey, quarter acre } \\
\text { section. }\end{array}$ & $\begin{array}{c}\text { House was located in } \\
\text { Wallacetown. Simple, wooden, } \\
\text { modest building. }\end{array}$ & $\begin{array}{c}\text { House was located in } \\
\text { Christchurch. "Well it was a } \\
\text { bungalow, built in ... probably in } \\
1926 \text {... in a good, middle class } \\
\text { suburb of Christchurch, St Albans ... } \\
\text { in those days it was considered as } \\
\text { one of the ... better houses in the } \\
\text { street.". }\end{array}$ & $\begin{array}{l}\text { House was located in Gisborne. } \\
\text { "It was a wooden house, as they all } \\
\text { are, one storey-ed ... quite large ..." }\end{array}$ \\
\hline 5 & $\begin{array}{l}\text { From what materials was the house } \\
\text { constructed? Walls, floor, roof, etc. }\end{array}$ & Timber with an iron roof. & $\begin{array}{l}\text { Weatherboard cladding with a } \\
\text { corrugated iron roof. }\end{array}$ & Timber with an iron roof. & Timber. \\
\hline 6 & Did your parents rent or own the house? & $\begin{array}{c}\text { Owned the house, }- \text { I don't } \\
\text { know they ever paid the mortgage } \\
\text { off }\end{array}$ & Owned the house. & Owned the house. & Owned the house. \\
\hline 7 & $\begin{array}{l}\text { What do you think were the main reasons } \\
\text { for your parents choosing to rent/buy this } \\
\text { house? Location, cost, size/number of rooms, } \\
\text { external appearance, internal fittings, outdoor } \\
\text { space, etc. }\end{array}$ & $\begin{array}{c}\text { "... well they wanted to stay on the } \\
\text { North Shore, they liked it ... Aunty } \\
\text { Dora was quite a sports woman, } \\
\text { she liked swimming and tennis and } \\
\text { so on, and that was the place to do } \\
\text { it ... and the garden, I think, was a } \\
\text { big attraction.... }\end{array}$ & $\begin{array}{l}\text { Father was a carpenter and } \\
\text { built the house himself. }\end{array}$ & It was a good suburb. & $\begin{array}{l}\text { Relocated to Gisborne because } \\
\text { of father's work. }\end{array}$ \\
\hline 8 & $\begin{array}{l}\text { Can you describe each of the rooms in the } \\
\text { house? What were they like and how were } \\
\text { they were used? Sleeping areas, living areas, } \\
\text { kitchen, washing/storage areas, etc. }\end{array}$ & $\begin{array}{c}\text { Sitting room, a small kitchen, a } \\
\text { bathroom with a calofont, three } \\
\text { bedrooms ... Mother and aunty } \\
\text { Dora shared one bedroom, } \\
\text { children shared another } \\
\text { bedroom and third bedroom } \\
\text { was kept free for boarders. }\end{array}$ & $\begin{array}{l}\text {.... typical of modest houses in } \\
\text { Invercargill in those days, and it } \\
\text { had ... two bedrooms and two sun } \\
\text { rooms off the front veranda and a } \\
\text { principal living room ... and behind } \\
\text { that ... What was called the good } \\
\text { room in those days, which was a } \\
\text { dead loss of a room because we } \\
\text { seldom used it.". }\end{array}$ & $\begin{array}{c}\text { Sitting room, main bedroom, } \\
\text { dining room, bedroom and } \\
\text { kitchen. Internal bathroom with } \\
\text { bath and separate shower } \\
\text { which was never used as it was } \\
\text { not connected to the water. } \\
\text { Washhouse with two tubs and a } \\
\text { gas copper. Toilet was located } \\
\text { off the washhouse. Sun porch } \\
\text { off the second bedroom. } \\
\text { Garage. }\end{array}$ & $\begin{array}{l}\text { Five bedrooms, dining room and } \\
\text { living room. Laundries to the } \\
\text { rear of the house and two } \\
\text { toilets, one to the rear of the } \\
\text { house and one inside the } \\
\text { house. }\end{array}$ \\
\hline
\end{tabular}

Figure 5: Section of a completed spreadsheet

\section{Recorded oral interviews with the current inhabitants of British case study houses and}

the elderly interviewees were analysed in the same way for ease of comparison.

Number of persons per dwelling Number of adults per household

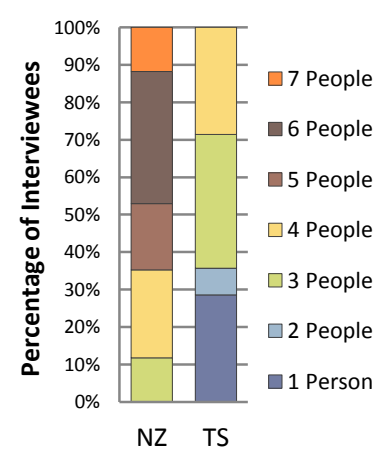

Interviewees

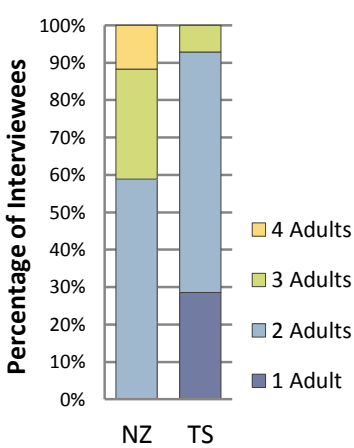

Interviewees

\section{Home ownership}

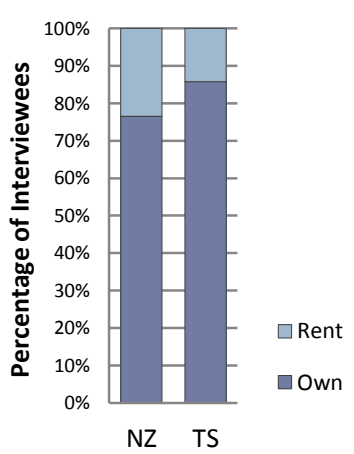

Interviewees

Figure 6: Example of bar charts containing data from the completed spreadsheet 


\subsubsection{Recruitment of Volunteers}

Four groups of interviews were undertaken for this research, two in New Zealand and two in England. Each group was allocated a two or three letter code:

\section{New Zealand}

- Current inhabitants of the Tarikaka Settlement houses (TS)

- Elderly people of an age to be able to recall housing and lifestyle in the 1930s and/or 1940s (NZ)

\section{England}

- Current inhabitants of the Silver End houses (SE)

- Elderly people of an age to be able to recall housing and lifestyle in the 1930s and/or 1940s (ENG)

\subsubsection{Tarikaka Settlement Volunteers}

Current inhabitants of the TS houses, most of whom were also owners, were approached by letter in January 2012, producing 14 volunteers. The data collection took place between April and June 2012. Interviews, although planned for 45 minutes, varied in length from 35 minutes to 2 hours depending on the depth of responses. In three households, two people wished to participate in the interview and this was not discouraged, so both interviewees feature on the recordings. After conducting the 14 interviews, it was clear where revisions to the questions would be of benefit to the interviewee and revisions were made for the subsequent case study house interviews. A sample of questions and answers are presented below. References to the oral quotes are given in the following format: Interviewee reference, Hours: Minutes: Seconds, e.g. [TS_10, 0:03:29], where TS_10 refers to volunteer number 10 from the Tarikaka Settlement.

What were the main reasons for choosing to rent/buy this house? Location, cost, size/number of rooms, external appearance, internal fittings, outdoor space, etc. 
"...so we had quite a strict criteria for what we wanted and a lot of it was based around afternoon sun and...good water pressure, and, you know, all those sort of practical things that you don't really find often in the same place in Wellington. But eventually we saw this place and we thought, oh yes, it meets our criteria..." [TS_11, 0:02:27]

What are the main activities that take place in the outdoor space? How much time do you and your family spend in the outdoor space? Who is responsible for maintenance of the outdoor space?

\begin{abstract}
"I don't tend to use the outdoor area for much, except for gardening. I do enjoy gardening, so that's good, I probably don't get out as much as I should... unfortunately the outdoor area...even in the summer it tends to lose the sun... and so it's not that user friendly for...entertaining out there." [TS_13, $0: 12: 57]$
\end{abstract}

What do you consider are the best and worst things about the house and place where you live?

"...we live in a small house, and there's very little storage, and we're both hoarders, so you know, there are moments in time where you think, oh God, this is just getting too much...but I love that it is an old house, I love the history part of it, I love the street and I reckon we've got one of the best houses on the street because...in summer time, we 've got the sun until nine or ten o'clock...it's lovely..." [TS_06, 0:31:17]

\title{
2.2.4.2 Elderly People in New Zealand
}

The recruitment and interviewing of the elderly interviewees in New Zealand took place over three months. They were identified by a 'snow-ball' method, each interviewee being asked if they knew someone else willing to be interviewed. Using this method of recruitment, 18 people participated, 8 male and 10 female. Some know each other today, but none knew each other during the 1930s and 1940s. All of the interviewees now live in the wider Wellington region, although the majority were born 
and spent their childhood elsewhere in NZ. None had grown up in the Tarikaka Settlement, although one had lived in two different railway houses in Frankton and Morrinsville [NZ_17] and one had lived in an adjacent street [NZ_01]. The fact that interviewees did not live in the Tarikaka Settlement was not an issue, as the purpose of these recorded oral interviews was to gain insight into the common issues and attitudes towards housing during this period, and verifying these against the relevant literature.

Interestingly, the majority of interviewees stated their housing and lifestyle had been very ordinary, and similar to that of most people living at the same time. Interviewees were all NZ Pakeha as this study purposefully excluded Maori men and women in an attempt to make the scope of the research manageable. Some researcher in the future may find interest in not only the experiences of Maori but also the contrast with the Pakeha responses. Interviewees were from a variety of backgrounds, a mix of poor and wealthy families, and shared memories of their housing and lifestyle in city, town and/or rural settings.

It was soon realised that not all interview material would be suitable for analysis. Although 18 people were interviewed, one interview was excluded in the analysis because the interviewee, although willing, had a very poor memory and was unable to answer many of the questions. As intended, these interviews took place in the elderly interviewee's own home, avoiding travel and with the advantage of helping participants feel relaxed. After conducting 8 interviews, it was clear some revisions to the questions would be of benefit to facilitate recall. As a result, the ordering and phrasing of some of the questions were revised.

An extremely high degree of repetition was discovered in answers to many of the questions, which allowed the recruitment to cease after 18 interviews had been completed. This concurs with similar work undertaken in New Zealand on the ecological footprint project, where 4 focus groups were held with 22 people who had lived in Wellington during the 1950s. It was found that consistent results emerged after the first 3 sessions of 15 people and that the final focus group just repeated these (Field, 2011). 
Interviews were planned to last 45 minutes, but in fact varied in length from between 35 minutes to 1 hour 20 minutes. In shorter interviews, the interviewee would simply answer each of the questions with some explanation but little expansion. In longer interviews, the interviewee would recollect information in much greater detail adding information of relevance as well as personal opinions, thoughts and feelings. A sample of questions and answers are presented below.

What type of house did you live in and where was it located?

"...typical of modest houses in Invercargill in those days, and it had...two bedrooms and two sun rooms off the front veranda and a principal living room...and behind that... what was called the good room in those days, which was a dead loss of a room because we seldom used it." [NZ_10, 0:03:29]

Do you recall what types of waste were generated in the house and garden? How was waste disposed of?

"My mother had dug a hole in the garden, and she would use that as a compost hole... what other rubbish would we have?...all the vegetables peelings and stuff went into a hole in the garden...so we were green-ies even in those days." [NZ_15, 0:09:10]

Who was responsible for garden maintenance? Approximately how much time was spent per week on garden maintenance? Did you or your siblings (if relevant) help with taking care of the garden?

"Mum didn't like gardening very much, she was too busy anyway, cooking and washing and ironing, and just generally being a good mum... we helped out on occasion, but it wasn't necessary... and Dad enjoyed it. It was just a nice garden to enjoy, it was the right size..." [NZ_06, 0:17:03]

What forms of private transport did you have at home? How often were these used and for what purposes? 
"... I'd made my own bike up from bits and pieces, and I painted it red ... from leftover paint from the house roof ... it was a good bike, but it had no brakes, and so it was never pinched because it was ... so brightly painted and stood out ... I got a lot of use from it because I worked from ... when I was thirteen to when I was about twenty three ... every summer vacation, and I used to bike to get to work and back ... and my father went to work on a bike, brother went to work on a bike, and my mother had a bike that she would go to pick up groceries on ..." [NZ_10, 0:34:51]

\subsubsection{Silver End Volunteers}

The inhabitants of the modernist houses on Silver Street and Broadway at Silver End were approached by letter in January 2013 producing 9 volunteers. The data collection took place in April 2013.

\subsubsection{Elderly People in England}

Three volunteers carried out recorded oral interviews in England. These were carefully selected and all volunteered to participate in the data collection due to their interest in history and research. The ENG interviewees were found by the three volunteer interviewers, being people that they knew of who fitted the criteria of being willing and able to recall memories of the early years of their life, specifically their housing and lifestyle during the 1930s and 1940s, and share them whilst being recorded. Identifying suitable volunteers did not appear to be a problem, with one interviewer acknowledging that they could have undertaken many more interviews, as a number of elderly people in the same friendship circles as those previously interviewed were beginning to ask why they themselves had not been interviewed. Again, recruitment ceased after 12 interviews, due to the extremely high degree of repetition which was discovered in answers to many of the questions. 


\subsection{Quantitative Data Collection}

All of the case study houses were surveyed and photographed (where permission was given) on the day of the interview. House plans were analysed and compared to the original house plans, and alterations were identified. The sets of plans were then compared to look for patterns in the way the houses had been changed, both in terms of layout and finishes and fittings. In many cases, the oral interview could corroborate the house survey data, the latter being a visual representation of what was shared verbally. From each group of case study houses, one house was selected for more thorough analysis. The selected house represented a layout typical of most of the houses surveyed.

Floor plans, sections and elevations were created in AutoCAD. These included the current mechanical and electrical layouts and services information. The original floor plan of a Tarikaka Settlement house is contained in Appendix F, and a present day floor plan is contained in Appendix G. Appendix $\mathrm{H}$ contains the original floor plan of a Silver End Stuart house, and Appendix I contains a present day floor plan of this same house. Where floor areas have been calculated, the floor area has been measured as the area within the inside face of the external walls and, in the two storey houses, the area of the first floor includes the area over the staircase.

\subsubsection{Embodied Energy Analysis}

The environmental impact of the case study houses was assessed in terms of the embodied energy of the building materials invested in the house between construction in 1928 and 2012. A detailed analysis of the materials used in the original construction of the house was undertaken and the embodied energy per square metre of the original house was calculated. Changes to the embodied energy per square metre of each of the case study houses from alterations to the building fabric were also calculated.

The base data was gathered through house surveys, building construction drawings, schedules, planning and building regulations documentation, journal and newspaper 
articles and other published information that related to similar houses. The energy implications of alterations to the fabric of the house were explored and assessed.

\subsection{Comparative Data Analysis}

In order to best manage the data and to assist with analysis, the results will be separated into three categories which form a direct link with the three main research questions (section 1.6). The three categories each include information regarding both the original and present day inhabitants of the case study houses.

\subsubsection{Time Use}

This category explores the amount of time spent in different areas of the house and outdoor space, as well as details of time spent elsewhere. Information regarding time spent working in paid employment, time spent on household work, cooking and garden maintenance, and time spent on undertaking other activities such as recreation and travel was obtained primarily through the recorded oral interviews. The lifestyle of the original inhabitants was explored including their own assessment of their quality of life. Attitudes towards housing during the 1930s and 1940s were considered and compared. Similarly, the lifestyle of the present inhabitants was examined and their assessment of their quality of life noted. Attitudes towards the house were considered and compared.

\subsubsection{Space Use}

This category analyses the houses spatially in terms of use, with drawings used to illustrate alterations which had taken place to the inside and outside spaces. The activities undertaken in each named space by the different household members were recorded and compared. Evidence about the people for whom the house was originally designed was gathered, focussing on activities which would have once taken place in the various indoor and outdoor spaces, and attitudes towards these spaces. The same information was recorded for the present inhabitants of the case study houses, together with their opinions about the quality of these spaces. 
This information was gathered through recorded oral interviews, house surveys, building construction drawings, photographs, and planning and building regulations documentation. Comparisons were drawn between the lifestyle of the original inhabitants of the case study houses and the present day inhabitants. The ability of the case study houses to support inhabitants with differing lifestyles was also investigated. The adaptability and practicality in use of the case study houses, both after construction and in the present day, was explored and assessed.

\subsubsection{Energy Use}

Information regarding services, appliances, fuel and waste, both after construction and in the present day was collected for analysis. Methods of space and water heating were recorded, as well as the frequency and extent of use of both. As discussed in chapter 1 , the additional complexity of including an analysis of operational energy has meant this has been excluded from this research.

The embodied energy of the building materials invested in the house from construction in 1928 to 2012 was calculated (see section 2.3.1). This information was gathered through recorded oral interviews, house surveys (floor plans, sections and elevations, mechanical and electrical layouts), building construction drawings, journal and newspaper articles and other published information.

\subsubsection{Embodied Energy Analysis}

The embodied energy calculations have been done for the house as originally constructed and then as a consequence of all the subsequent changes, including routine maintenance such as painting the outside of a timber clad house. As far as possible, a complete history of the house was constructed, but where this was not possible assumptions were made about, for example, the frequency of exterior painting. Using standardised embodied energy coefficients for materials, it was then possible to work out a life-time energy input for the materials of the house.

The house was analyzed at various stages of its life and for each stage schedules detailing the quantities of materials used in the construction, alteration and 
maintenance of the house were compiled in an MS Excel spreadsheet. The house was broken into 10 elements; foundations, structural framing, building envelope, internal joinery, internal finishes, heating, plumbing and drainage, electrics and lighting, kitchen fittings, utility fittings and bathroom fittings. An example of part of a schedule is shown in Figure 7.

\begin{tabular}{|c|c|c|c|c|c|}
\hline $\begin{array}{l}\text { Material / } \\
\text { Component as named } \\
\text { in ICE V2.0* }\end{array}$ & Building elements & $\begin{array}{l}\text { Embodied } \\
\text { energy } \\
\text { coefficient }\end{array}$ & Calculation of weight & $\begin{array}{r}\text { Weight } \\
(\mathrm{kg})\end{array}$ & $\begin{array}{l}\text { Embodied } \\
\text { energy (GJ) }\end{array}$ \\
\hline \multirow[t]{3}{*}{$\begin{array}{l}\text { Timber Sawn } \\
\text { Softwood }\end{array}$} & $\begin{array}{c}\text { Boards for roof decking } \\
\text { (assume } 25 \mathrm{~mm} \text { thick) } \\
40.60 \mathrm{~m}^{2} \times 0.025 \mathrm{~m}= \\
1.015 \mathrm{~m}^{3}\end{array}$ & 7.40 & $\begin{array}{l}\text { Norway Spruce } 405 \mathrm{~kg} / \mathrm{m}^{3} \\
\text { (http://www.wood- } \\
\text { database.com) } \\
405 \times 1.015=411.075 \mathrm{~kg}\end{array}$ & 411.08 & 3,042 \\
\hline & $\begin{array}{l}\text { Floor boards for ground } \\
\text { floor (assume } 13 \mathrm{~mm} \\
\text { thick) } 30.68 \mathrm{~m}^{2} \times 0.013 \mathrm{~m} \\
=0.39884 \mathrm{~m}^{3}\end{array}$ & 7.40 & $\begin{array}{c}\text { Norway Spruce } 405 \mathrm{~kg} / \mathrm{m}^{3} \\
\text { (http://www.wood- } \\
\text { database.com) } \\
405 \times 0.39884=161.53 \mathrm{~kg}\end{array}$ & 161.53 & 1,195 \\
\hline & $\begin{array}{l}\text { Floor boards for first } \\
\text { floor (assume } 13 \mathrm{~mm} \\
\text { thick) } 40.60 \mathrm{~m}^{2} \times 0.013 \mathrm{~m} \\
=0.5278 \mathrm{~m}^{3}\end{array}$ & 7.40 & $\begin{array}{l}\text { Norway Spruce } 405 \mathrm{~kg} / \mathrm{m}^{3} \\
\text { (http://www.wood- } \\
\text { database.com) } \\
405 \times 0.5278=213.759 \mathrm{~kg}\end{array}$ & 213.76 & 1,582 \\
\hline Iron General & $\begin{array}{l}\text { Nails for roof decking } \\
\text { and floor boarding } \\
\text { (assume } 60 \text { nails per } \mathrm{m}^{2} \text { ) } \\
\left(40.60 \mathrm{~m}^{2}+30.68 \mathrm{~m}^{2}+\right. \\
\left.40.60 \mathrm{~m}^{2}\right) \times 60=6713 \\
\text { nails }\end{array}$ & 25.00 & $\begin{array}{l}\text { Assume } 100 \text { iron nails } \\
\text { weigh } 139 \mathrm{~g} \\
\begin{array}{c}6713 \text { nails } \times 1.39 \mathrm{~g}=9331 \mathrm{~g} \\
=9.331 \mathrm{~kg}\end{array}\end{array}$ & 9.33 & 233 \\
\hline $\begin{array}{l}\text { Asphalt 6\% Binder } \\
\text { Content }\end{array}$ & $\begin{array}{l}\text { Roof covering (assume } \\
13 \mathrm{~mm} \text { thick) } 40.60 \mathrm{~m}^{2} \mathrm{x} \\
0.013 \mathrm{~m}=0.53 \mathrm{~m}^{3}\end{array}$ & 3.93 & $\begin{array}{l}\text { Crushed asphalt weighs } \\
721 \mathrm{~kg} / \mathrm{m}^{3} \\
\text { (www.simetric.co.uk) } 0.53 \\
\text { x } 721=382.13 \mathrm{~kg}\end{array}$ & 382.13 & 1,502 \\
\hline Iron General & $\begin{array}{c}\text { Cast iron gutters and } \\
\text { down pipes } 5.842+ \\
3.302+2.545+1.823= \\
13.512 \mathrm{~m}\end{array}$ & 25.00 & $\begin{array}{c}100 \mathrm{~mm} \text { outer dia. } 15.60 \mathrm{~kg} \\
\text { per } \mathrm{m} . \text { (www.hibid.co.uk) } \\
15.60 \times 13.512=210.79\end{array}$ & 210.79 & 5,270 \\
\hline $\begin{array}{l}\text { Timber Sawn } \\
\text { Softwood }\end{array}$ & $\begin{array}{l}\text { Front door } 1.73 \mathrm{~m}^{2} \mathrm{x} \\
0.025 \mathrm{~m}=0.043 \mathrm{~m}^{3}\end{array}$ & 7.40 & $\begin{array}{l}\text { Norway Spruce } 405 \mathrm{~kg} / \mathrm{m}^{3} \\
\text { (http://www.wood- } \\
\text { database.com) } \\
405 \times 0.043=17.52 \mathrm{~kg}\end{array}$ & 17.52 & 130 \\
\hline
\end{tabular}

Figure 7: Part of a schedule of materials and quantities

For each material identified, its weight $(\mathrm{kg})$ or volume $\left(\mathrm{m}^{3}\right)$ was calculated based on measurements of the actual house or from the plans. Where it was not possible to 
obtain exact measurements, assumptions were made. For example, the original cast iron porcelain enamel bath could not be weighed, so the weight of a similar product today was used. Reasons for the assumptions were documented on the spreadsheet, but are not presented here. Once the weight $(\mathrm{kg})$ or volume $\left(\mathrm{m}^{3}\right)$ of a material was calculated, this figure was multiplied by the embodied energy coefficient. Embodied energy is expressed in GJ and consists of both direct and indirect energy, the former being the energy required to transport materials to site and assemble them there, and the latter the energy used in the extraction and manufacture of raw materials, including the equipment required for this purpose and all other related services, for example insurance and banking (Mithraratne et al., 2007, p. 47). The embodied energy coefficient is given as $\mathrm{MJ} / \mathrm{kg}$ or $\mathrm{MJ} / \mathrm{m}^{3}$ and researchers have calculated embodied energy coefficients for a wide range of materials in both New Zealand (A. Alcorn \& Wood, 1998), (A Alcorn, 2003) and England (Hammond \& Jones, 2008). Embodied energy coefficients from each of these sources were utilized in the LCA calculations. Completed spreadsheets containing the LCA data for both groups of case study houses are located on the accompanying CD-ROM.

Following the calculations of the embodied energy for each material in the house, the embodied energy (GJ) of the whole house at different stages was assessed. Rather than analyze each house, a sample house was used for the Tarikaka Settlement and Silver End (see section 2.3).

The TS house was analyzed at three stages of its life: the first immediately after construction in 1928; the second following the 1960s renovations; and the third following alterations and improvements post-1988. The impact of the regular maintenance of the house after each of these stages was also considered. For the analysis of the house as constructed, original architectural drawings and schedules of timber were consulted. The quantities of materials used in the renovations and improvements undertaken during the 1960s by NZGR were based on the memorandum from the Chief Engineer to the General Manager (Clark, 1962). Quantities of materials utilized in alterations and improvements made by the house owner's post 1988 were mostly measured on site. 
The SE house was also analyzed at three stages of its life and similarly, the impact of the regular maintenance of the house after each of these stages was considered. The results of the embodied energy analysis for the two groups of case study houses can be found in Appendix $\mathrm{J}$ and Appendix K.

Where embodied energy per person was calculated, average national occupancy figures were used. The 2012 occupancy level of each case study house was recorded in the interviews, but it was impossible to discover the number of people who lived in the same house immediately after it was constructed. As such, the only robust way to calculate the embodied energy per person was to use average national occupancy figures.

\subsection{Summary}

The outcome of the application of the HAMH is a detailed series of both qualitative and quantitative data presented for the most part in graphical form. The data for analysis is separated into three categories which link directly to the research questions; time use, space use and energy use. Recorded oral interviews with both present inhabitants of the case study houses and a group of elderly people in their $70 \mathrm{~s}$ and 80 s are one of the primary methods of data collection. House surveys record the ways in which the case study houses have been altered, both in terms of special layout and finishes and fittings. The calculations of embodied energy for both groups of case study houses are located on the accompanying CD-ROM. Chapters 3 and 4 present the findings from the application of the HAMH to build a picture of how lifestyles have changed and the environmental impact of the alterations to the building fabric as a result of such changes. 
Page $\mathbf{6 0}$ of $\mathbf{3 3 2}$ 


\section{Chapter 3 - Method Development: The Tarikaka Settlement}

For the investigation of the Tarikaka Settlement houses, the data included the original construction drawings issued by New Zealand Railways (NZR), original documentation related to the houses and their inhabitants in NZR files held at Archives New Zealand, newspaper articles and other books (Moroney, 2004). This was in addition to data obtained through the interviews with present inhabitants of the case study houses, which were sometimes supplemented by interviewee's drawings and photographs from when work had been done on the houses.

In this chapter, a number of the graphs provide a comparison between the older interviewees (NZ) and those people currently living in the TS case study houses (TS).

\subsection{History}

In early twentieth century New Zealand, poor housing was a primary concern of government and health officers (Evening Post, 1905, p. 5). The 1916 census highlighted overcrowding in metropolitan areas (Fraser, 1919) and by 1919, a number of government reports addressing the housing problem had been published (Paul, 1919), (W. Ferguson, Elliott, \& Newton, 1919, p. 4),(Wilkinson, 1919, p. xxxiii), (Unknown, [Board of Health], 1919, p. 14). The Workers' Dwellings Act, 1905, was the first attempt by central government to provide housing for workers (New Zealand Government, 1905, p. 439), although the first houses constructed under its aegis at Petone were criticized because they were sited away from places of employment (Evening Post, 1906, p. 3).

The Department of Railways began providing houses for its workers in 1895 (Unknown, [Chief Engineer's Office], 1895) and by 1920, possessed its own forests and mills for construction of these which were pre-cut and shipped by rail for later assembly on site (Evening Post, 1920, p. 5). North Island settlements existed at Frankton, Taumarunui, Tekūiti, Ōhakune, Taihape and Marton.

The Frankton Housing Factory opened in July 1923 equipped with modern machinery (Coates, 1924, p. viii) and the consequent standardization of house plans resulted in 
increased efficiencies with a rise in production. In 1921, the average cost of the houses was $£ 700, £ 200$ less than the same class of conventionally built house (Auckland Star, 1923). By 31 ${ }^{\text {st }}$ March 1924, 255 standardised five-roomed houses had been cut, with 61 completed and occupied (Coates, 1924, p. viii), and with 400 houses per annum the aim (Coates, 1924, p. viii). By the time the factory closed in 1929, it had produced almost 1,400 pre-cut houses, as well as pre-cut timber for wagons, signals, office furniture, stockyards, sheds, huts and other buildings (Schrader, 2005). In 1982, when the New Zealand Railways Corporation (NZRC) began selling its housing, it owned about 4000 houses (Cleaver \& Sarich, 2009).

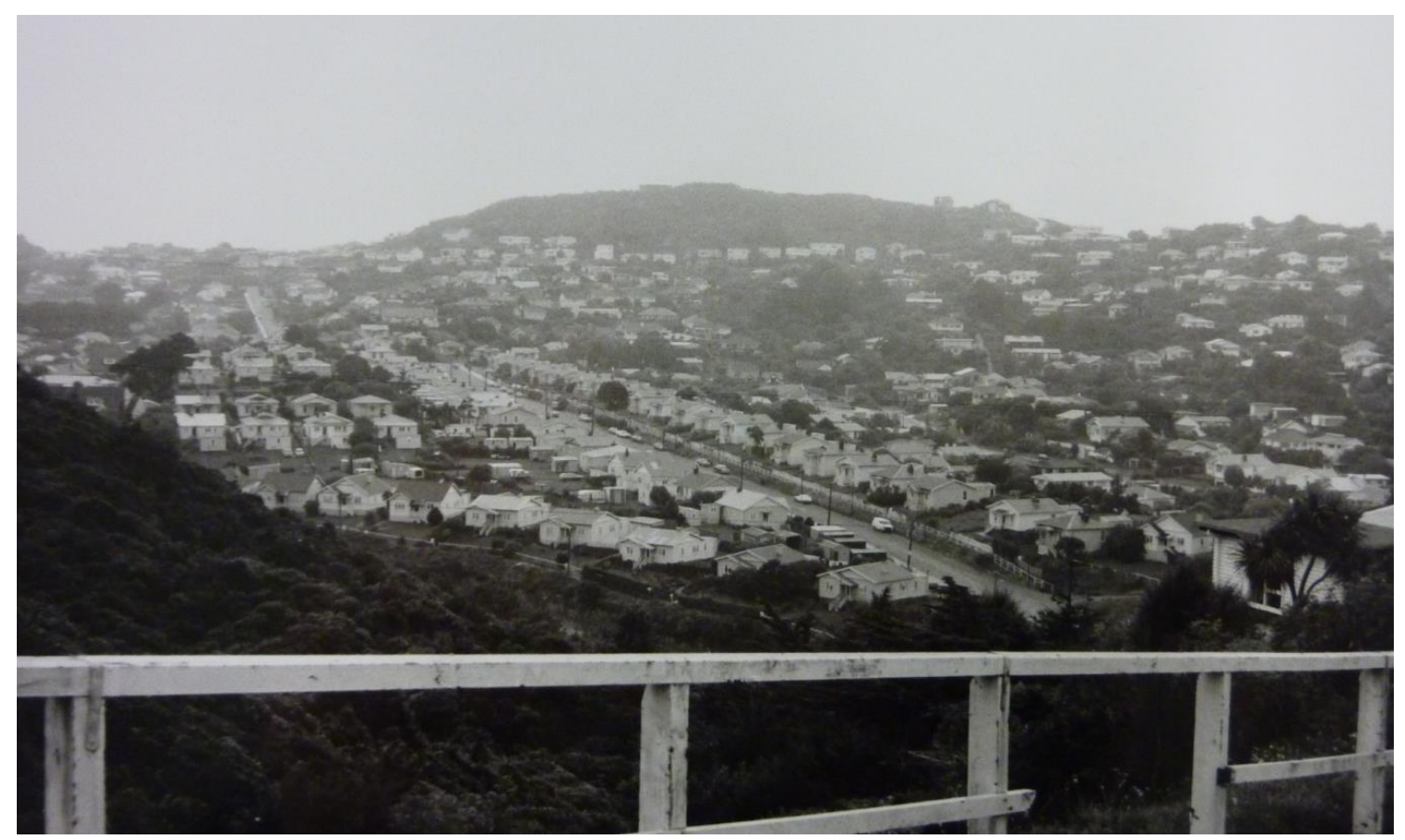

Figure 8: Tarikaka Settlement, c.1980 (Unknown, 1986)

Land in the Wellington suburb of Ngaio was purchased for the Tarikaka Settlement in 1927 (Evening Post, 1927, p. 10). It was to have 80, five-roomed, factory-cut houses with electric light, water and drainage at a weekly rental of one day's pay. Although identical in plan, a number of different elevations gave variety to the streetscape (Evening Post, 1927, p. 10). The houses, nominally "Standard House, Plan A.B.1123, Factory Cut", were erected between 1928 and 1929 (Unknown, [Architectural Branch], 1929). Today, 67 of these houses remain in their original locations and 11 of the sections (plots) have been sub-divided, with new houses built on the rear of these (Figure 8 and Figure 9). 
A resident of Tarikaka during the 1930 s and 40 s recalled the houses were painted every five years and kept in good repair by the Department of Railways (Moroney, 2004, p. 2) echoing a Frankton Settlement resident recalling in interview, "...the houses were very well maintained...painted...every five years...wallpapered..." [NZ_17, 0:09:45].

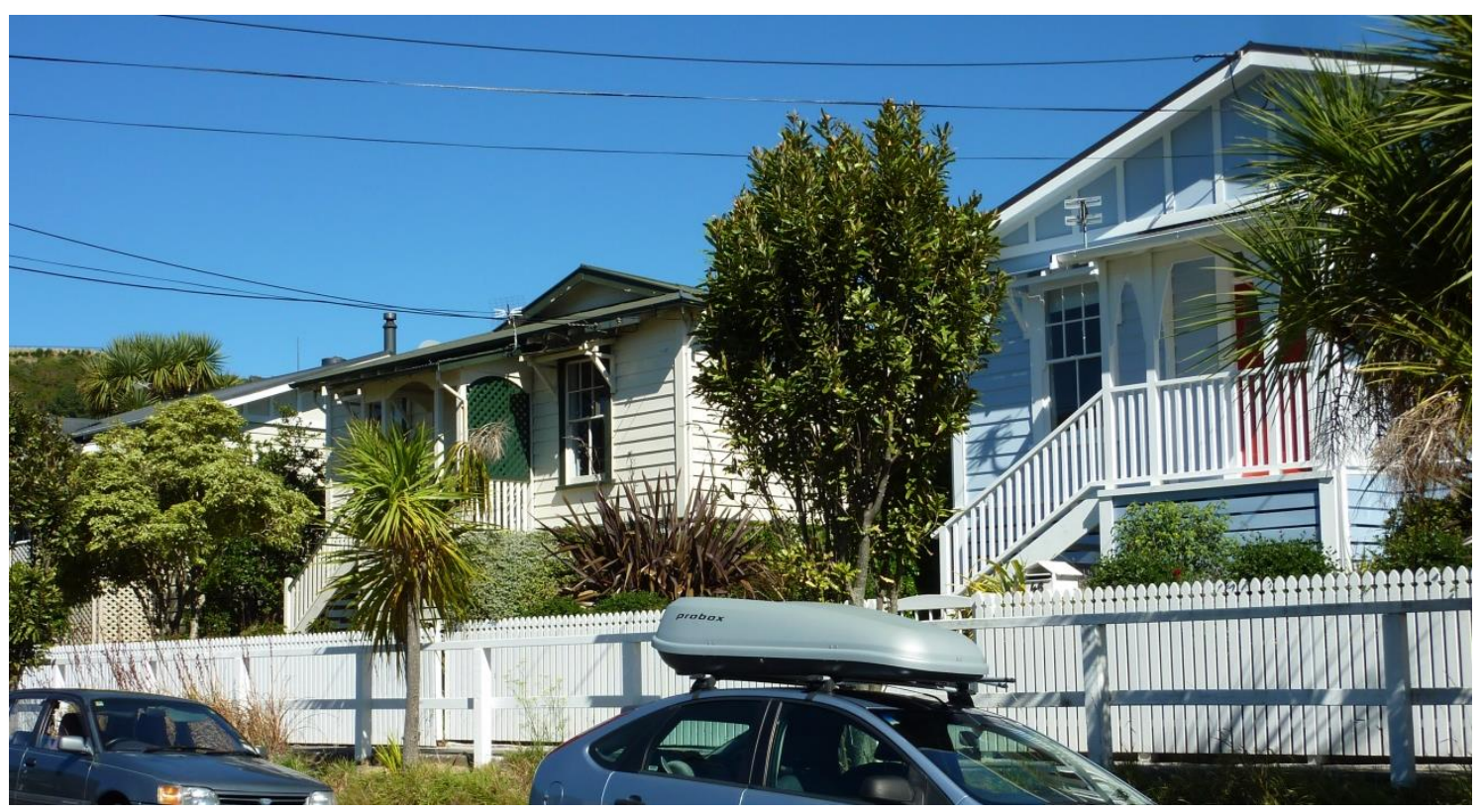

Figure 9: Tarikaka Settlement houses, 2013

The approved site plan (Figure 10) had a central street (later named Tarikaka Street, after nearby Tarikaka Hill), two branch streets (Ngata Street and Pomare Street) and a connecting street which was an extension of Bombay Street and later connected to Swansea Street (Unknown, [Architectural Branch], 1927b). The building line was $15 \mathrm{ft}$ (4.6m) back from the road boundaries (Unknown, [Architectural Branch], 1927a). The existing layout of the houses differs slightly from the layout illustrated in Figure 10, but there is no 'as-built' plan available in the Wellington City or in National Archives. A resident during the 1930s and 1940s recalled Tarikaka Street, now tar sealed, was a gravel road which was dusty in the summer (Moroney, 2004, p. 2). 


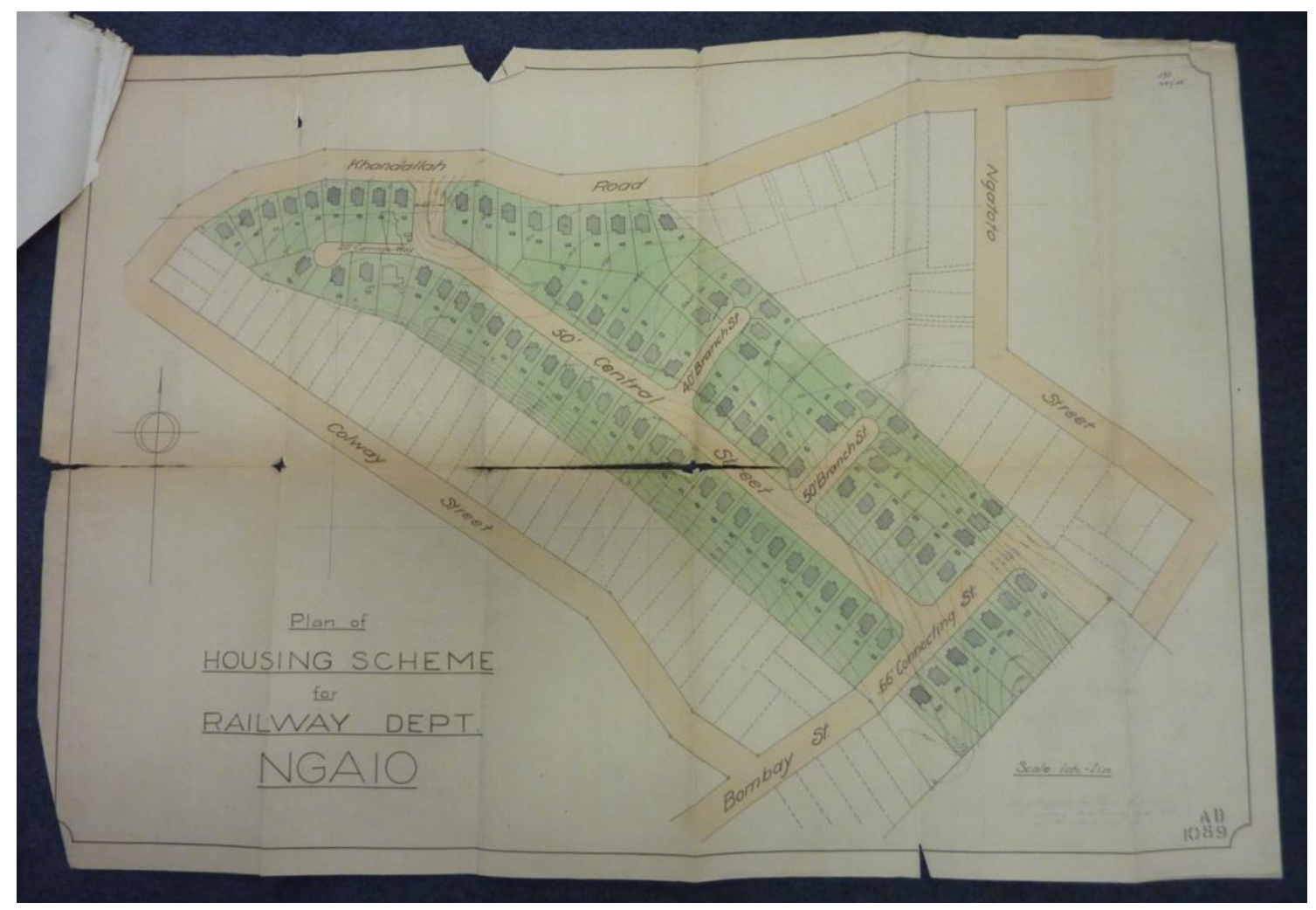

Figure 10: Plan of Housing Scheme for Railway Department, Ngaio, A.B. 1089, c.1927 (Architectural Branch, 1927)

Original inhabitants of the houses were railway workers, including clerks, engine drivers, cleaners, labourers and firemen (Unknown, [Architectural Branch], 1929). The original average household size in the 3 bedroom Tarikaka houses is not known, but average occupancy in the 1921 Census was 4.43 persons/dwelling in the Wellington urban area (Census and Statistics Office, 1921, p. 15). Despite being new, the houses had their critics,

\footnotetext{
"One of the upsetting things was that a lot of the early residents in Ngaio felt that The Settlement was a bit of a blot on their area and in some cases and in certain aspects of the community the Railway people were not socially acceptable." (Moroney, 2004, p. 2)
}

NZRC sold the houses in the late 1980s (Clarke, 1989) and only a few are still inhabited by railway workers. A present inhabitant who purchased their house from the NZRC in 1988 describes the transformation of the area: 
"When we first moved in here, both our parents came down and turned white as a sheet...they identified these as being sort of run down places that the underclass lived in...Since then, it's just kind of transformed to now they're actually quite trendy and fashionable..." [TS_10, 0:10:44].

The interviewee continued by discussing the potential of the area and knowing that gentrification would come, “...we just thought we couldn't go wrong." [TS_10, 0:11:39].

\subsubsection{Heritage Status}

There is some confusion over the listing of the Tarikaka settlement as a Historic Area by the New Zealand Historic Places Trust (NZHPT) (since July 2013 Heritage New Zealand). The documents referenced below are in the archives, but the settlement does not appear to be recorded in the Heritage New Zealand list (Heritage New Zealand, 2014).

In a 1980 report on the Tarikaka settlement for the Historic Places Sub-Committee, the Wellington City Planner wrote,

"The area as a whole is very untidy and in need of an uplift and comprehensive clean up. Street litter includes... beer bottles, clothing, shoes, paper and...on the whole, does not reflect very well on [the] Railways Department. There are a number of cars parked along the roadside and some of these are obviously immobilised, which add to the detraction from the amenities of the neighbourhood." (Clarke, 1980)

Fences also needed repair and grass verges required mowing. Garages had been constructed by residents at the western end of Tarikaka Street and were considered unsightly. Clarke concluded the area was in need of significant upgrading, but felt that, unless the Department of Railways spent money, conditions would remain the same (Clarke, 1980).

Following this, in 1983, the NZRC sought to upgrade the roads, water and drainage to Wellington City Council standard, so these roads could be legalised and handed over as 
public services. This would allow subdivision of the individual housing plots and selling the houses (Harding, 1983). In response to the proposed subdivision, the Director of Parks and Recreation recommended paying the reserves contribution partly in land and partly in amenity works (Director of Parks and Recreation, 1983). Creation of the larger area would mean removing five houses, and Figure 11 is a photograph of the recreation reserve today. Amenity works included planting up the larger area, developing a park and planting road frontages. The City Planner advised that all but 20 properties (on the southern side of Tarikaka Street) could achieve off-street parking (McCutcheon, 1983) and dispensation from the off-street parking requirement was later given for these because of the difficulty of achieving access. Another dispensation was needed to retain the existing $40 \mathrm{ft}(12.2 \mathrm{~m})$ section widths (which were too narrow to meet the requirements of the Council's district plan) (Truebridge Callender Beach Limited, 1985).

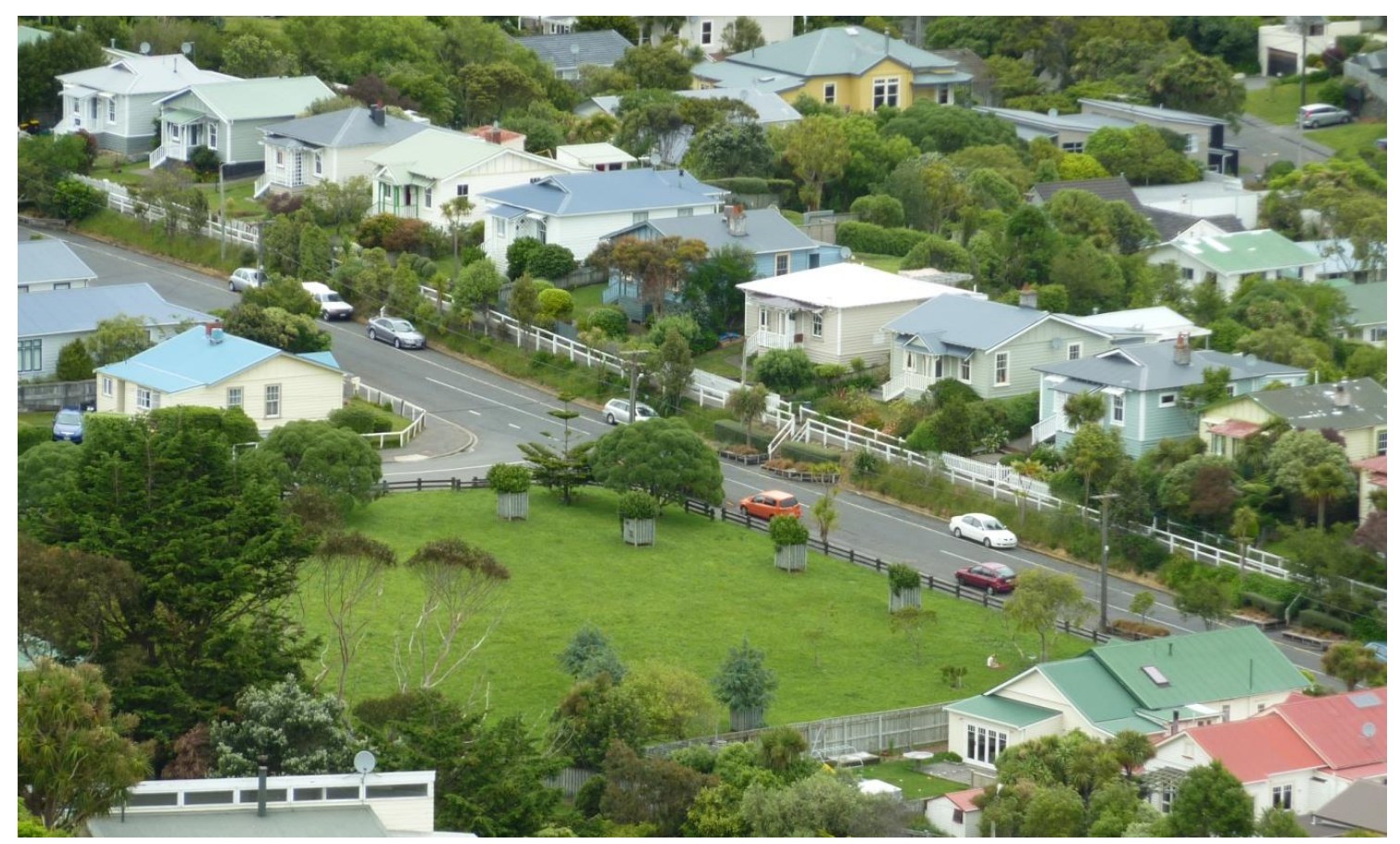

Figure 11: Recreation Reserve, 2013

In 1986, a member of Onslow Historical Society campaigned for the preservation and restoration of the houses and area through having it zoned by the NZHPT (McArthur, 1986b). 
"These cottages are deteriorating at present and are a constant source of embarrassment to local residents and a dampener on property values ... the cottages could become the leading area in Ngaio and Khandallah showing by example how old houses respond to restoration and colour schemes." (McArthur, 1986b)

Not all residents were happy about this prospect, "A home is what you make it, how you see fit, particularly where finance is concerned. We are not on exorbitant wages, but manage to live happily and comfortably." (Te Whare, 1986).

Binning, a member of the Ngaio Progressive Association stated at a meeting that $45 \%$ of the inhabitants were permanent tenants whose houses had been allowed to deteriorate by the Department of Railways adding, "They have now become a singular community within the broader community...it is critical that something be done to upgrade these house as soon as possible." (McArthur, 1986a). The Ngaio Progressive Association wanted to avoid the sale of the now sub-standard houses to tenants who might later find that they could not afford the necessary repair and maintenance work. Despite these and other concerns, "...Tarikaka Street housing should remain affordable to those in lower income brackets." (Fanning, 1986). The settlement was classified as a Historic Area by the NZHPT in March 1986 (Daniels, 1986) but, as mentioned, the settlement no longer appears on the web-site list.

\subsubsection{The Sale of the Houses}

During the 1980s, the NZRC was restructured. In 1983, income from rental of its houses was $\$ 2.5$ million, but costs incurred in connection with these were $\$ 7.5$ million and consultants recommended that the NZRC act quickly to reduce its housing stock (Cleaver \& Sarich, 2009, p. 249). In 1989, the Chief Executive of the NZRC explained it was not essential for Railways to provide housing, as employees no longer worked in remote areas with operations becoming more centralised. As the majority of its housing stock was located within cities, the need for housing to attract staff had become questionable. The houses, which were not let at market rents, were both expensive to maintain and administer (Cleaver \& Sarich, 2009, pp. 250-251). 
The disposal of railway houses by NZRC was firstly by sale to occupants, followed by sale to Housing Corporation or Maori Affairs, sale by ballot to other Railways staff and finally on the open market (McQueen, 1986), although over 1000 railway houses elsewhere in New Zealand were reportedly sold to Stone Key Investments Ltd and this sale remains controversial (Dyer, 2010).

In March 1988, a Trust was formed by the Ngaio Residents' Housing Committee to buy the houses and maintain the character of the settlement (Clarke, 1988). One year later, 10 of the 95 houses had been sold publicly, 8 were vacant, and the remaining 77 were purchased by original railway tenants through the Trust, 50 of which had qualified for Housing Corporation assistance. In a report the City Planner stated that,

"The area has a lot of community spirit with over $50 \%$ being Maori or Pacific Islander and the families age groups starting in the early 20's [sic] with the oldest person being 55 years. Although the Housing Corporation has offered some funds for the renovation of the properties, these funds average $\$ 5,000$ per house and is [sic] to bring the property up to Health standards which does not include the full extent of the renovations needed to be done to each property." (Clarke, 1989, p. 2)

In 1989, Wellington City Council approved the Tarikaka settlement as a community improvement area due to its special characteristics (Hume, 1989). At the first two public meetings residents suggested constructing planters in the street to slow vehicles and make the area safer for children, and installing play equipment in the park at the junction of Tarikaka and Ngata Street. Hume noted an apparent large number of children living in the area (4 per household being common) with 12 children in one family.

In 1990 , the Council approved $\$ 65,000$ for the Tarikaka Street environmental improvements (Renovation Advice Office, 1990) which funded the construction of numerous railway sleeper planters the length of Tarikaka Street and additional planters at the junctions (Figure 12). The play equipment was not installed. 


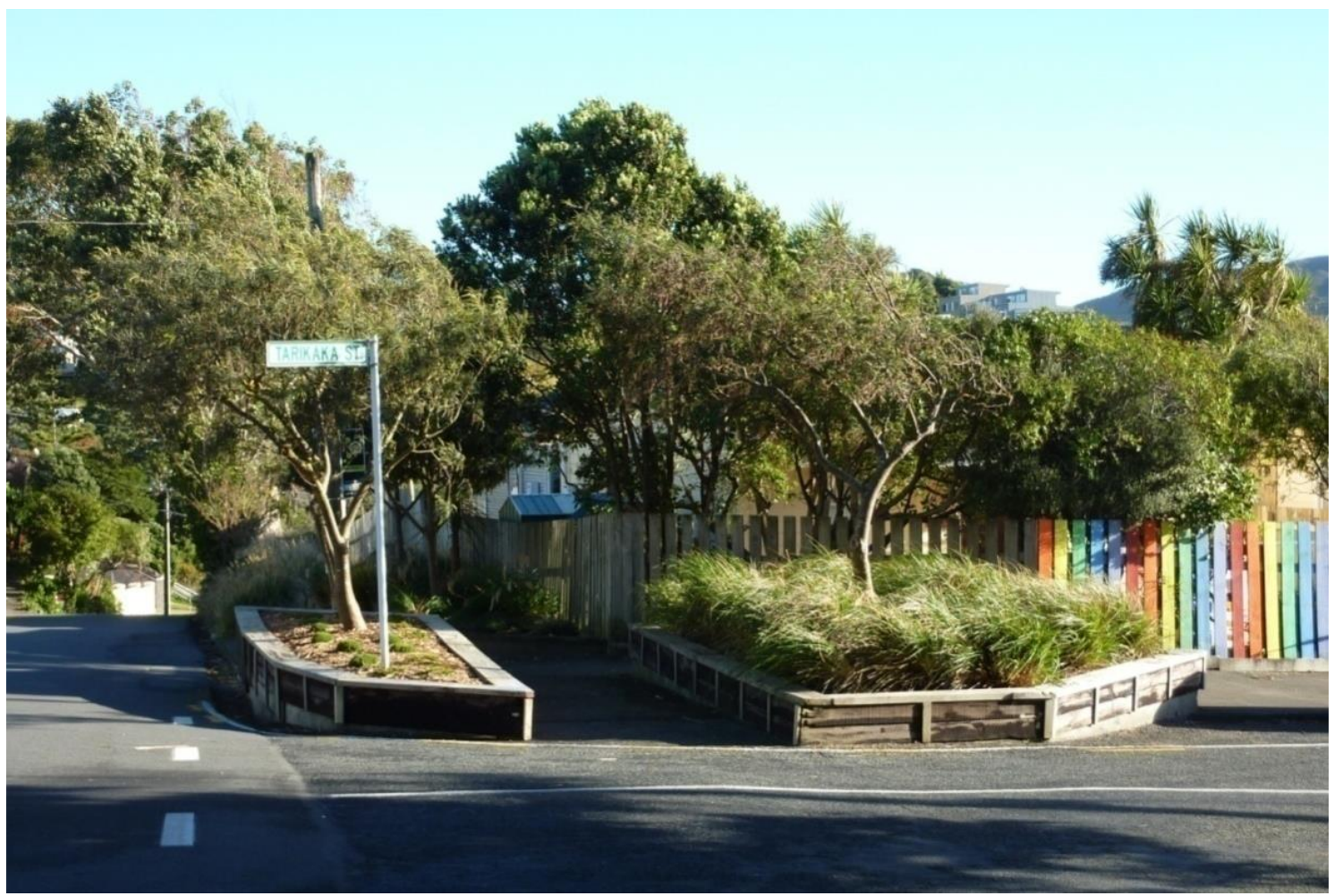

Figure 12: Planting at junction of Tarikaka Street and Bombay Street, 2012

Today, under the Wellington City District Plan permitted activities include repairs and maintenance and internal additions and alterations. All other activities are discretionary requiring consent, which include demolition work (for example, removal of a chimney or outbuilding), extensions which increase the building footprint by more than $10 \%$ and construction of any new building on the site (Wellington City Council, 2013, p. 21/1). Where possible, street elevations are not to be altered, and new work should be sympathetic to the existing building in proportion, materials and craftsmanship (Wellington City Council, 2013, p. 21/6). Alterations to improve energy efficiency should also be discreet, new window joinery for double glazing should closely match original profiles, and solar and photovoltaic panels must be fixed in the plane of the roof slope so they are not visible from the street (Cochran \& Murray, 2010, p. 5). 


\subsection{Time Use}

The way that the original and present inhabitants of the TS case study houses spend, or spent, their time was investigated.

\subsubsection{House}

The original occupants of the TS houses were railway workers and their families.

Typically, fathers would be in full-time paid employment, and mothers usually homebased and responsible for household work. Of the 17 interviews with the older New Zealanders, father was employed full-time in 16 (94\%) of the households, with mother not engaged in any form of paid employment (Figure 13). The exception was a household where a mother had been widowed. Of those interviewed, 14 (82\%) stated that mother had been solely responsible for household work (Figure 14). One interviewee recalled that his mother left work as soon as she was married.

"...that was a wife's role... when she first got married...she immediately left work and her employer... was a Canadian and said, in Canada you know, women carry on working after...they are married, and she thought this was utterly...out of the question..." [NZ_16, 0:13:46]

In contrast to the 1930 s and 1940 s lifestyle interviews, only in $2(14 \%)$ of the present day TS households was an adult not engaged in some form of paid employment. One was a retired person and the other a stay-at-home mum. In 5 (36\%) households, father worked full-time and mother part-time, and in the remaining households all adults worked full-time. The occupations of current TS householders included accountants, solicitors, lecturers, teachers, ICT and other professionals.

This highlights the biggest change in the use of the houses between when they were constructed and present day; the house is no longer continually inhabited, but usually occupied only during the weekday evenings/nights and for part of the weekends. The TS interviews also revealed that, unlike the 1930 s and 1940 s, household work is no longer solely undertaken by the mother, but is the responsibility of the sole inhabitant (29\%), both mother and father (14\%), or a cleaner (14\%) (Figure 14). 


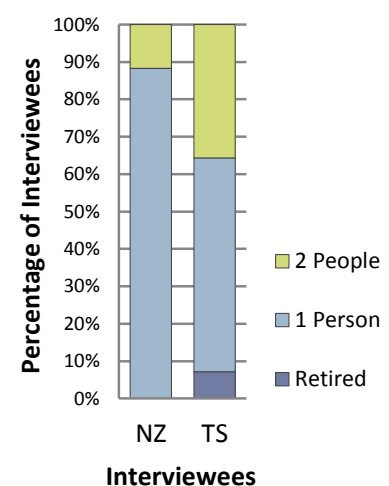

Figure 13: Persons per

household engaged in full-time paid employment (NZ TS)

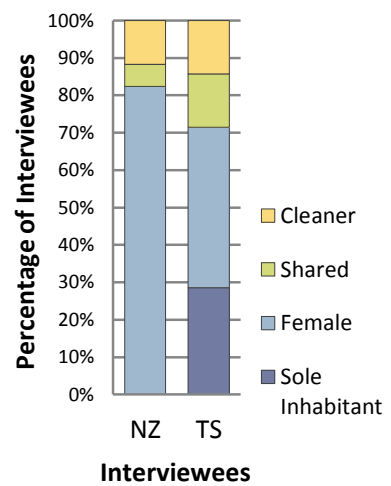

Figure 14: Person responsible for household work (NZ TS)

Since the TS houses were constructed, household work has become less labour intensive due to developments in technology and the plethora of appliances designed to minimise time spent undertaking domestic chores. The 1930s and 1940 s lifestyle interviewees often stated that their mothers had spent a lot of time undertaking household work, "...l know that she (mother) used to boil the washing, make bread...wash floors..." [NZ_07, 0:20:52].

In 1982, the Wellington Branch Society for Research on Women in New Zealand published the results of interviews with 51 women born in Wellington at the turn of the century, many of whom share similar information, "...mother never worked after she was married, heavens no, she had enough to do didn't she?" and another interviewee recalled, "...you spent all day doing housework. It really was full time..." The authors also commented on the physical hardships suffered by women before the introduction of labour saving devices (Society for Research on Women in New Zealand, 1982, p. 51).

The 1930s and 1940s lifestyle interviewees recalled that clothes washing took place once a week, most usually on a Monday, "...well Mondays would be all day really...getting the copper going, then boiling the bed linen, then rinsing it and putting it through a hand wringer, then pegging it out onto the line..." [NZ_13, 0:22:02], "...we had a copper...it did have firewood when I was little and that was changed to gas at 
some stage...Monday was always known as the wash day, but if the weather wasn't quite so good, then it did have to move from day to day..." [NZ_15, 0:07:00].

This contrasts with the modern TS households, some of whose washing machines are used daily or twice daily [TS_10, 0:40:08]. TS interviewees often struggled to estimate the weekly time spent on household work, as much of it is automated [TS_01, 0:20:38], "...we'll go to bed most nights and flick the dishwasher on and time delay some washing...so that kind of stuff happens for you while you sleep..." [TS_03, 0:45:58]. Vacuum cleaners, dishwashers and other labour saving devices mean household work can be done more quickly than in the past allowing inhabitants to spend time on other activities. Present day methods of space and water heating have also freed inhabitants from the time involved in the lighting and maintain of a coal range, and especially the cleaning and black leading.

The case study houses were constructed with a bathroom containing a cast iron bath with a hot and cold water supply. Many of the 1930s and 1940s lifestyle interviewees recalled bathing once a week and it was not uncommon to share bath water with other members of the household, "...l used to have a bath with my mother very often...I think the water used to sort of run out, it didn't seem to be continuous like it is now..." [NZ_02, 0:07:06].

All of the TS case study houses have since been fitted with showers, either over the bath, or in a separate shower cubicle. Water heating is usually continuous and the interviewees suggest that daily showers have become more popular than taking a weekly bath. This is supported by the findings of the HEEP study, where it was observed that while $25 \%$ of $1971 / 72$ households used the shower, or mainly the shower, by the late 1990 s $94 \%$ of households used the shower, or mainly the shower, in preference to the bath (Isaacs et al., 2010, p. 255).

Food preparation has changed considerably since the 1930s and 1940s with a far greater variety of food now available. The introduction of fridges and freezers has enabled the purchase of pre-prepared food, and in many households, to a greater or lesser extent, the time involved in food preparation has shifted from house to industry. 
During the 1930s and 1940s, bought food was usually basic ingredients such as flour, sugar, butter, milk and eggs. There were no fridges or freezers and interviewees recall that fresh food such as milk, meat and poultry was often purchased daily [NZ_06, 0:53:40]. One interviewee described the food safe,

"... which stuck out from the house with wire netting, very fine netting around it, so it could get a breeze through it, and slats to keep any sun off, and slatted shelves, and you hung a muslin over a milk container into a bowl of water to keep things cool...meat didn't keep well...if you bought on Friday, you needed to have it cooked...by Sunday..." [NZ_15, 0:22:59]

Many of the 1930s and 1940s lifestyle interviewees recall breakfast was typically porridge or Weet-bix and toast, lunch was soup or a sandwich, and dinner was meat and two or three vegetables followed by a home-made pudding [NZ_01, NZ_06, NZ_08]. In most cases, mother prepared the food and would spend a similar amount of time on this each day, "...she would start preparing around about four o'clock in the afternoon...she'd have a cup of tea in the afternoon and then start preparing the vegetables...Saturday morning was cake and biscuit baking..." [NZ_13, 0:34:10].

The time spent in food preparation today does not appear to be so fixed. One TS volunteer stated they could take anywhere between 10 minutes and an hour to prepare dinner [TS_06, 0:49:45], and two other interviewees stated that they spent approximately 30 minutes a day preparing dinner [TS_03, 1:00:07; TS_10, 0:48:25]. TS volunteers often struggled to describe typical main meals eaten during the course of week, with many mentioning a variety of dishes from different cultural backgrounds, involving rice, pasta and potatoes [TS_05,0:35:16; TS_08, 0:34:21]. The person responsible for food preparation today is not always mother (Figure 15), as one male TS volunteer, responsible for the preparation of his children's lunches, indicated:

"...the kids complained about their lunches, so I was given a list of what goes on what days...and they get quite flash lunches I think...cold toasted sandwiches on Mondays, Tuesdays is a ham cheese roll with fruit and a biscuit, Wednesdays...I 
think Wednesdays was rice salad for a while...Thursday they have wraps... Friday they have cold sausage and bread." [TS_07, 0:31:27]

Eating out is common amongst the TS interviewees with $5(36 \%)$ doing this weekly and 4 (29\%) fortnightly. This contrasts with the 1930s and 1940s interviewees, none of whom recalled eating out (Figure 16). This again illustrates a shift in a portion of the time involved in food preparation from house to the fast food outlet, café or restaurant.

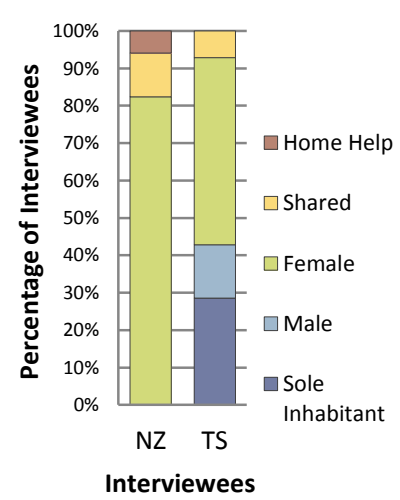

Figure 15: Person responsible for food preparation (NZ TS)

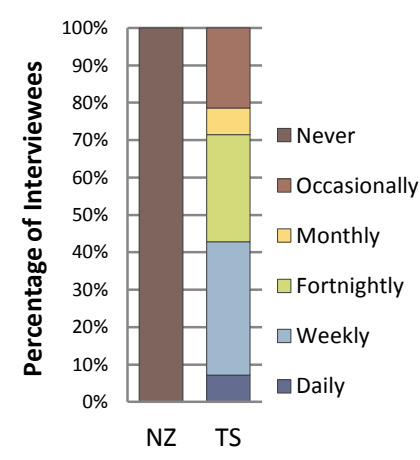

Interviewees

Preservation of food was not part of the recorded oral interview guide, but was mentioned by several of the 1930s and 1940s lifestyle interviewees, "....mother used to preserve, because there weren't any freezers, and she had a large cupboard...it would be full of these preserves... we had to stone peaches and things, it took ages..." [NZ_02, 0:22:27], “...she made...shelves and shelves of bottled fruit..." [NZ_07, 0:23:02].

How food is purchased has also changed, with most TS volunteers travelling by car to a supermarket for a weekly shop. Many of the 1930s and 1940s lifestyle interviewees recalled food being delivered [NZ_13, 0:28:16], as does one of the women interviewed as part of the Wellington Branch Society for Research on Women in New Zealand study.

"We didn't have a rubbish collection and there was night soil. We had the milkman come right to the back door and ladle out our milk for us. Bread was 
delivered each day, the man would come up with the basket." (Society for Research on Women in New Zealand, 1982, p. 51).

An early TS resident described milk being delivered by a horse drawn cart and dispensed into billies (Moroney, 2004, p. 4). An Indian fruiterer visited the settlement selling produce and wares from his van. An interviewee who lived in Wadestown (a nearby suburb) during the 1930s and 1940s also recalled the same gentleman,

"...a green grocer would come around on a truck, he was an Indian and he was always, 'the Hindu', and he would park his truck...on the corner, and all the housewives would go up and go into the truck...he'd take all the money, then he'd drive onto the next bit..." [NZ_14, 0:20:39].

Bread and buns were delivered by van from Denhard Bakeries, and stale buns were given to children and greatly appreciated (Moroney, 2004, pp. 4-5). Time spent purchasing food could be minimal, with products brought directly to the house or street, making the 1930 s and 1940s street a vibrant and busy place, with mothers congregating around the various food and hardware sellers.

During the 1930s and 1940s, the house was very much a place of production and many interviewees recall time spent sewing and mending, "...we did all our own sewing, everything we wore, we sewed and knitted..." [NZ_17, 0:47:52] and, "...my mother...she made all my clothes, she was a sewer...I was always dressed quite nicely actually, and of course, during the war when things were scarce, she even unpicked jerseys and re-knitted them into something else..." [NZ_11, 0:36:43]

During the Depression, one interviewee recalls that soap was made in the coppers which were also used to cook the Christmas ham [NZ_17, 0:32:20].

TS current occupants did not describe similar occupations, indicating that inhabitants are not spending as much time producing goods inside their house as people did during the 1930 s and 1940 s. 
It would also appear that people are spending more time inside their houses today than in the past, which potentially may be to do with the improved levels of internal comfort found in some houses today. The 1930s and 1940s interviewees spent a lot of time outside, "...in the early days in Frankton, there was so little traffic... we played tennis up and down the road, we'd just have to scatter off when a car came along..." [NZ_17, 0:49:04], and "...we were always encouraged to be outside unless the weather was really bad and we would play on the lawn...often we would play with other children on the street..." [NZ_13, 0:15:49]. Children's activities then appear less structured, with more free and exploratory play, often in the street.

TS occupants with school aged children mentioned a range of organised out-of-school activities (including ballet, swimming, rugby and Girl Guides) which their children did weekly [TS_3, 1:20:22; TS_6, 1:00:20; TS_7, 0:35:19]. Often, private transportation is used for travel to and from these activities, highlighting another change in time use.

In contrast, an early TS resident recalls children and their families blackberry picking, gathering wood, taking biking trips to Titahi Bay, trolley races down Colway Street, and fishing on the wharf at night to catch mackerel (Moroney, 2004, pp. 16-17).

"There was no time to get bored with fishing at Boom Rock at Makara and also on the Wellington wharves and opposite the floating dock. There was sport to which we walked or biked, family picnics, swimming, making canoes from old corrugated iron, gathering pine cones, trolley races and in general thinking up ideas that would keep us occupied." (Moroney, 2004, p. 15)

During the Depression many Tarikaka housewives walked to Thorndon to collect their husbands' pay from them, pick up fresh supplies and catch the steam train home. This trip would often be turned into a picnic and was a good outing for the children (Moroney, 2004, p. 7). Many interviewees recollected with fondness the freedom they experienced as children and the community spirit they felt, "...there was more friendship, or more sort of co-operation among people..." [NZ_07, 0:39:42]; "...well I think there was a greater sense of community...of necessity really because...at the beginning, most people didn't have cars and there were no shops...some people found 
that very oppressive..." [NZ_13, 0:56:17]; "...I was not aware of being a member of the lowest sections of society when I lived there [Frankton]...[people were] all the same, that was really the great thing..." [NZ_17, 0:58:42]. It would appear that during the 1930s and 1940s, people spent more time with neighbours and inhabitants of the street, possibly out of necessity because of the lack of alternatives and private transport. Similarly, there does not appear to be as much social activity taking place in the house as formally. A typical evening during the week for most TS interviewees is spending time at home with their immediate household members. Typical activities are cooking and eating dinner, bathing children, watching television and working on computers. It is more common for current TS interviewees to spend time with extended family or friends at the weekend, than during the week.

\subsubsection{Outdoor Space}

The function of the outdoor space associated with the TS houses has changed since the houses were constructed and, as a consequence, the amount of time spent in the outdoor space has also changed. An early TS resident recalls that, "The sections were quite large and everyone endeavoured to put down a large vegetable garden and the competition was fierce." (Moroney, 2004, p. 2).

All of the 1930s and 1940s lifestyle interviewees recall part of their garden was set aside for growing vegetables. Many remember having a flower garden at the front and a vegetable garden at the rear of their house, with father mainly responsible for the latter. Father was wholly responsible for garden maintenance in 7 (41\%) of the interviewees' households, the exceptions being fathers not in good health, one interviewee whose mother had been widowed and two whose parents employed a gardener (Figure 17). In some cases, children were also involved, "I had my own veggie garden; I used to sell veggies, even to my mother." [NZ_03, 0:34:15]. 


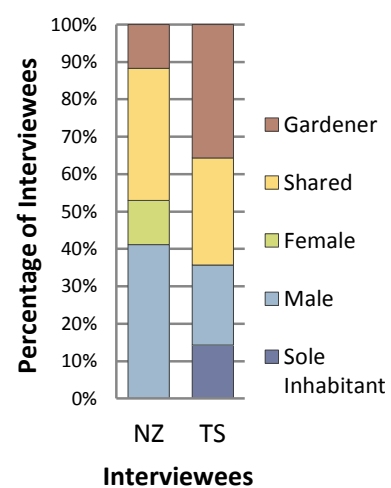

Figure 17: Person responsible for garden maintenance (NZ TS)

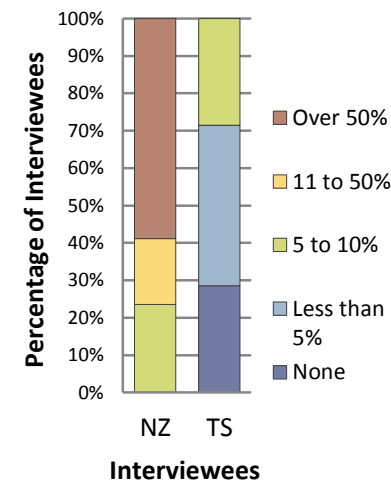

Figure 18: Percentage of consumed vegetables grown at home (NZ TS)

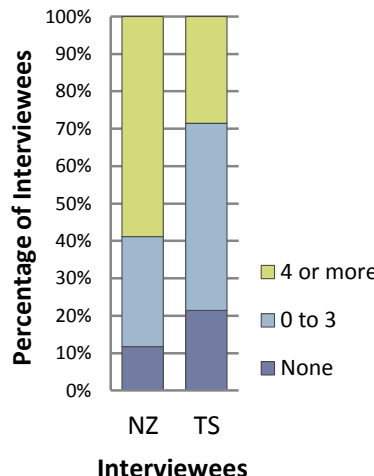

Figure 19: Number of different types of fruit grown at home (NZ TS)

For most interviewees, a large percentage of vegetables came from the garden, "...we had quite a large vegetable garden, and grew potatoes and kumara and cabbages and beans, peas sometimes...we ate a lot from the garden." [NZ_09, 0:18:07] (Figure 18).

"You would buy potatoes out of season, and I'm sure my mother did buy other things, I couldn't give a proportion to it, but l'd hazard a guess that, over a year, a majority of the vegetables came from the garden, but there'd be a substantial minority came from a shop..." [NZ_01, 0:57:37].

When money was short during the depression the gardens, ".... were a great source of food for the table..." (Moroney, 2004, p. 6), "...we were very hard up during the depression and, my word, the garden was a very essential component in our standard of living." [NZ_11, 0:12:10]. One interviewee recalls that at one stage, the entire garden had been given over to potatoes [NZ_05, 0:10:16]. Fruit was also grown in 15 (88\%) of interviewees' gardens, with $10(59 \%)$ producing four or more different varieties (Figure 19). One interviewee recalls,

"...there was a bit of a pattern...that the wife would look after the front garden and the flowers, and the husband would look after the vegetable garden, but there were lots of exceptions to that...there was a man opposite who was...a sales manager for a very large engineering firm that imported earth moving equipment...he used all of his back garden for growing prize daffodils...that was 
his thing, he wasn't the slightest bit interested in vegetables...my parents' would of needed the vegetable garden as part of...managing...my father's wages...whereas, some families, their income was higher, so they weren't dependent on having a vegetable garden." [NZ_13, 0:01:43].

Chickens were kept by 7 (41\%) interviewees (Figure 20) and one who had lived in a Frankton railway house recalled, "...there was a man along the road who turned his whole place into a poultry... farm ... we bought eggs from him...he was a Shunter...he made quite a thing of producing eggs and fowls you know..." [NZ_17, 0:35:39]. Many of the interviewees stated their fathers enjoyed looking after the garden and would spend considerable time doing this, and one mentioned that his father did not have much else to do [NZ_10, 0:14:09]. In terms of time, one interviewee recalled garden maintenance taking a couple of days a week [NZ_09, 0:20:24], the same time as someone's father who spent all weekend in the garden [NZ_01, 0:17:37]. In contrast, one interviewee felt his father was not fond of gardening and only did what was necessary [NZ_16, 0:07:39]. The productive nature of gardens during the 1930s and 1940s meant that it was essential to spend time outside looking after them.

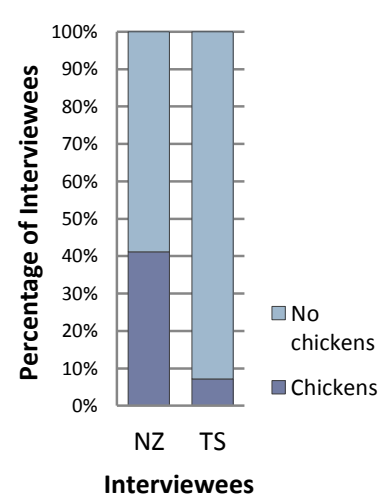

Figure 20: Percentage of interviewees keeping chickens at home (NZ TS)

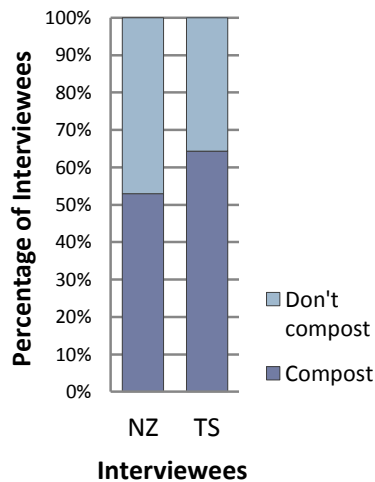

Figure 21: Number of interviewees composting household waste (NZ TS)

The 1930s and 1940s lifestyle interviewees generally struggled to recall what had happened to house and garden waste, "...what on earth did we do with our rubbish?...I've no idea!" [NZ_17, 0:13:16], although 9 (53\%) mentioned composting, 
"...my father had a trenching system with the garden, that all the vegetable scraps went into a trench which he would cover over and create another trench...it was a very elementary form of composting." [NZ_13, 0:13:43]. "My mother had dug a hole in the garden, and she would use that as a compost hole... what other rubbish would we have?...all the vegetables peelings and stuff went into a hole in the garden...so we were green-ies even in those days." [NZ_15, 0:09:10] (Figure 21). Slightly more composting now seems to be happening in the TS houses, though this maybe because 1930s and 1940s interviewees could not remember what happened to household waste.

Today, kitchen waste is composted by $9(64 \%)$ of the TS volunteer households, mostly in a compost bin, rather than trenches or holes in the garden. This may reflect moves by the local Wellington regional Council to encourage composting and reduce organic rubbish going to landfill (Greater Wellington Regional Council, 2014). A current TS interviewee had discovered a lot of rubbish buried at the bottom of their garden, "...there was no rubbish collection for the people living in these houses...so digging in the garden was an adventure...trees went in where I could get them in." [NZ_01, $0: 13: 40]$. Another stated their garden was full of filled-in hangi pits which had dropped down, "...there were lots of stones, which obviously had been used for the heating, but also, probably because they were railway workers, they had used excess bits of railway iron, and they were down in the hangi pits as well...they would have conducted the heat brilliantly." [TS_03, 0:28:15], illustrating that in this TS household, the garden had once been used in the preparation of food.

Vegetable gardening is still popular amongst the TS interviewees, with 10 (71\%) growing vegetables, however gardens are far less productive than in the past, with 6 (43\%) estimating they grow less than $5 \%$ of all their vegetables and the remaining 4 (29\%) between 5 and 10\% (Figure 18). Only 1 (7\%) of the current TS households keep chickens (Figure 20). Garden maintenance is either undertaken by the sole inhabitant (14\%), the male member of the household (21\%), or is shared $(29 \%)$. In $5(36 \%)$ households a gardener is employed, or assistance comes from someone outside the household, commonly a father-in-law (Figure 17). In 4 of these 5 households, all adults 
are working full or part-time, which may explain the need for assistance with the garden. Far less time is spent gardening now than in the past, even though gardening is still considered pleasurable. The fact most adults now work for money is clearly one reason for this, although another might be the availability of other types of recreational activity, "I don't tend to use the outdoor area for much, except for gardening. I do enjoy gardening, so that's good, I probably don't get out as much as I should..." [TS_13, 0:12:57].

Gardening is often less labour intensive today than in the past, due to the availability of electric lawnmowers, trimmers, hedge clippers and other petrol or electric powered garden equipment. One retired TS interviewee said of modern garden maintenance, "...some days it's only half an hour as I wander round with a bucket, other days I can spend five hours..." [TS_01, 0:16:40]. Weather is mentioned by many of the TS interviewees as preventing them spending lots of time outside [TS_06, 0:25:45; TS_10, 0:26:18], although one interviewee would spend as much time as possible outside, which normally amounted one day a week [TS_12, 0:11:34], much less than the two days spent on garden maintenance by fathers in the past. Many modern interviewees have invested considerable time and money landscaping their gardens, "...we flattened out the back and we built some retaining walls and moved some earth about... we built a new fence out the front and concreted various areas...planted a few trees..." [TS_07, $0: 14: 38]$. For one TS interviewee, the garden had been redesigned with the intention of making it low maintenance [TS_11, 0:23:25], while another interviewee mentioned that due to the size of the section, gardening was both a pleasure and a chore [TS_09, $0: 15: 26]$. This same interviewee estimated that they spent approximately one hour a week maintaining the garden [TS_09, 0:16:39], again very much less than fathers in the past.

For $2(14 \%)$ present day interviewees, the garden was the main reason for choosing to buy the house and $2(14 \%)$ gave the deck and indoor/outdoor flow as being the best thing about it. Double doors to the rear are found in 11 (79\%) of the houses, commonly opening onto a deck or area of hard landscaping and several interviewees mentioned having these doors open in good weather. Most appeared to appreciate 
having a good sized section, although few spend much time outside (apart from the retired interviewee and those undertaking DIY landscaping work). Clearly there has been a shift from the high maintenance productive garden, to a low maintenance garden for looking at, or spending time in when the sun shines. It would also appear that gardening is no longer something that automatically comes with house ownership in New Zealand, "...I will only garden if it's not windy and the sun is shining..." [TS_02, $0: 15: 47]$. The general picture of gardens today is that they are not often used but, at the same time, absorb money as people landscape and replant them. It seems today that the garden is a desirable thing to have but not necessary for the household's economic survival. The view from the window may have become more important than being part of the outside world.

Only 2 of the 1930s and 1940s lifestyle interviewees recalled work to the garden, both times being the construction of a wood shed.

The 1930s and 1940s lifestyle interviewees often indicated children were expected to be out of the house as much as possible, "...we were always encouraged to be outside, unless the weather was really bad and we would play on the lawn... we couldn't go anywhere near the vegetable garden...often we would play with other children on the street..." [NZ_13, 0:15:49].

A number of the TS gardens contain formal play equipment, such as trampolines, sand pits, tree houses and rope swings. Interviewees indicated that they wanted their children to spend time outside in the gardens although bad weather would still tend to prevent this. No TS interviewees mentioned their children playing in the street, emphasising a change in use of the public space from somewhere for people to somewhere for the car. Interestingly, no-one mentioned using the 1983 Recreation Reserve.

\subsubsection{Sense of Community}

During the 1930s and 1940s, children seemed to spend a lot of time with other children who lived nearby, thus strengthening links with neighbours and building and reinforcing the sense of local community. As mentioned previously (section 3.2.1), 
mothers would congregate at the food delivery vans, giving the opportunity to form and strengthen relationships with those living nearby.

One TS interviewee felt there was no strong sense of community in the street today, but explained that there were still friendship groups [TS_01, 0:34:13], something reiterated by other interviewees [TS_11, 0:47:48]. This concurs with research undertaken in the UK, in which residents of new housing developments were interviewed to obtain their views on the design of new housing. In most of the developments there appeared to be little social interaction between residents, not simply because the public spaces were not conducive to this activity, but because the residents felt that they were busy and did not seek to form relationships within the development (Commission for Architecture and the Built Environment, 2005).

\subsection{Space Use}

\subsubsection{House}

The 1920 report of the Women's Committee of the N.Z. Town-Planning Association detailed what the committee considered essential for an average family, where the mother looked after the children and undertook the housework (Platts-Mills, Crawford, \& Watt, 1920, p. 1). Foremost was a well-planned and functional interior with a simple external style. This report is archived in the "Railway Department's House Building Programme" file (Platts-Mills et al., 1920) and appears to have influenced the design of the railway houses (G. Ferguson, 1994, pp. 81-82). The monthly magazine, New Zealand Building Progress reported that in 1920, the Women's Committee of the Town Planning Association had inspected, and approved the Railway Department's new houses near Wellington (Unknown, [New Zealand Building Progress], 1920). The class A.B.1123 factory-cut house of $87.5 \mathrm{~m}^{2}$ (which includes the wash house and WC) comprised a short hall, a parlour with an open fireplace, a living kitchen, kitchenette, bathroom with bath, and 3 bedrooms (Unknown, [N.Z.R. Architectural Branch], Unknown). The original floor plan and a typical front elevation are shown in Figure 22 and Figure 23. 


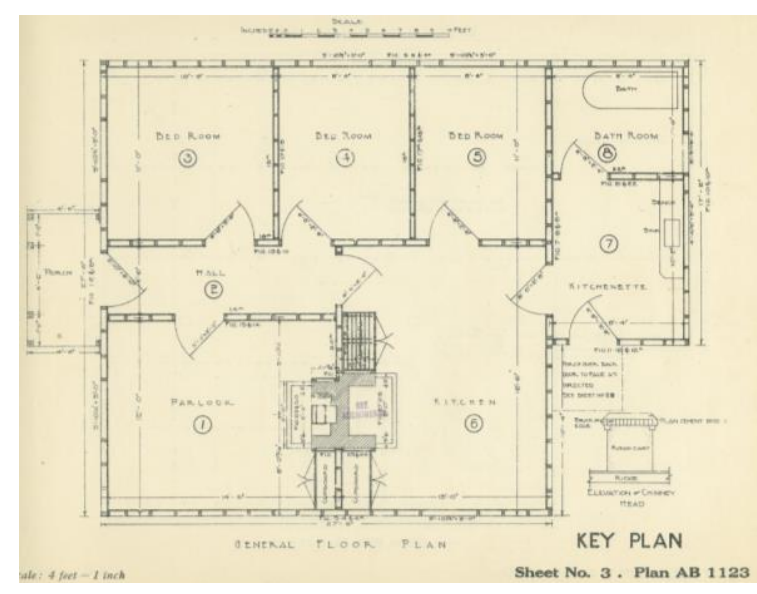

Figure 22: Original Floor Plan, Standard House,

Plan A.B.1123, Factory Cut

(Unknown, [N.Z.R. Architectural Branch], Unknown)

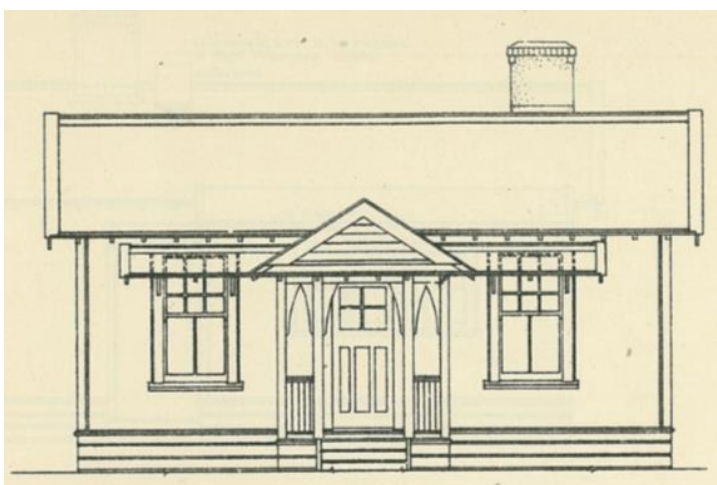

ROOFA, PORCHA

Figure 23: Typical Front Elevation, Standard House, Plan A.B.1123, Factory Cut

Figure 24 shows the original floor plan redrawn to include the wash house and toilet.
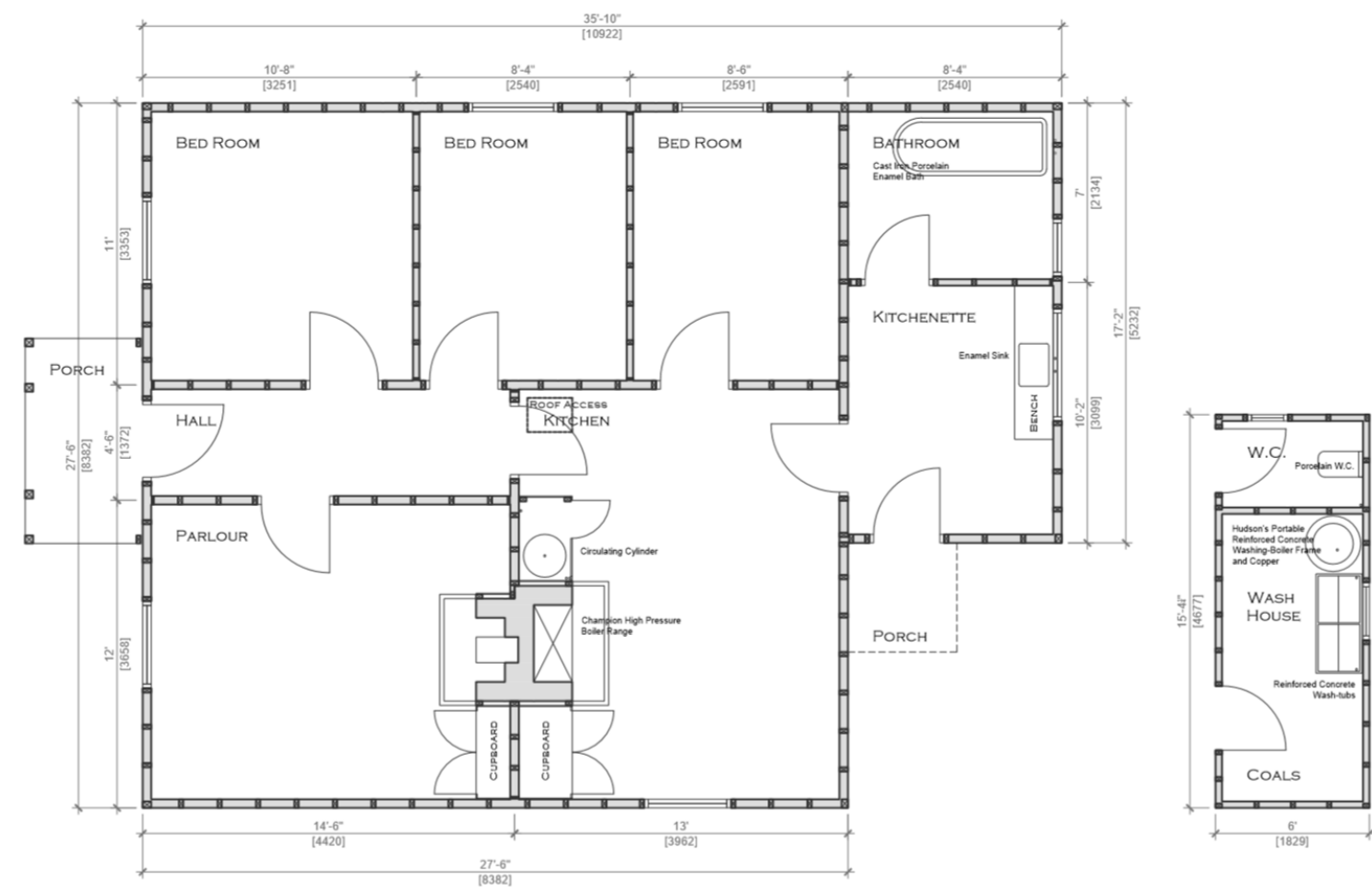

Figure 24: Original floor plan of the TS house redrawn to include the wash house and toilet

As noted earlier, average occupancy in the 1921 Census was 4.43 persons per dwelling in the Wellington urban area (Census and Statistics Office, 1921, p. 15). In 9 (54\%) of the 1930s and 1940s interviewees households there were between 3 and 5 persons per dwelling, and in 6 (35\%) there were 6 inhabitants (Figure 25). In $8(47 \%)$ 
households, a person outside the nuclear family (most commonly a relative, such as grandmother, but also possibly a family friend or boarder) had also lived with them. There were 3 or more adults residing in $7(41 \%)$ of households (Figure 26$)$. The average occupancy was 5.10 for the NZ interviewees. Home ownership was common amongst interviewees, and 13 (76\%) stated their parents owned (or had a mortgage for) the house, while the remaining 4 (24\%) rented (Figure 27).

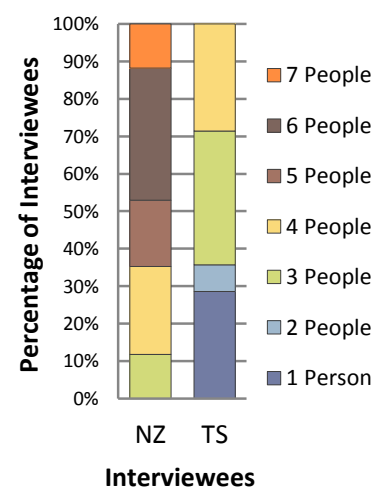

Figure 25: Number of persons per dwelling (NZ TS)

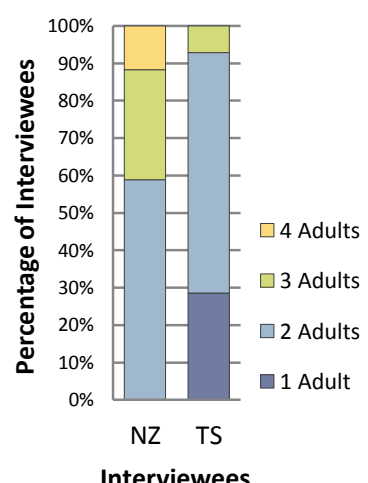

Figure 26: Number of adults per household (NZ TS)

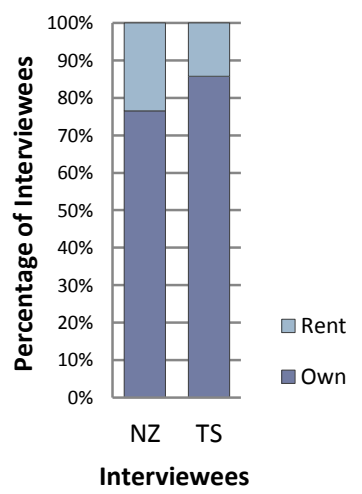

Figure 27: Home ownership (NZ TS)

In sharp contrast, average occupancy in the 1996 Census was 2.77 persons per dwelling (Statistics New Zealand, 1998, p. 45) and 2.64 in this survey of 14 households, none of which contained more than 4 inhabitants (Figure 25). Figure 28 illustrates the drop in the number of persons per dwelling in New Zealand, from 1925 to 2012, based on Census data. 


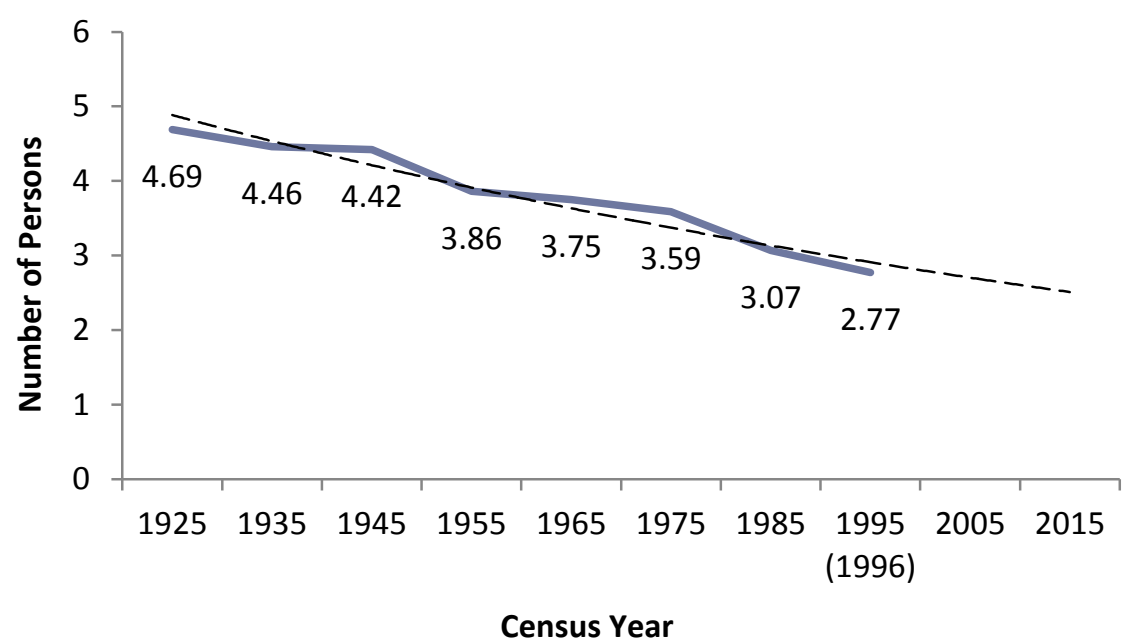

Figure 28: Number of persons per dwelling from 1925 to 2012

Of the 77 houses purchased in 1989 by railway tenants through the Ngaio Railway Housing Trust, 25 years later very few currently remain inhabited by railway workers, none of whom volunteered to participate in this study. TS interviewees were predominantly middle aged, with 12 (86\%) between 21 and 50 years old and many were not native to NZ, with only 9 (64\%) born in New Zealand. The TS houses are no longer solely inhabited by families, with 4 (29\%) of the volunteer households being single persons. Couples with one or two school aged children comprised 8 (57\%) households (Figure 25$)$. Only $2(14 \%)$ of the interviewees were renting their house and, of the remaining 12, 9 had bought post 2000 (Figure 27). Home ownership is similar in both groups of interviewees. Today, lower occupancy levels impact the way that spaces inside the TS houses are used. Figure 29 illustrates the current floor plan of a TS case study house with a floor area of $87.5 \mathrm{~m}^{2}$. 


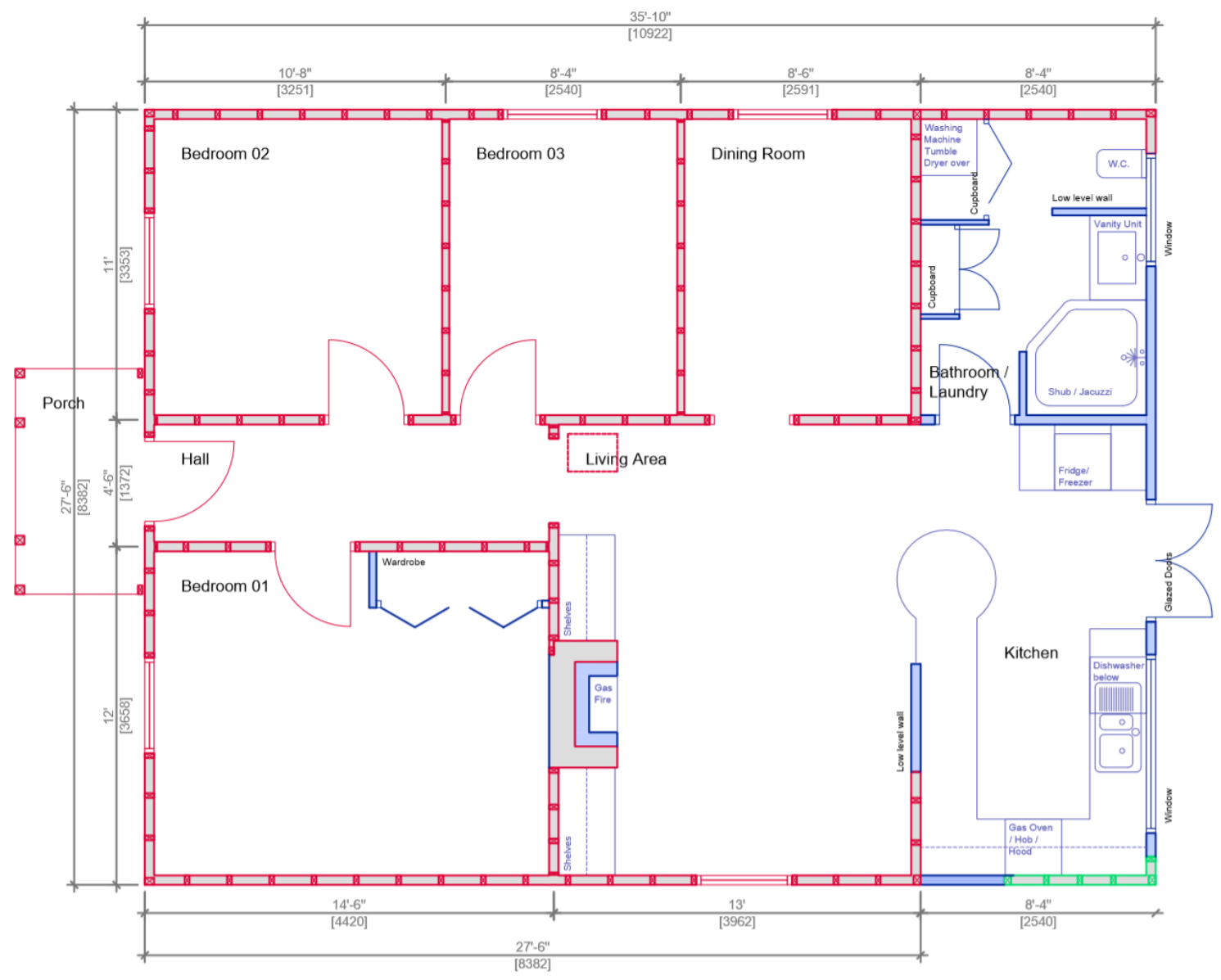

Figure 29: Current floor plan of a TS case study house

\subsubsection{Bedrooms}

In 13 (93\%) of the 14 houses, the original parlour is now the master bedroom and for all these cases, what was originally bedroom 3 has another function, such as a dining area, television room or study. In most of the investigation houses, what were originally bedrooms 1 and 2 are still bedrooms, but now only one person is normally in occupation.

This contrasts with the use of these spaces during the 1930s and 1940s, when bedrooms would have been for more than one child of the same sex. At this time, it was usual for every bedroom to be used as a bedroom and one interviewee recalled not having a bedroom at all:

"...and I slept out on the veranda in the open...the fantails used to come in a poop on my bed in the morning and I did get very wet one time I remember. My 
father, at the other end of the veranda to where I was sleeping, put up a small wall for my older sister to sleep in as she got older..." [NZ_03, 0:06:51].

\subsubsection{Parlour}

One 1930s and 1940s interviewee described the drawing room, or parlour, "...not often entered except without a certain air of respect and it was where my parents entertained their guests or people they judged to be of note, or wanted to impress, or whatever, it was rather more formal..." [NZ_01, 0:07:42], and similarly another interviewee recalled having a best room, which they never went into [NZ_04, 0:11:28].

"Well, there was the family room, as it's called now... and then there was a lounge or sitting room that was used for more formal occasions, when people came for afternoon tea with my mother...or we had relations round for special occasions..." [NZ_08, 0:03:50].

Many of the 1930s and 1940s lifestyle interviewees recounted similar memories of a drawing room or parlour which was not used very often, "...and behind that... what was called the good room in those days, which was a dead loss of a room because we seldom used it." [NZ_10, 0:03:29]. The 1920 report of the Women's Committee of the N.Z. Town-Planning Association required that the sitting room have a fireplace and not be a passage room, it was to be, "...generally used in the evenings when quiet is needed, or for visitors, or as a bedroom in cases of sickness..." (Platts-Mills et al., 1920).

In only one of the TS case study houses, inhabited by a single person, does this front room bear any resemblance to the original parlour. Amongst the TS interviewees, it appears there is no longer a requirement for a sitting room separate from the kitchen, or that the priority has shifted to the need for a larger bedroom. Presumably in cases of sickness, the present inhabitants would occupy a bedroom or the living/kitchen/dining space and visitors would spend time in the living area. 


\subsubsection{Spare Room}

The spare room has become a feature in a number of the TS houses, primarily those occupied by single people and couples with one or no children. This room often serves as a contingency room for overnight visitors [TS_02, 0:04:05; TS_05, 0:07:29]. The study, spare room, storage room or, "...dumping ground..." as one TS interviewee described it [TS_01, 0:05:04], often contains computer equipment and a spare bed. In one of the TS single person households, the interviewee described having two spare bedrooms [TS_02, 0:04:05], and another interviewee was using the third bedroom as a sewing room [TS_09, 0:03:47]. Since the TS houses were constructed, the computer has emerged as a primary method of communication, and all of the TS houses contain a desktop computer, a laptop, or another portable device.

This contrasts with the 1930s and 1940s lifestyle interviewees, only 1 of whom recalled a study space, which was full of books and had a fireplace, where all members of the household would congregate during the evenings and at the weekend [NZ_01, 0:07:42].

\subsubsection{Kitchen}

For the majority of the 1930s and 1940s interviewees, the kitchen was the centre of activity, the room most frequently inhabited and regularly heated, with the parlour seldom used. The kitchen typically contained the coal range, which provided heat for warmth and cooking. The original TS houses were designed with a kitchen and a small kitchenette, or scullery. The kitchenette has since disappeared, with only 3 (21\%) of the TS case study houses retaining the original floor plan ( 2 of which are rented houses). In the remaining 11 (79\%) TS case study houses the back of the house has been remodelled to incorporate a larger kitchen area accommodating the cooking, food storage and washing facilities [TS_03, 0:25:07; TS_04, 0:06:12]. In these houses, the kitchen zone is where cooking takes place, with an adjacent dining area and a lounge area for sitting in, which usually contains the television. This one space commonly contains three distinct areas and is large in size compared to the kitchen of the original house. The relationship between the kitchen area and dining area is 
important, as is the connection between the kitchen and living space. In all 11 (79\%) of the re-modelled houses, double doors open out into the rear garden, highlighting the desire for connection between the internal and external spaces. A timber deck or an area of hard landscaping adjacent to these doors is a feature of all of these houses. Several interviewees explain that the deck is an attempt to create more space, and for some, this acts as an additional living space, "...l kind of consider the deck to be an extension of the open plan living/dining, we spend a lot of time with those doors open, it's surprisingly low wind out there..." [TS_05, 0:07:29].

\subsubsection{Bathroom}

Bathrooms have mostly been remodelled to enable the creation of this open plan living area. In 4 (29\%) cases, the bathroom is now located in what was originally bedroom 2, bringing it into the centre of the house [TS_04; TS_08; TS_09; TS_10]. In $11(78 \%)$ TS houses, the toilet is in the bathroom, and in 12 (85\%) a shower has been fitted, either over the bath (in 6 cases) or in a separate cubicle. Recessed lights and modern fittings and fixtures are a common feature in 9 (64\%) of the TS remodelled bathrooms.

\subsubsection{Laundry}

The original TS houses were designed with a detached outhouse containing the coal store, toilet and clothes washing facilities. The concrete wash boiler (the 'copper') and a pair of concrete tubs were replaced by the utility area which was constructed as an addition to the house by NZGR in the 1960s. All of the TS interviewees have a washing machine, but only 10 (71\%) have a tumble dryer. In many of the TS houses, the utility area has been relocated in a fitted cupboard, in most cases in a re-modelled bathroom. In one case study house, the fitted utility cupboard is located in the living area [TS_06], and in another house [TS_08] the tumble dryer is located in the master bedroom. Many of the TS interviewees state that they would always attempt to dry washing outside, with the tumble dryer offering a back-up in poor weather, or a means of 'finishing clothes off' [TS_12, 0:21:29; TS_14, 0:13:27]. In 3 (21\%) of TS households, 
the tumble dryer is used most of the time. The washhouse today is used as a storage space.

\subsubsection{House Alterations}

Of the 17 1930s and 1940s lifestyle interviewees, 11 (65\%) do not recall any alterations being made to their home whilst they lived there. Alterations to verandas were mentioned by $3(18 \%)$ interviewees and improvements to services, for example the introduction of piped or heated water, were mentioned by 5 (30\%). Only $3(18 \%)$ interviewees stated their house was extended; one whose father was a doctor built a surgery attached to the house [NZ_15, 0:13:49], one who constructed a bedroom in the roof space himself [NZ_03, 0:14:19], and the other whose parents won the lottery:

"Well it was a small wooden house to start with, and then when I was about seven or eight...my father won the lottery, and so we made the house much bigger... we were able to...extend the sun porch into a big living room and make the kitchen dining area much, much bigger and put on a bathroom, and a laundry and...an indoor toilet." [NZ_05, 0:01:55].

The TS houses were not altered for many years, presumably because the inhabitants were renting the houses and were not allowed to undertake any alterations or improvement work themselves. The 1930s and 1940s interviews would suggest, however, that undertaking work on houses was not as common then as it is today, possibly due to the lack of resources, the lack of desire to change things, or simply not seeing a need to change things.

It would appear from the TS interviews that the house is perceived as being more malleable today than in the past, and to many interviewees, bringing about change, refurbishing and modernising their house to suit their functional and aspirational lifestyle is both enjoyable and rewarding. When asked about significant moments in recent years, 3 (21\%) TS interviewees mentioned buying their house or undertaking work to it. 


\subsubsection{The Size of the House}

TS interviewees gave their reasons for choosing to buy or rent the house as well as what they liked best and least about it. Among the latter, 6 (43\%) mentioned the cold and the difficulty of heating it, with its small size mentioned by 6 (43\%) interviewees. Lack of storage space and the continual need for maintenance were other dislikes, “...it's not a lock and leave house ... there's a constant round of mowing, pruning, cleaning, sweeping..." [TS_10, 0:44:46]. One interviewee commented that the houses are often for sale and thought that the small size was one of the reasons for this:

"The worst thing about the house is its size, which didn't used to be a problem, but it is now, and I think that these houses, they suit people for a time, but then you almost get over being in a little cottage, and you want to move on..." [TS_05, 0:24:22].

Concerns regarding the small size of the house were re-iterated by other interviewees, “...it's just not big enough and if I could make it bigger, I would..." [TS_08, 0:17:49]; "...we live in a small house, and there's very little storage, and we're both hoarders, so you know, there are moments in time where you think, oh God, this is just getting too much..." [TS_06, 0:31:17], and "...so everything we have done when it comes to renovation has been to find more space, we are often thinking about how we can get another cubic foot of space here and there...so for me the house just isn't big enough..." [TS_03, 0:37:18]. This reflects the fact that houses in New Zealand are getting bigger, highlighting a desire for more space (Page, 2012),

Storage space has been increased through fitted wardrobes in bedrooms of many of the TS houses. Loft ladders have been installed in often widened loft hatches. Outhouses now contain bicycles, gardening equipment and tools, with space beneath the houses utilised for the storage of other outdoor equipment.

As previously discussed (section 3.2.1), the house has shifted from being a place of production to a place for sleeping and storage. More people are spending time inside the house than in the outdoor space (section 3.2.2) and it could be argued that the house has become a place for the containment of technology and a depository for 
consumer goods. Today, consumerism, which was not so prevalent during the $1930 \mathrm{~s}$ and 1940s, dictates that an increasing number of goods are required to support a contemporary lifestyle, resulting in more storage space (Cwerner \& Metcalfe, 2003).

Several of the 1930s and 1940s lifestyle interviewees shared that they didn't lock their doors because they didn't have anything worth stealing, "...the doors weren't locked, windows weren't locked...nobody broke in, there wouldn't have been much for them to take anyway..." [NZ_09, 0:52:14]. Most recalled that they felt safe in their houses, and that there wasn't the need for security, "...we always locked the door, because that was the responsible thing to do, and you put the key under the mat in front of the door... and that was the practice everywhere, the key was under the mat..." [NZ_10, 1:00:27].

Similarly, while the majority of TS interviewees feel safe in their houses, they all mentioned locking their doors, illustrating the wider social change which has taken place since the case study houses were constructed, and which may also reflect the feeling (or fact) that people now have more items worth stealing.

\subsubsection{Outdoor Space}

\subsubsection{The Garden}

As previously discussed (section 3.2.2), since the 1930s and 1940s the function of the outdoor space associated with the TS houses has changed enormously. In contrast to the post and wire fences which divided rear gardens in the 1930s and 1940s, many interviewees have erected fences to contain children or animals, making the once transparent boundary lines more solid, as inhabitants seek to make their property more secure. Externally, timber decks and retaining walls have created flat areas of garden bringing order and structure to the original sloping sites. Level gardens are easier to maintain and safer for young children to play in, they also allow for trampolines which are a common feature in many of the gardens. When asked about alterations to the house and outdoor space, 13 (93\%) of TS interviewees mentioned undertaking work to the garden, the most common answer (Figure 30), and many interviewees have invested considerable time and money in landscaping garden areas. 


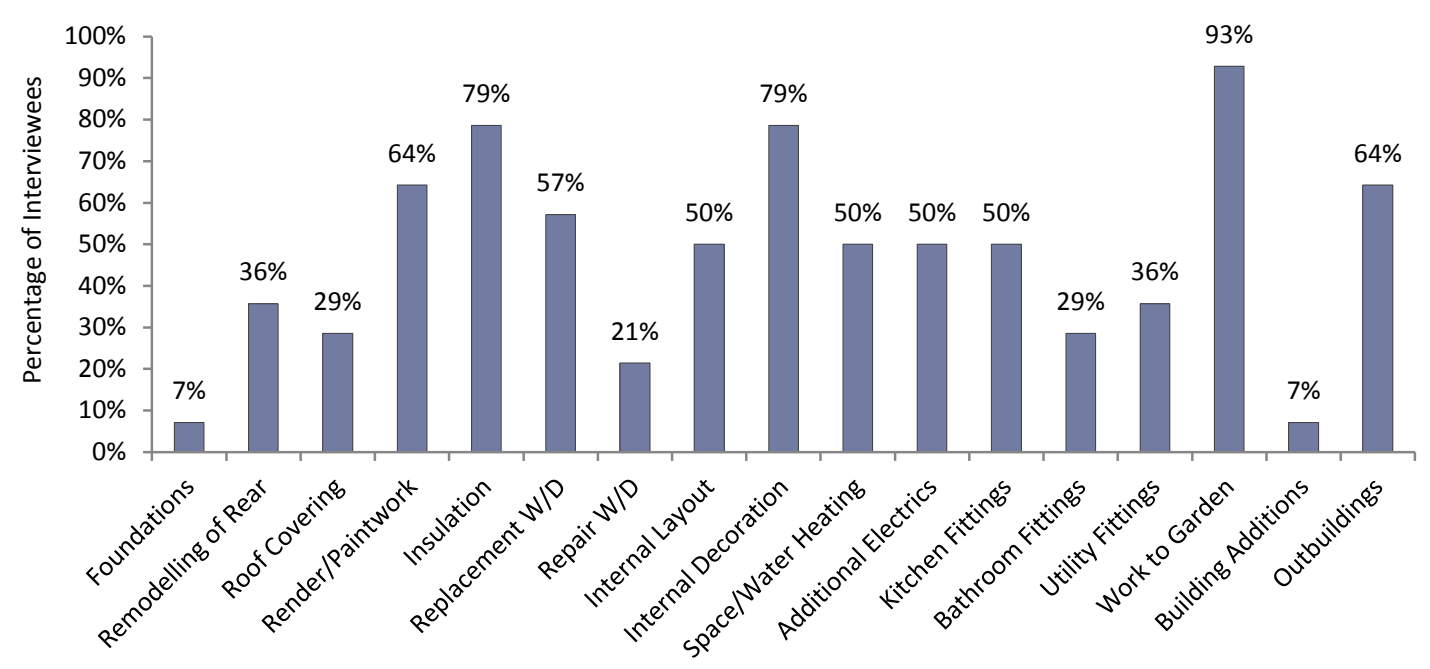

Figure 30: Alterations undertaken by the TS interviewees

As discussed in section 3.2.2, during the 1930s and 1940s, a significant part of the garden was set aside for growing vegetables, and one interviewee recalled that at one stage, the entire garden had been given over to potatoes [NZ_05, 0:10:16]. In contrast, present day gardens are far less productive, with many inhabitants growing vegetables, but on a greatly reduced scale. In many of the TS interviewee's gardens, an area of no more that $2 \mathrm{~m}^{2}$ is set aside for this. Today, far more time is being spent inside the house than in the outside area (section 3.2.2), and as such, it is important that gardens are easy to maintain, and grassed areas, not only to the rear, but also at the front of the TS houses are common.

\subsubsection{Garden Structures}

As described in section 3.3.1, the function of the original wash house has been relocated inside the house, usually in the form of a cupboard in the bathroom containing a washing machine and tumble dryer. Where original wash houses remain, these are generally used as a storage space for gardening equipment or bicycles. There are washing lines in many gardens, mostly the rotary type. The introduction of double doors to the rear of the house, for connection between the internal and external spaces has resulted in areas of hard landscaping (usually a timber deck) being constructed at the rear of the houses (section 3.2.1). One TS interviewee mentioned a shed, in which he spends a lot of time [TS_10, 0:26:18], and another described the summer house, "...perfect for days when you want to be outside and it's windy and yet 
it's sunny and so we positioned it such that the two glassed walls...get maximum sun, so it's a very nice place to sit..." [TS_03, 0:28:15]. Clearly, there is a strong desire amongst TS inhabitants to be able to enjoy the garden, whilst at the same time being sheltered from the elements.

\subsubsection{Space for the Car}

Car ownership was uncommon during the 1930s and 1940s, with 9 (53\%) of the interviewees' families having no car, 7 (41\%) having one and 1 (6\%) having two (Figure 31). The Tarikaka workers mainly went to work by train. One interviewee recalled that, "...from the mid-fifties on, more families in the street had a car and we were one of the few families that didn't, and my father was incredibly conservative as far as...buying new things were concerned...they had a policy that they didn't buy anything until they had saved for it..." [NZ_13, 0:12:49].

In contrast, most current TS households have one car, in 7 (50\%) at least one member uses public transportation regularly, with $2(14 \%)$ never using it and the remainder using it occasionally (Figure 32). Many households have bicycles for recreational purposes, with only 1 household using a bicycle regularly for commuting. This contrasts with the 1930s and 1940s lifestyle interviewees, where bicycles were well used in 12 (71\%) households (Figure 33).

"...l'd made my own bike up from bits and pieces, and I painted it red...from leftover paint from the house roof... got a lot of use from it...and my father went to work on a bike, brother went to work on a bike, and my mother had a bike that she would go to pick up groceries on..." [NZ_10, 0:34:51]. 


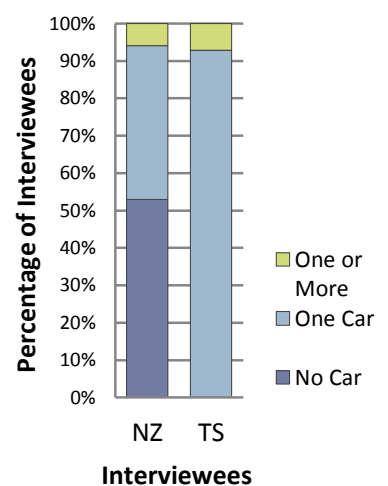

Figure 31: Number of cars per household (NZ TS)

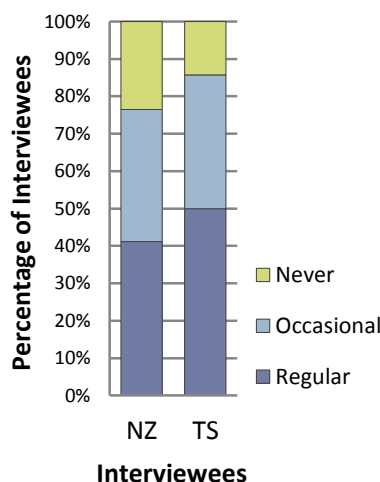

Figure 32: Use of public transportation (NZ TS)

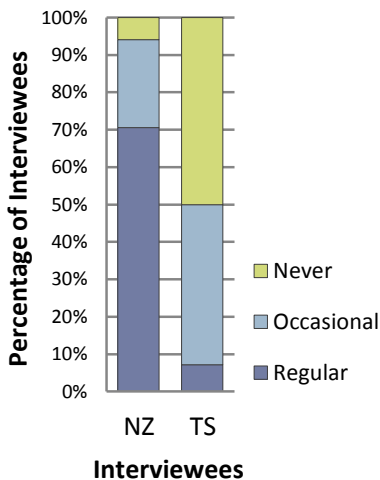

Figure 33: Number of households where bicycles are used regularly (NZ TS)

The introduction of the car has impacted outdoor space use through the driveways and garages to accommodate it, which now occupy space once dedicated to garden area. One TS interviewee described having a car port which was too narrow for a child's car seat to be transferred easily. For this reason, the entrance was blocked off and the side was opened up, with the intention of it being a covered play area for their daughter, “...but in reality it's just ended up turning into a bit of a junk storage sort of shed area...the idea hasn't quite panned out there...if we were to sell the house, we would definitely turn it back into a car port..." [TS_05, 0:20:35].

\section{$3.4 \quad$ Energy Use}

Although energy use is normally thought of as occurring inside the house, the more extensive use of the garden area has resulted in energy also being used there.

\subsubsection{House}

This section reviews the different energy utilities and the main energy uses in the house, past and present.

\subsubsection{Utilities}

Unlike some NZ houses at the time, the original TS case study houses had mains water and electricity. Of the 17,1930 s and 1940s lifestyle interviewees, $3(18 \%)$ were 
without a mains water supply (Figure 34 ) and $1(6 \%)$ had no mains electricity (Figure 35). Gas was supplied to 6 (35\%) of interviewees' houses (Figure 36 ) which were in towns.

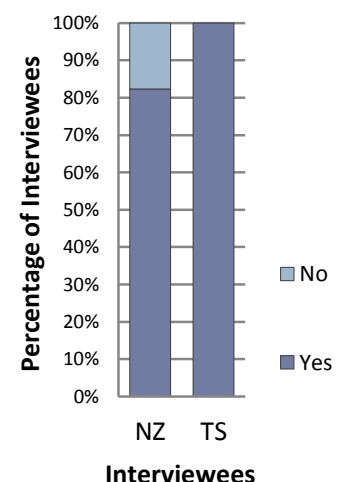

Figure 34: Households with a mains water supply (NZ TS)

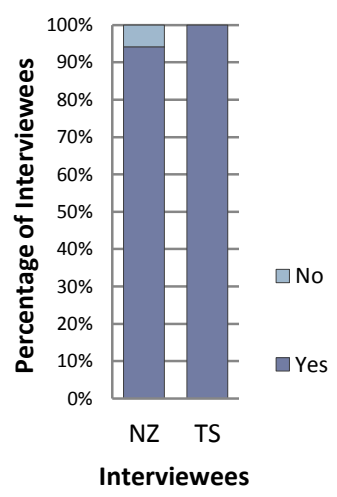

Figure 35: Households with a mains electricity supply (NZ TS)

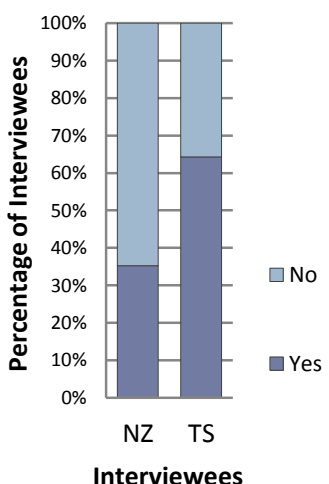

Figure 36: Households with a mains gas supply (NZ TS)

The original TS house had a single drop light in each room, the exception being the parlour which had a two light pendant. A single electric socket was provided in the kitchen (Figure 37). The outhouse had no electricity, with the copper being heated directly by a wood or coal fire. 


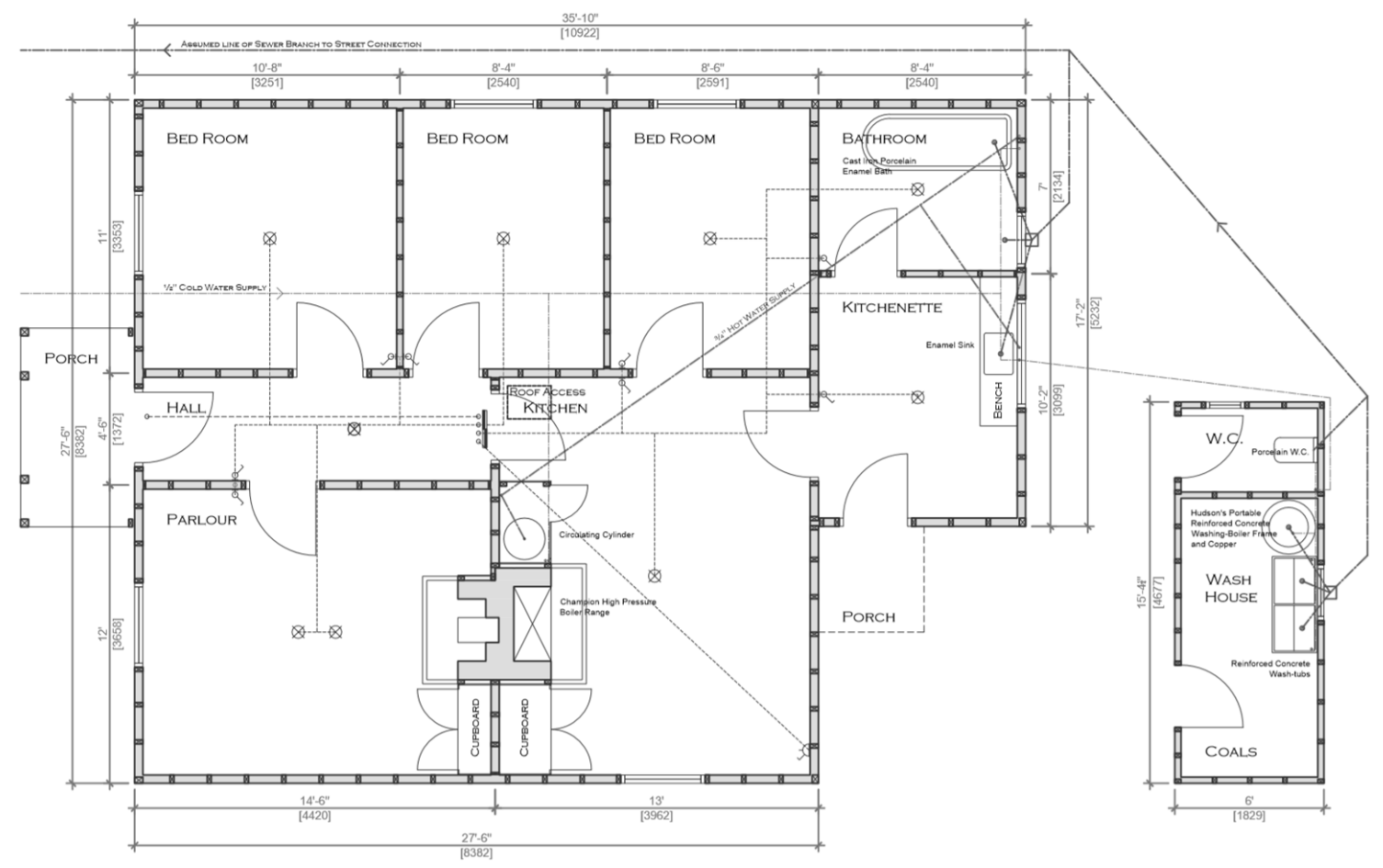

Figure 37: Original floor plan of a TS house showing mechanical and electrical layout

All of the TS case study houses are still on mains water and electricity, and, since being sold by the NZR during the 1980s, 9 (64\%) have been connected to mains gas (Figure 36). In many of these houses, multiple electrical sockets are now positioned in each room, with electricity no longer restricted to a single location, but accessible throughout the house. In most case study houses single drop lights have been replaced with fittings with multiple lights and recessed lighting is common in kitchen and bathroom areas. Figure 38 illustrates the present day floor plan of a TS house. Each room has at least two double electrical sockets and mains wired intruder and smoke alarms. 


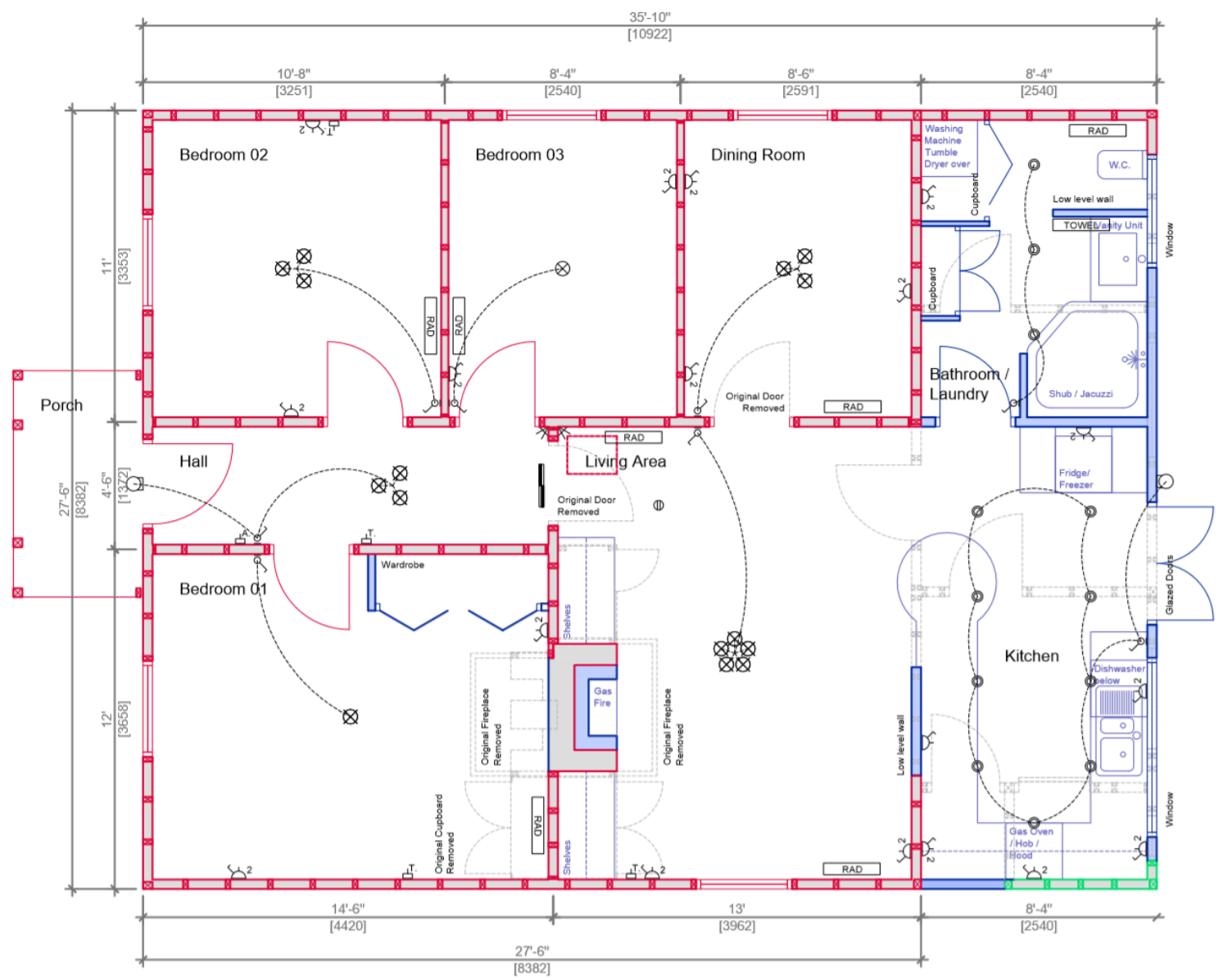

Figure 38: Present day floor plan of a TS house showing mechanical and electrical layout

During the 1930s and 1940s, energy for space and water heating was often a byproduct of the cooking energy, with the coal range fulfilling all functions. In contrast, present day houses usually have different pieces of equipment for the different tasks; for example, a heatpump for space heating, a cylinder for hot water and an electric oven and gas hob for preparing food. Electric fridges, freezers, dishwashers, washing machines, tumble dryers and microwave ovens were not widely available when the TS houses were constructed and their present inhabitants are utilising a far greater number of household appliances than the original occupants.

Most of the 1930s and 1940s interviewees recalled keeping food cool in a food safe (see section 3.2.1). Bread makers, slow cookers, food processors and food mixers and blenders help people to prepare meals more quickly and easily today, but all have energy implications. There has been a small shift in the energy involved in food preparation from house to some type of catering establishment. Another energy shift 
occurs because people buy pre-prepared food which is then assembled or heated up at home rather than making it from scratch.

\subsubsection{Space Heating}

Since the TS houses were constructed, there has been a move from one room to whole house heating. During the 1930s and 1940s, it was usual for houses to have one commonly used heat source in a fixed location. The TS houses were designed with a coal range in the kitchen for cooking, and an open fire in the parlour which was seldom lit (see section 3.3.1.2). An interviewee whose father worked for railways during the 1930s recalled, "... and a wonderful thing being members of staff of railway, we got free coal ... the house was always warm..." [NZ_17, 0:03:17]. Of the 17, 1930s and 1940s lifestyle interviewees, 12 (71\%) recalled the house being primarily heated by an open fire and $3(18 \%)$ by coal range. Only $2(12 \%)$ remembered the house being heated by electricity in the form of a plug in, electric fire (Figure 39). Solid fuel, most commonly coal, was used to heat the house in 15 (88\%) cases (Figure 40). Only 3 $(18 \%)$ interviewees mentioned an additional form of space heating, $2(12 \%)$ of which recalled a gas fire and $1(6 \%)$ an electric radiator.

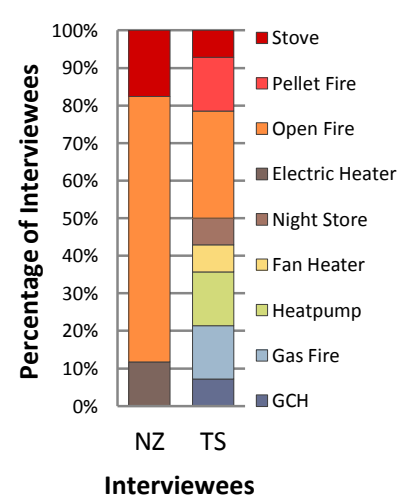

Figure 39: Primary method of space heating (NZ TS)

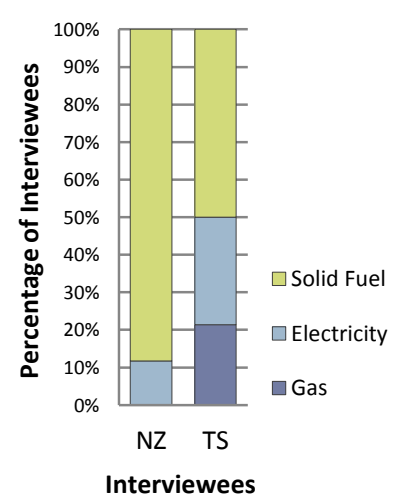

Figure 40: Fuel type in the primary method of space heating (NZ TS)

In sharp contrast, the 14 TS case study houses have as many as 8 different primary sources of heating (Figure 39 ). In 7 (50\%), solid fuel is used to heat the house by open fire/wood burner, pellet fire or wood stove. In the remaining case study houses, 4 
(29\%) are primarily heated by electricity (heatpump, fan heater or night storage heater), and 3 (21\%) by gas (gas central heating or flued gas fire) (Figure 40 ). This reflects the numerous heat sources in NZ houses today, many of which can be moved from room to room. Of the 14 TS interviewees, 11 (79\%) mentioned at least one additional form of space heating, with 9 (65\%) having oil filled radiators located in bedrooms. Additional methods of space heating include; bottled gas heaters, night store heaters, underfloor heating and fan heaters. The fuel used for additional forms of space heating is electricity in $89 \%$ of cases. In addition, heated towel rails in bathrooms are common in several of the TS case study houses.

In the past, windows were opened for ventilation and the removal of condensation. Since the case study houses were constructed, many have been sealed to prevent heat loss which means condensation is more of a problem, so people have dehumidifiers to remove moisture from the air. Ventilation systems in the bathroom and extractor hoods over cooking hobs in the kitchen are found in many of the TS case study houses.

When asked about the things that they liked least about their house, 5 (36\%) TS interviewees mentioned that the houses are cold, "These are very cold houses, quite frankly, if you don't put carpet down." [TS_01, 0:07:55]. One TS interviewee stated, “...we are used to UK dwellings where you've got central heating and a bit of thermal mass... we do miss that..." [TS_04, 0:12:55] and another mentioned, "...I mean ideally you would want to have double glazing and insulation in the walls, but you know, it's a money question isn't it..." [TS_06, 0:17:50]. "The first thing we did was we took out this wall and that made a big difference to the way that air flowed, 'cause the fire didn't heat the house, it only heated this room and very inefficiently..." [TS_10, 0:20:22].

Similarly 4 (27\%) of the 1930s and 1940s lifestyle interviewees mentioned that cold had been the worst thing about their house, indicating that retaining heat has been a problem in the TS houses, as in other NZ houses. One TS interviewee explained the change they experienced after installing under floor insulation,

"...for us, that made the biggest difference because if muffled the noise inside, it was like a big drum, sort of echoing, and it stopped the wind blowing through 
and up...come winter, all of a sudden, it retained its heat from the day and it felt lovely...it just felt cosy." [TS_11, 0:05:22].

\subsubsection{Water Heating}

In the original TS houses, the coal range was used for cooking and a supplementary water heating coil in the firebox (locally called a 'wet back') provided hot water. Figure 37 illustrates the original layout of a TS case study house with the water supply. Cold water was supplied to the wet back, the bathroom, kitchenette and the outhouse. Hot water was transported through galvanised iron pipes from the wet back to the bathroom and the kitchenette.

Water heating for the 1930s and 1940s lifestyle interviewees was varied, with 6 (35\%) recalling a wet back and 6 (35\%) an electric hot water cylinder. A further 3 (18\%) heated water in the copper, or in kettles on the range, with $2(12 \%)$ having a gas califont heater (Figure 41). Fuel for water heating was solid fuel in 9 (53\%) households, electricity in $6(35 \%)$ households and gas in 2 (12\%) households, contrasting with the present day TS houses where water is heated by electricity in $8(57 \%)$ households and gas in the remaining 6 (43\%) (Figure 42). Water is now heated by an electric hot water cylinder in 7 (50\%) of the 14 TS houses, with an instantaneous gas water heater used in $6(43 \%)$ and a night storage system in 1 (7\%) (Figure 41). Hot water is supplied to multiple locations, commonly to bathroom sink and bath, washing machine, utility sink and kitchen sink. Cold water is typically supplied to these locations and also to the dishwasher. 


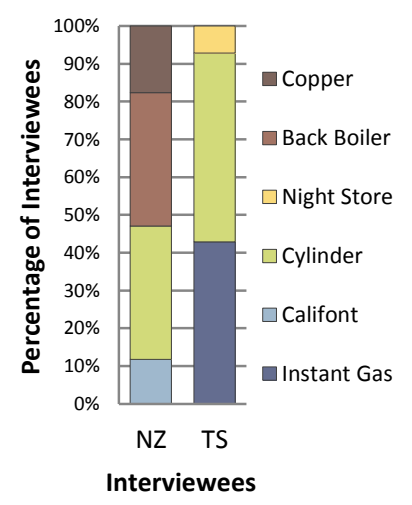

Figure 41: Primary method of water heating (NZ TS)

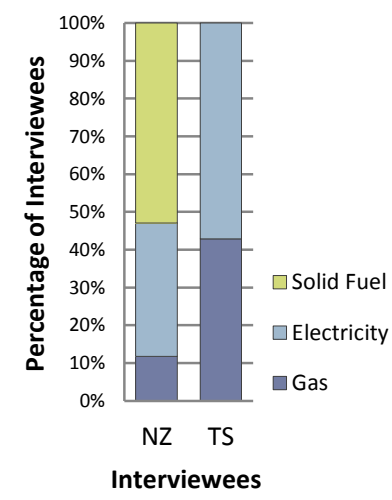

Figure 42: Fuel used in the primary method of water heating (NZ TS)

Many of the 1930s and 1940s lifestyle interviewees recalled that water was heated once a week for washing clothes or for bathing, and this would certainly have been the case for the $3(18 \%)$ households whose water was heated by the copper.

In all of the TS volunteer households, water is available at any time, to allow for regular, frequent bathing. Some washing machines heat water as and when required, while timer control allows clothes washing to be undertaken at any time of the day or night. Water is typically heated more regularly than in the past, but is also heated more efficiently, and no longer as a by-product of space heating. Tumble dryers are frequently used to dry clothes in wet weather, and this has an energy implication.

\subsubsection{Transportation}

As previously discussed in section 3.3.2.3, car ownership is much more common now than it was during the 1930s and 1940s when many families did not have any means of private transportation at home, other than bicycles. At that time, public transportation was often used for commuting to and from work, with the train being the main method of transportation for the Tarikaka workers. As discussed in section 3.2.1, during the $1930 \mathrm{~s}$ and $1940 \mathrm{~s}$ food was delivered direct to the street, contrasting with today, with most of the TS interviewees using a car to go shopping. The car has enabled parents to engage their children in out of school activities which are not local and friendship circles are no longer restricted to those within the local community. 
The use of the car has an energy implication, however this has not been calculated or analysed, being considered outside the scope of this research.

\subsubsection{Outdoor Space}

As discussed in section 3.2.2, less time is now spent in gardens than in the 1930 s and 1940s. This has heating energy implications as people are spending more time inside their houses than in the past, although this will not be investigated further in this research. Gardens are no longer highly productive and garden maintenance is not as labour intensive as it once was, with electric lawnmowers, trimmers and hedge cutters being common in many of the TS volunteer households. External lighting is a feature in modern gardens, also with an energy implication, like the ever present $\mathrm{BBQ}$.

Section 3.3.2.1 discussed the alterations carried out to rear gardens by the TS interviewees, including the erection of fences along boundary lines and the construction of retaining walls to create flat areas of garden connected by steps. The original sloping sites have in most cases been formalised and structured. Timber is the retaining wall material with concrete providing the connection with the ground. However, the energy implications of these external works, which in some cases are considerable, are currently outside the scope of this research.

\subsubsection{Embodied Energy Analysis}

As discussed in section 2.4.3.1, a typical TS house was analyzed at three stages of its life: the first immediately after construction in 1928; the second following the 1960s renovations; and the third following alterations and improvements post-1988. The impact of the regular maintenance of the house after each of these stages was also considered (Figure 43). The embodied energy calculations include the wash house and WC. 


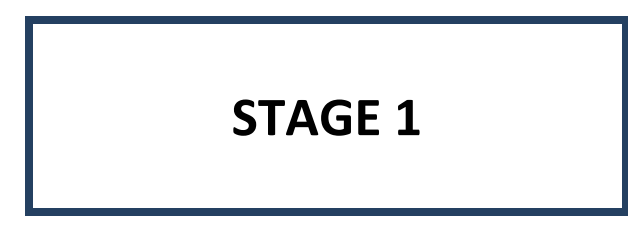

STAGE 2

\section{STAGE 3}

\section{House}

1928 - 1960 Maintenance (30 years)

\section{House (NZGR Alterations)}

\section{0 to 1988 Maintenance (30 years)}

\section{Owner's Alterations}

1988 - 2012 Maintenance (20 years)

Figure 43: The Three Stages of the TS EEA

For each stage, schedules detailing the quantities of materials used in the construction, alteration and maintenance of the house were compiled in an MS Excel spreadsheet. The house was broken into 10 elements; foundations, structure/structural framing, building envelope, internal joinery, internal finishes, heating, plumbing \& drainage, electrics \& lighting, kitchen fittings, utility fittings and bathroom fittings. The complete spreadsheet is on the attached CD-ROM and the TS results tables are in Appendix J.

Figure 44 contains a list of the assumptions used in the embodied energy calculations for the TS houses. 


\section{STAGE 1}

\section{House}

- $\quad$ As original drawings

- Linoleum in kitchen and bathroom

\section{8 - 1960 Maintenance (30 years)}

- $\quad$ Paint to roof $(x 3)$

- $\quad$ Paint to external timber $(x 3)$

- $\quad$ Paint to downpipes ( $x 3$ )

- $\quad$ Paper to internal walls $(x 2)$

- $\quad$ Linoleum in kitchen and bathroom (x3)

- Varnish to internal doors (x3)

\section{STAGE 2}

\section{House (NZGR Alterations)}

- Renewal of house piles

- Construction of addition

- Renewal of house roof

- Renewal of outhouse roof

- New hot and cold water pipework

- New hot water cylinder

- $\quad$ New water tank

- New kitchen including freestanding oven

- New utility fittings

- New bathroom and toilet fittings

- Vinyl in kitchen, bathroom, utility and toilet

\section{0 to 1988 Maintenance (30 years)}

- $\quad$ Paint to roof $(x 3)$

- $\quad$ Paint to external timber (x3)

- $\quad$ Paint to downpipes (x3)

- $\quad$ Paper to internal walls (x2)

- $\quad$ Vinyl in kitchen, bathroom, utility and toilet ( $\mathrm{x} 2)$

- $\quad$ Varnish to internal doors (x3) 


\section{STAGE 3}

\section{Owner's Alterations}

- Creation of open plan living/kitchen/dining area

- Installation of loft ladder

- Renewal of house roof

- Renewal of outhouse roof

- Increased glazing on the rear elevation

- Replacement of rotten timbers in porch

- Insulation to roof, walls and floor

- $\quad$ Replacement of internal wall and ceiling linings

- $\quad$ Paint to internal walls, ceilings and joinery

- Replacement of skirting board

- Renewal of architraves

- Installation of fitted wardrobes

- Installation of fitted cupboards in utility space

- $\quad$ Carpet throughout

- Vinyl in bathroom and utility

- $\quad$ Ceramic tiling to bathroom, kitchen and utility

- Installation of heatpump

- Installation of instantaneous gas water heater

- $\quad$ Full re-wire with additional light fittings and sockets

- New fitted kitchen including base and wall cupboards, oven, hob, extractor hood and dishwasher

- $\quad$ New utility fittings

- $\quad$ New bathroom fittings including separate shower cubicle and heated towel rail

\section{8 - 2012 Maintenance (20 years)}

- $\quad$ Paint to roof $(x 3)$

- $\quad$ Paint to external timber $(x 3)$

- $\quad$ Paint to downpipes (x3)

- $\quad$ Paint to internal walls, ceilings and joinery $(x 2)$

- Vinyl in kitchen, bathroom and toilet (x2)

- Varnish to internal doors (x3)

- $\quad$ Carpet throughout (x1)

Figure 44: Assumptions behind the TS EEA

For the analysis of the house as constructed, the original architectural drawings and schedules of timber were consulted. The TS houses were built of native timbers, including totara piles. The embodied energy (GJ) in each of the building elements of the TS house in 1928 is shown in Figure 45, and that of the building elements expressed as a \% of the 1928 total in Figure 46. 


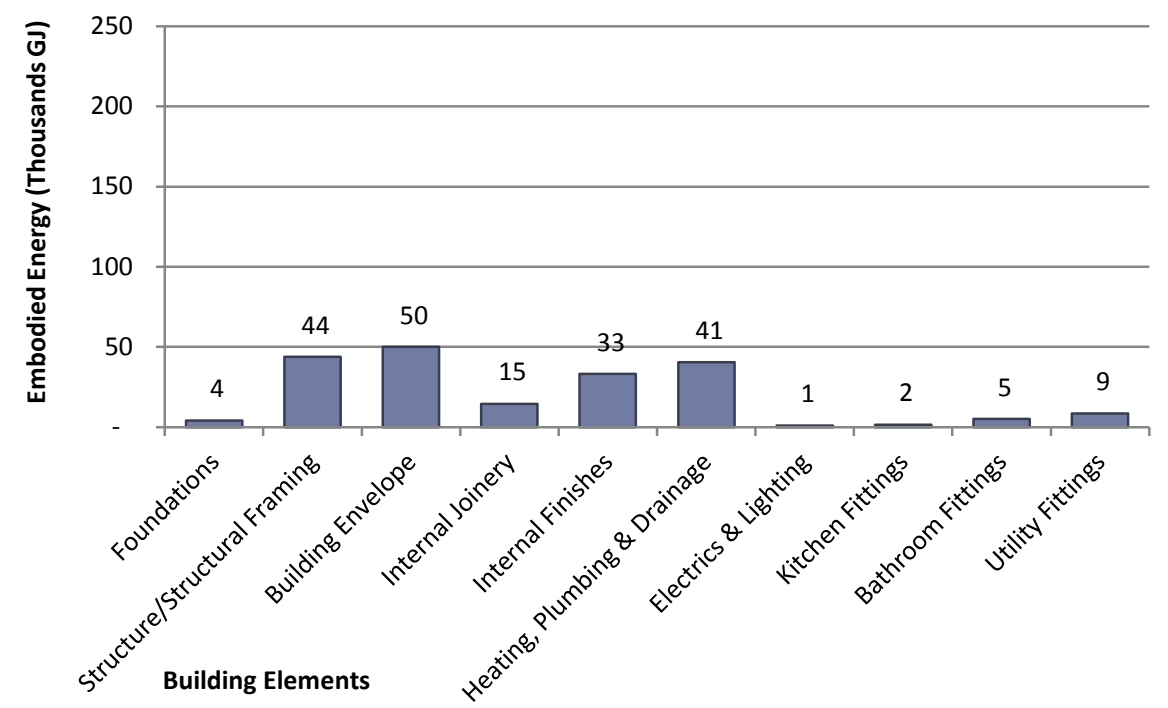

Figure 45: Embodied Energy (GJ) in the Building Elements of the TS House in 1928

The calculations show that the original TS house had 50,112 GJ (25\%) of embodied energy in the building envelope (external timber and paintwork, windows and roof covering). The structure/structural framing (walls, brick chimney stack, floor and roof structure) amounted to 43,866 GJ (22\%) of embodied energy. Heating, plumbing \& drainage accounted for 40, 607 GJ, (20\%) and internal finishes were 33,147 GJ (16\%). The total embodied energy of the original TS house was $202,500 \mathrm{GJ}$.

The embodied energy (GJ) in each of the building materials of the TS house in 1928, expressed as a $\%$ of the total is shown in Figure 47 . Iron accounted for $30 \%$ of the total, followed by timber (23\%), bricks (13\%), copper (10\%) and wallpaper (10\%). The remaining $14 \%$ consisted of 10 additional building materials including plaster (6\%), concrete (3\%) and paint (2\%). 


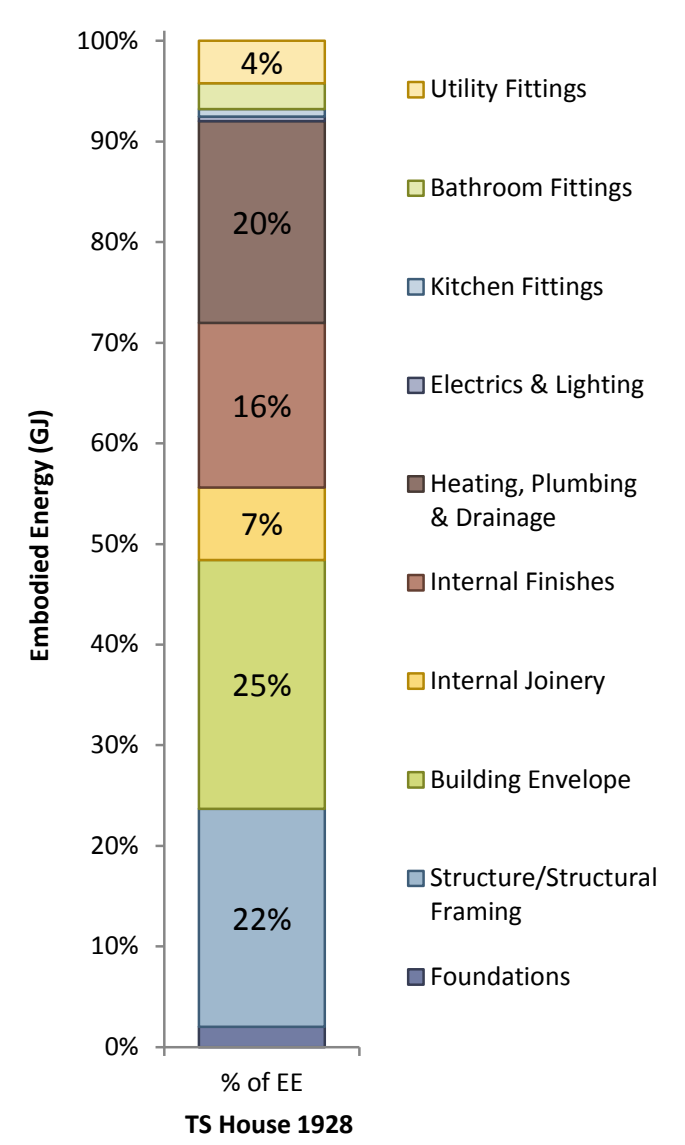

Figure 46: Embodied Energy (GJ) in the Building Elements of the TS House in 1928, expressed as \%

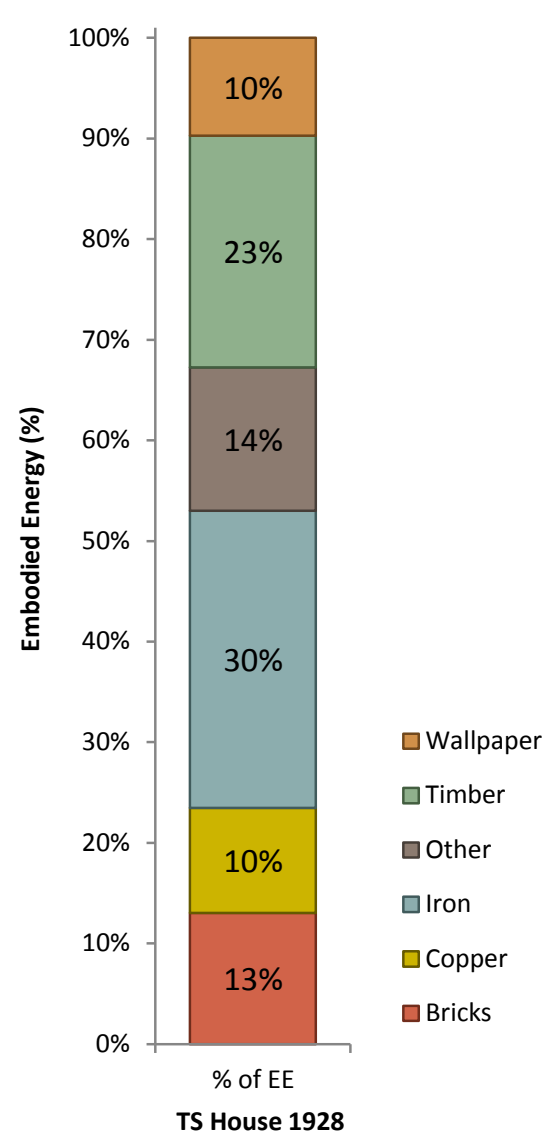

Figure 47: Embodied Energy (GJ) in the Building Materials of the TS House in 1928, expressed as \%

Wellington City Council Archives have no permits for alterations to the Tarikaka Settlement houses by NZGR, as Government departments were not required to report on their building work to local councils until 1991. The only documentation available dates from a 1962 memorandum from the Chief Civil Engineer to the NZGR General Manager, which outlined improvements that included re-piling using concrete piles, relining of walls and ceilings and renewal of architraves, renewal of hot and cold water systems in copper, the construction of an extension to the main dwelling to contain the wash-house and WC, renewal of roofs in corrugated iron, renewal of sanitary fittings and re-papering and re-painting after repairs and re-lining (Clark, 1962). In this memorandum, Clark expressed concern that repair work could be costly and suggested which improvements would necessitate an increase in rent due to the increased capital value of the house, and which could be charged to working expenses. 
Clark also suggested adopting a policy that required houses to be replaced after sixty years, thus reducing the cost of maintenance and repair of the houses, higher quality houses for staff, and a greater number of houses generating higher rent. This policy was not adopted.

From inspection and survey of the 14 houses for this research, it seems the NZGR carried out the re-piling, renewed the water systems, renewed the wash-houses and WCs, renewed the roofs and replaced the sanitary fittings (Figure 44). However, by the 1980s, the houses were still inhabited by railways workers and there is some evidence to suggest the majority were still in original condition (Simons, 1986). "The majority of houses still have outside toilets, substandard wiring, no laundry and in some cases use a coal range to heat their water." (Clarke, 1989, p. 2).

Regular maintenance is required to maximize the building life as well as provide a clean, comfortable living environment. This includes painting external walls and roof, wallpapering or painting internal walls and ceilings and the replacement of floor coverings such as carpet, although each will be on a different schedule. However, the NZGR renovations moved beyond such regular maintenance to include upgrading the structure and envelope. The embodied energy in these renovations and improvements is calculated to be $124,589 \mathrm{GJ}, 62 \%$ of the embodied energy of the original house.

Quantities of materials utilized in alterations and improvements made by the inhabitants of the house post 1988 were mostly measured on site. As previously discussed in section 3.3.1, in many cases TS interviewees have undertaken significant alteration and improvement work to their houses (Figure 30). Most common is work to the garden, mentioned by 13 (93\%) interviewees, followed by installation of insulation (79\%) and internal decoration (79\%). Outbuildings have been changed by 9 (64\%) interviewees.

The house surveys revealed that in 11 (79\%) of the houses, the rear of the house has been remodelled to create an open plan living ( 2 of the non-remodelled houses are rented). Also, the majority of the houses have insulation in the ceiling and under the 
floor, with several inhabitants in the process of insulating external walls. The embodied energy of typical alterations undertaken post-1988 by house owners is significant, totalling $187,213 \mathrm{GJ}$ (93\% of the 1928 original).

The cumulative embodied energy (GJ) in each building element of the TS house in 2012 is shown in Figure 48 and the embodied energy in the building elements expressed as a $\%$ of the 1928 total in Figure 49.

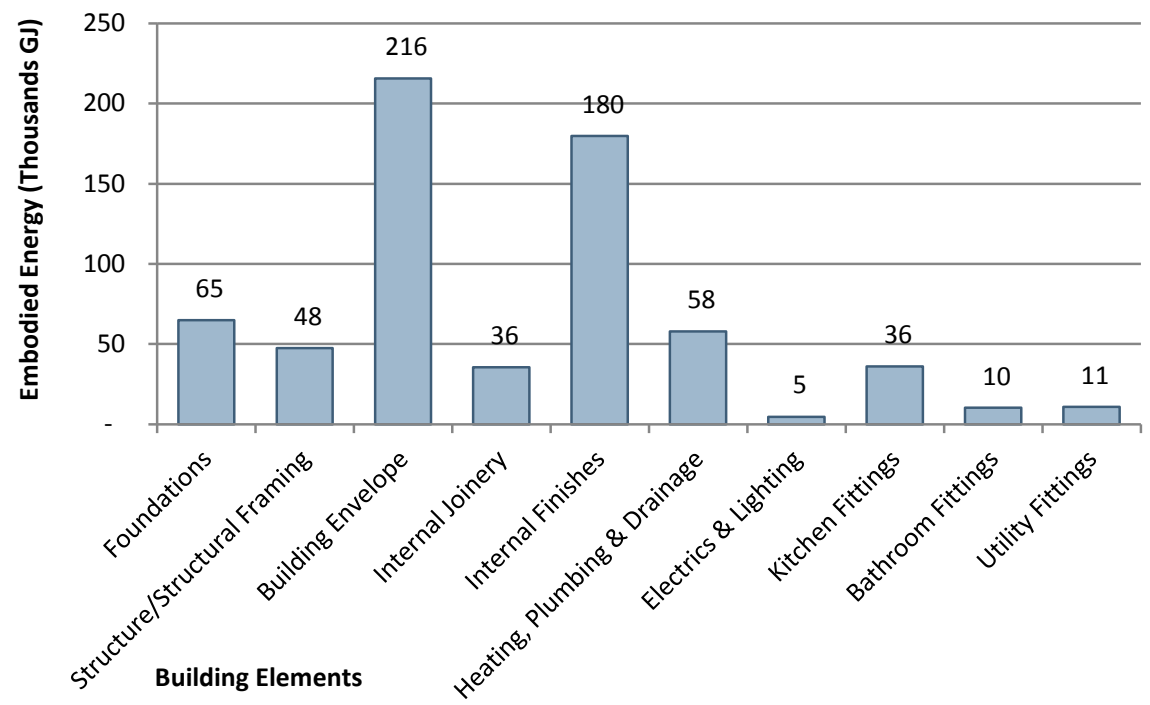

Figure 48: Embodied Energy (GJ) in the Building Elements of the TS House in 2012

The 2012 TS house had 215,776 GJ (33\%) of embodied energy in the building envelope (external timber and paintwork, windows and roof covering), while the internal finishes were $179,936 \mathrm{GJ}$ (27\%). The foundations accounted for $64,928 \mathrm{GJ}(10 \%)$ and heating, plumbing \& drainage for $57,948 \mathrm{GJ}(9 \%)$. The structure/structural framing (loadbearing external and internal walls, floor and roof structure) were 47,617 GJ (7\%) and kitchen fittings were $36,011 \mathrm{GJ}(5 \%)$. The cumulative embodied energy of the TS house in 2012 was $663,637 \mathrm{GJ}$, an increase of $328 \%$ since it was constructed.

The embodied energy (GJ) in each of the building materials of the TS house in 2012, expressed as a \% of the total is shown in Figure 50 . Iron accounted for $15 \%$ of the total embodied energy, followed by timber (13\%), wallpaper (12\%), concrete (10\%) and paint (9\%). The remaining $40 \%$ consisted of 16 other building materials including insulation (8\%), plaster (5\%), steel (5\%), vinyl (5\%) and copper (4\%). There have been 6 
new materials introduced to the TS house since 1928, these being aluminium, carpet, insulation, various plastics, stone and vinyl. Bricks for the chimney stack which accounted for $13 \%$ of embodied energy (GJ) in the 1928 TS house are less significant in the 2012 TS house (4\% of embodied energy).

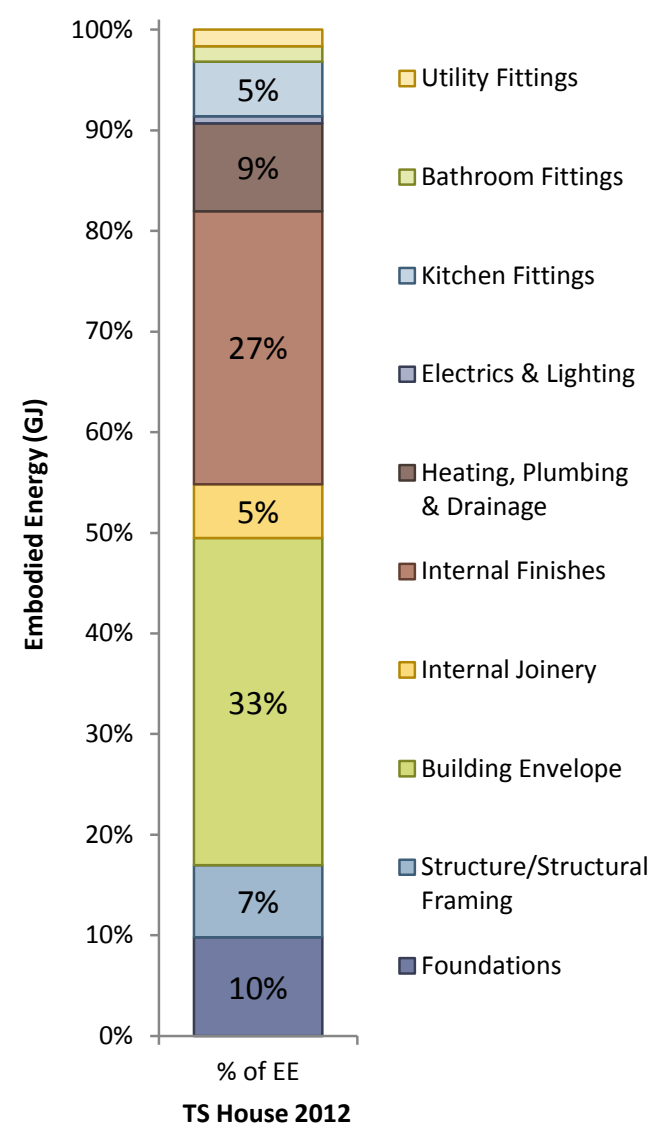

Figure 49: Embodied Energy (GJ) in the Building Elements of the TS House in 2012, expressed as \%

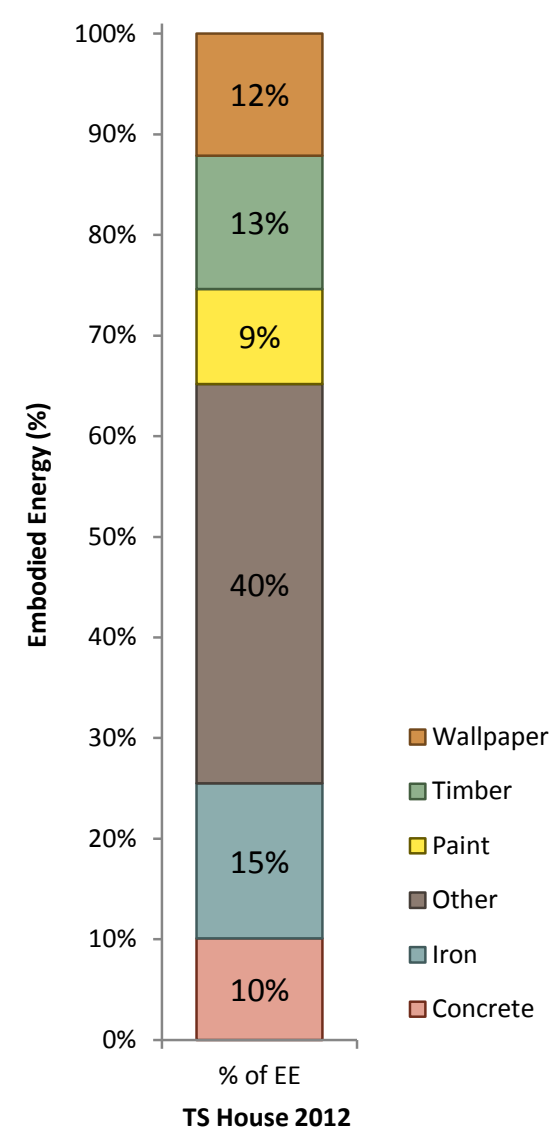

Figure 50: Embodied Energy (GJ) in the Building Materials of the TS House in 2012, expressed as \%

The increase in embodied energy of the 10 building elements including their regular maintenance is shown in Figure 51. Figure 52 compares the embodied energy (GJ) in the building elements of the TS house in 1928 and 2012 expressed as \% of the total. 


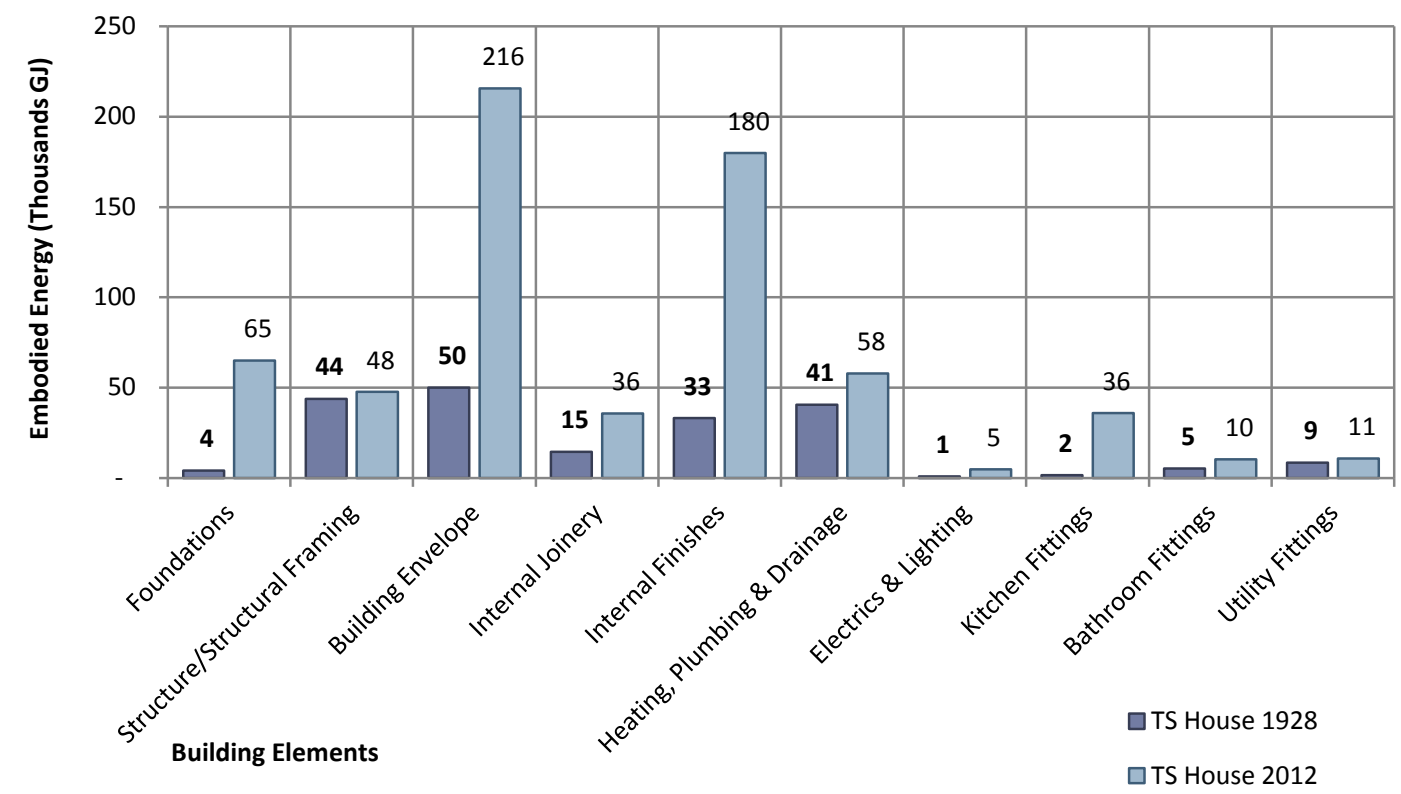

Figure 51: Embodied Energy (GJ) in the Building Elements of the TS House in 1928 and 2012

The greatest increases are for the foundations (replacement of the original totara piles with concrete), building envelope (replacement of the iron roof and regular repainting of external surfaces) and internal finishes (plastering of internal walls, wallpapering, regular repainting and fitting of carpet). Not all materials added to the 1928 house are present in the house today as many items have been replaced. For example, iron water pipes have been replaced with copper pipes and the iron roof covering has been replaced twice. For the purpose of this section of analysis, the embodied energy of replaced materials has not been deducted from the totals which are cumulative. One interesting change is the replacement of the kitchen fittings and the installation of fitted appliances such as, oven, hob, extractor hood and dishwasher. This has increased the embodied energy of this building element significantly to over 18 times the original. The embodied energy of the internal joinery has doubled due to the installation of fitted cupboards in bedrooms, the construction of utility cupboards and the replacement of skirting boards and architraves. Heating, plumbing \& drainage have seen a significant increase in embodied energy due to replacement of pipework and installation of new forms of heating. The embodied energy of bathroom fittings has doubled. 


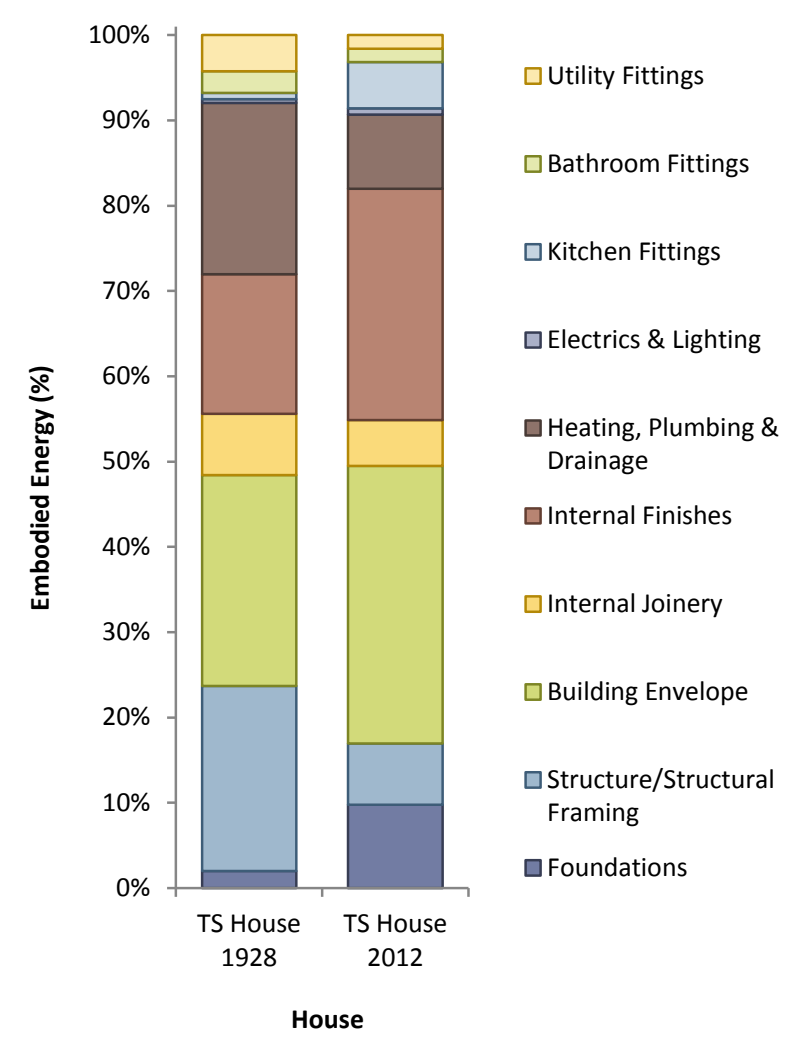

Figure 52: Embodied Energy (GJ) in the Building Elements of the TS House in 1928 and 2012 expressed as $\%$ of the total

The increase in the embodied energy (GJ) of the house for each of the stages is shown in Figure 53.

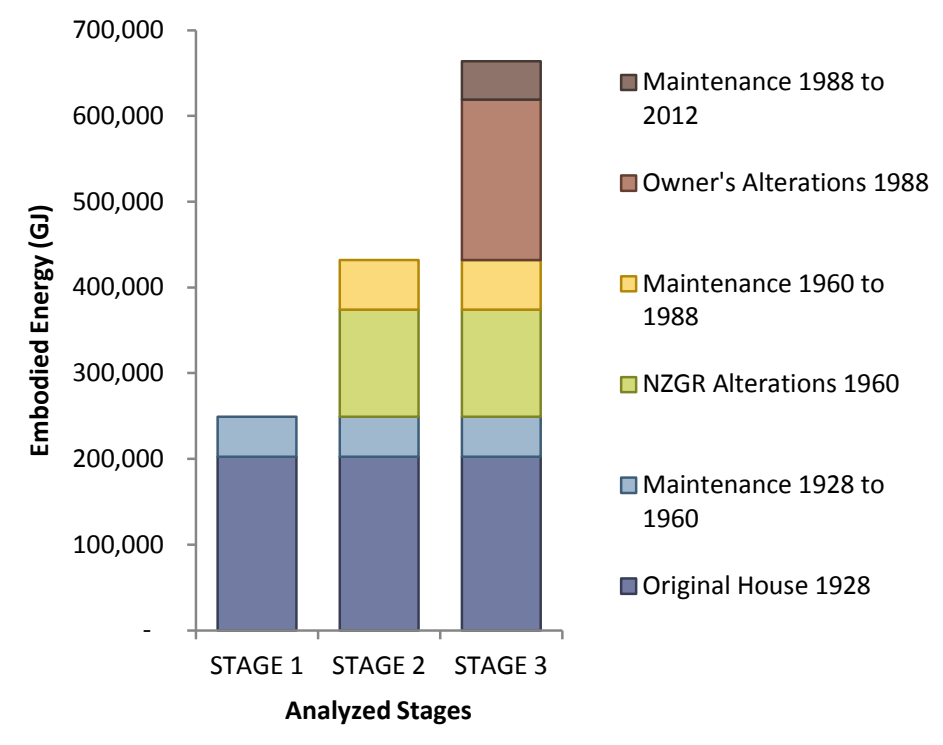

Figure 53: Increase in the Embodied Energy (GJ) of the TS House for each of the stages 
The building materials of the original 1928 TS house are $31 \%$ of the total cumulative embodied energy. NZGR alterations in 1960 represent 19\% and owner's alterations post-1988 a further $28 \%$. Maintenance is significant, amounting to $23 \%$ of the total cumulative embodied energy.

\subsubsection{Embodied Energy per $\mathrm{m}^{2}$ and per Person}

During the past ninety years, the number of persons per dwelling in New Zealand has decreased from 4.69 persons in the 1925 census to 2.77 persons in that of 1996 (Figure 28). Figure 54 illustrates the increase in the embodied energy of the house from its construction to the present day. Although the reduction in number of people per dwelling is largely a linear decrease, the embodied energy is a linear increase.

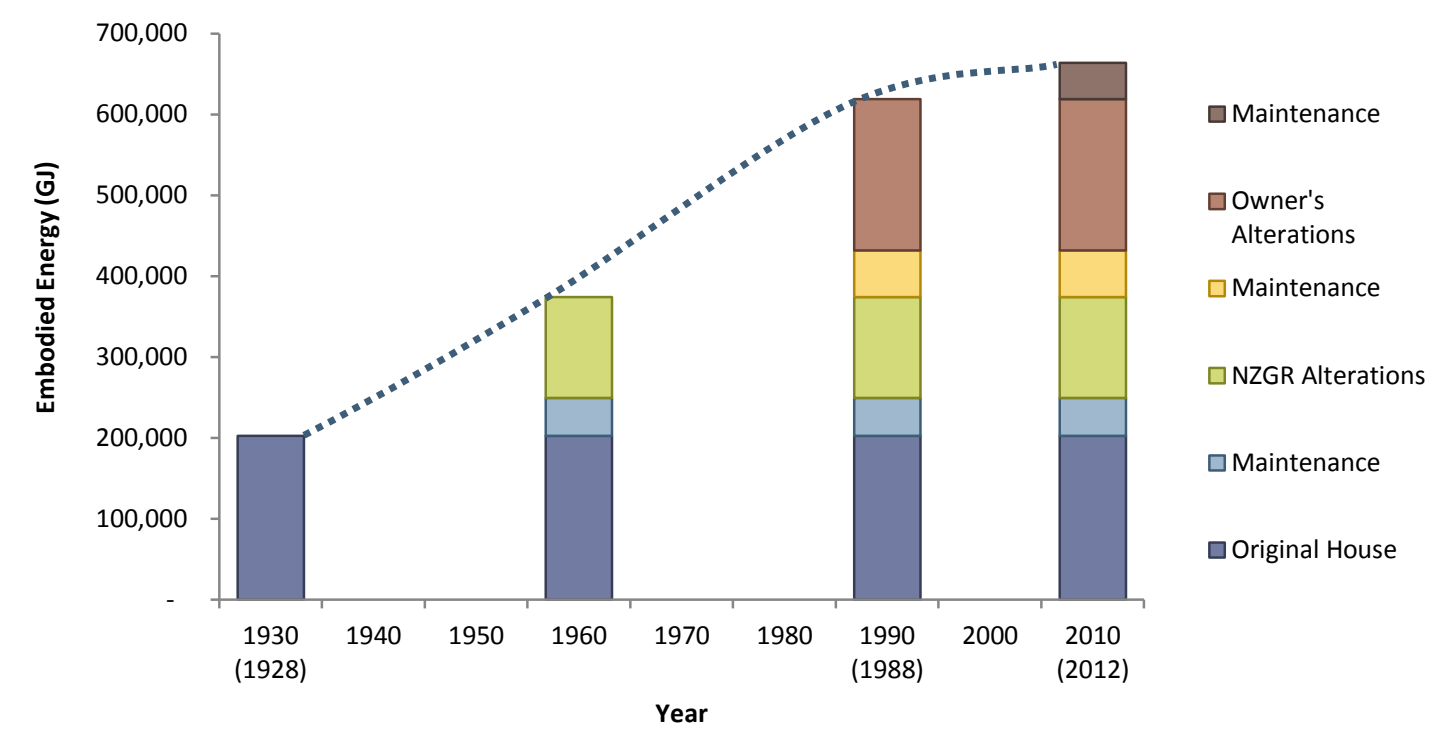

Figure 54: Increase in Embodied Energy (GJ) of the TS House from 1928 to 2012

In order to investigate the significance of design decisions, the house was analyzed at three points in time and a maintenance period of 50 years for each house was calculated. These houses are referred to as the snap shot houses, being a snap shot of the materials contained within the house at a particular moment in time, with no regard for the materials which have been replaced prior to this.

The snap shot houses show the embodied energy (GJ) of these as if as unchanged for 50 years, apart from maintenance. The three snap shot houses represent what people 
want/expect to find in their house at each date, and hence is really comparing the embodied energy of expectations and aspirations when it comes to the facilities and function of the house. The house was analyzed as constructed in 1928, as if the 1960 version (immediately following the NZGR renovations) was built new, and the same for the 2012 typical TS house. The results from this analysis are shown in Figure 55. The embodied energy per unit area $\left(\mathrm{GJ} / \mathrm{m}^{2}\right)$ of the 1928, 1969 and 2012 TS snap shot houses is shown in Figure 56 and per person in Figure 57.

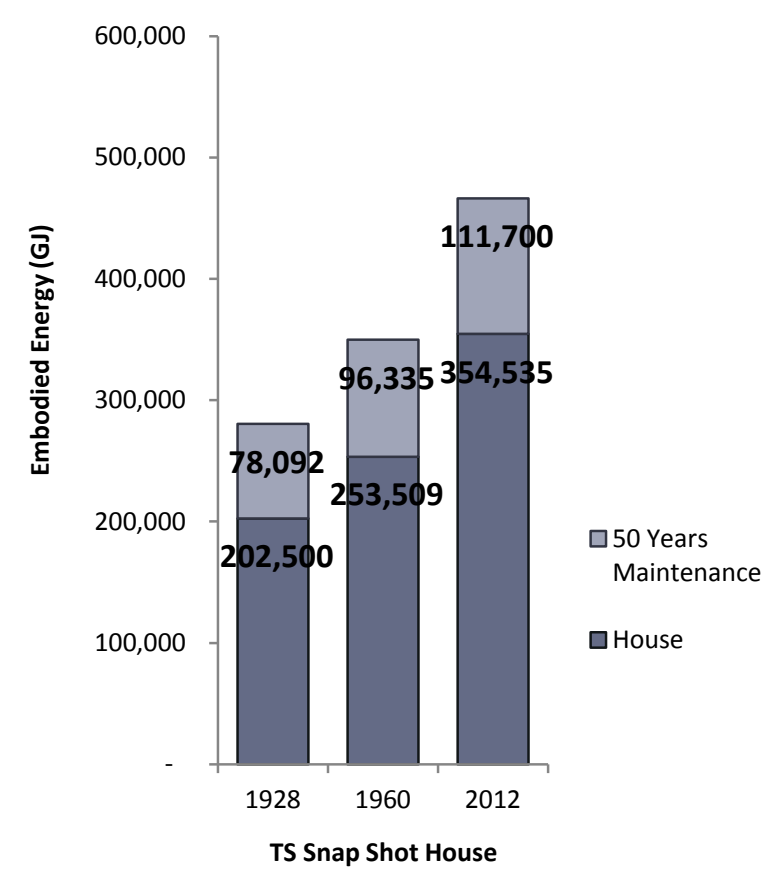

Figure 55: Total Embodied Energy (GJ) of the 1928, 1960 and 2012 TS Snap Shot Houses

The embodied energy of the materials in the 1928 snap shot house was $280,591 \mathrm{GJ}$ or $3,207 \mathrm{GJ} / \mathrm{m}^{2}$. This is approximately $60 \%$ of the 2012 snap shot house $(466,235 \mathrm{GJ}$ or $5,328 \mathrm{GJ} / \mathrm{m}^{2}$ ). The embodied energy of the materials in the 1960 snap shot house was $349,844 \mathrm{GJ}$ or $3,998 \mathrm{GJ} / \mathrm{m}^{2}$ which is approximately $75 \%$ of the 2012 snap shot house. One of the reasons for these differences is the use of modern materials which often have higher embodied energy than traditional materials, for example, particle board (14.5 MJ/kg) versus sawn hardwood flooring (10.40 MJ/kg) (Hammond \& Jones, 2008). Other reasons include the replacement of the original totara piles with concrete as the latter has higher embodied energy, the addition of insulation to the roof, walls and 
floor, the installation of modern fittings, fixtures and appliances, and different types of heating equipment, and carpets.

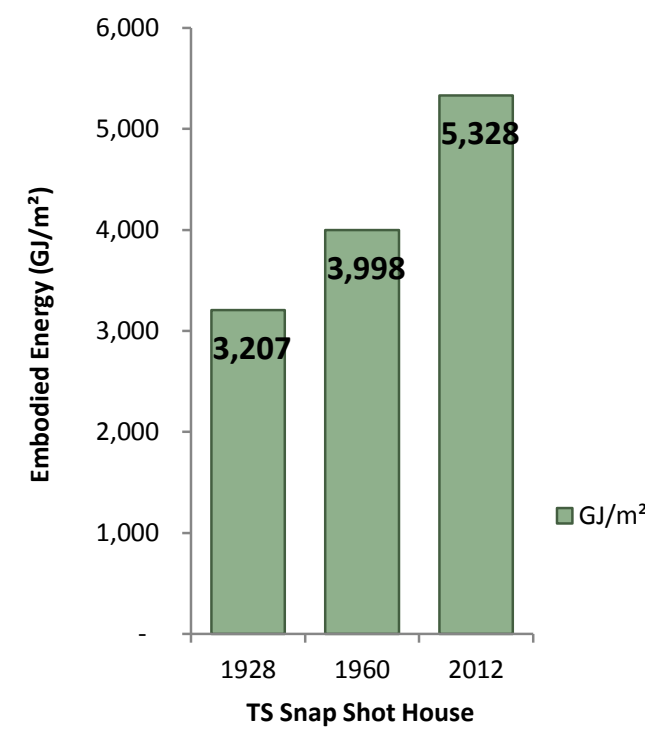

Figure 56: Embodied Energy $\left(\mathrm{GJ} / \mathrm{m}^{2}\right)$ of the 1928, 1960 and 2012 TS Snap Shot Houses

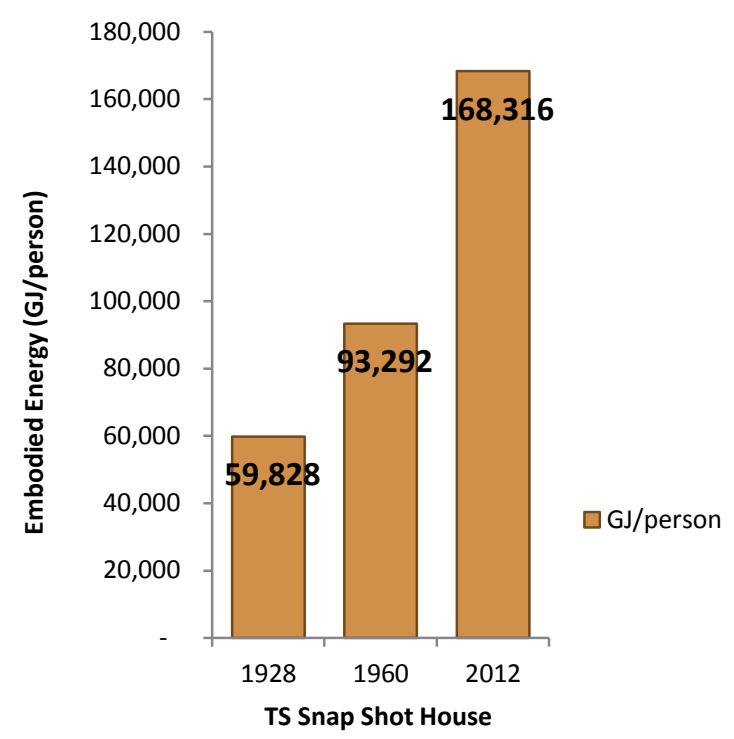

Figure 57: Embodied Energy (GJ/person) of the 1928, 1960 and 2012 TS Snap Shot Houses

To investigate the significance of household occupancy, the embodied energy per person of the snap shot houses was calculated (Figure 57). The average occupancy based on census data was used making the embodied energy of the 1928 snap shot house $59,828 \mathrm{GJ} /$ person, $36 \%$ of the 2012 snap shot house (168,316 GJ/person). The embodied energy of the 1969 snap shot house was 93,292 GJ/person, 55\% of the 2012 snap shot house, and these results confirm that the occupancy levels are as important for embodied energy as the building materials. Lower occupancy levels result in a higher embodied energy per person, which is significant when comparing a three bedroomed house with a sole inhabitant, to the same house inhabited by a family of four, five or six.

\subsection{Summary}

It would appear from the interviews that the TS houses are no longer predominantly inhabited by families. The family households who volunteered for the study mostly had young children, with many interviewees feeling that the house was too small for teenagers, "... when the kids are a bit older, we might actually rent, rather than selling 
this house...because it's such a nice house to keep...for two people..." [TS_07, 0:19:52]. Railway work is no longer something inhabitants hold in common and people do not travel to work together. The TS interviewees only tended to know only adjoining neighbours, with small clusters of friendships being common within the settlement. A current inhabitant felt there was not a strong sense of community, but explained that there were friendship groups [TS_01, 0:34:13]. This was reiterated by a number of other interviewees, one of whom described how they had united with neighbours in an application to Wellington City Council (WCC) for plants for the roadside. Together, they obtained and planted 150 native plants, helping to maintain the areas adjacent to their houses, which would ordinarily be the responsibility of WCC [TS_11, 0:47:48].

Cars stopped children from playing in the street and every interviewee owned at least one. Interviewees tend to use cars for travel to and from clubs or activities and to spend time with friends and relatives that live in different areas of the city. Clubs no longer need to be local. During the 1930s and 1940s, the street would have been full of activity; food delivery vans, children playing, and people walking or cycling. Today, cars are used to fetch shopping and children often play in rear gardens, hidden from view. The street is a transportation zone, primarily for the car. The 1983 Recreation Reserve was not mentioned by a single interviewee suggesting that this area is not considered to be important.

Interviewees, although sharing a genuine love for their houses, do not have the shared inside and outside-of-work interests that characterised the area during the 1930s and 1940s. Community spirit and friendships between inhabitants around the street are not perhaps as necessary as they once were, although houses in the settlement are much sought after, fulfilling the aim of those campaigning for the area to be zoned 'historic' during the late 1980s (Simons, 1986, p. 1).

Today the houses are no longer affordable for those on low incomes. However, they have endured the test of time, being appreciated and valued by those who live in them today and the settlement must be considered a success. The location, design and quality of construction of the houses are three important factors which have contributed to this success. Changing lifestyles over the past 85 years have greatly 
impacted the use of the public and private areas of the settlement, and the changing needs, aspirations, and priorities of the different inhabitants have not only affected the use, but also the appearance of these areas. This is not unique to the Tarikaka Settlement, but is a reflection of what has happened in housing developments throughout Wellington and NZ. When reflecting on the history of the TS, questions emerge for those involved in the planning and design of houses today. Is it possible to plan and design houses that encourage community and if so, is it important to do this, or is a local community no longer important in the way people live today?

TS houses now appear to be owned by the middle classes (accountants, solicitors, lecturers, teachers, ICT and other professionals) and house prices reflect this. In many of the volunteer households women are in paid employment, often leaving the houses uninhabited during weekdays. The interviewee's gardens are no longer highly productive, but are being landscaped with outlook to and connection with the garden being of great importance. Landscaping is often designed around the intention of the garden being "low maintenance" (paved areas, decking and flat areas of lawn). Many interviewees no longer spend a lot of time gardening as they work more and other forms of recreation have become popular, gardens no longer need to be productive. Garden function has changed enormously, whereas the house function has changed to a lesser extent, but it is still recognisable.

Over time, the houses have been altered to meet the requirements of owners with different sets of values, requirements and expectations from previous inhabitants. In this respect the houses must be considered malleable, "...Capable of being fashioned or adapted; adaptable, pliable..." (Oxford English Dictionary). One TS interviewee stated that one of the reasons that they purchased the house was its potential for renovation, "...we were looking for a do-er up-er at that stage..." [TS_04, 0:02:10]. Many TS interviewees are investing considerable time and money in their houses, updating and renovating these often to high standards. For some, altering their house to suit their functional and aspirational lifestyle requirements has been both rewarding and enjoyable, despite the drain on their energy and finances [TS_09, 0:02:21]. For others, their house remains a work in progress with changes and improvements being 
carried out when time and finances allow [TS_06, 0:17:50; TS_08, 0:14:08] . Changing home-owner values, notions of contemporary living, the idea of a house as an expression of identity, and the impact of consumerism have resulted in home owners investing a considerable amount of energy in their houses through the introduction of new materials and technologies. The result is houses with lower occupancy levels and increasing levels of embodied energy, meaning the environmental impact of the houses is now much greater than when they were first constructed. While this is due to the modifications and alterations, the embodied energy impact of maintenance should not be forgotten. Figure 54 suggests the impact of the various maintenance activities over the life of the house in terms of embodied energy, are comparable in importance to the major renovations undertaken by either NZGR or the owner. 


\section{Chapter 4 - Method Testing: Silver End}

For the investigation of the Silver End houses the available data included limited original construction drawings, newspaper articles and books (Carpenter, 2007; Jensen, 2012). This was in addition to interview data from the present inhabitants of the case study houses, which were sometimes supplemented by interviewee's drawings and photographs from when work had been done on the houses.

In this chapter, a number of graphs provide a comparison between the elderly interviewees (ENG) and current inhabitants of the SE case study houses (SE).

\subsection{History}

During the early 1920s there was a shortage of houses in Braintree with inadequate accommodation for the number of workers required by the Crittall Manufacturing Company (Crittalls) (manufacturers of steel framed windows) (Braintree and Witham Times, 1930). In 1925 Crittalls purchased 220 acres of farmland for building a factory and houses for their workers. The Silver End Development Company was formed shortly afterwards (Jensen, 2012, pp. 27-28). Plans for the village were quickly produced by C. Murray Hennell, advised by Richard Reiss, a significant figure in the Garden City movement (Carpenter, 2007, p. 25). Hennell was also part of the garden city movement having worked with Parker and Unwin at Welwyn (Aslet, 2010).

Francis Henry Crittall laid the foundation stone of the first house in 1926 (Crittall Magazine, 1926). One elderly SE interviewee, born in Silver Street in 1937, remembered building materials were transported through the village on rails using a gravity system running from north to south, with deliveries being made at the north end. Rails are visible in part of Silver Street today. This same interviewee recalled sand came from nearby pits, and that Crittalls' employees were involved in the construction of the houses [SE_01, 1:45:29]. By 1928, 250 houses had been built, with a further 250 planned (Crittall Magazine, 1928). Several architects produced designs for the houses (Jensen, 2012, p. 29) resulting in groups of houses both traditional and 
modernist in appearance. The latter, about a third of the houses constructed, are the focus of this study.

One SE interviewee recalled that his grandfather, grandmother, mother and two aunts were living in London just after the war, when his grandfather was offered a job at Crittalls. They all moved to Silver End and, after first living in a house in another part of Silver End, they were offered a house on Silver Street, "...my Nan says that, apart from marrying my Granddad and having the three girls, the best move that she ever made in her life was to move to Silver End..." [SE_06, 0:03:48]. The family of another SE interviewee had come to Silver End from Wales, where her father had been a coal miner, "...he [father] said, that if he'd have stayed living down there, he would have probably died in his forties... he did think he'd come to heaven, even though he was working very hard, and sometimes he would still be operating that machinery in bed, asleep, his limbs would go..." [SE_01, 1:38:34].

One elderly SE interviewee said her parents rented the house, but there was the option to buy it from Crittalls, "...some people did and some people had to back out ...lack of funds." [SE_01, 0:03:01]. This is confirmed by another SE interviewee:

“...Mr Crittall...said...he thought that people shouldn't just pay rent, so it was rent and purchase...it was nine and sixpence rent and six shillings to buy over twenty years, but times were so hard in the mid-thirties that everybody, except one or two people who had...other income withdrew from it..." [SE_08, 0:04:09].

The remaining land was used by Crittalls farms, which had their own piggeries and orchards [SE_01, 1:00:44] as one elderly SE interviewee recalls:

"...that barn used to be full of apples...then they had three piggeries, an abattoir and their own cattle...dairy... bakery, buses, their own barbers down there you know...it was just good for work people in those days...bowling green, football, cricket, tennis courts..." [SE_05, 0:07:20].

In 1969, Silver End was sold to Braintree District Council (BDC) (Jensen, 2012, p. 34) and shortly afterwards, the council removed the original Crittall steel windows with 
the horizontal glazing bars from the SE houses and replaced them with the then modern Crittall windows, without the horizontal glazing bars, which remain in many of the houses today. One elderly SE interviewee reflected:

"...and it made them look very average, it spoiled the whole look of the village, with having the wrong windows put in...the council did that themselves...it was a blanket thing, actually before they introduced the conservation I believe." [SE_01, 0:36:34].

The 1980 Housing Act gave tenants the opportunity to purchase their houses (United Kingdom Government, 1980) and alterations carried out by new owners were not always in keeping with the original appearance of the houses. In 1983, to conserve and enhance the village, BDC designated the "Silver End Conservation Area" (Braintree District Council, 1999). Concurrently, BDC removed permitted development rights by introducing an Article 4 Direction, necessitating that owners submit a planning application for work not normally needing one (including alterations affecting windows, doors, roofs, porches, porch canopies and external render and paint finishes) to prevent further deterioration of the character of the area (Braintree District Council, 2013). The Silver End Conservation Guide noted a previous lack of vigilance in overseeing changes, mostly to windows and doors, with some owners being required to reinstall original features and others not (Braintree District Council, 1999, p. 5). However, because of control over the windows and doors, the Article 4 also affects issues that might be involved in thermal upgrading of the houses, meaning maintaining the heritage status currently means maintaining the comfort level of the houses comparable with when they were first built. 


\subsection{Time Use}

The way that the original and present inhabitants of the SE case study houses spend, or spent, their time was investigated.

\subsubsection{House}

Original occupants of the SE houses were Crittalls' workers and their families. One elderly SE interviewee recalled:
"...they were very, very good, Crittalls...I was a foreman there for thirty odd years...our son used to work there...father worked there...mother worked there in the war...my brothers did...but it was like that because if you didn't work for Crittalls, you didn't get a house... and consequently...you knew everybody you see. The children all went to school together, you knew their parents, you knew where they lived...that was one of the great things about the place..." [SE_05, 0:01:43].

Fathers were typically in full-time employment and mothers were usually home-based and responsible for household work. Of the 12 1930s and 1940s lifestyle interviewees, father was employed full-time in 11 (92\%) of the households, the exception being a household where the father was unwell [ENG_08]. Mother was not in any form of paid employment in 7 (58\%) of these households, but was in $1(8 \%)$, where both father and mother were farm workers [ENG_12]. In 4 (33\%) households mothers were in paid part-time work, such as scrubbing doorsteps and cleaning floors, "...she knew she had to do it, it was a way of life wasn't it..." [ENG_02, 0:25:59]. Another mother also did odd jobs and cleaning [ENG_01], one was a part-time teacher [ENG_05] and another was a dressmaker:

"...she sewed for all the local dignitaries... and they used to come to the house for fittings and if she was expecting someone to come for a fitting then the house was tidied up and we had to make ourselves scarce while the ladies were having their dresses fitted..." [ENG_09, 0:14:30]. 
The number of adults in each household of the 1930s and 1940s interviewees was much higher than in the SE case study houses today (Figure 58), with 7 (58\%) households containing 2 adults, 4 (33\%) 3 adults and 1 (8\%) 4 adults. Of all those interviewed, 2 (17\%) households had live-in maids and 3 (25\%) had lodgers. In 5 (41\%) households there were adults, apart from father and mother, in full-time paid employment (Figure 59).

In $6(66 \%)$ of the current SE households, all adults were in full time work, with the remaining 3 (33\%) households being retired people (Figure 59). In contrast to the 1930s and 1940s interviews, there were no stay-at-home wives or mothers. The occupations of SE householders included an electrician, lecturer, government worker, ICT professional and members of the police. Apart from the 3 (33\%) retired households, the case study houses are usually only occupied during weekday evenings/nights and for part of the weekend. This means a number of them are unoccupied for considerable periods of time. One SE interviewee stated that she enjoyed working in London, but appreciated the fact that she could drive back to Silver End in 45 minutes, to her house in the country, "...it's quite nice to drive here and just have that separation and retreat..." [SE_04, 0:26:36]. This interviewee worked 42 hours a week, which meant her house was uninhabited for at least 49 hours a week. Another SE interviewee also drives to London for work, leaving the house at 5.45am and returning at $5.00 \mathrm{pm}$, Monday to Friday, in addition to working on a Saturday morning [SE_07, 0:30:25]. Other interviewees mentioned not returning home from work until seven or eight o'clock in the evening [SE_09, 0:11:35], "...to be honest, for me, I'm literally...out of the house by seven thirty in the morning and I'm back seven thirty in the evening... at the moment... I don't have a set rota... when I come home, it's just sort of having dinner, perhaps watching some television and go to bed really..." [SE_03, 0:38:31]. 


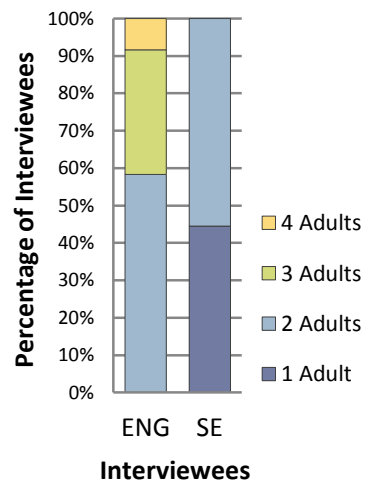

Figure 58: Number of adults per household (ENG SE)

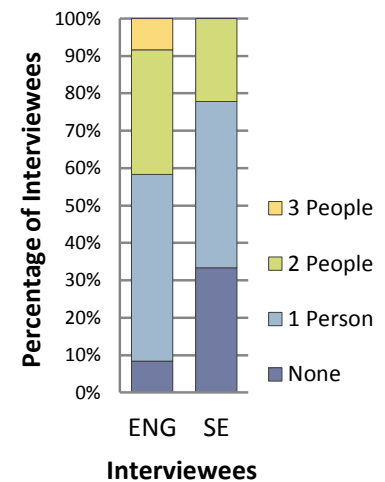

Figure 59: Persons per household engaged in full-time paid employment (ENG SE)

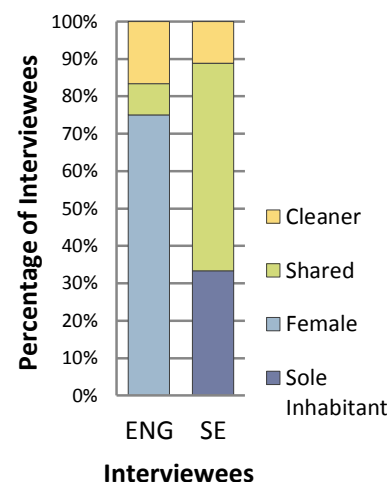

Figure 60: Person responsible for household work (ENG SE)

Of the 12 1930s and 1940s interviewees, 9 (75\%) stated that mother was solely responsible for household work, $1(8 \%)$ remembered that it had been shared and 2 (17\%) had a live-in maid (Figure 60). One interviewee recalled occasionally helping her mother with the housework:

“...I often used to tidy up, 'cos I was quite a fanatic over being tidy in those days. My father was very good at washing up, I remember that, and I would occasionally dry up, you didn't have dishwashers in those days...l liked ironing, often in the evenings I'd do the ironing..." [ENG_10, 0:00:09].

This same interviewee felt that one of the reasons that they were often at home, was because of all that needed to be done [ENG_10, 0:00:09].

The SE interviews indicated that housework, unlike in the 1930 s and 1940 s, is no longer solely undertaken by women, but is the responsibility of the sole inhabitant (33\%), both male and female household members (56\%), or a cleaner (11\%) (Figure 60). One SE interviewee said, "...I'll be very honest, he's a very modern man...it is literally 50-50..." [SE_03, 0:56:25]. Since the SE houses were constructed, housework has become less labour intensive due to developments in technology and the numerous appliances designed to minimise time spent on domestic chores. Several of the 1930s and 1940s interviewees stated their mothers spent a lot of time on housework, and that it was hard work, "...it was like slavery really, it was I mean, to 
bake and that like she did, with just a fire on..." [ENG_02, 0:55:00]. Another shared thoughts about the change that came with the introduction of labour saving devices, "...I mean we used to have to struggle to get everything done and that, now it's easy really, isn't it..." [ENG_12, 0:56:47]. Another interviewee recalled that his mother was a good seamstress:

"When you think she never stopped working from morn 'till night... a lot of the kids were very poorly dressed but we weren't, mother could alter clothes. I got my older brothers hand-me-downs, she altered them and she was good at it. That was her job I suppose. I think the woman's role was very important..." [ENG_03, 0:24:16].

Other interviewees did not remember their mothers spending a lot of time doing domestic chores, although one elderly SE interviewee thought her mother would have done a lot of housework whilst she was at school, and as such, did not remember this:

"...I can remember my mother spending a fair amount of time cooking, but housework, she seemed to get over quite quickly. She scrubbed the front and back step and drain every week without fail, she cleaned the windows quite often, but it didn't seem as though nothing else could be done, because this, that and the other had to be done..." [SE_01, 0:53:48].

Many of the 1930s and 1940s lifestyle interviewees recalled weekly clothes washing, most commonly on a Monday, with an elderly SE interviewee mentioning, "...if you did it on a different day, somebody'd have their drying and airing out and then it'd have all smuts [smoke and ashes] over it..." [SE_01, 0:59:16]; "...wash day was always on a Monday and we would be at school ... well me mother would be starting washing before we went to school and she would still be washing when we got home... she pinned it out in the garden... [and for wet weather] we used to have lines hanging up in the scullery..." [ENG_01, 0:17:27]. Several 1930s and 1940s interviewees remembered washing as a lengthy process, involving lighting a fire (hence the smuts), waiting for the water to boil, and washing and wringing clothes by hand, "My mother had a copper in the shed...I'm not quite sure what they put on to start it with, just any old rubbish that 
they could burn I think, underneath, I can remember them putting...old cardboard boxes and bits and pieces..." [SE_01, 0:05:30]. This interviewee also recalled there was no sink in the shed and explains that her mother had to carry hot water from the copper into the house [SE_01, 0:28:34].

In contrast, many modern SE interviewees washed clothes frequently, with one explaining that both she and her husband wear uniforms to work and to avoid using their tumble dryer, clothes are spun twice in the washing machine and then hung on a clothes horse to dry inside [SE_03, 0:56:25].

The time spent undertaking domestic chores is far less now than it was during the 1930s and 1940s, with one SE interviewee estimating she spends four hours per week on household work [SE_03, 0:58:51], and others stating they do not spend much time on this, only undertaking chores as and when required [SE_02, 0:36:12]. Labour saving devices make housework quicker than in the past, allowing inhabitants to spend time on other activities.

Present day methods of space and water heating have also freed inhabitants from the cleaning and maintenance of some pieces of equipment, "...l used to have to polish the brass...on a Thursday night they would let the fire go out and then you had to rake all the ashes out from underneath, I used to love doing it... with this long rake...it had to be cleaned out you see for the oven... and then we used to black-lead the front of the oven..." [ENG_04, 0:23:22].

The case study houses were constructed with an upstairs bathroom containing a cast iron bath with a hot and cold water supply. This was uncommon for this period, and the majority of the 1930s and 1940s interviewees recalled a tin bath, which was usually hung up outside and brought into the house once a week [ENG_02, 0.08:17]:

\footnotetext{
"We had a tin bath on the wall outside and it was brought in every Saturday night, and there was five of us so hard luck to the last one that got into the water because it was cold and scummy...and we would all have this bath, and then... we all had to sit on the table and me dad would cut our nails..." [ENG_01, 0:07:43].
} 
All of the 1930s and 1940s interviewees recalled baths once a week and a number remember sharing bath water with other household members.

Of the 9 SE case study houses, 7 (78\%) have since been fitted with showers, either over the bath, or in a separate shower cubicle, with daily showers more popular than taking a weekly bath.

Since the 1930s and 1940s, food preparation has changed significantly with a far greater variety of food now available. As in New Zealand, the introduction of fridges and freezers has made pre-prepared food possible, with a shift in the time taken preparing food from house to industry. One elderly SE interviewee recalled a pantry behind the toilet on the north side of the house, which was quite cool, "...there didn't seem to be any need for a fridge actually..." [SE_08, 0:18:35] and another stated, "...we used to have a cupboard with a shelf in, they used to call the pantry, pantry-cupboard and it used to have a concrete slab on it, and that's where you kept everything you wanted keeping cool, on a concrete slab..." [ENG_12, 0:24:13].

During the 1930s and 1940s, bought food was usually basic ingredients, and apart from meal preparation, baking was common. One 1930s and 1940s interviewee said her mother used to baked bread every Wednesday and Friday:

"... a lady, we used to call her the balm lady, she used to come round with a big wicker basket...and she had all these little packets of yeast, already weighed up in ounces or half-ounces...twice a week she would bring that, because they bake the bread twice a week..." [ENG_04, 0:29:36].

Routine and planning were extremely important in the lives of women during the 1930s and 1940s, and for some, this translated into a repeated weekly menu, "...we would have a roast on a Sunday and then you would have it cold with rice pudding on a Monday, and then on Tuesday you would have a stew sort of thing... Friday we always had fish..." [ENG_04, 0:23:22].

One elderly SE interviewee remembered the long hours her father had worked for Crittalls, and shared about his diet: 
"...he always had a fried breakfast to go to work on, always...eggs, bacon and a piece of fried bread probably...I think because they were working quite hard, I mean, they'd start at half seven and probably literally had a ten minute tea break at half past ten, so...you needed something to sustain you, otherwise you'd be falling over by midday...they had an hour for lunch and then work right through until half four...my father used to take a big sandwich box and I think basically it would be egg sandwich and cheese sandwich, a piece of cake, it was quite a substantial sandwich box..." [SE_01, 1:08:43].

For many of the 1930s and 1940s lifestyle interviewees a typical breakfast was cereal and toast, lunch (dinner) was meat and two or three vegetables, and tea was bread and butter or jam [ENG_01; ENG_03; ENG_04; ENG_05]. In 11 (92\%) households, mother was responsible for the preparation of food (Figure 61) and one interviewee recalled that her mother spent a lot of time in the kitchen [ENG_10, 0:06:12], "...there wouldn't be time for me mam to play with us or 'owt like that, we would just make our own amusement..." [ENG_02, 0:17:19].

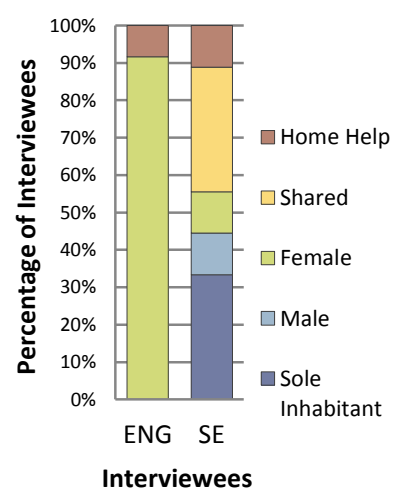

Figure 61: Person responsible for food preparation (ENG SE)

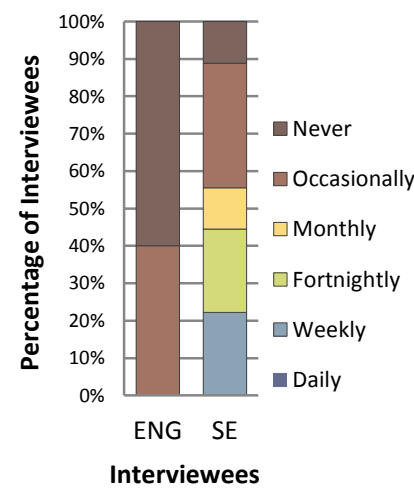

Figure 62: Frequency of eating out (ENG SE)

Many of the 1930s and 1940s lifestyle interviewees did not recall how much time their mothers spent preparing food, but one remembered her mother spending all morning preparing lunch [ENG_01, 0:40:39] and another recalled her mother spent a lot of time cooking [ENG_09, 0:14:30]. 
Time spent preparing food today varies, depending upon household priorities. One SE household spent as little time as possible cooking [SE_02, 0:38:54] whilst another was reluctant to cook for one [SE_0:39:07]. A further SE interviewee said they either prepared a meal very quickly or would spend hours, depending upon what they were cooking and the time available [SE_06, 1:02:30], indicating that for some people, cooking is recreational as well as a necessity. Many SE interviewees mentioned eating a variety of dishes from different cultural backgrounds each week, involving rice, pasta and potatoes. Unlike in the 1930s and 1940s, the female in the household is not always responsible for food preparation (Figure 61). In 3 (33\%) households males and females shared the cooking and in $1(11 \%)$ household the male did it, noting a further 3 (33\%) households were single inhabitants.

Eating out was common for the SE interviewees with only 1 (11\%) never eating out. Of the remaining 8 (89\%) interviewees, 2 (22\%) ate out weekly, 2 (22\%) fortnightly, 1 (11\%) monthly and 3 (33\%) occasionally. This again illustrates a shift in the time involved in preparing food from the house to a fast food outlet, café or restaurant and contrasts with the 1930s and 1940s interviewees, who only ate out occasionally or never (Figure 62). For most ENG interviewees, this was buying chips from a fish and chip shop [ENG_06, 0:49:05].

Preservation and bottling food was mentioned by several 1930s and 1940s lifestyle interviewees [SE_08, 0:39:52], and this activity was not limited to the poorer households, "...and my mother had a home canner and we used to can it all... we used to can all sorts...it was hard work, all our Sundays were taken up with topping and tailing blackcurrants and preserving stuff..." [ENG_05, 0:10:49]. Fridges, freezers, and the availability of imported food stuffs in all seasons have removed the need to preserve produce today, and none of the SE interviewees mentioned doing this.

How food is purchased has also changed, with most SE households using the car for a weekly supermarket shop, often on the way to or from work. In contrast, most of the 1930s and 1940s lifestyle interviewees recalled food being delivered, and one remembered a lot of delivery vans in Silver Street in her early years: 
"... the milkman called... we also had a van that came from Coggleshall ... who brought the paraffin round, and of course, he had a lot of washing powders, soaps, matches... when the van pulled off the two mums would be standing talking... we used to have a man come from Tollsbury with shrimps and probably cockles and things, but we only ever bought shrimps..." [SE_01, 1:00:44].

The same interviewee recalled how, "...during the war time, a chappie who kept land up...the road there, he used to bring my mother pheasants... and I think rabbits, but we liked pheasants better..." [SE_01, 1:06:59]. Similarly, another interviewee recalled:

"...we had a veg man, came round with a van and we would buy extra veg from the veg man...and we had a baker came round with a van and we bought bread and everything... and the milkman came round... and we had a travelling shop came round once a week and if you wanted anything mid-week you went on board the travelling shop..." [ENG_09, 0:17:21].

Time spent purchasing food could be small in the 1930s and 1940s, with products and produce brought directly to the house or street, making it a focal point where mothers could meet and chat around the various food and hardware sellers. Most 1930s and 1940s interviewees recalled that milk was delivered daily by horse and cart [ENG_01, $0: 36: 51]$

A number of the 1930 s and 1940 s interviewees recalled their fathers occasionally providing food, with one household eating, "...whatever there was going, a rabbit, because me dad used to go and catch rabbits, that was a popular meal for us.

Pheasants what we shouldn't have been eating, pigeon..." [ENG_02, 0:39:17]. Another interviewee said, "...me dad spent half of his life poaching and we never went short of pheasants, or rabbits, or hares...there was always good food on the table..." [ENG_09, $0: 12: 21]$. One interviewee recalled they had free fish because his grandfather worked at the Hull fish dock, "... we never bought any fish, I mean that was free, and lots of it, I mean, you could have lived on fish, and absolutely superb fish as well..." [ENG_06, $0: 43: 33]$ 
During the 1930s and 1940s, the house was a place for producing goods, and one interviewee recalled mother making rag rugs:

“...you cut 'em up, old coats, anything old skirts, 'owt what there was... we used to sit cutting 'em up for me mam, then she would have a bit of hessian, I mean it wouldn't be none o' that good stuff, and she would sew it on sacking like you know... when she'd finished, they weighed a tonne you couldn't shake 'em hardly...they looked lovely at first and then they flattened down..." [ENG_02, 0:49:03].

One elderly SE interviewee mentioned her mother made a lot of her clothes [SE_08, 0:37:09], and a 1930s and 1940s interviewee recalled both her mother and aunt doing a lot of sewing, with her mother making all her clothes [ENG_10, 0:17:40], “...my aunt was a wonderful cook and dress-maker, she could see somebody in something and just copy it..." [ENG_10, 0:20:20]. SE volunteers never mentioned similar occupations, indicating they are not spending much, if any, time producing goods at home as people did in the 1930s and 1940s.

It also appears people spend more time inside their houses today, than in their gardens. The 1930s and 1940s interviewees spent a lot of time outside and one stated, "...I have photographs of us all sitting round a little table at the top of the garden having tea...our visitors used to come in the garden a lot..." [ENG_10, 0:05:58]. The same interviewee recalls having a large, weather-proofed dolls house (Wendy house) in the garden which she thought was wonderful [ENG_10, 0:16:30]. During the 1930s and 1940s, most children's activities appear to have been unstructured, with more free and exploratory play, often in the street:

"...we played in the street a lot but we were fortunate in that at the bottom of the street going to the docks... we had one, two, three fields in actual fact to play in... and there were a lot of boxes stacked along back of the field at one time and we used to play in them and move them around...it was just ideal for a kids playground..." [ENG_06, 0:21:31]. 
However, this was different for the families whose fathers worked for Crittalls, as one SE interviewee recalled that, during the 1930s and 1940s, there were clubs in Silver End for archery, football, cricket, tennis badminton and angling, "...Crittalls had... a club for everything didn't they, you could do anything you fancied really...if you worked for Crittalls...you got it stopped, about two pence a week, so you were a member of anything you wanted to be..." [SE_01, 1:24:44]. Another SE interviewee mentioned a rifle range in the village hall, Boys Brigade, Army Cadets, Scouts and Cubs [SE_05, 0:00:30], indicating that there was a great deal of choice in out-of-work and school activities for the inhabitants of Silver End. One elderly SE interviewee played a lot of tennis in her early years and explained there were four grass and two hard courts behind the houses on the opposite side of Silver Street and a further two hard courts behind the hotel, all of which were well used [SE_08, 0:41:11].

Many of the 1930s and 1940s interviews recalled with fondness the freedom they experienced as children and the community spirit they felt:

"...when we was kids we could go out anywhere playing, you know, 'cos we lived on the farm and we used to go out and play in the woods and everything...come back dinner time or we used to have a pack-up...for lunchtime and then come back, you know, tea-time... why I had a childhood I suppose that people never, ever again will have..." [ENG_12, 0:55:51].

Certainly, during the 1930s and 1940s in Silver End, people spent more time with neighbours and people they knew in the street, partly because they did not have private cars, and the fact their fathers all worked for Crittalls. In contrast, not as much social activity seems to be taking place in the houses as formerly. A typical evening during the week for most SE interviewees is being at home with their immediate household members, cooking, eating dinner and watching television. SE interviewees usually only spend time with extended family or friends at the weekend.

Of the 12 1930s and 1940s interviewees, 10 (83\%) attended Sunday School on a Sunday afternoon and several mentioned having to wear their best clothes and not being allowed to play out [ENG_03, 0:29:59; ENG_06, 0:59:22], “...but on a Sunday, you 
couldn't breathe... used to go to Sunday school on Sunday morning, you would go Sunday school again in the afternoon, and you weren't allowed to play out...you couldn't sew, you couldn't knit, you couldn't do anything...you always had Sunday best...in the winter you would have brown long stockings for Sunday and black ones for through the week..." [ENG_04, 0:41:26]. In contrast, none of the SE interviewees mentioned going to church and Sunday is now often a day to work on the house or in the garden, enjoy family time, or catch up with friends.

Few of the 1930s and 1940s interviewees recalled going away for holidays, "...oh no...nobody did [go on holiday], I can't remember anybody who I knew going on holiday..." [ENG_02, 0:49:54], and for many of those that did, holidays were spent with the extended family [ENG_04, 0:47:47; ENG_08, 0:24:58, ENG_09, 0:27:33]. One said her family would take a taxi to an aunt's house, fifteen miles away, once or twice a year, but did not remember going anywhere else, "... we used to help Aunty Lily with her gardening, she used to grow cobnuts in her hedges... and she used to have a running stream, we all used to get wet in there though...yes we used to have some fun..." [ENG_12, 0:47:00]. Another interviewee described staying in a bungalow at Withernsea with his mother and aunties for two weeks every year, going by train taking their food with them, and that half way through the holiday some of them would return to Hull to replenish their supplies. This interviewee presumed food was cheaper to purchase in Hull than Withernsea [ENG_06, 1:06:56]. One 1930s and 1940s interviewee recalled a holiday in a caravan at Hornsea, "... and I can remember, it was a friend of me dad's at work who had this, well it wasn't a caravan, I think it was maybe a static one, and I remember there were thirteen people all together, all sleeping together on the floor..." [ENG_07, 0:58:41].

Of the 9 SE interviewees, 4 (44\%) had recent holidays abroad and 3 (33\%) had regular holidays visiting family. 


\subsubsection{Outdoor Space}

Most SE interviewees spend far less time outdoors than those living in Silver End in the 1930s and 1940s. This is primarily due to change in the function of the private outdoor space, but also indicates change in household recreational activities. One elderly SE interviewee stated her current ornamental garden had once been a working one [SE_01, 0:20:30], and that at one time half the front lawn had been dug up for potatoes, “...I don't recall my mother buying very many vegetables... and there were five of us to feed..." [SE_01, 0:21:21]. Another SE interviewee mentioned his grandfather living in a house in Silver End during the 1930s and 1940s, where the whole garden had been a smallholding, with a goat, geese, chickens and a pig. His grandfather had bolted together three large Crittall greenhouses in which he grew vegetables [SE_03, 1:06:58]. Of the 12 1930s and 1940s lifestyle interviewees, 9 (75\%) recalled part of their garden being set aside for vegetables, and in most cases, father did the gardening, the exceptions being one household where both parents were farm workers and shared this task, and another household with a gardener (Figure 63). One 1930s and 1940s interviewee said although his father was not a keen gardener, he still grew the basics, mentioning potatoes, carrots and beetroot, suggesting for some growing vegetables was a necessity rather than a pleasure. In this household, the boys were expected to help in the garden and the girls to help mother in the house. This interviewee recalled that the siblings were treated quite differently, and the girls did not have as much play time as the boys, presumably because there was a lot more work inside the house than outside [ENG_03, 0:14:52]. Another of the 1930s and 1940s interviewees recalled being given a patch of ground in the garden for growing what they wanted, "...flowers mostly...l used to try some potatoes sometimes..." [ENG_12, 0:13:02]. The productive nature of gardens during the 1930s and 1940s meant it was essential to spend time outside looking after them. 


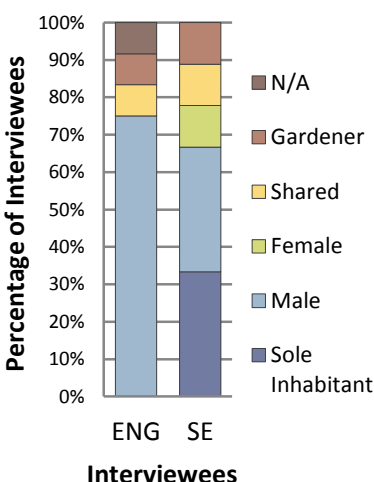

Figure 63: Person responsible for garden maintenance (ENG SE)

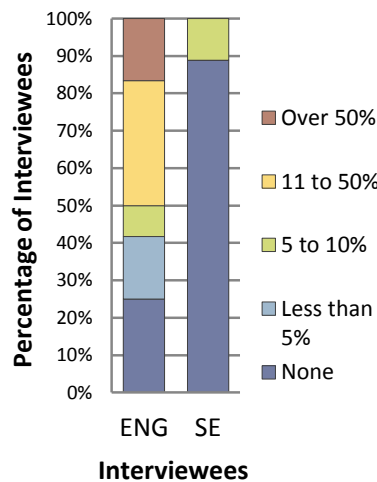

Figure 64: Percentage of consumed vegetables grown at home (ENG SE)

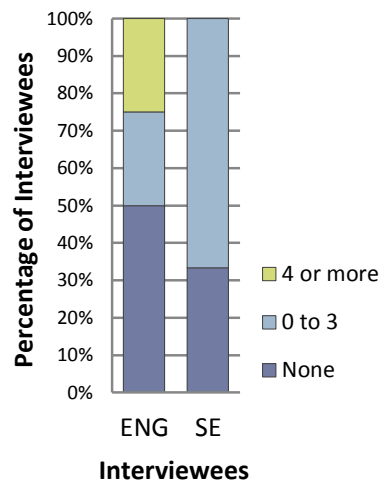

Figure 65: Number of different types of fruit grown at home (ENG SE)

For $6(50 \%)$ of the 121930 s and 1940s interviewees, over $11 \%$ of their vegetables came from the garden and one elderly SE interviewee remembered that when the SE houses were first built anyone who wanted an allotment could have one, with allotments located all over the village [SE_05, 0:42:31]. In direct contrast, only 1 (11\%) retired SE interviewee currently grew vegetables, although several have done this in the past. Numerous SE interviewees mentioned spending very little time in the garden [SE_02, 0:24:52], with several explaining the lack of free time is what prevents them growing vegetables [SE_04, 0:36:00; SE_06, 0:45:20]. One SE couple discussed their lack of success in growing their own vegetables, probably because they underestimated the time required [SE_03, 1:03:50]. One elderly SE interviewee reflected on the knowledge and time needed for a vegetable garden:

"...when we were young, because there was nothing else to do socially...no television or nothing... whenever two men got together, they started to talk about their allotment, so by the time you was six, seven, you knew all there was about allotments...in the war...we had to go and help mother on the allotment, and we was only six, seven, eight then... and so consequently...you didn't need teaching. Now they [young people] see Alan Titmarsh on telly... with a nice little plot... with the soil straight out of a bag, where you can turn it over as easy as anything, and they think gardening's like that, but it's not, it's hard work, unless you keep on top of it, but unfortunately, of course, a lot of 'em can't. You need 
a half hour on most days, and as soon as you see a weed, you hoe it. But most of 'em...they just get a weekend now and again and they... kill themselves...make themselves fed up and they don't come back for two months and it's all grown up again..." [SE_05, 0:39:38].

Fruit was grown in 6 (50\%) of the 1930s and 1940s interviewees' gardens (Figure 65), and one elderly SE interviewee recalled her father saying the garden was not big enough to grow both fruit and vegetables, so they purchased fruit from Crittalls farms [SE_01, 1:00:44]. Today, fruit is grown in 6 (67\%) of the SE interviewees gardens, most commonly being an apple tree or gooseberry bushes which, in many cases, were not planted by the current inhabitants. Many of the 1930s and 1940s interviewees did not eat fruit very often, "...there was never a bowl of fruit...if there was fruit in the house you were allocated it...you can have an apple...maybe an orange...and we used to go thieving them... around orchards..." [ENG_03, 0:14:24]. Another interviewee recalled:

"...to have fruit it was something special...you would get apple, not very often bananas, maybe an orange...you never got a lot of other fruit... after the war, one of our absolute treats was to go into that greengrocers shop and nanny would buy us a peach... we thought peaches were marvellous because we never had them at home, and now you can walk into a shop and buy a packet..." [ENG_01, 0:35:52].

Imports now mean that fruit is far less seasonal, hence the changing nature of fruit consumption. Fresh fruit today would have been preserved fruit in the past.

Chickens were kept by 6 (50\%) of the 1930s and 1940s interviewees (Figure 66) with 2 (17\%) households also keeping rabbits for meat [ENG_07; ENG_12], and 1 (8\%) ducks for meat [ENG_09]. One SE interviewee reflected, "...when my mum lived at Silver Street, half the garden was allotment...everybody had chickens, or every other house had chickens, so you shared the eggs with your neighbours..." [SE_06, 0:54:15]. 


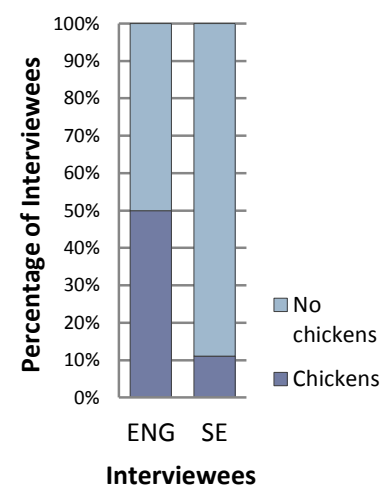

Figure 66: Percentage of

interviewees keeping chickens at home (ENG SE)

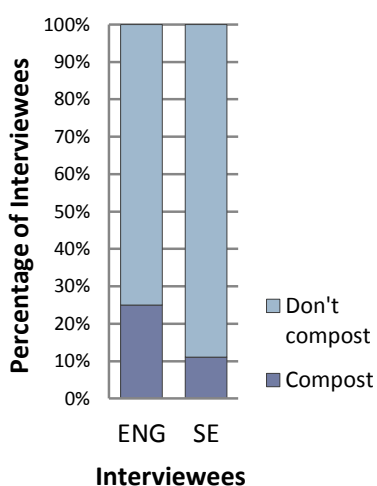

Figure 67: Number of

interviewees composting household waste (ENG SE)

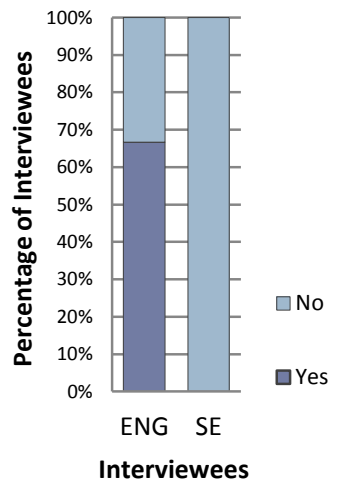

Figure 68: Number of interviewees burning household waste (ENG SE)

With regard to waste, one 1930s and 1940s lifestyle interviewee stated:

"...well we had a dustbin...and the dustman would come once a week and it were a galvanised dustbin ... all potato peelings and all such as that, all used to go on the fire...because that was in the days before the big Acts of Parliament about smoke/smog... we used to get bad smog, terrible smogs, you couldn't see in front of your hand..." [ENG_01, 0:19:37].

Of the 12 1930s and 1940s interviewees, only 3 (25\%) recalled composting food waste (Figure 67), compared with 1 (11\%) SE household today. However, the remaining 8 (89\%) SE interviewees used the recycling bins provided by the council, one of which is for food waste. Several of the 1930s and 1940s lifestyle interviewees mentioned potato peelings were burned [ENG_02, 0:16:28] (Figure 68) and a number that there would have been very little waste [ENG_04, 0:14:27], "...it was just food waste, you know, peelings and not so much packaging then, apart from brown paper bags... and it would go in a galvanised dustbin that was collected once a week..." [ENG_08, 0:05:06]; “...my father had a bonfire, but I don't remember us having garbage bins like we have today, we had a dustman call once a week, but I don't think my mother was overburdened with rubbish..." [ENG_10, 0:04:17]. One interviewee recalled very little household waste being removed from the house and outdoor space, illustrating that 
since the 1930s and 1940s, the time and energy involved in dealing with waste has in part shifted from household to local authority:

"...well you'd have all of your vegetable peelings and I can remember my mother throwing peelings on the fire, and banking up the fire on a night before they went to bed with like potato peelings. All of the waste went on the compost heap, apart from meat waste, there wouldn't be any meat waste...there would be no packaging waste, my mother saved every bit of string and every bit of paper..." [ENG_09, 0:07:29].

Far less time is spent gardening now than in the past, even though for some gardening is still considered enjoyable. The fact most adults in the SE households now work for money, and many work very long hours, are clearly reasons for this, although another might be the availability of and preference for other types of recreational activity. During the 1930s and 1940s recreation was often playing music, cards or board games, sewing and knitting or reading, with one 1930s and 1940s interviewee struggling to describe a typical evening, "...well I suppose it would be...mainly reading, my father must have been reading, occasionally he would play cards with us or a game, you know...but I can't recall, because we didn't watch the television, it seems strange really..." [ENG_10, 0:11:56]. One elderly SE interviewee recalled when she was older her mother considered the television to be a time waster because, unlike listening to the radio, she could not knit at the same time as watching television [SE_01, 1:14:35]. Another elderly SE interviewee recalled her parents both played the piano and she remembers learning to play the piano and sing as a child [SE_08, 0:38:19]. Today, television is clearly an important part of people's recreation time, being mentioned by all SE interviewees, and for those working long or anti-social hours, the technology that means television programmes can be recorded and watched at any time is an advantage [SE_03, 1:20:37].

When asked about the balance between work, family and recreation, 5 (56\%) SE interviewees felt they were doing too much work [SE_04, 0:50:53; SE_07, 0:35:04], with only 1 (11\%) feeling satisfied and the remaining 3 (33\%) retired (Figure 69). This contrasts with 9 (82\%) of the 1930s and 1940s interviewees feeling the balance of life 
during their early years was satisfactory, although a number acknowledge that it would have been hard work for their parents, and particularly their mothers, "...can't remember being bored, saying to anybody I'm bored, no, we hadn't enough hours in the day for us, oh happy times for us, I mean hard times for our mam, but you didn't realise did you 'till you look back now..." [ENG_02, 0:57:35]. One 1930s and 1940s interviewee explained that in the past people did not seem to want more than they had and were happy [ENG_10, 0:29:53], "...we were all contented with our lives, you know. I didn't hear anybody moan about anything being hard work, my mother certainly didn't and she certainly worked hard..." [ENG_10, 0:29:26].

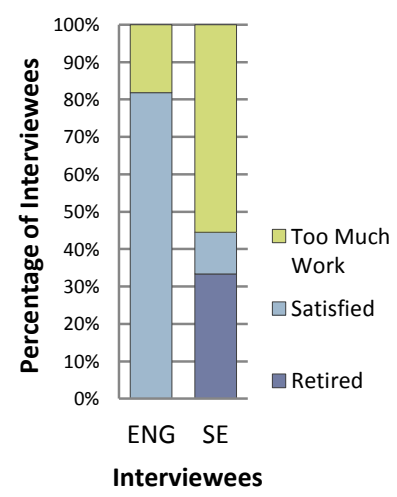

Figure 69: Balance between

work, family and recreation time

(ENG SE)

Gardening is often less labour intensive today than in the past, because of electric lawnmowers, trimmers, hedge clippers and other powered garden equipment. One retired SE interviewee preferred to be outdoors and would spend as much time as possible outside in the garden, weather permitting [SE_01, 0:25:01], whilst another retired SE interviewee spent about half an hour a day maintaining the garden [SE_05, 0:43:11]. Of the SE interviewees who worked full-time, only 1 (11\%) spent a significant amount of time outside whatever the weather, having recently undertaken considerable work to the driveway, with more outdoor work planned [SE_03, 0:17:29]. Another mentioned spending about half a day a week during the summer maintaining the garden [SE_09, 0:07:24], much less than the time spent on garden maintenance in the past. When asked about planned future alterations, 4 (44\%) SE interviewees 
wanted to undertake work to their garden. Weather is mentioned by several interviewees as preventing them spending a lot of time outside, with 4 (44\%) spending a lot more time outside during the summer months. Only 1 (11\%) SE interviewee mentioned the garden as a reason for choosing to buy the house [SE_07, 0:01:53] and only $1(11 \%)$ interviewee gave the garden as one the best things about their house [SE_06, 0:27:20]. This indicates that for the younger SE interviewees, the garden was not a prime reason for buying the house, with location and affordability being more important.

Today, the garden may be a desirable thing to have, but is certainly not necessary for the economic survival of the household, and there has been a clear shift from the high maintenance productive garden, to a low maintenance garden for looking at, or using occasionally.

The 1930 s and 1940s lifestyle interviewees stated as children they spent a lot of time outside, and many recalled playing in the street [ENG_04, 0:17:51], "...but mostly you played out in the street, played hop-scotch and such ...me dad did like gardening and tending his bit of garden...me mother never did much, a bit too busy indoors feeding us..." [ENG_01, 0:21:18]. One SE interviewee described Silver Street during the 1940s:

“...it wasn't tarmac'd in those days, it was concrete...it was rough, so we couldn't learn to roller skate very well... we used to play skips, skipping with all sorts of rhymes and things out there...there were so many children up this street and we all used to play...you'd have all the workmen coming out of work, lunchtime and tea time, so where it's just...cars buzzing up and down now, it was people, it was better really." [SE_01, 0:23:38].

Today, the many cars make it dangerous for children to play in the street, emphasising a change in use of this public space from somewhere for people to somewhere for the car. Outdoor play equipment during the 1930s and 1940s was often a football, a skipping rope, or a cricket bat, and one interviewee recalled, "...and then I used to make myself a bogie, which was just a plank of wood with four wheels on it...I used to 
make one almost every year..." [ENG_06, 1:03:12]. When asked about recreation time, one 1930s and 1940s interviewee explained:

"...I used to knit when I was younger...used to go up the garden and play...rounders or anything like that, my brother used to play cricket with me dad...boys used to kick a football around, we used to have a goalpost at the farm...used to saw up logs for the fire... we used to saw up logs during the summer, ready for the fire in the winter..." [ENG_12, 0:45:18].

For this interviewee, being outdoors was an important part of recreation time, and she remembers sawing and splitting wood for the fire as a part of this.

\subsubsection{Sense of Community}

During the 1930s and 1940s, children seemed to spend a lot of time with other children who lived nearby, thus strengthening links with neighbours and building and reinforcing the sense of local community. As mentioned previously (section 4.2.1), mothers would congregate at the food delivery vans, giving the opportunity to form and strengthen relationships with those living nearby. One SE interviewee recalled:

"...when we were growing up, to go anywhere with my mum in Silver End was an absolute nightmare, 'cause Mrs Dunn had her little corner shop then, and to go from Silver Street to Mrs Dunn's would take about three hours, because she just knew everybody in the village, and you don't get that anymore..." [SE_06, 0:07:13].

Most of the 1930s and 1940s lifestyle interviewees did not have a telephone, and the main form of communication with family and friends took place face to face, "...you just had to go and see people..." [ENG_02, 0:50:02]. 


\subsection{Space Use}

\subsubsection{House}

The houses surveyed were designed by three different architects: Thomas Tait designed 1 to 32 Silver Street, houses which are now Grade II listed, J.Stuart designed the remainder of the houses on Silver Street and James Miller designed the houses on Broadway (English Heritage, 2013b), (Sir John Burnet and Partners Architects, 1927), (Carpenter, 2007, p. 29), (J. Stuart, 1928), (Miller, 1929).

In his autobiography, Francis Henry Crittall recalled the rooms were planned first, with the external appearance of the houses being of less importance.

\footnotetext{
"In planning the houses we decided to sacrifice traditional design in the cause of light and air and space. For too long, we claimed, houses had been designed and rooms made to fit. We decided to invert the operation by planning the rooms first and then building the houses to accommodate them. In a large number of cases, we built cottages with flat roofs, this being the simplest solution to the problem of achieving maximum space with the material at our command." (Crittall, 1934, pp. 129-130).
}

\subsubsection{The Tait Houses}

There are 4 types of Tait houses on Silver Street: 2 pairs of semi-detached houses which were cottages for cowmen and pigmen, 6 pairs of semi-detached houses with the $V$-shaped first floor window, 4 pairs of semi-detached houses without this feature but with the same plan, and 2 blocks of four houses ( 32 houses in total). Figure 70 is the redrawn original ground floor plan of the Tait semi-detached house with the Vshaped first floor window (nos. 10/12, 14/16, 18/20 and nos. 9/11, 13/15, 17/19 Silver Street). The original first floor plan and front elevation are shown in Figure 71 and Figure 72. The front elevation shows the V-shaped window to the left side and the ordinary window to the right side. Figure 73 shows the front appearance of numbers 17 and 19 Silver Street in 2013. 


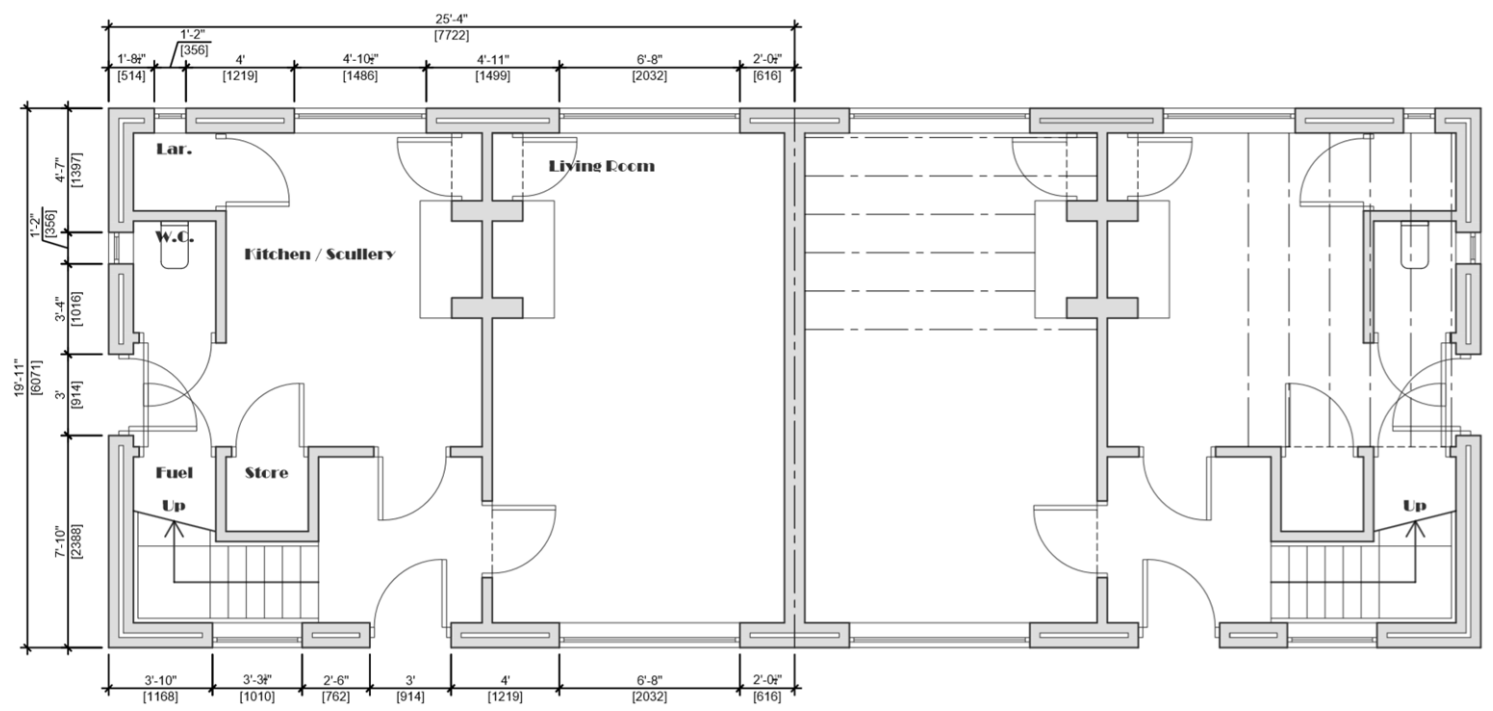

Figure 70: Original Ground Floor Plan of a Tait House

The original drawings of the Tait houses were not available and may have been destroyed. It was necessary to make assumptions as to the original layout and appearance based upon surveys of the case study houses today and information gained from elderly SE interviewees.

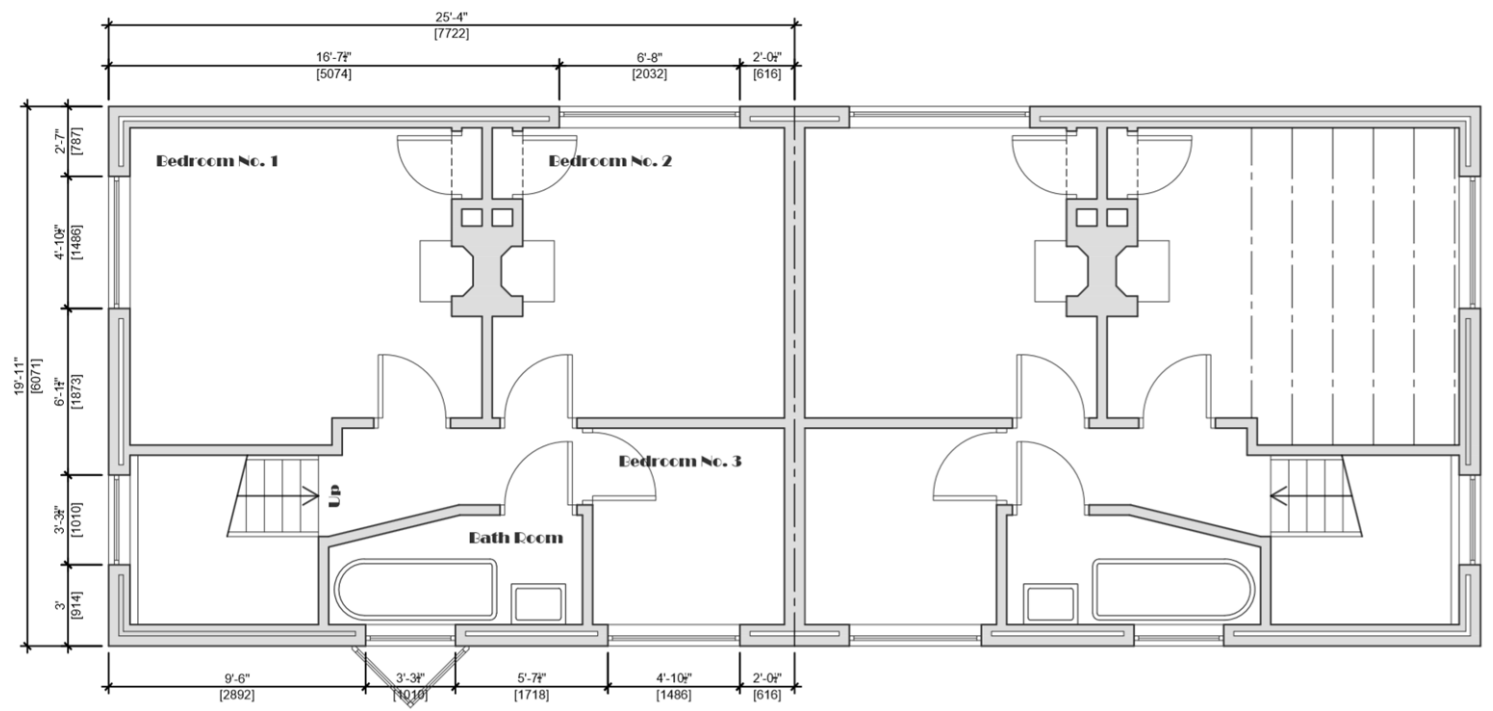

Figure 71: Original First Floor Plan of a Tait house 


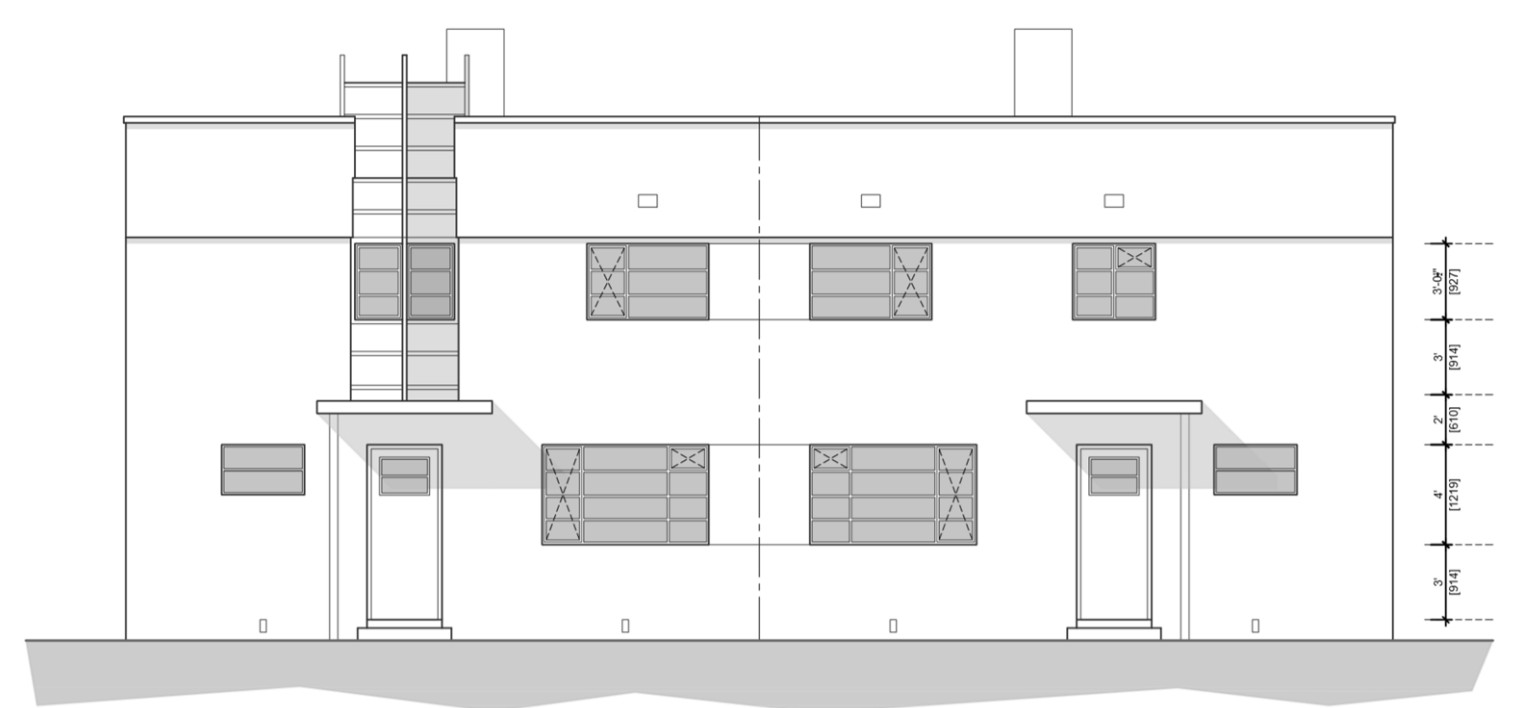

Figure 72: Original Front Elevation of a Tait house

Based on the available information, the Tait houses $\left(82 \mathrm{~m}^{2}\right)$ comprised a living room with an open fireplace, a kitchen/scullery with a triplex coal range, a larder, a fuel store and a toilet on the ground floor with three bedrooms (two with open fireplaces), and a bathroom with bath on the first floor. The house and water were heated by the triplex range which also was used for the cooking. Hot and cold running water were supplied to the kitchen/scullery and upstairs bathroom. Clothes were washed in a cast iron wash boiler (copper) in the timber outhouse, semi-detached to that of next door [SE_01, 0:28:34]. The houses were supplied with electricity, with a central light in each room and a single power point in the living room.

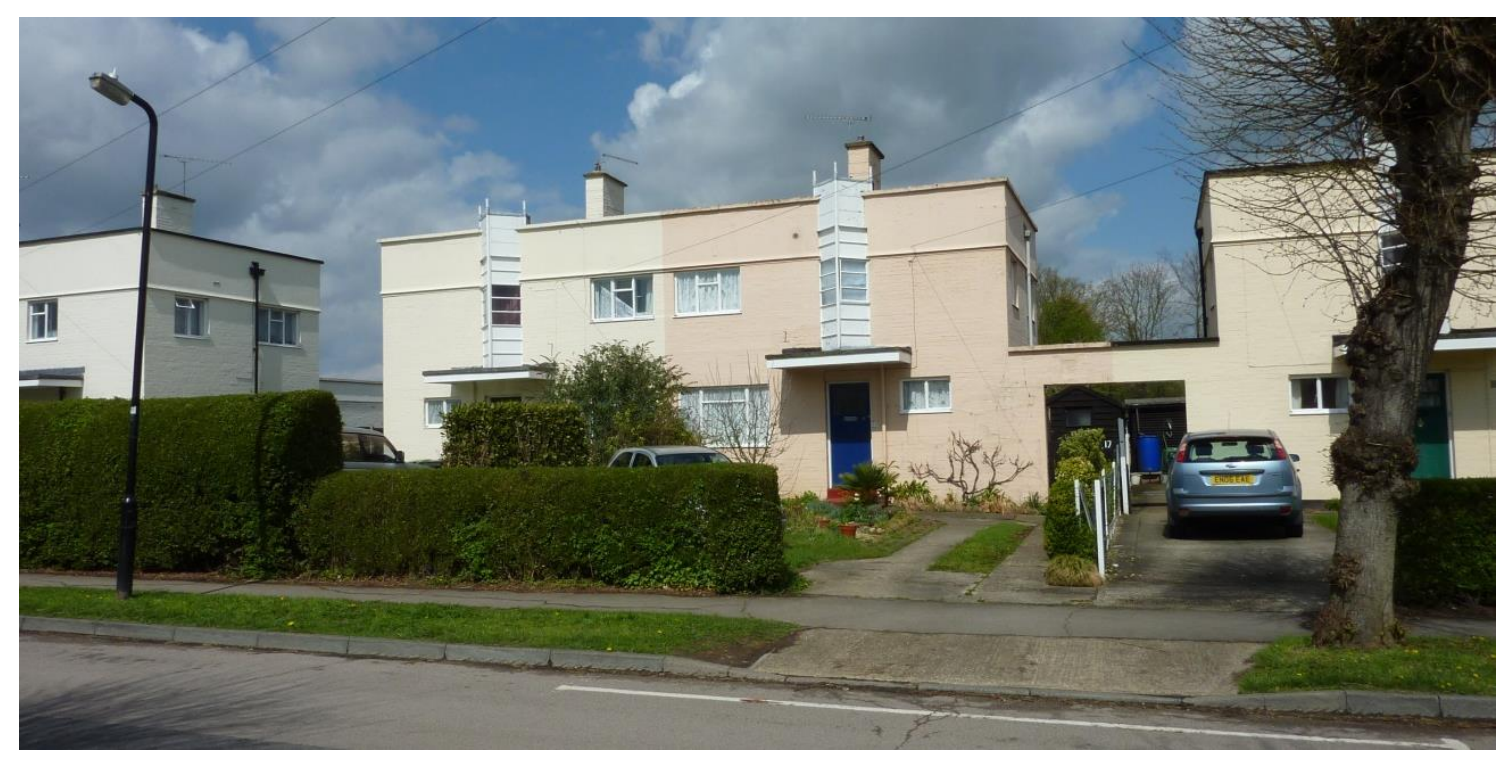

Figure 73: Numbers 17 and 19 Silver Street, 2013 


\subsubsection{The Stuart Houses}

There are 2 types of Stuart house on Silver Street (to the east of Broadway): 6 pairs of semi-detached houses with a flat front façade, and 8 pairs of semi-detached houses with part of the front façade pulled forward (28 houses in total).

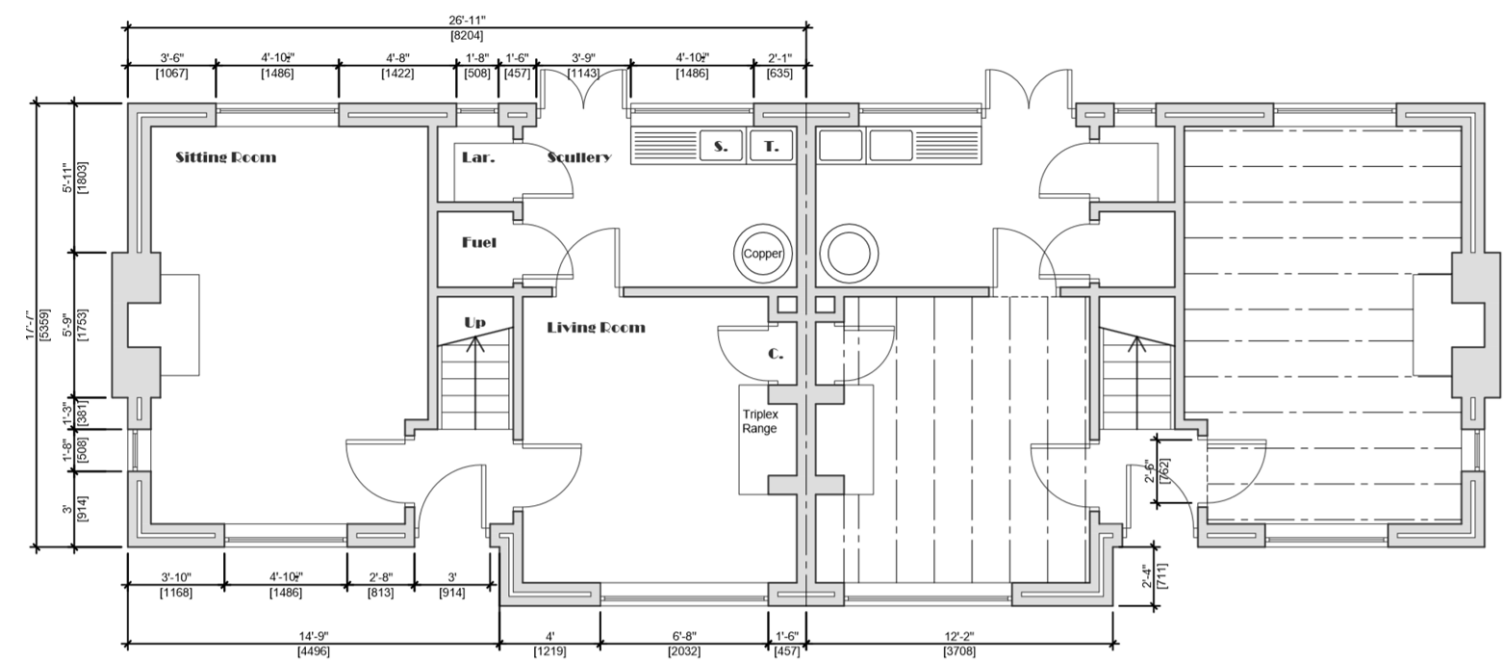

Figure 74: Original Ground Floor Plan of a Stuart House

Figure 74 is the redrawn original ground floor plan of the Stuart house with part of the front façade pulled forward (nos. 38/40, 42/44, 50/52, 54/56 and nos. 37/39, 41/43, 49/51, 53/55 Silver Street).

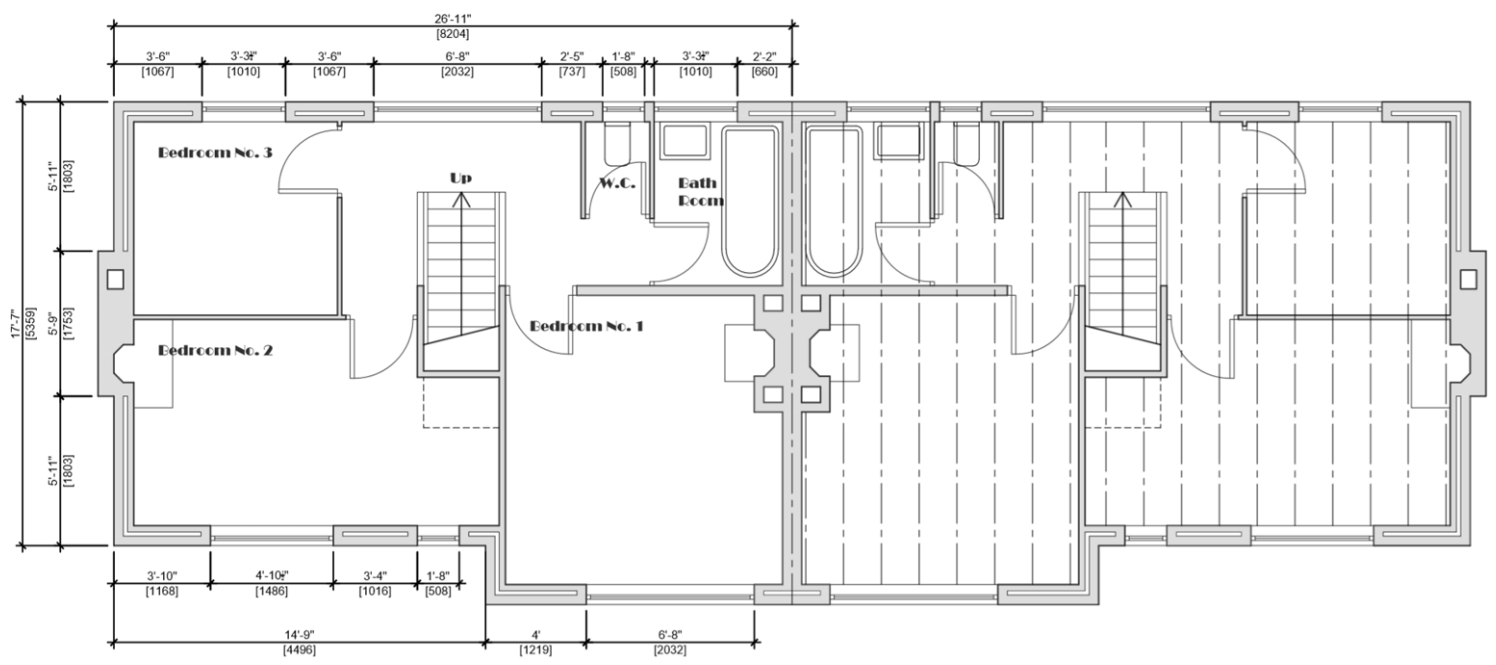

Figure 75: Original First Floor Plan of a Stuart house 
The original first floor plan and front elevation are shown in Figure 75 and Figure 76, and Figure 77 is 54 and 56 Silver Street in 2013. The house to the left has windows similar to the originals, whereas the house to the right has the replacement windows installed by BDC following their purchase of the village in 1969.

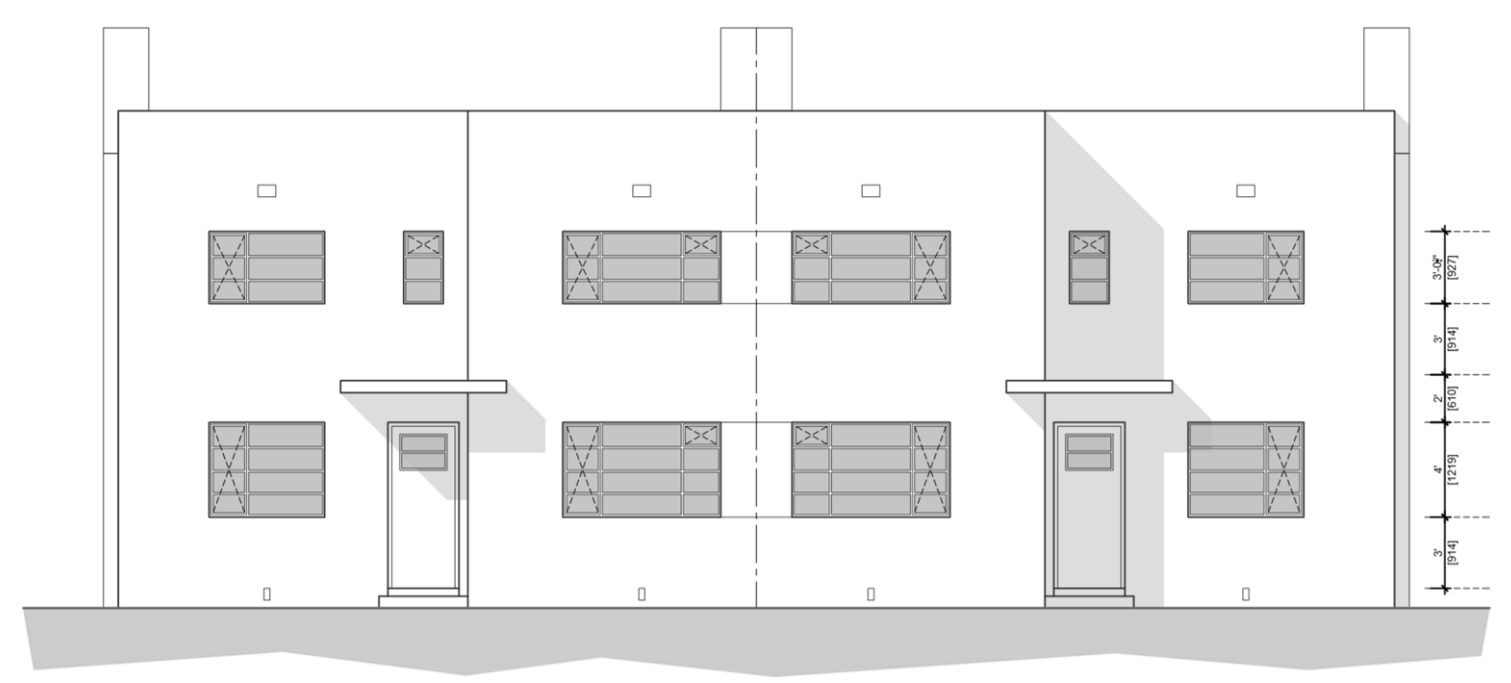

Figure 76: Original Front Elevation of a Stuart house

The original drawings of the Stuart houses are held by BDC Planning Department (J. Stuart, 1928). The Stuart houses $\left(80 \mathrm{~m}^{2}\right)$ comprised a living room with a triplex coal range, a sitting room with an open fireplace, a scullery, larder and a fuel store on the ground floor with three bedrooms (two containing open fireplaces), a bathroom with bath and sink, and a separate WC on the first floor (J. Stuart, 1928). In common with the Tait houses, the house and water were heated by the triplex range which also did the cooking. Hot and cold running water were supplied to the scullery and upstairs bathroom. Clothes were washed in a cast iron wash boiler (copper) in the scullery. The houses also had electricity, with a central light in each room and a single power point in the living room. 


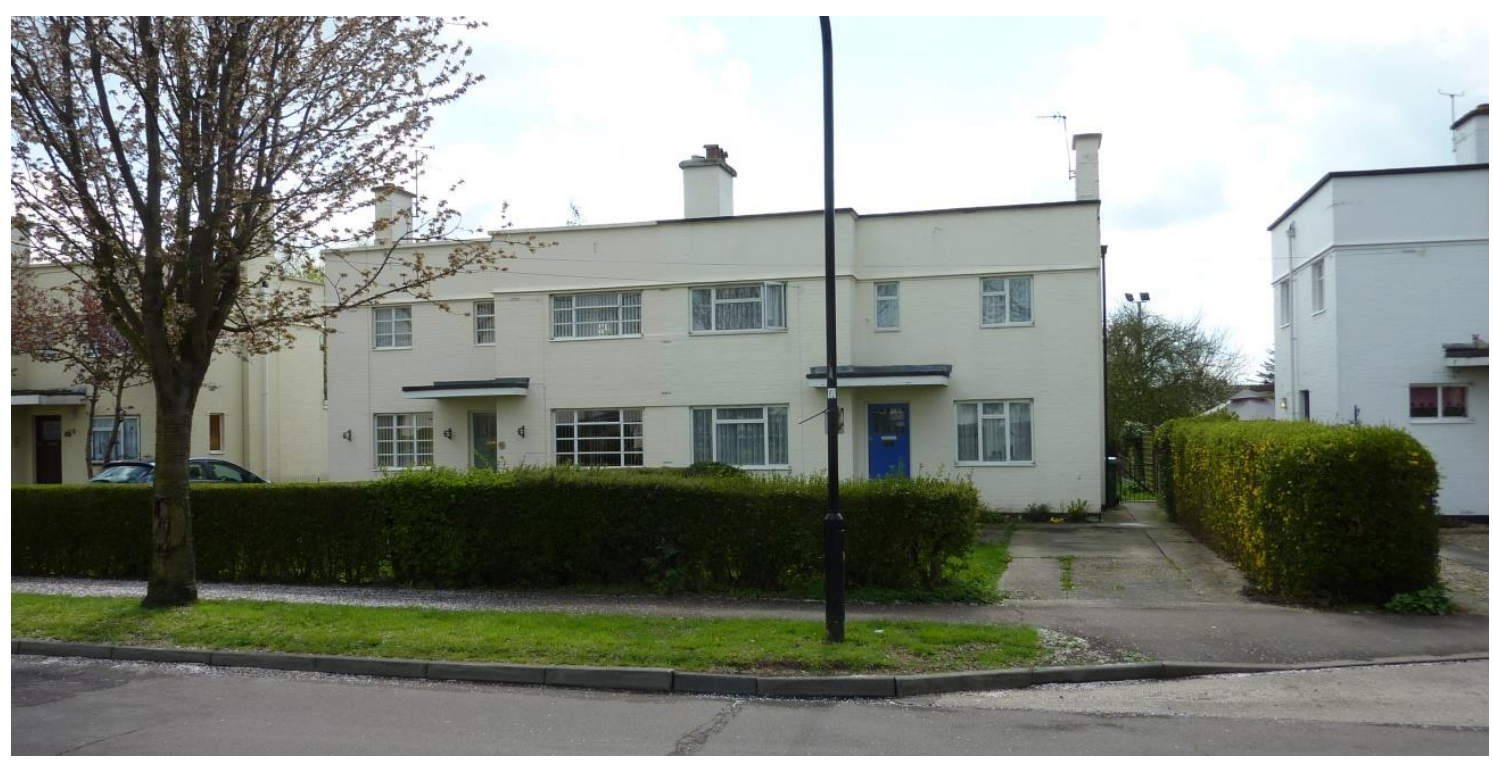

Figure 77: Numbers 54 and 56 Silver Street, 2013

\subsubsection{The Miller Houses}

There are 4 types of Miller house on Broadway: 4 pairs of semi-detached corner plot houses (with pitched roofs), 2 pairs of semi-detached houses, 4 blocks of four houses with parapet walls and 4 blocks of four houses with extended eaves ( 44 houses in total). The original floor plans of the Miller houses are missing, although BDC Planning Department have some original elevations and a section drawing (Miller, 1929), so assumptions have been made regarding the original layout, based on the available drawings and survey of the case study houses today.

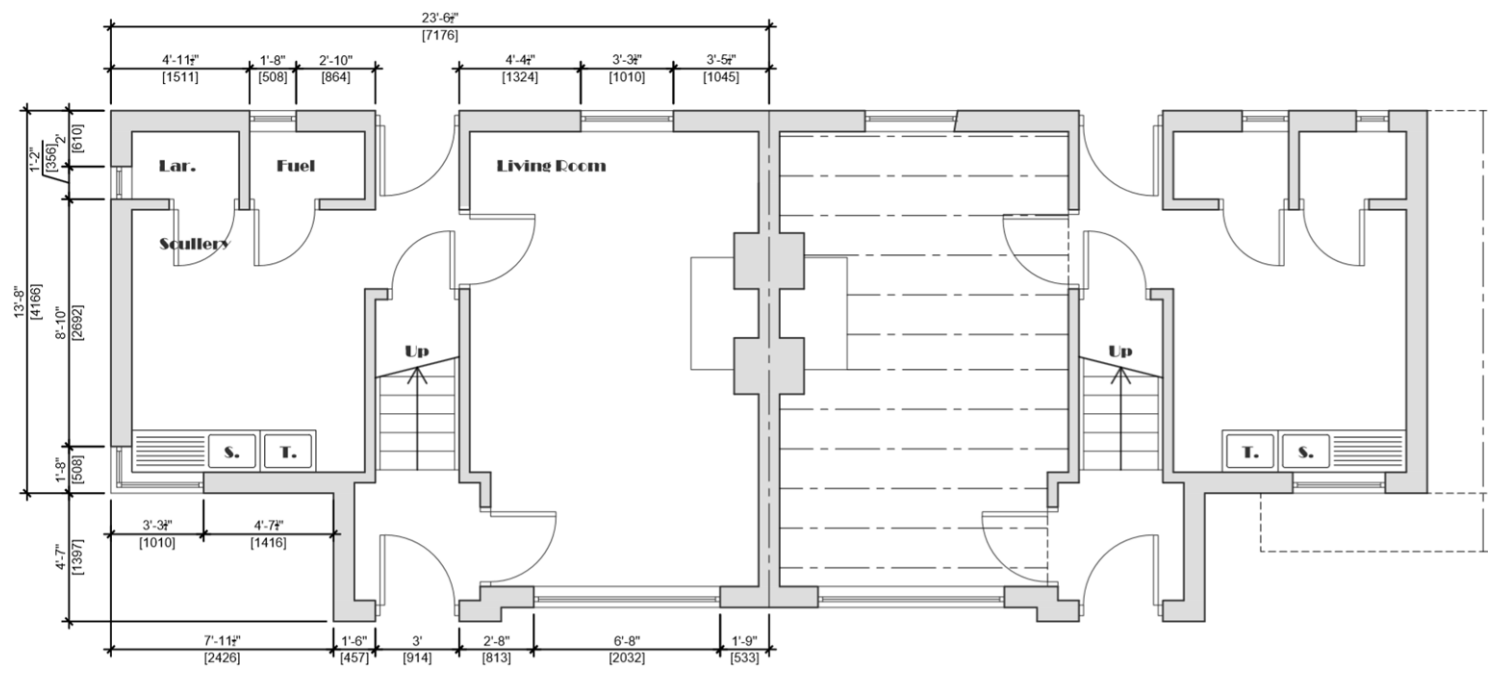

Figure 78: Original Ground Floor Plan of a Miller House 
Figure 78 is the redrawn original ground floor plan of the Miller house with a parapet wall (nos. 20/22/24/26, 36/38, 48/50/52/54 and 21/23/25/27, 37/39, 49/51/53/55 Broadway).

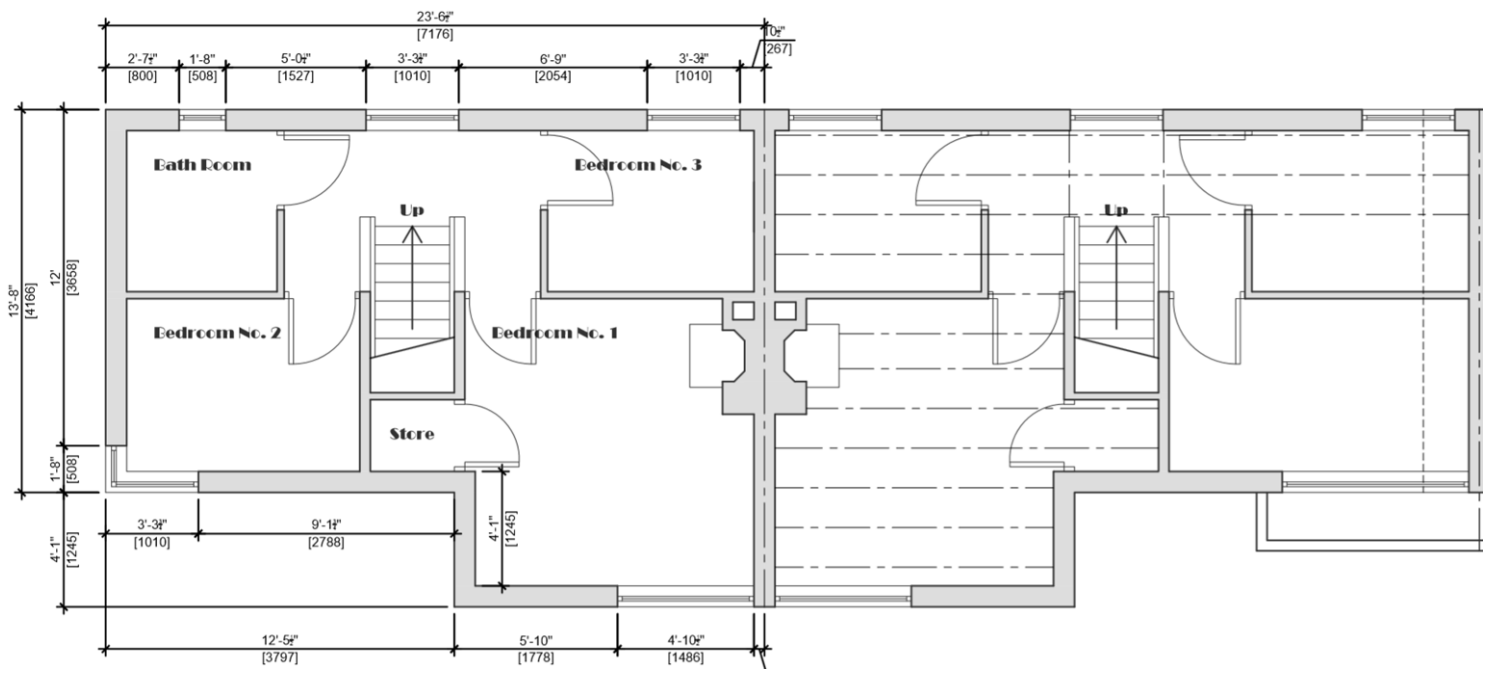

Figure 79: Original First Floor Plan of a Miller house

The original first floor plan and front elevation are shown in Figure 79 and Figure 80 and Figure 81 is a photograph of 22, 24, 26 and 28 Broadway in 2013.

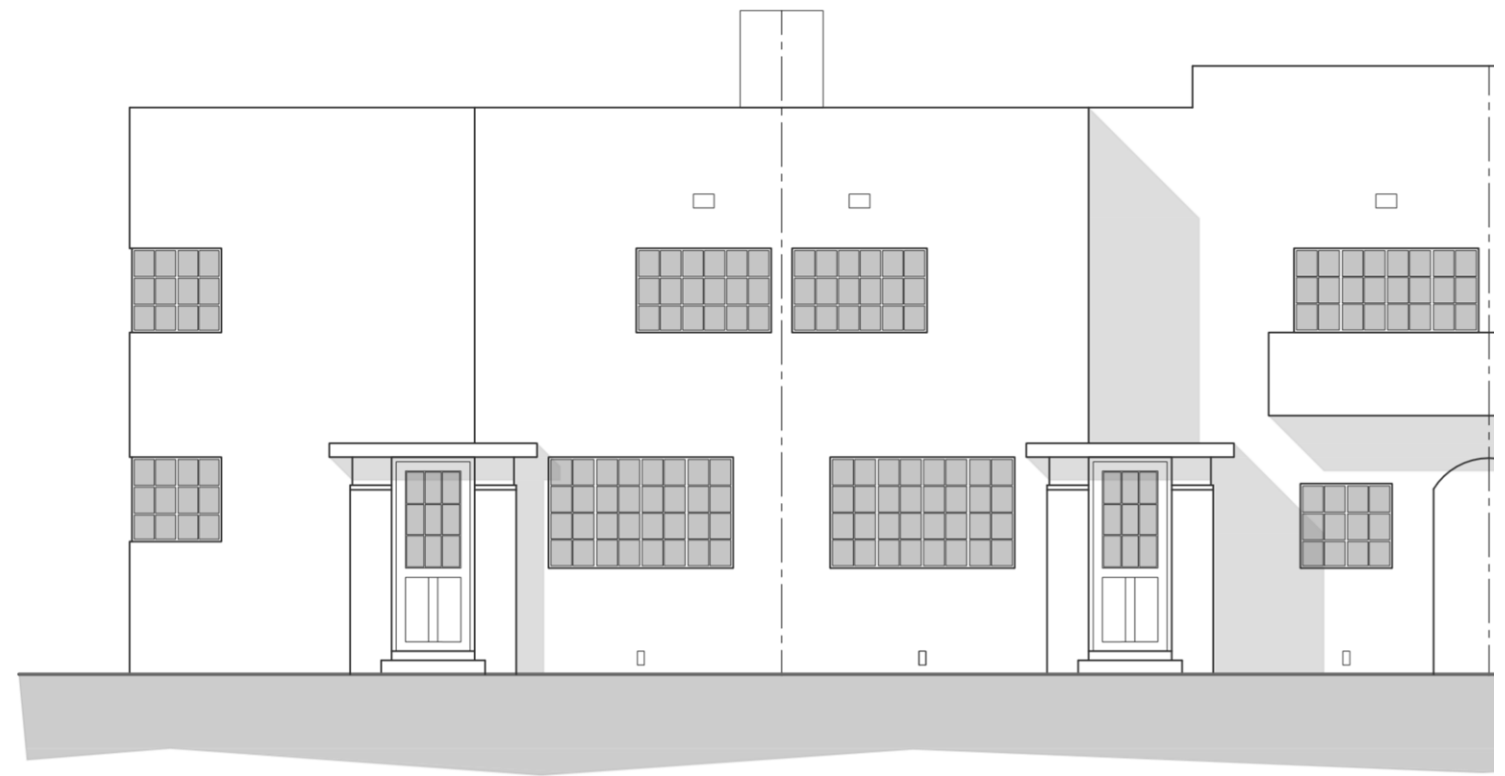

Figure 80: Original Front Elevation of a Miller house

The Miller houses $\left(60 \mathrm{~m}^{2}\right)$ comprised a living room with a triplex coal range, a scullery, larder and a fuel store on the ground floor with three bedrooms (two containing open 
fireplaces), a bathroom with bath, sink and WC on the first floor. In common with the Tait and Stuart houses, the house and water were heated by the triplex range which also did the cooking. Hot and cold running water were supplied to the scullery and upstairs bathroom. Clothes were washed in a cast iron wash boiler (copper) in the scullery. The houses had electricity, with a central light in each room and a single power point in the living room. "The James Miller houses were built last and for financial reasons the planned cavity walls became single layer brick walls" (Jensen, 2012 , p. 34). Lack of finance may also explain the lower floor area of these houses, compared to the Tait and Stuart houses.

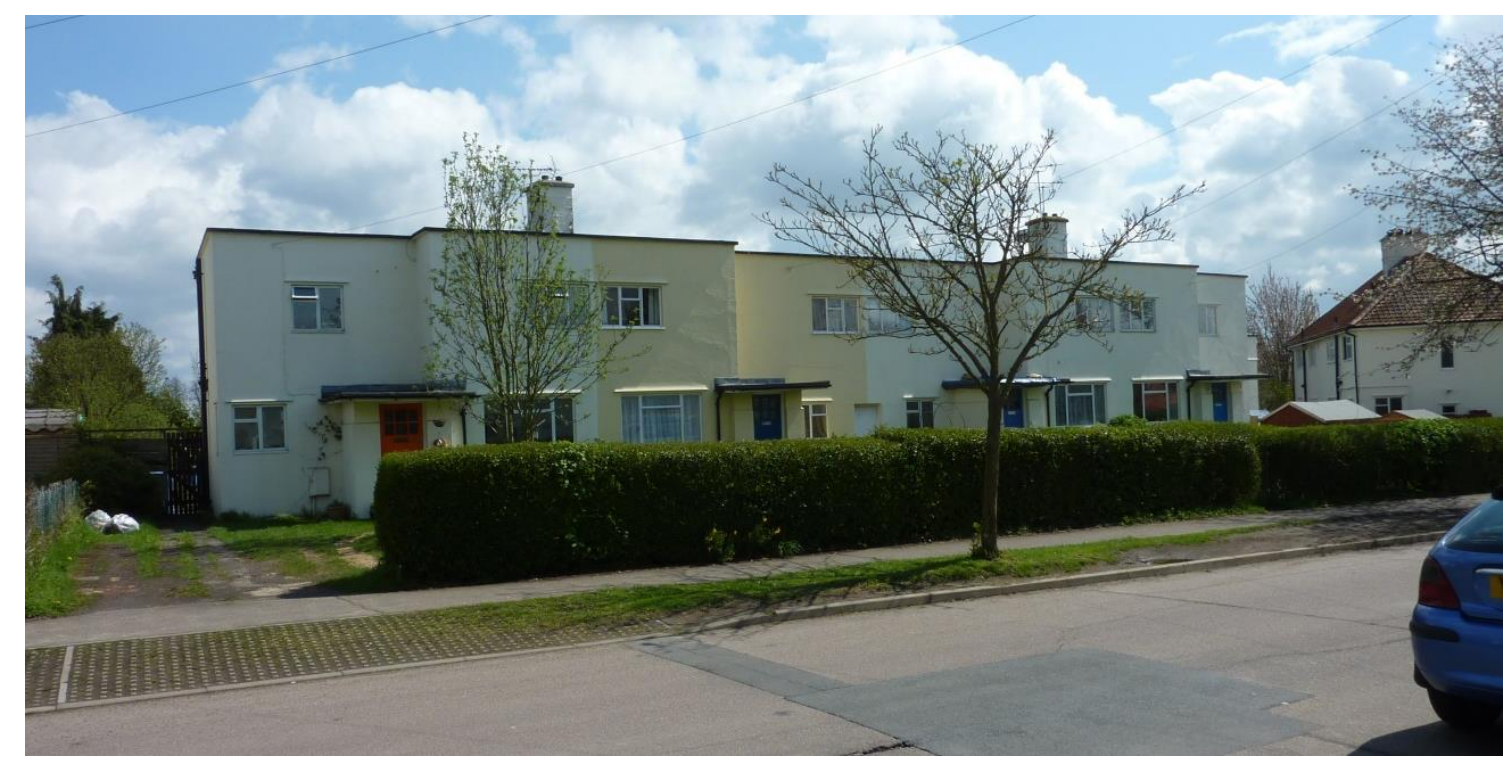

Figure 81: Numbers 22/24/26/28 Broadway, 2013

From inspection and survey of the 9 houses for this research, it seems that when BDC took ownership of the village, they not only replaced the original Crittall windows, but also carried out work to the space and water heating systems (section 4.4.1.5).

\subsubsection{Household Size}

In the 1911 Census the national average occupancy was 4.3 persons per dwelling (Office for National Statistics, 2013). The average number of persons per dwelling in the 1930 s and 1940s interviewees' households was 5.8 (Figure 82) which is significantly higher. Of these 12 interviewees, 7 (58\%) lived in a household of 6 or more people, and no-one lived in a house with fewer than 4 people. In 5 (42\%) 
households someone outside the nuclear family (a relative or a lodger) also lived with the interviewee's family (Figure 83). One 1930s and 1940s interviewee lived with her mother, father and two sisters in a three bedroom house and, following the death of her grandmother, her aunt also came to live with them [ENG_10, 0:20:20]. Another interviewee, who was one of five children, recalled that they always had a lodger [ENG_01, 0:02:13]. One elderly SE interviewee described living in a Tait terraced house during the 1940s:

"Well this room, the bigger room here, was used...for my grandmother and aunty, because they then cooked on the triplex open fire there, which had an oven...flues and all that, I can remember them cleaning it and black leading it...my mother, father and myself were in the front room, the smaller room...how we got in there with all the things, I don't quite know, but it didn't seem too cramped to me, probably it was, but I didn't notice it, you were used to things you see...my mother cooked in the kitchen on a paraffin cooker until gas and electric..." [SE_01, 0:03:37].

Renting was common amongst the 1930s and 1940s lifestyle interviewees, and 8 (67\%) stated their parents rented the house, and the remaining 4 (33\%) owned it (Figure 84). A number of interviewees recalled there was little choice of accommodation, and 2 (17\%) presumed they lived in their house because it was the only available option [ENG_02, 0:06:38, ENG_03, 0:07:57]. A further 5 (42\%) interviewees lived in council owned properties which were assigned to them, and 3(25\%) presumed that their parents chose their house due to its location (Figure 86). 


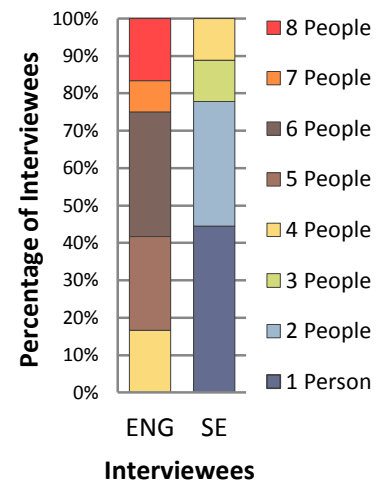

Figure 82: Number of persons per dwelling (ENG SE)

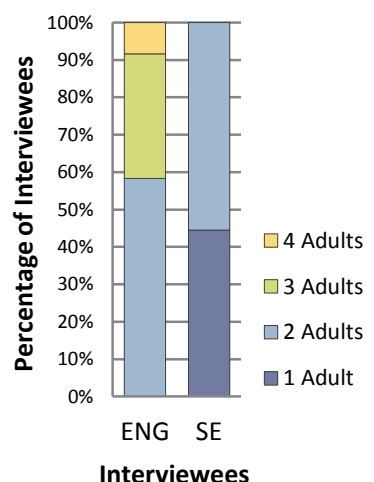

Figure 83: Number of adults per household (ENG SE)

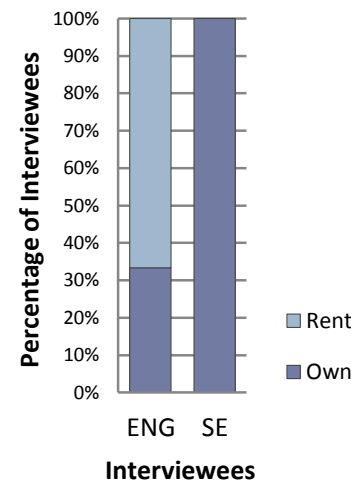

Figure 84: Home ownership (ENG SE)

In contrast, in the 2011 Census the average occupancy was 2.3 persons per dwelling (Office for National Statistics, 2013), and 1.9 in this survey. Of the 9 volunteer households, only 2 (22\%) had over 2 people, with $4(44 \%)$ having just one person. Figure 85 illustrates the drop in the number of persons per dwelling in England, from 1911 to 2012 based on Census data.

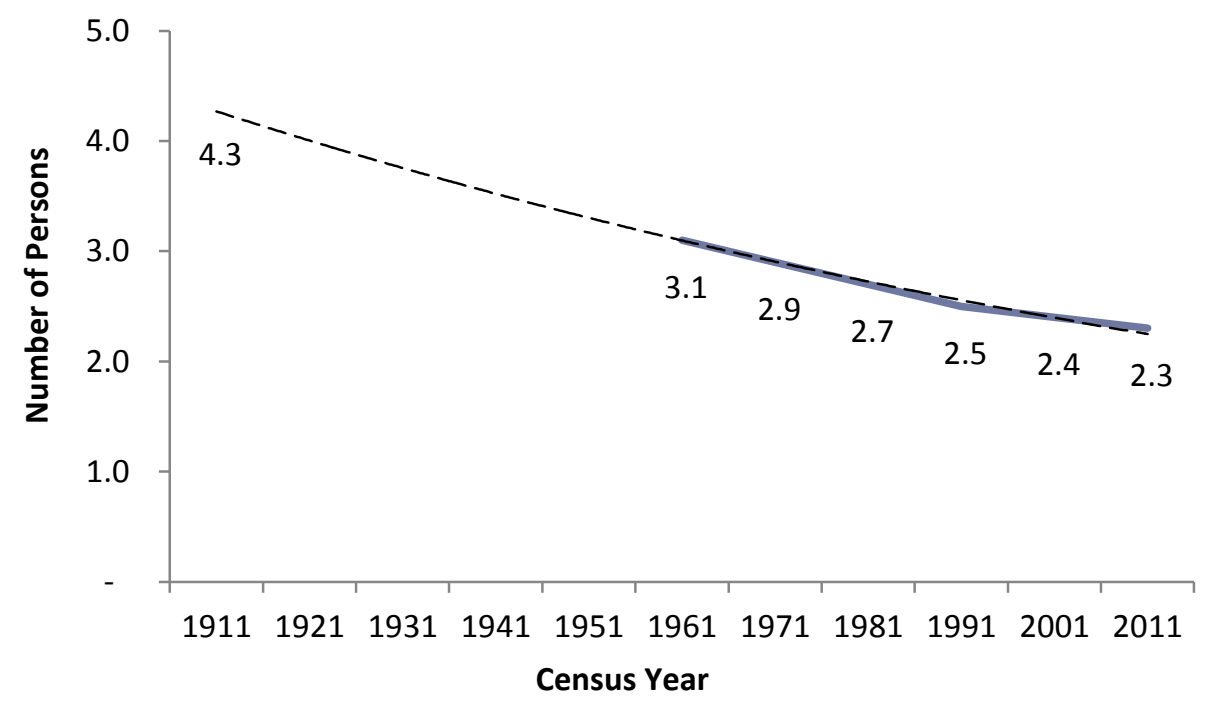

Figure 85: Number of persons per dwelling from 1911 to 2012

As previously mentioned (section 4.1), in 1969 Silver End was sold to Braintree District Council (BDC) (Jensen, 2012, p. 34) and today, few houses appear to remain inhabited by Crittall families. In this survey of 9 houses, the inhabitants' occupations included government workers, trades and sales persons. Of the SE volunteers, 3 (33\%) were 
retired, 2 (22\%) were single people in full-time employment and the remaining 4 (44\%) were young couples, 2 (22\%) of which had children. This indicates that the SE houses are no longer typically inhabited by families, but are occupied by a wide variety of people, of different ages and situations. One SE interviewee said that often people come to Silver Street, rent a house for six months and then leave:

“...up until ten years ago, people bought a house to make money you see, 'cause they were gonna sell it on a few years later and make some more money...but of course, that all come to a halt...like the house over there, a man couldn't sell it...so he lets it now... a couple of them are owned by the nursing homes, where they put nurses in cheap, foreign nurses, you know..." [SE_05, 0:26:17].

In sharp contrast to the 1930 s and 1940s lifestyle interviewees, all SE interviewees own, or are paying a mortgage on their house (Figure 84$)$, with $6(66 \%)$ having lived in their house for 10 years or less, and the remaining 3 (33\%) for over 40 years. When asked about the reason for choosing to buy their house, the first response of 7 (78\%) of the SE interviewees was the location (Figure 86). However, one younger SE interviewee stated, "...only place I could afford unfortunately...I knew the village...at the time it was about fifty thousand pound cheaper to buy a three bedroom flat roofed house in Silver End than what it was to buy a two bedroom house in another village..." [SE_06, 0:02:23]. Of all the reasons given by the SE interviewees for choosing to purchase their house, $26 \%$ were financial (Figure 87 ). 


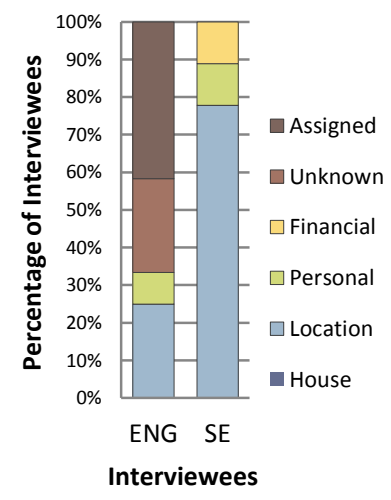

Figure 86: Reasons for choosing to buy or rent the house (first answer) (ENG SE)

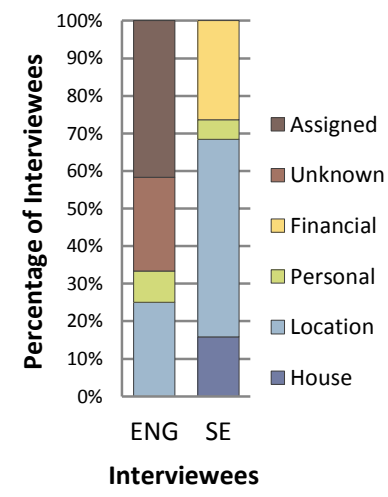

Figure 87: Reasons for choosing to buy or rent the house (all answers) (ENG SE)

Today, lower occupancy levels and the different work situations of many SE inhabitants impact the way that spaces inside the SE houses are used. Figure 88 illustrates the current floor plans of a SE Stuart case study house.

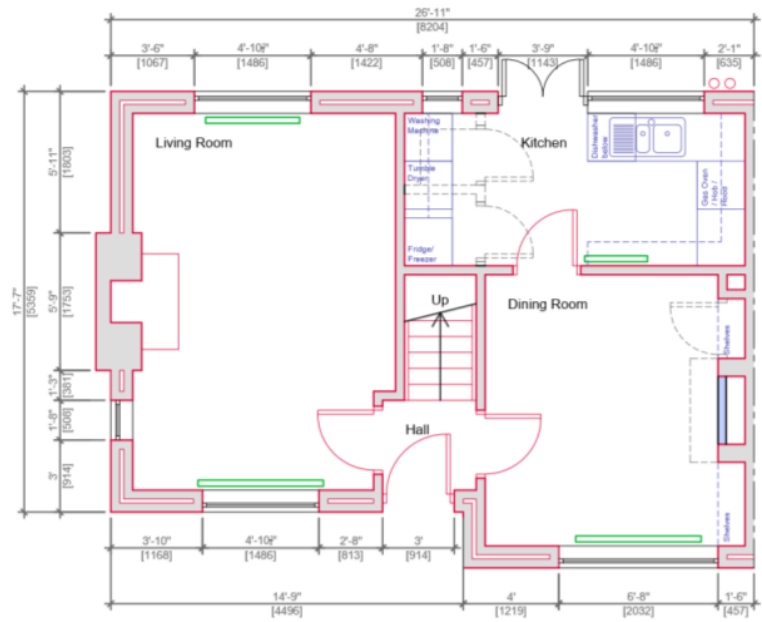

Ground Floor Dlan

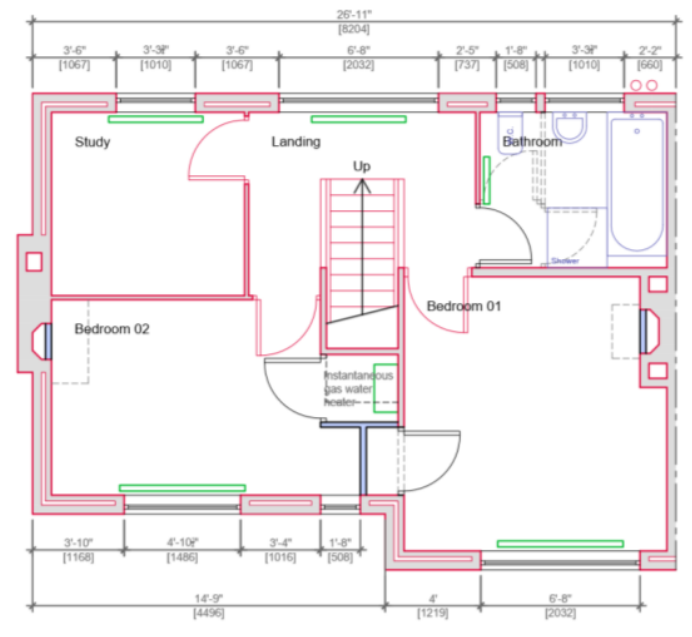

First Flocr Dlan

Figure 88: Current floor plans of an SE Stuart case study house

\subsubsection{Bedrooms}

In 7 (78\%) of the case study houses today, only one of the three bedrooms is used for sleeping on a regular basis, due to the low occupancy. This contrasts with the use of these rooms in the 1930s and 1940s, when every bedroom was a bedroom, and bedrooms were often for more than one child of the same sex. Today, the spare 
bedroom has become a feature in many of the SE case study houses, primarily those occupied by single people and couples with no children, serving as a space for overnight visitors [SE_03, 0:04:25]. In addition, an upstairs study, often containing computer equipment, is also a feature in a number of the houses [SE_02, 0:12:50; SE_09, 0:02:44]. One elderly SE interviewee explained that bedroom 1 has retained its original function, bedroom 2 has twin beds and is the guest bedroom and the small back bedroom is used as an office [SE_01, 0:11:30]. A 1930s and 1940s lifestyle interviewee reflected on the council house that her family moved into, recalling that it, "...had three bedrooms and a bathroom and this was seen as the height of luxury..." [ENG_09, 0:02:06].

Since the SE houses were constructed, the computer has become an important piece of household equipment and 7 (77\%) of the SE houses have a desktop computer, a laptop, or another portable device such as an IPad. This contrasts with the 1930 s and 1940s lifestyle interviewees, only 2 (17\%) of whom recalled a study space and one interviewee who mentioned that this room was later used for a lodger [ENG_11, 0:07:43]. Similarly, none of these interviewees described having a spare bedroom.

\subsubsection{Ground Floor Spaces}

Of the 12 1930s and 1940s lifestyle interviewees, 4 (33\%) recalled having a sitting room or a parlour that was only used occasionally, with one interviewee recalling it being used, "...on high days and holidays...sometimes on a Sunday..." [ENG_01, 0:07:43]. Many of the remaining interviewees said their house was small [ENG_03, 0:03:32] and that all of the spaces were used, "...you walked through [the] front door straight into [the] living room then the backroom, [there was] no kitchen or 'owt like that...we did have a water closet..." [ENG_02, 0:08:17]. This interviewee later described three bedrooms upstairs, one of which was small and did not have a window, yet the house was inhabited by six people. Another interviewee stated:

"...well it was a brick house and it consisted of two up and two down...there was an outside toilet and just one tap in the yard, and that was basically it, and I remember helping my uncle...and we actually built a veranda on the back so we 
had an addition... a wooden veranda which was used quite extensively...we'd a tiny, tiny postage stamp piece of soil, garden..." [ENG_06, 0:05:23].

For the majority of the 1930s and 1940s interviewees, the kitchen was the centre of activity, containing the coal range that provided heat for warmth and cooking. One interviewee explained the range was lit all day every day, and kettles were put on the fire for hot water [ENG_02, 0:08:17]. For many interviewees the coal range was the only form of heating. The original SE Stuart houses were designed with a sitting room, a living room (kitchen) and a scullery. One elderly SE interviewee recalled a kitchen dresser that came with the original house, "...it was quite a sensible thing really...quite a big cupboard, two nice deep drawers and open shelves..." [SE_01, 0:25:50].

In the Stuart houses today, the original living room (kitchen) is typically used as a dining area, and the scullery has been remodelled as a fitted kitchen incorporating cooking, food storage and clothes washing facilities (Figure 88). To many SE interviewees, the relationship between the kitchen and dining area is important. One elderly, retired SE interviewee living in one of the Tait terraced houses explained that she now spends most of her time in the main room at the back of house, so she can look out onto the rear garden. The front room contains a piano and a dining table and chairs which she uses when she has guests, although she thought a door connecting this room with the kitchen would be ideal [SE_01, 0:09:47]. In 6 (66\%) of the case study houses, the small rooms which were once the larder and fuel store have been removed to make the kitchen area larger, the fridge/freezer having replaced the larder, and central heating having removed the need for solid fuel. One SE interviewee described knocking the small larder and cupboard out of the kitchen to create a more functional space [SE_01, 0:25:50], and one single person living in a Stuart house commented on the size of the kitchen, "...too small really, I mean it...kind of does for me on my own...how a family would manage with it, I really don't know..." [SE_02, 0:04:33].

Only $1(11 \%)$ of the case study houses has been significantly altered, with the remaining houses keeping the original internal walls. The owner of the altered Tait house described the kitchen as it was when he moved in (1971): 
"...well, the toilet was just inside the back door...the toilet door was more or less in the kitchen and you had... a walk-in pantry...and another cupboard and a low cupboard which was built for coal years ago which went under the stairs and a sink under the window, and that was it..." [SE_05, 0:30:13].

This interviewee described building an extension to create a larger kitchen and dining room, and making space on the ground floor for a large bathroom.

\subsubsection{Bathroom}

One elderly SE interviewee mentioned that when she and her husband started to get older, they removed the bath and installed a corner shower in the bathroom [SE_01, $0: 11: 30]$. A number of interviewees have remodelled the upstairs bathroom, with some knocking the bathroom and toilet into one room, creating room for a separate shower cubicle [SE_06, 0:21:32]. In the original Tait semi-detached house, the toilet was on the ground floor, adjacent to the kitchen. One SE interviewee recalled that shortly after BDC purchased the village from Crittalls, they relocated toilets upstairs, into the somewhat cramped bathroom:

"...it's like when they put the toilets up here, the council run...the drain pipe down that corner...inside the house...but me, I crafted one...I put the smelly pipe outside where the drain pipe used to be...I didn't want one in here, you know... and nobody's ever said anything..." [SE_05, 0:16:03].

Recessed lights and modern fittings and fixtures are a common feature in many of the remodelled bathrooms.

\subsubsection{Laundry}

The original Tait houses had a semi-detached timber outhouse containing a concrete wash boiler (the 'copper') [SE_01, 0:28:34]. Today, very few outhouses remain. In the original Stuart houses, the copper was located in the corner of the scullery (J. Stuart, 1928) and has since been replaced by the washing machine and tumble dryer, which in most cases are in the remodelled kitchen. Only $1 \mathrm{SE}$ interviewee had no washing 
machine, and 5 (56\%) have a tumble dryer which is used occasionally, with most interviewees attempting to dry washing outside or inside on a clothes horse.

\subsubsection{House Alterations}

Of the 9 SE case study houses, 7 (77\%) have a ground floor addition to the rear of the house, and in most cases, this is a conservatory or sun room, reflecting both the desire for more space and connection with the rear garden. One SE interviewee explained that the house used to be inhabited by a disabled lady and during the 1980s a ground floor extension was built containing a bedroom and bathroom. This interviewee has since renovated the bathroom and intends to use the bedroom as a dining room [SE_04, 0:03:36]. Only one other SE house has been altered significantly (section 4.3.1.6). One elderly SE interviewee described how they had a Crittall conservatory constructed at the rear of their house thirty years previously, with Crittall doors replacing the rear lounge window [SE_08, 0:08:00].

Alterations to their house were mentioned by $5(42 \%)$ of the 121930 s and 1940 s lifestyle interviewees, with $3(27 \%)$ recalling improvements to space and water heating, 2 of whose fathers undertook the work themselves. One interviewee recalled helping his uncle build a timber addition to the rear of the house [ENG_06, 0:24:18] and another work to the garden. The SE houses were not altered for many years, presumably because the inhabitants were renting the houses from Crittalls and were not allowed to undertake any alterations or improvement work themselves. Since the case study houses have been in private ownership, many owners have undertaken essential maintenance work:

...all the rooms upstairs have all been taken back to the brickwork, they've all been re-pointed and then they've all been lime-rendered in the original lime render and then just a skim of modern plaster just over the top...the whole of the outside of the house again, all that render was blowing and was awful, the whole of the house has been taken back to the brickwork, re-pointed, rerendered and painted..." [SE_04, 0:17:22]. 
Refurbishing and modernising their house to suit their functional and aspirational lifestyle is both enjoyable and rewarding for some SE interviewees, with two couples mentioning not going on holiday in recent years, but rather choosing to invest time and money in their houses [SE_03, 1:25:43; SE_09, 0:24:43].

\subsubsection{The Size of the House}

One SE interviewee thought their main room downstairs was just the right size for two people [SE_03, 0:04:25] but another felt the house was too small, even for two people, "... when people come to stay...for any more than about two days...you're climbing over each other which is surprising... when you think people lived in here with families..." [SE_09, 0:14:04]. One elderly SE interviewee recalled her parents buying a piano that is still in the house:

"...that was the most expensive thing on my father's itinerary [inventory], cost forty pounds in 1916...it was a lot of money then...l've looked at it and wondered how on earth they ever got it through the front door, but I suppose they manoeuvred it in somehow...it's rather large..." [SE_08, 0:38:19].

The lack of storage space within the houses was mentioned by several SE interviewees [SE_02, 0:04:33], and for one Christmas decorations and other possessions are stored in their parents' loft [SE_06, 0:27:20], whilst another has two sheds in the rear garden for storage [SE_09, 0:06:25]. When asked for the best things about the house, 1 (11\%) stated the size, but also mentioned that they would not have bought it without the sun room, "... we probably wouldn't have bought this house but for this extension, because it makes a massive difference to the house, having this here ..." [SE_07, 0:05:11]. During the 1930s and 1940s, people did not appear to have many possessions making storage space within houses less important than today, "...I used to play shops and I remember getting stuff out of cupboards, well there wouldn't be a lot in the cupboards, however, I used to play shops..." [ENG_02, 0:45:00]. Another interviewee reflected:

"...that's one of the strange things as well, I did mean to say that earlier on, I don't ever, ever remember the front door being locked, in fact, as far as I remember they [his grandparents] lost the key and never replaced it and that 
was it and it was never locked... anybody could have walked in, but there was nothing to steal...nothing worth having..." [ENG_06, 1:14:18].

People today generally seem to require more space than those who lived during the 1930s and 1940s, possibly due to more possessions, but also because of higher expectations and aspirations. When asked about what was better about life during the 1930s and 1940s than life today, one interviewee responded, "...well we didn't all seem to want more than we had, you know, we were all so happy together..." [ENG_10, $0: 29: 53]$.

\subsubsection{Outdoor Space}

\subsubsection{The Garden}

Since the 1930s and 1940s, the function of the outdoor space attached to the SE case study houses has undergone significant change (section 4.2.2). One SE interviewee felt his rear garden was huge and overgrown, "...apparently, the idea of it was, when they built the village...that people could have large gardens and grow their own fruit and veg...I think that's largely sort of gone by the by..." [SE_02, 0:21:58]. When asked about alterations to the house and outdoor space, 6 (67\%) SE interviewees mentioned work on the garden (Figure 89), and for one elderly SE interviewee this was making her garden more ornamental, rather than productive [SE_01, 0:20:30]. Another elderly SE interviewee felt he had done a lot of work to the garden, "...'cause when we moved in, it was all dug up ... as the children grew older we put lawns down ... and when I got the allotment, I finally filled the last bit in ..." [SE_05, 0:43:59]. One younger SE interviewee stated that their rear garden was all grass when they first moved in, but since they have dug out several flower beds [SE_09, 0:07:53]. Another thought the front garden was a problem, "...it's horrible...because it just gathers litter... we put a hedge in to try and get people to stop walking along it..." [SE_06, 0:15:25]. This interviewee also described work to the rear garden:

"...when I moved in, it was all overgrown, the concrete path was all smashed up, so...my friend...he bought his mini digger 'round, levelled it all off for me...we put a fence up...half of the garden was a veg patch which I 
maintained...then it got too much work, so I turned that back into garden..." [SE_06, 0:15:25].

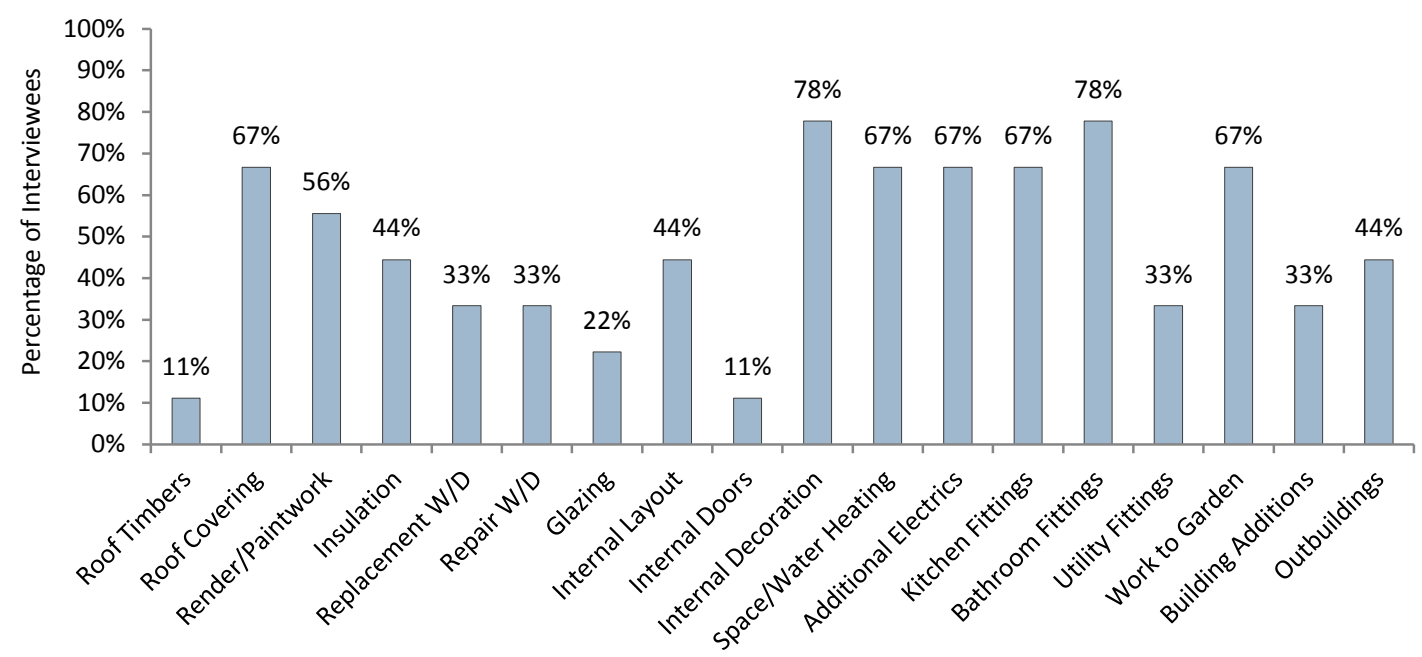

Figure 89: Alterations undertaken by the SE interviewees

The most common alterations which have been undertaken by 7 (78\%) of the 9 SE interviewees are internal decoration and replacement of bathroom fittings. These are followed by replacement of the roof covering, improvements to the space and water heating, work to the electrics, replacement of kitchen fittings and work to the garden, all of which have been undertaken by $6(67 \%)$ interviewees. When asked about planned future alterations, 4 (44\%) SE interviewees would like to undertake specific work to their garden, in three cases involving landscaping and planting and in the other, erecting new fences [SE_09, 0:10:10].

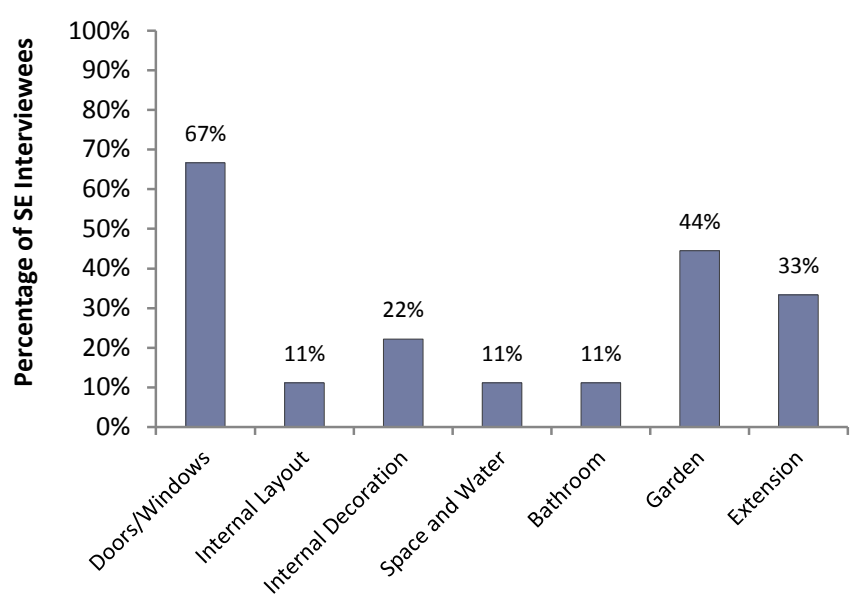

Figure 90: Alterations planned by the SE interviewees 
As discussed in section 4.2.2, during the 1930s and 1940s, a significant part of gardens were set aside for growing vegetables. One elderly SE interviewee said her father loved gardening, growing vegetables in the rear garden and in the allotment beyond. Flowers were grown in the front garden, for which her father had won a prize [SE_08, $0: 11: 00]$. This interviewee also mentioned spending a lot of time outdoors in her early years, as did her parents. Another elderly SE interviewee described her front garden when she was young as being, "...all lawn, apart from the war time when half of it was dug up for potatoes, because it was 'dig for victory' wasn't it..." [SE_01, 0:21:21]. One 1930s and 1940s interviewee whose parents worked on a farm said her father grew:

“...some of everything, potatoes, onions, marrows, we used to grow radishes for your salad, and your own lettuce all that sort of thing...dad used to grow plenty 'cos then you had your keeping potatoes...late potatoes he called them...keeping potatoes for through the winter..." [ENG_12, 0:26:12].

In contrast, present day SE gardens are far less productive with far more time spent inside the house than in the garden (section 4.2.2), making it important for gardens to be easy to maintain. Grassed areas at both the front and rear of the SE houses are common.

\subsubsection{Garden Structures}

As discussed in section 4.3.1.8, the original Tait houses were designed with a semidetached timber outhouse and in the majority of cases this no longer exists. Of the 9 SE interviewees, 3 (33\%) have constructed an addition to the rear of their house (section 4.3.1.9) and 4 (44\%) have built or altered outbuildings (Figure 89). The latter has involved alterations to the original timber outhouse [SE_01, 0:16:43], construction of a large concrete shed rendered to match the house [SE_04, 0:12:05], and the erection of a summer house [SE_05, 0:55:27] and a greenhouse [SE_09, 0:07:53]. As discussed in section 4.3.1.10, garden structures are used for storage to compensate for the lack of storage space in the house. Also, in one household the summer house is a place to dry clothes in the winter [SE_05, 0:55:27]. Washing lines are found in many 
gardens, mostly the rotary type. The sun room or conservatory is often accompanied by an area of hard landscaping to the rear of the houses.

\subsubsection{Space for the Car}

Car ownership was uncommon during the 1930s and 1940s with $9(75 \%)$ of the 12 1930s and 1940s lifestyle interviewees households having no car, 2 (17\%) with one and 1 (8\%) with two (Figure 91). One interviewee said her father never owned a car, “...nobody had cars really in our road..." [ENG_10, 0:09:30]. One elderly SE interviewee believed that Silver Street was once perceived as the most desirable street in the village, but felt that this was no longer the case, primarily due to the car. He acknowledged that the houses were designed for the working man, and that working men did not have cars in the 1920s:

"... when the village was built, the only transport on the road was...the CO-OP coal lorry once a fortnight, the milkman, who pushed it anyway, and the baker come...in a van, once, twice a week, and...the buses every hour, but the buses then were only half the size they are now...the only cars in the village were the big houses up there which were the managers, the district nurse, the doctor... so there was probably only a dozen cars in the whole village, but now...our neighbour, until recently, they've had four cars...now they've got three...they just don't know what to do with 'em, and so consequently...they're up on the grass verges...mud churned up, whereas, years ago...everything was nice." [SE_05, 0:46:54].

Of the 9 SE volunteer households, 8 (89\%) had at least one car, and $3(33 \%)$ had two. None of the SE interviewees used public transport regularly, with $2(22 \%)$ using it occasionally, and 7 (78\%) never using it (Figure 92). Many SE interviewees felt public transport was expensive, and one stated that running a car was cheaper than using public transport, even with the cost of fuel [SE_03, 1:16:55]. This opinion was shared by another interviewee who commented that, "...it is quicker and easier and cheaper to drive ..." [SE_04, 0:43:12]. This contrasts with the 1930s and 1940s lifestyle interviewees, 5 (42\%) of whom recalled using public transport regularly and 7 (58\%) 
using it occasionally. One elderly SE interviewee said her father worked for Crittalls on the window assembly plants [SE_01, 0:08:22] and recalled that a bus was provided for the Crittall workers from Silver End to the Witham factory [SE_01, 0:08:50]. This is confirmed by another elderly SE interviewee who stated Crittalls had their own buses, with three hundred people employed at Silver End, three hundred at Witham and three hundred at Braintree [SE_05, 0:00:30].

Only $2(22 \%)$ of the SE volunteer households had bicycles and in both these were used occasionally. This contrasts with the 1930s and 1940s lifestyle interviewees, as bicycles were used regularly in 3 (25\%) households and occasionally in 8 (67\%) (Figure 93). One elderly SE interviewee remembered having a bicycle in her early years, as did her mother and father, "... we used to cycle everywhere..." [SE_08, 0:25:35].

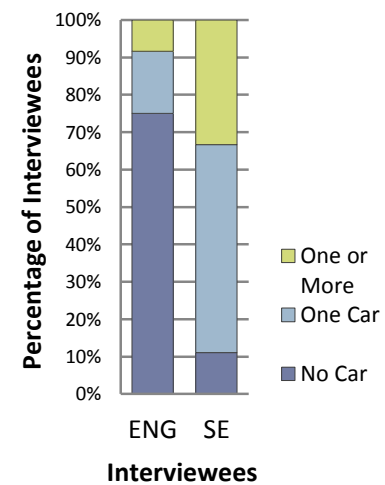

Figure 91: Number of cars per household (ENG SE)

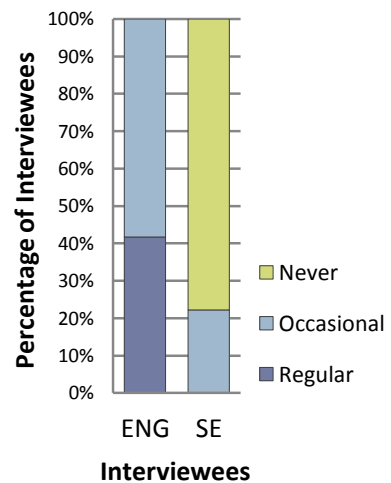

Figure 92: Use of public transportation (ENG SE)

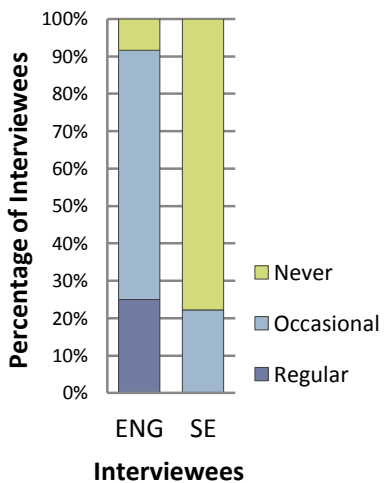

Figure 93: Number of households where bicycles are used regularly (ENG SE)

The introduction of the car has impacted outdoor space use through the driveways needed to accommodate it. Driveways now occupy space once dedicated to garden area. In both Silver Street and Broadway cars line both sides of the carriageway, and in Silver Street many are parked upon the grass verges. One interviewee thought one of the worst things about living in their house was the excessive traffic [SE_09, 0:14:43]. 


\subsection{Energy Use}

\subsubsection{House}

This section reviews the different energy utilities and the main energy uses in the house, past and present.

\subsubsection{Utilities}

The original SE case study houses had mains water and electricity supplied by a local power plant, "...we had electric, but that was provided by Crittalls direct, what they call direct current..." [SE_01, 0:03:37]. Of the 12 1930s and 1940s lifestyle interviewees, 1 (8\%) household had no mains water supply (Figure 94) and 3 (25\%) no mains electricity (Figure 95). One such interviewee recalled an outside cold water tap in the yard but no running water inside, and described how his father attempted to modernise the house by fitting an old bath in the corner of the kitchen, with a wooden door on top [ENG_02, 0:08:17].

Gas was supplied to 4 (33\%) interviewees' houses (Figure 96), "...we had electricity and water... we didn't have any gas in the village then...there was certainly a light in each room and I think there will only be one socket in each room ...in the winter, all the windows froze up inside and in the bathroom your flannel was frozen..." [ENG_09, 0:05:43]. One 1930s and 1940s interviewee who did not have electricity remembered two gas mantles for lighting, one downstairs and one in an upstairs bedroom. He also recalled taking a candle to bed [ENG_02, 0:12:34]. Another interviewee said:

"...there was four lights for four rooms... and I believe there was one plug only...I don't think there was a hoover, we didn't have an electric iron, I can remember seeing my grandma putting the iron on the open fire...to heat, two or three of those, she always ironed on a little table, it wasn't an ironing board as such...oh, there was a radio, of course, we had a radio...it was electric plug in...there was a gramophone but it was a wind up one...but it didn't work...I tinkered with it many, many times and couldn't get it to work..." [ENG_05, 0:16:20]. 


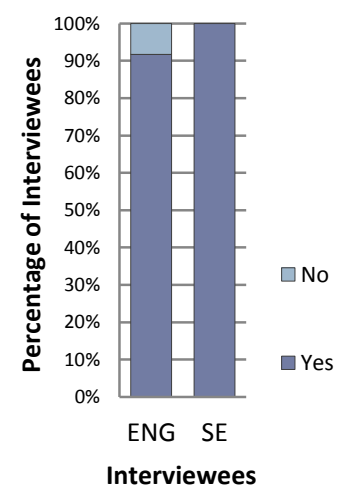

Figure 94: Households with a mains water supply (ENG SE)

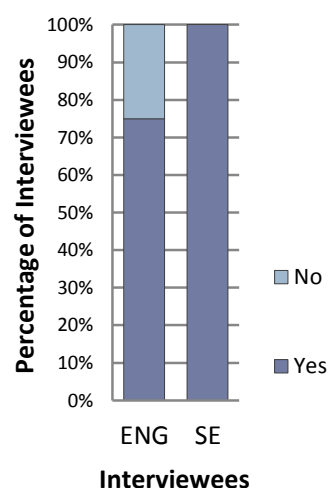

Figure 95: Households with a mains electricity supply (ENG SE)

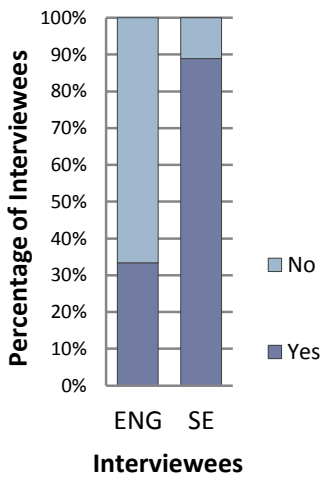

Figure 96: Households with a mains gas supply (ENG SE)

The original SE Stuart house had a single drop light in each room, and two single electric sockets, one in the scullery and one in the kitchen (Figure 97). One elderly SE interviewee recalled:

"...they wired the houses up, Eastern Electricity in the 1940s... all you got was a place for the cooker... and...one plug for the iron, the electric iron, you see, people used to run everything off of them, or plug into the lights with a wire coming down, you know. But I had a ring main put in... which I'm glad I did, because the electrician who done it...he put the wires in, then I...hid them. But when the council modernised the village, they put 'em all in pipes...down the walls... and the radiator pipes were all exposed, whereas mine all run under the floor..." [SE_05, 0:19:25]. 


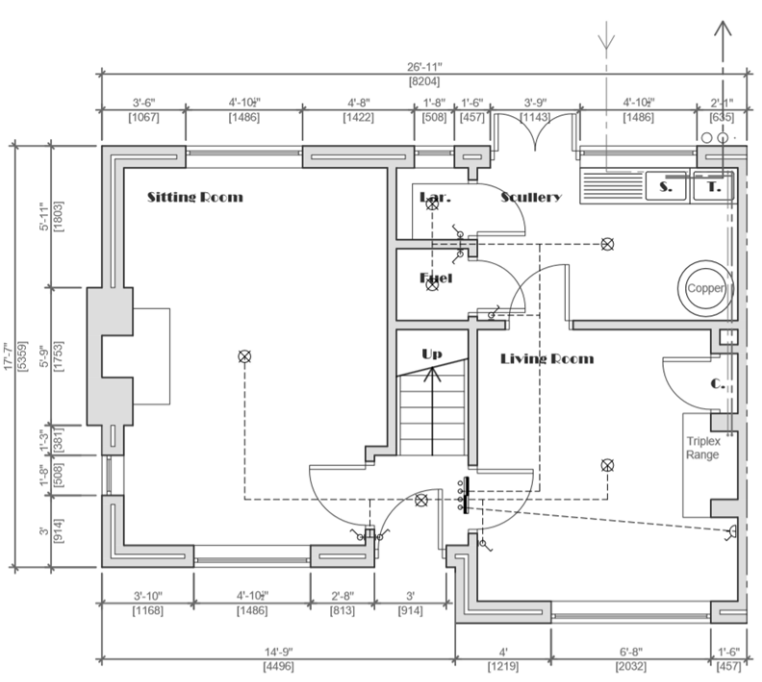

Ground Flocr Dlan

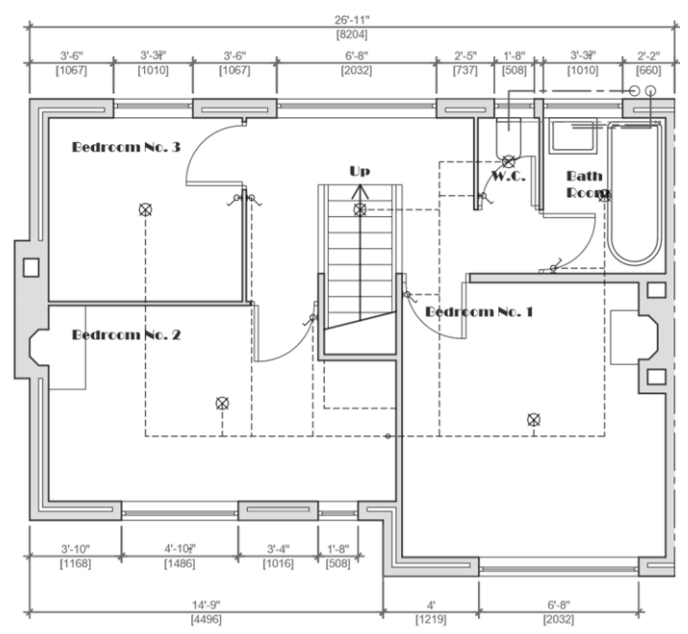

First Floor Dlan

Figure 97: Original floor plans of a SE Stuart house showing electrical layout

All of the SE case study houses are still on mains water and electricity, and since being sold by Crittalls to BDC in 1969, 8 (89\%) have been connected to mains gas (Figure 96). Today many of the SE case study houses have multiple electric sockets in each room, with electricity accessible throughout the house and no longer restricted to specific locations. One SE house owned by an electrician has been fully re-wired, with numerous electric sockets in each room, and the main room downstairs having ten double sockets [SE_03, 0:08:10]. In several houses the single drop lights have been replaced with fittings with multiple lights and recessed lighting is common in kitchen and bathroom areas. One SE interviewee regretted choosing light fittings for their aesthetic qualities rather than energy efficiency:

"...at the time, I was very naive and...I put them [the light fittings] in because they looked nice, massive regret now, because the entire house has got mostly halogen bulbs or spotlights, which not only cost an absolute fortune to run... when they pop, they cost a fortune to replace..." [SE_06, 0:09:58].

Figure 98 illustrates the present day floor plan of a SE Stuart house. Each room has at least two double electrical sockets. 


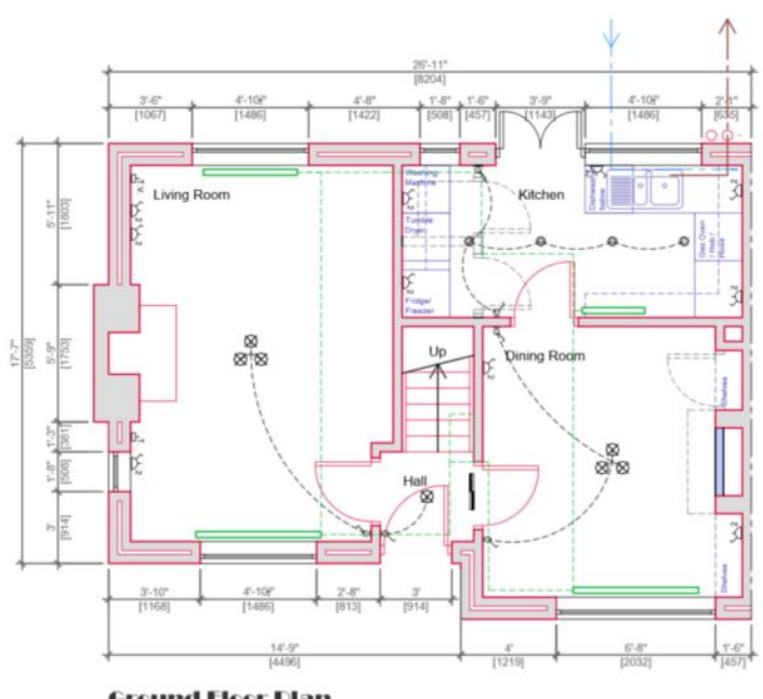

Cround Floc Dlan

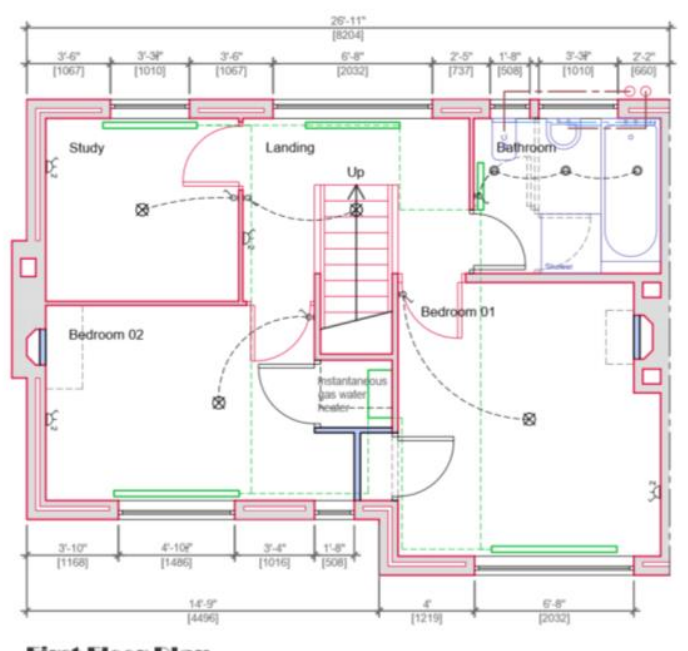

First Floer Dlan

Figure 98: Present day floor plans of a SE Stuart house showing electrical layout

During the 1930s and 1940s, energy for space and water heating were most commonly a by-product of the cooking energy. One SE interviewee recalled the original back boiler and the pipes going from it around the room to the bathroom [SE_01, 0:05:02], "...if you wanted hot water, you had to light the fire in the earlier days...but there came a time when we had an immersion heater, so in the summer, you didn't have to feel hot indoors with the coal fire." [SE_01, 0:18:25].

The present SE houses often have different pieces of equipment for different tasks; for example, gas fired central heating for the space heating, an electric immersion tank for hot water and an electric oven and gas hob for cooking. The present inhabitants of the houses are thus using far more household appliances than the original occupants, who in most cases kept food cool in a pantry (see section 4.2.1). Small kitchen appliances such as slow cookers, food processors and blenders help people to prepare meals more quickly and easily, but all have energy implications. As previously discussed in section 4.2.1, there has been a shift in the time involved in food preparation from house to industry. Another energy shift occurs because rather than making meals from basic ingredients people often buy pre-prepared food which is then assembled or heated up at home. 


\subsubsection{Space Heating}

Since the 1930s and 1940s, there has been a significant move from one room to whole house heating. During the 1930s and 1940s it was usual for houses to have one heat source that was used more often than others, and most heat sources were fixed. The SE houses were designed with a coal range in the kitchen for cooking and heating, an open fire in the sitting room and open fires in two of the three upstairs bedrooms. Of the 12 1930s and 1940s lifestyle interviewees, 6 (50\%) recalled their house primarily being heated by an open fire and $6(50 \%)$ by coal range (Figure 99$)$, with solid fuel, commonly coal, being used (Figure 100), “...oh it was heated from coal...there were little fireplaces in each room...in the bedrooms but they were very, very rarely used, and there was one in the front parlour which was lit on special occasions..." [ENG_04, 0:09:57]. Only 3 (25\%) interviewees mentioned an additional form of space heating, with $2(17 \%)$ recalling electric fires and $1(8 \%)$ a gas fire. One elderly SE interviewee stated:

"...you only had the fire in one room, you went to bed and that was cold, mother used to put house bricks in the oven, wrap 'em in a bit of a towel and put 'em in the bed...like a hot water bottle you see, and that was the only warmth you had, other than putting another blanket on..." [SE_05, 0:04:54].

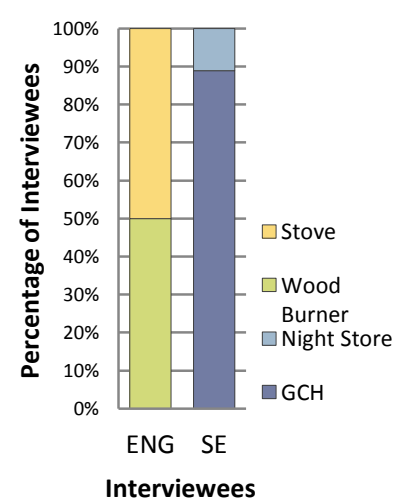

Figure 99: Primary method of space heating (ENG SE)

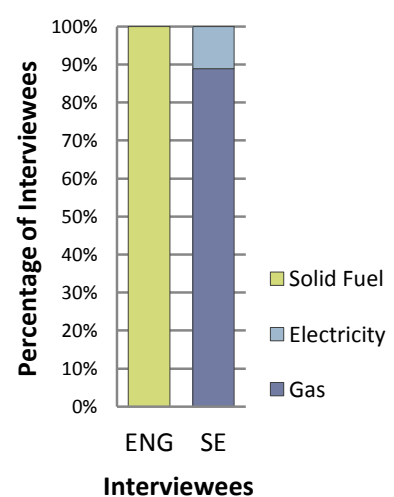

Figure 100: Fuel type in the primary method of space heating (ENG SE) 
Another elderly SE interviewee recalled how during the 1940s the house was heated by the coal range and a coal fire in the two downstairs rooms, but she also remembers the fires in the bedrooms being lit occasionally, especially when she was ill with the flu or chicken pox [SE_01, 0:15:29]. This same interviewee recalled that coal was delivered [SE_01, 0:20:21] and there was a big coal box outside [SE_01, 0:16:35]. Another elderly SE interviewee recalled, "...I used to bring a bag of wood home every day from work, and my wife did..." [SE_05, 0:34:05]. In this household, wood was stacked everywhere and a big wagon of coal would be ordered regularly and left on the grass at the front of the house, "... we used to cart it up the garden ..." [SE_05, 0:34:05]. Many of the 1930s and 1940s lifestyle interviewees also remember coal being delivered, "...me mother used to buy a ton of coal at a time and it used to go through a hole outside into the cellar..." [ENG_01, 0:14:46]. One such interviewee mentioned having plenty of coal, as her father had been a miner and coal was part of his wages [ENG_04, 0:14:04].

Following the sale of Silver End to BDC in 1969, there is evidence to suggest the council installed central heating in the houses. One SE interviewee remembered that when he moved into the house there was one radiator in each ground floor room, but only one radiator on the first floor located on the landing, "...I imagine at some point...in the 60s or 70s...the council must have fitted all these houses with central heating, but pretty minimal..." [SE_02, 0:15:45]. This interviewee explained that he had replaced the existing boiler and extended the system to include radiators in each bedroom and the bathroom. Today, 8 (89\%) of the 9 SE case study houses are heated by gas-fired central heating, with 1 (11\%) using electric night storage heaters (Figure 99). Consequently, gas is the main fuel for space heating (Figure 100). Only 1 (11\%) household mentioned having a gas fire as a secondary method of space heating, which was occasionally used in warmer weather rather than heating the whole house [SE_05, $0: 32: 44]$. Extractor hoods over cooking hobs in the kitchen were found in $4(44 \%)$ of the 9 SE case study houses.

When asked what they liked least about their house, 4 (44\%) SE interviewees mentioned something in connection with thermal comfort, including the cost of 
heating, the lack of insulation and the single glazed windows. One SE said if the central heating was not on in the mornings there would be ice in his glass of water and the windows would be frozen solid [SE_06, 0:21:32]. Many of the case study houses do not have a cavity wall, and consequently no thermal barrier, as one interviewee noted:

“...because it's a solid brick property, there's no insulation, there's limited ventilation because...we've got secondary glazing...and it's not like you can say, well, I'll just open the windows for an hour, 'cos you...get...Atlantic air coming in, you know..." [SE_03, 0:12:29].

Several SE interviewees mentioned the previous winter (2012/2013) had been extremely cold [SE_02, 0:19:08], and one interviewee said it had been one of the only times that she had ever worried about the cost of heating the house [SE_01, 0:19:27]. Another interviewee worried about the cost of heating, "... every time I turn it on ..." [SE_03, 0:14:15] and another stated, "...I try to be quite good in the fact that I don't like to waste energy...I don't want to, you know, spend loads of money for the sake of it, so rather than put the heating on, if I can put a jumper on or something, then I do that..." [SE_04, 0:10:44]. Most SE interviewees wanted to conserve energy and keep the cost of fuel to a minimum [SE_06, 0:13:42; SE_07, 0:09:01]. Cold coming up through the ground floor was mentioned by one household:

“...it's a wooden floor here... when we first moved in we only had a carpet in the middle, and when you had an East wind, the carpet used to lift up...they're only just, when they're doing the houses up now, they're only just putting insulation down there...I'm seriously thinking about it...we only have it really warm in here, 'cause we're here on our own..." [SE_05, 0:17:53].

This interviewee explained how he had lowered the hall ceiling upstairs in an attempt to conserve heat. Another SE interviewee mentioned gaps in the windows, "...in the winter... we had...curtains up, and we'd be sitting here watching TV, and they'd be blowing...in the wind..." [SE_06, 0:30:49]. Many of the SE interviewees dislike the 1960s Crittall windows and would replace them with double glazed units if the council would let them and if they had the money [SE_01, 0:38:15; SE_02, 0:30:05]: 
"...there's a lot of tension between people who live in the houses and...the

Parish Council and the District Council about...the regulations which

restrict...people's ability to change them...those windows are well past their sell buy date and don't fit with how people live now..." [SE_02, 0:04:33].

One SE interviewee said they would love double glazing, but that the windows they are allowed to install were two to three times the price of normal double glazing, and the value of the house makes replacement windows unjustifiable [SE_09, 0:10:10].

As previously discussed (section 4.2.1) a number of the case study houses are uninhabited for long periods of time each day, and as a result several SE interviewees have developed particular strategies for heating the house:

"...because we both work full-time, it [the house] can be empty twelve hours a day...if you get home at say eight o'clock at night, by the time you then try to heat the house up, you're probably going to bed, so we put it on a timer, even if it's on a low temperature...it means there's a bit of warmth in the house..." [SE_03, 0:09:25].

Another SE interviewee said the back of their house was noticeably warmer than the front, due to it being south facing and double glazed. He had therefore relocated the study from a front bedroom, to the rear bedroom [SE_02, 0:12:50].

Condensation and mould are clearly a problem for many of the volunteer households, and one stated, "...we're trialling some techniques, methods to try and help with damp and mould, 'cause unfortunately, changing the windows is a very expensive [option]...so we're seeing if we can work our way around it..." [SE_03, 0:14:15]. When asked about the things that they liked least about their house, 2 (22\%) SE interviewees mentioned the condensation and mould. There is evidence that damp was also a problem for the SE houses in the past:

"...my mum grew up in a house in Silver Street and they used to have to have the wardrobes in the bedroom away from the walls... the damp used to travel 
through the walls, through the wardrobe and their clothes used to be sopping wet..." [SE_06, 0:30:49].

Only $1(8 \%)$ of the 1930 s and 1940s lifestyle interviewees mentioned the cold as the worst thing about their house, although he also said that as a child he had accepted things as they were and that it was only on reflection that he realised his house would have been better with central heating [SE_08, 0:07:55]. Of the 12 1930s and 1940s interviewees, 9 (75\%) were unable to think of something they disliked about their house.

\subsubsection{Water Heating}

In the original SE houses the coal range was for cooking with a back boiler for hot water. Cold water was supplied to the wet back, the bathroom and the scullery. Hot water travelled through galvanised iron pipes from the back boiler to the bathroom and scullery. One elderly SE interviewee remembered the house originally had a ceramic (Belfast) sink in the scullery, with hot and cold water taps fixed to the wall above it [SE_01, 0:28:34].

Water heating varied among the 1930s and 1940s lifestyle interviewees, as 6 (50\%) mentioned a back boiler, $3(25 \%)$ a copper, $2(17 \%)$ kettles on the range and $1(8 \%)$ an electric hot water cylinder (Figure 101). Solid fuel was used for water heating in 11 (92\%) households and electricity in $1(8 \%)$, contrasting with the present day SE case study houses where water is heated by gas in $6(67 \%)$ households and electricity in the remaining 3 (33\%) (Figure 102). Of the gas use, 4 (44\%) SE households use a combination boiler and 2 (22\%) a condensing boiler. All electricity users have an electric hot water cylinder (3 households (33\%)) (Figure 101). Hot water is commonly supplied to bathroom basin and bath, utility sink, kitchen sink and washing machine. Cold water is typically supplied to these points as well as to the dishwasher. 


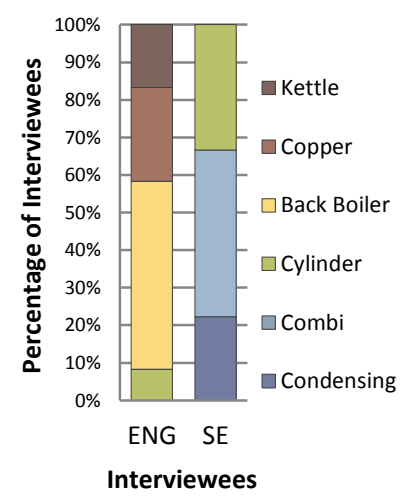

Figure 101: Primary method of water heating (ENG SE)

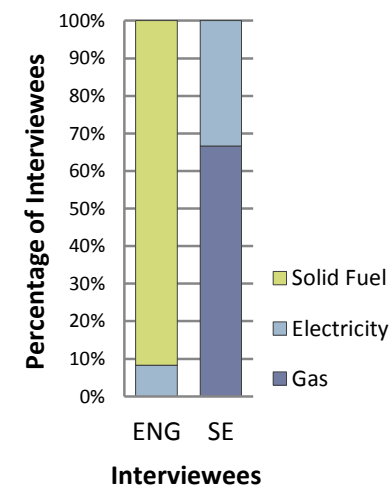

Figure 102: Fuel used in the primary method of water heating (ENG SE)

Many of the 1930s and 1940s lifestyle interviewees recalled water being heated once a week for washing clothes or for bathing, and this would certainly have been the case for the households heating water with the copper or kettle. One 1930s and 1940s interviewee recalled his father being involved with the laundry:

"...me dad would light the fire on a Monday morning to boil enough water, and then they used to boil all the whites... they had a tub by the wringer... a little three legged stool at the bottom, swished the things around and then you used to put them through this thing and then you put them in the copper, the whites to boil and then you would have to get them out with a big pair of wooden tongs or something and then take them across the kitchen to rinse them in the sink..." [ENG_04, 0:11:31].

With regard to bathing, one elderly SE interviewee stated, "...you had a bath once a week and your sister or brothers went in...after you did...the oldest one got the hot water... and you washed in the sink every day, but compared to most, we were really well off, you know..." [SE_05, 0:11:37]. Similarly, one 1930s and 1940s lifestyle interviewee explained:

"...it was a tin bath or a zinc bath which was kept in the yard during the week and bought out on a Friday night, and of course the water used to come out of the boiler, ladled into the bath and once all the water was gone that was it 
wasn't it, there wasn't any more. So, I think me mother used to go in, and after she got out we chucked some soda in and somebody else got in, and be time three or four of us had gone in there was a scum about that deep at the top, I don't know if me dad went in or if he didn't bother, no he probably went in last with all the scum..." [ENG_07, 0:33:06].

In all of the SE volunteer households, hot water is always available allowing for frequent bathing. Washing machines heat water as and when required meaning water is heated more regularly than in the past. Tumble dryers are occasionally used in wet weather, but several of the SE interviewees also mention drying clothes on the radiators or on a clothes horse [SE_06, 0:43:53].

\subsubsection{Transportation}

As previously discussed (section 4.3.2.3), car ownership is much more common now than during the 1930s and 1940s when many families had no means of private transport, other than bicycles. At that time Crittalls provided a bus to and from the workplace (section 4.3.2.3). As discussed in section 4.2.1, during the 1930s and 1940s food was delivered direct to the street, contrasting with today, with most of the SE interviewees using a car to go shopping. The use of the car has an energy implication, however this has not been calculated or analysed, being considered outside the scope of this research.

\subsubsection{Outdoor Space}

As discussed in section 4.2.2, far less time is now spent in gardens than in the 1930s and 1940s. This has heating energy implications as people are spending more time inside their houses than in the past. Gardens are no longer highly productive and garden maintenance is not as labour intensive as it once was. One 1930s and 1940s interviewee recalled her father cutting the grass with a pair of clippers [ENG_12, $0: 24: 13]$, contrasting with today, where electric lawnmowers, trimmers and hedge cutters are common in many of the SE volunteer households. 
Several 1930s and 1940s lifestyle interviewees recalled making items fit for other purposes and mentioned that nothing was wasted, "...l used to cut them army petrol cans in half, put a hole in the bottom, stand 'em in water and grow tomatoes..." [ENG_02, 0:31:59]. Similarly, one elderly SE interviewee mentions that when the copper became redundant, they took it out and grew rhubarb in it, "... we always used everything...thirty inches diameter...very heavy, it was cast iron..." [SE_01, 0:28:34].

Section 4.3.2.1 discussed the alterations carried out to rear gardens by the SE interviewees. However, the energy implications of these are not investigated further in this research.

\subsubsection{Embodied Energy Analysis}

The Stuart house was measured for the EEA because it had the most complete set of original drawings. As previously discussed (section 2.4.3.1) this house was analyzed at three stages of its life: immediately after construction in 1928; following the sale of the houses to BDC in 1969; and following typical alterations undertaken by owners post1990. The impact of regular house maintenance after each stage was also considered (Figure 103).
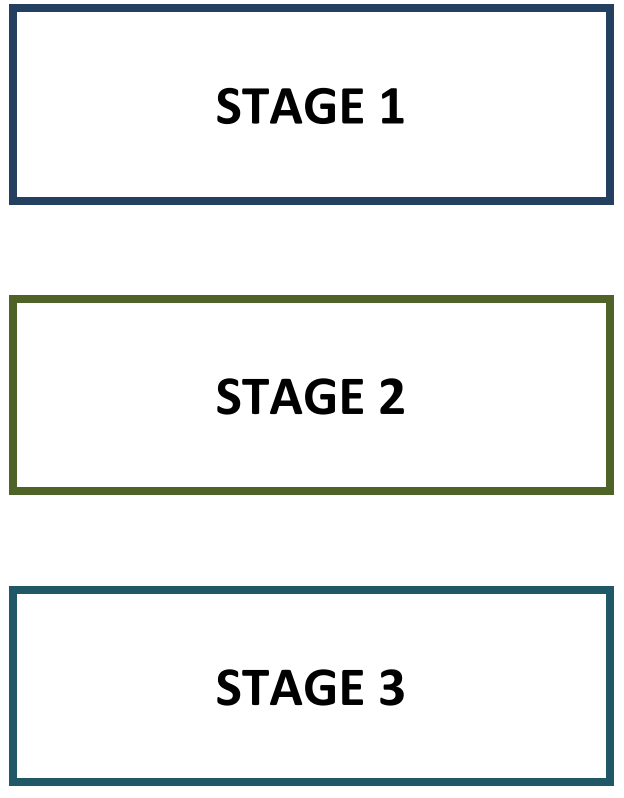

Figure 103: The Three Stages of the SE EEA

\section{House}

1928 - 1969 Maintenance (40 years)

\section{House (BDC Alterations)}

1969 to 1990 Maintenance (20 years)

\section{Owner's Alterations}

1990 - 2012 Maintenance (20 years) 
As previously described (section 3.4.1.5), for each stage schedules detailing the quantities of materials used in the construction, alteration and maintenance of the house were compiled in an MS Excel spreadsheet. The house was broken into 10 elements; foundations, structure/structural framing, building envelope, internal joinery, internal finishes, heating, plumbing \& drainage, electrics \& lighting, kitchen fittings, utility fittings and bathroom fittings. The complete spreadsheet is on the attached CD-ROM and the SE results tables are in Appendix K. Figure 104 contains a list of the assumptions for the calculation of the SE LCA, which is based upon information obtained through the interviews and house surveys. The ground floor additions/conservatories were all unique in terms of their age, size, construction materials and methods. It was impossible to identify a 'typical' ground floor addition and, as such, they were not considered in the EEA. 


\section{STAGE 1}

\section{House}

- $\quad$ As original drawings

- Linoleum floor covering in scullery, bathroom and toilet

\section{8 - 1969 Maintenance (40 years)}

- $\quad$ Replacement roof covering (x2)

- Paint to window frames and doors $(x 4)$

- $\quad$ Paint to external masonry ( $x 4)$

- $\quad$ Paint to downpipes (x4)

- $\quad$ Paint to internal walls, ceilings and joinery $(x 4)$

- Varnish to internal doors (x4)

- $\quad$ Linoleum in scullery, bathroom and toilet $(x 3)$

\section{STAGE 2}

\section{House (BDC Alterations)}

- Replacement of front door

- Replacement of original Crittall windows with (then) modern Crittall windows

- $\quad$ Carpet throughout

- Vinyl in kitchen, bathroom and toilet

- $\quad$ Plastering of internal walls (previously bare faced blockwork)

- Wallpapering internally

- $\quad$ New hot and cold water pipework

- New hot water cylinder

- New water tank

- New boiler

- $\quad$ Central heating (1 radiator for each room on the ground floor and 1 radiator on the first floor landing)

- New kitchen including freestanding oven

- New bathroom and toilet fittings

\section{9 to 1990 Maintenance (20 years)}

- $\quad$ Replacement roof covering ( $x 1$ )

- $\quad$ Paint to window frames and doors (x2)

- $\quad$ Paint to external masonry (x2)

- $\quad$ Paint to downpipes (x2)

- $\quad$ Paint to internal ceilings and joinery $(x 2)$

- Varnish to internal doors (x2)

- $\quad$ Vinyl in kitchen, bathroom and toilet $(x 1)$

- Wallpapering internally $(x 1)$ 


\section{STAGE 3}

\section{Owner's Alterations}

- Installation of loft ladder

- Replacement of front door

- $\quad$ Replacement of Crittall windows with UPVC windows (on rear elevation only)

- Re-rendering of external masonry

- $\quad$ Re-painting of external surfaces

- Insulation to roof (50mm) and ground floor $(100 \mathrm{~mm})$

- $\quad$ Replacement of skirting board

- Installation of built in cupboards in bedrooms 01 and 02

- $\quad$ Carpet throughout

- $\quad$ Vinyl in kitchen, bathroom and toilet

- Ceramic tiling to bathroom and kitchen

- Installation of instantaneous gas water heater

- $\quad$ Replacement of old radiators and additional radiators to bedrooms and bathroom

- $\quad$ Full re-wire with additional light fittings and sockets

- $\quad$ New fitted kitchen including base and wall cupboards, oven, hob, extractor hood and dishwasher

- New bathroom fittings including separate shower cubicle and heated towel rail

\section{0 - 2012 Maintenance (20 years)}

- $\quad$ Replacement roof covering (x1)

- $\quad$ Paint to window frames and doors (x2)

- $\quad$ Paint to external masonry (x2)

- $\quad$ Paint to downpipes (x2)

- $\quad$ Paint to internal ceilings and joinery ( $x 2)$

- Varnish to internal doors (x2)

- Vinyl in kitchen, bathroom and toilet (x1)

- Wallpapering internally (x1)

- $\quad$ Carpet throughout (x1)

Figure 104: Assumptions behind the SE EEA

For the analysis of the house as constructed the original architectural drawings were consulted. The embodied energy (GJ) in each of the building elements of the SE house in 1928 is shown in Figure 105, and the embodied energy in the building elements expressed as a \% of the 1928 total in Figure 106. 


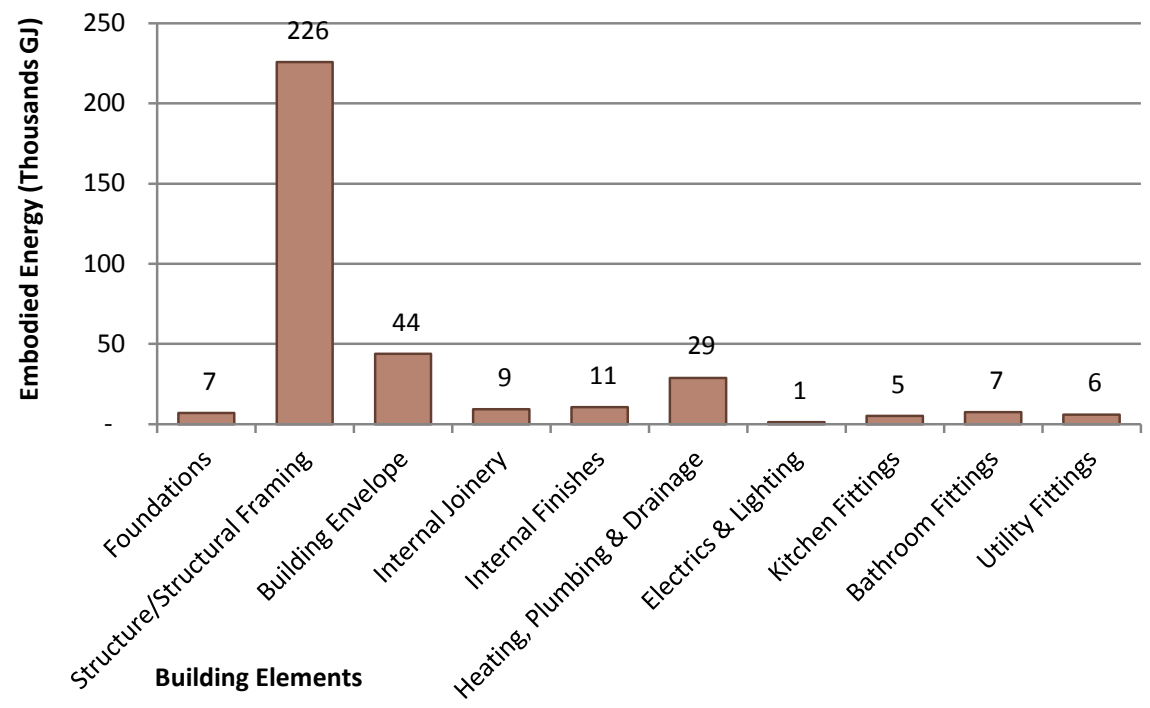

Figure 105: Embodied Energy (GJ) in the Building Elements of the SE House in 1928

The original SE house had 225,862 GJ (65\%) of embodied energy in the structure/structural framing (loadbearing external and internal walls, floor and roof structure). The building envelope (external render and paintwork, windows and roof covering) was $43,848 \mathrm{GJ}(13 \%)$ of total embodied energy. Heating, plumbing \& drainage accounted for $28,909 \mathrm{GJ}(8 \%)$. The total embodied energy of the original SE house was $345,164 \mathrm{GJ}$.

The embodied energy (GJ) in the building materials of the SE house in 1928, expressed as a $\%$ of the total is shown in Figure 107 . Bricks accounted for $42 \%$ of the total, followed by cement mortar (21\%), iron ( $8 \%)$, timber (6\%) and steel $(6 \%)$. The remaining $17 \%$ consisted of 13 additional building materials including copper (4\%), concrete (3\%) and paint (3\%). 


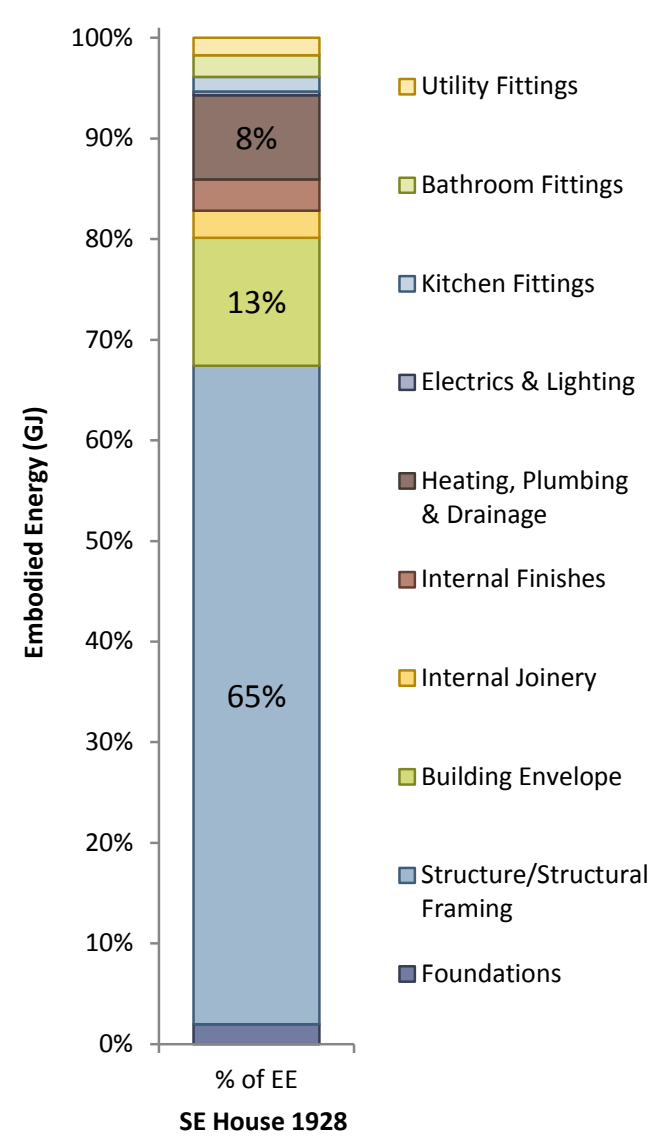

Figure 106: Embodied Energy (GJ) in the Building Elements of the SE House in 1928, expressed as \%

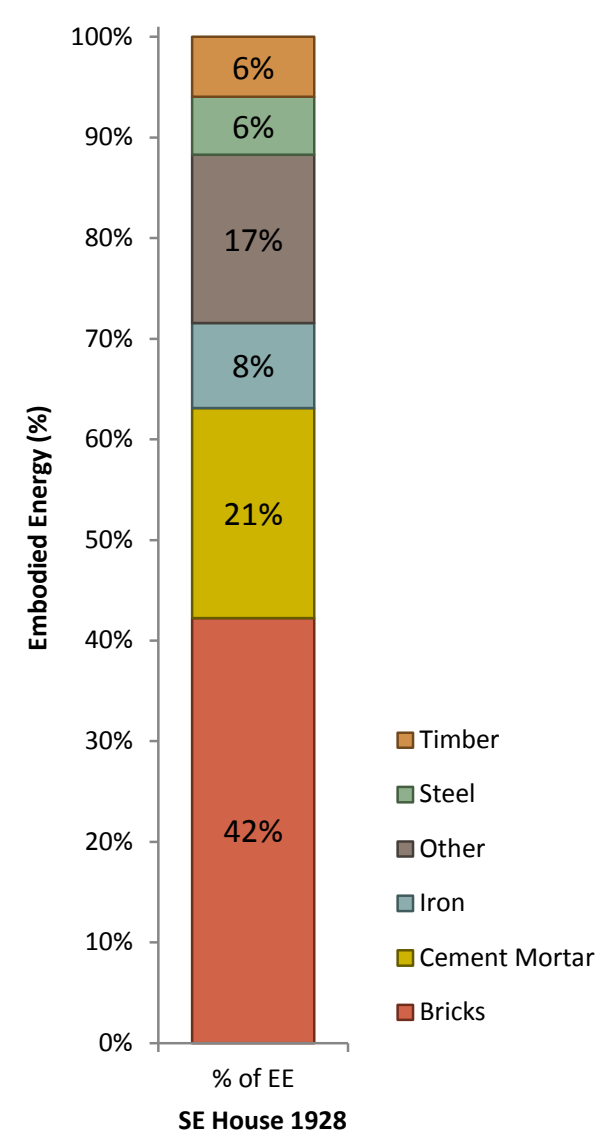

Figure 107: Embodied Energy (GJ) in the Building Materials of the SE House in 1928, expressed as \%

During World War II, the white render was removed back to brick, so as not to be seen from the air, and blast walls were constructed outside the windows [SE_01, 0:48:13] but this has not been considered in the LCA. Not all the houses were plastered internally [SE_05, 0:16:03], and one elderly SE interviewee recalled that her parents liked the house very much, "...apart from the un-plastered walls...not all of them were like that in the village, but this particular part of the street was..." [SE_01, 0:02:29]. This same interviewee remembered linoleum on the floors and big rugs [SE_01, $0: 50: 42]$.

BDC have no records of alterations to the SE houses in 1969 so assumptions were made based on information from the recorded oral interviews and data collected in the house surveys. From this it seems BDC replaced the windows and external doors, installed central heating, replaced kitchen and bathroom fittings and plastered internal walls (Figure 104), and the embodied energy for these is calculated as $86,115 \mathrm{GJ}$. 
Quantities of materials in alterations and improvements made by the owners of the SE houses post 1990 were mostly measured on site. In many cases SE interviewees have undertaken significant alteration and improvement work including replacement of windows to the rear elevation, re-rendering of external masonry, re-painting of external surfaces, installing insulation to roof and ground floor, replacement of existing radiators, re-wiring and the installation of a new fitted kitchen and bathroom. The most common alterations are internal decoration and replacement of bathroom fittings, mentioned by 7 (78\%) interviewees. Internal decoration brings other changes with it as in one house:

"...I put new skirting boards, brilliant those are...they screw on...so, when I decorate, I just undo, take 'em off...no cutting in...no touching the carpet...I take the skirting boards outside, clear varnish and back in...this room's mahogany and that one's teak..." [SE_05, 0:19:25].

Other popular alterations include replacement of the roof covering, upgrading of the space/water heating, alterations/additions to the electrics, replacement of kitchen fittings, and work to the garden, all mentioned by 6 (67\%) interviewees (Figure 89). Renewal of external render and paintwork was mentioned by 5 (56\%) interviewees. While replacing the roof covering, 4 (44\%) interviewees have taken the opportunity to add insulation to the roof. One elderly SE interviewee said the flat roof had been refelted three times during her lifetime, the last time being ten years ago when $50 \mathrm{~mm}$ of dense insulation board had be installed beneath the felt, "...so that does help...the chappie who came to do it the last time offered it to us and we snapped that up, we'd have been silly not to have done so." [SE_01, 0:31:31]. The embodied energy of typical alterations undertaken post- 1990 by house owners totals $88,752 \mathrm{GJ}$ ( $27 \%$ of the 1928 original).

The cumulative embodied energy (GJ) of each building element in the SE house in 2012 is shown in Figure 108 and as a \% of the total in Figure 109. 


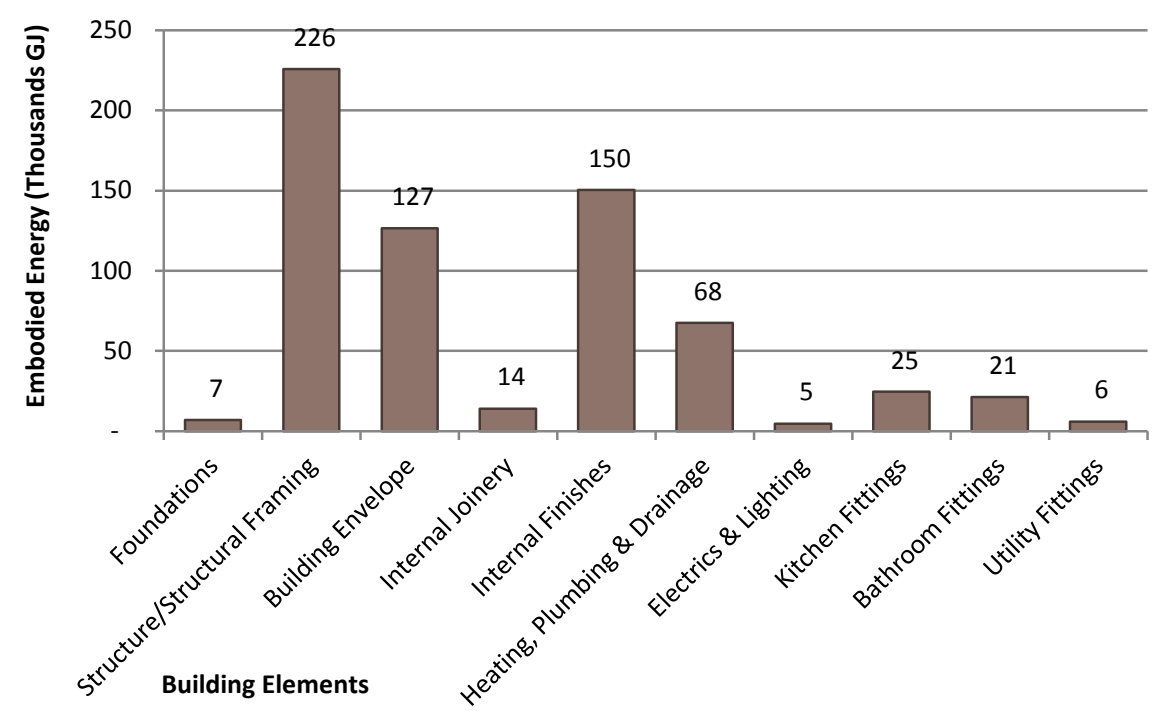

Figure 108: Embodied Energy (GJ) in the Building Elements of the SE House in 2012

The 2012 SE house had 225,862 GJ (35\%) of embodied energy in its structure (loadbearing external and internal walls, floor and roof structure), while the internal finishes were 150,451 GJ (23\%). The building envelope (external render and paintwork, windows and roof covering) accounted for 126,557 GJ (20\%), and heating, plumbing \& drainage for 67,587 GJ (10\%), kitchen fittings were $24,522 \mathrm{GJ}(4 \%)$. The cumulative embodied energy of the SE house in 2012 was 647,851 GJ, an increase of $188 \%$ since it was constructed.

The embodied energy (GJ) in the building materials of the SE house in 2012, expressed as a $\%$ of the total is shown in Figure 110 . Bricks accounted for $23 \%$ of the total embodied energy, followed by steel (12\%), paint (12\%), cement mortar (11\%) and carpet (6\%). The remaining $36 \%$ consisted of 20 other building materials including wallpaper (5\%), iron (5\%), timber (4\%), cement render (3\%) and copper (3\%). There have been 7 new materials introduced to the SE house since 1928 and these include aluminium, carpet, insulation and wallpaper. The basic structure of the SE house has remained the same, but the materials introduced internally have contributed to the increase in its embodied energy. 


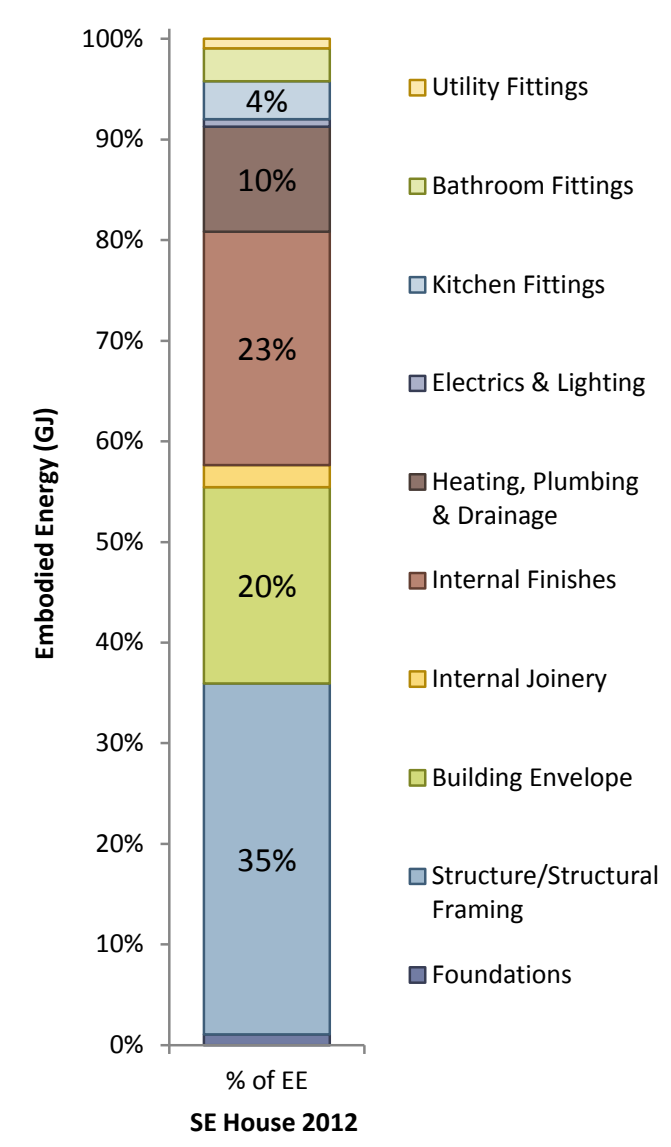

Figure 109: Embodied Energy (GJ) in the Building Elements of the SE House in 2012, expressed as \%

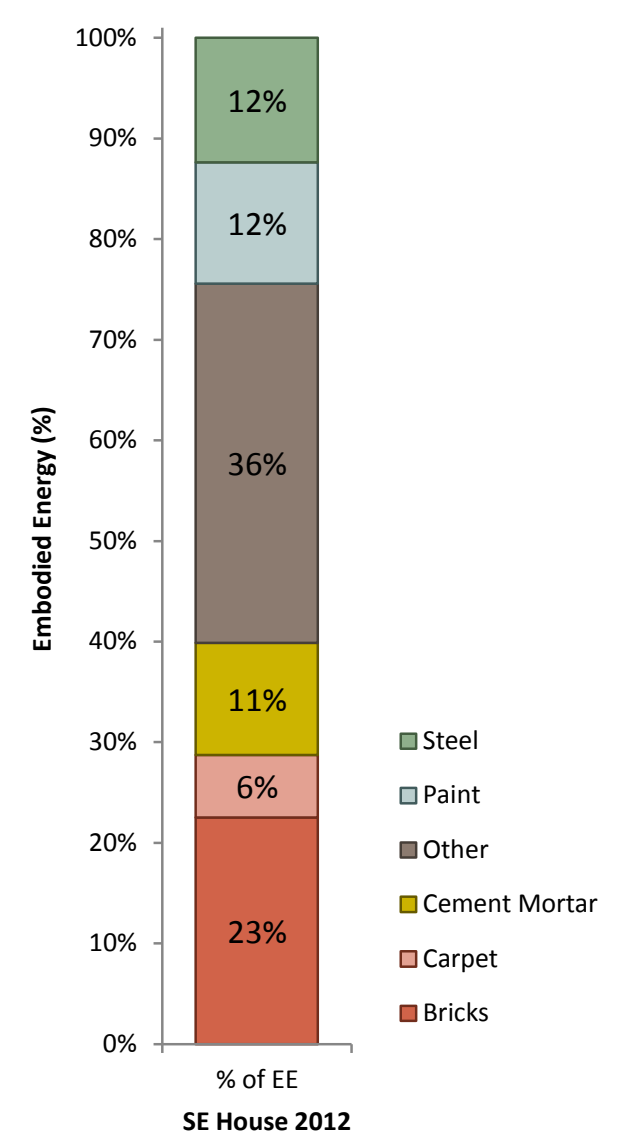

Figure 110: Embodied Energy (GJ) in the Building Materials of the SE House in 2012, expressed as \%

Figure 111 shows the increased embodied energy of the 10 building elements, including their regular maintenance. The greatest increases are for the internal finishes (plastering of internal walls, wallpapering and regular repainting, fitting of carpet), and the building envelope (replacement of the flat roof covering and regular repainting of external surfaces). Heating, plumbing \& drainage have seen a significant increase in embodied energy, due to replacement of pipework and installation of central heating. New kitchen fittings and fitted appliances have raised the embodied energy of this element to approximately 5 times the original. Changing aesthetics are also an important factor. The embodied energy of bathroom fittings has increased to approximately 3 times the original. Not all materials and their embodied energy added to the house at some stage remain today as many items have been replaced. For example, iron water pipes have been replaced with copper pipes and the asphalt roof covering has been replaced 4 times. Although the asphalt would have been scrapped the iron could be recycled, but this has not been considered here. 


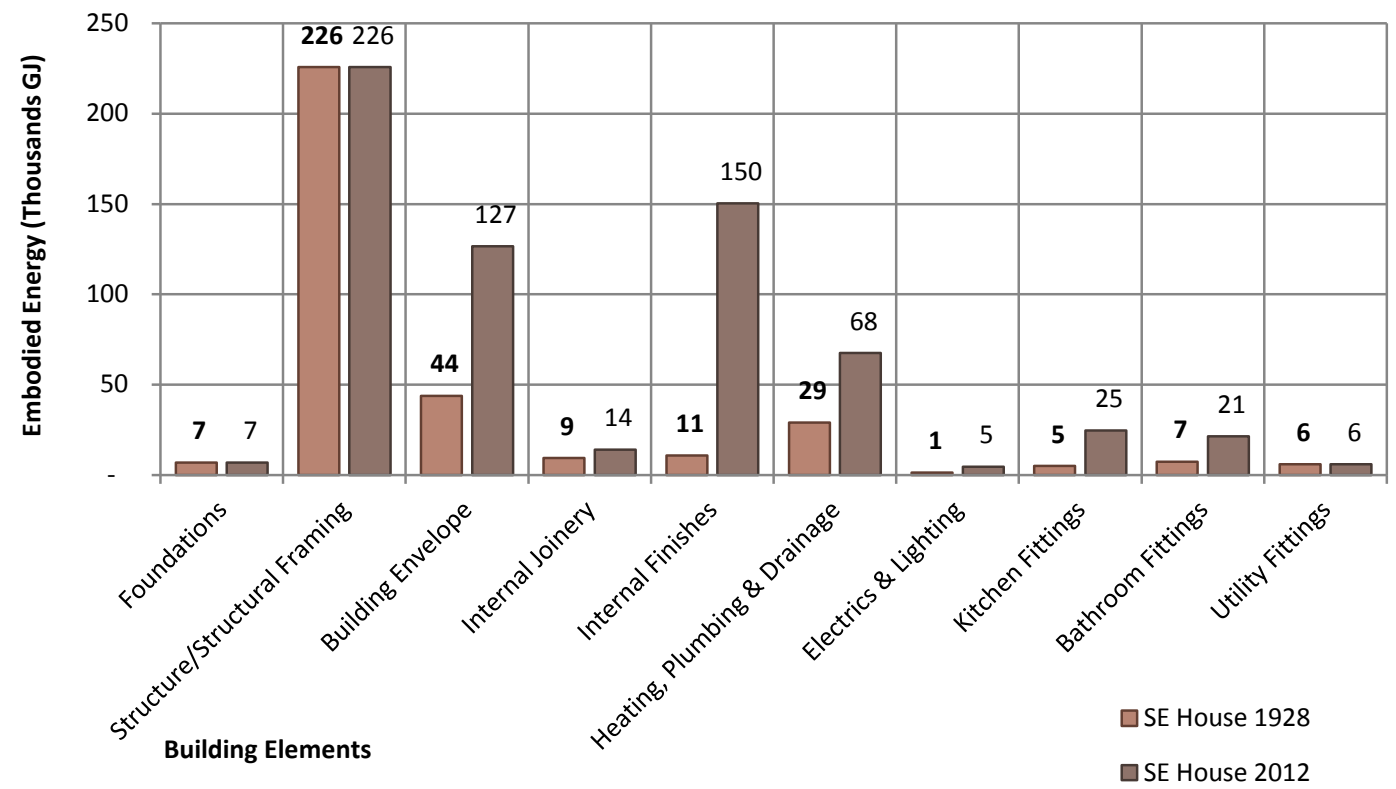

Figure 111: Embodied Energy (GJ) in the Building Elements of the SE House in 1928 and 2012

The increase in the embodied energy (GJ) of the house for each of the stages is shown in Figure 112.

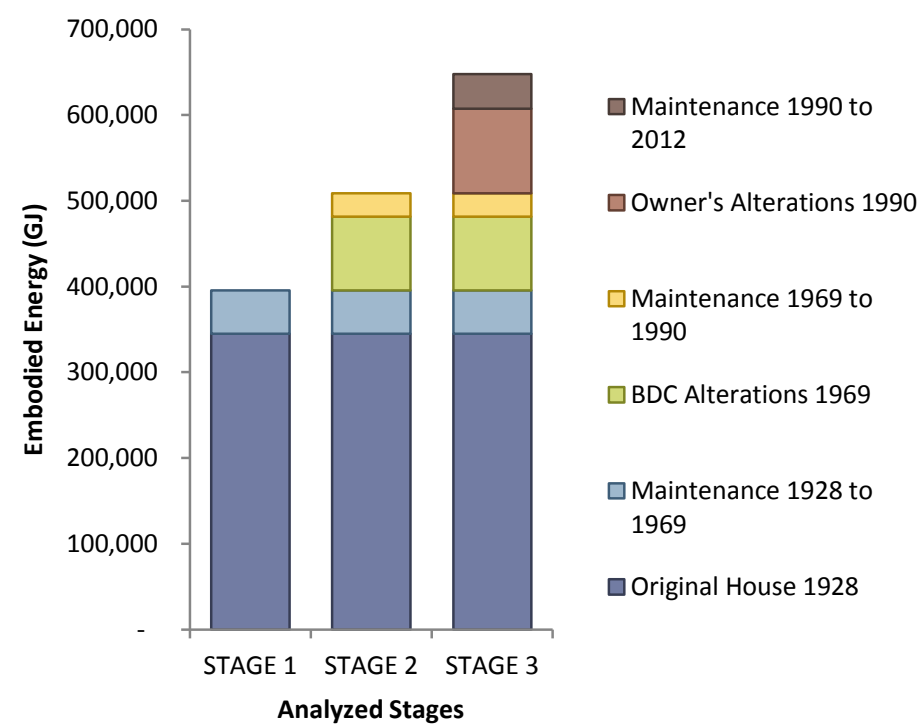

Figure 112: Increase in the Embodied Energy (GJ) of the SE House for each of the stages

The building materials of the original 1928 SE house are $53 \%$ of the total cumulative embodied energy. BDC alterations in 1969 represent 13\% and owner's alterations post-1990 a further $15 \%$. Maintenance is significant, amounting to $18 \%$ of the total cumulative embodied energy. 


\subsubsection{Embodied Energy per $\mathrm{m}^{2}$ and per Person}

During the past ninety years dwelling occupancy in England has decreased from 4.3 persons in the 1911 census to 2.3 persons in that of 2011 (Figure 85). Figure 113 illustrates the increase in the embodied energy of the house from its construction in 1928 to 2012 . Although the reduction in number of people per dwelling is largely a linear decrease, the embodied energy has a linear increase.

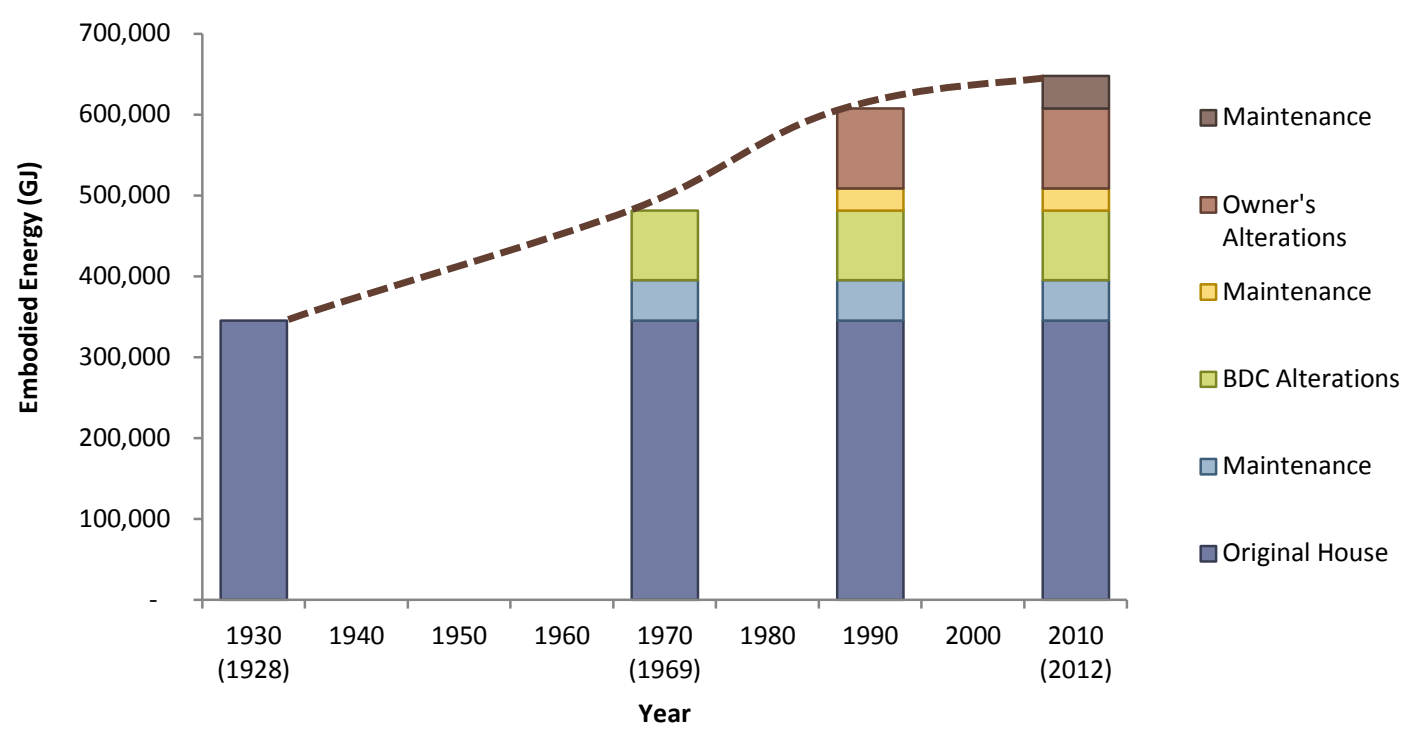

Figure 113: Increase in Embodied Energy (GJ) of the SE House from 1928 to 2012

As previously discussed (section 3.4.1.6), in order to investigate the significance of design decisions, the house was analyzed at three points in time and a maintenance period of 50 years was calculated. These houses are referred to as the snap shot houses. The house was analyzed as constructed in 1928, as if the 1960 version (immediately following the BDC renovations) was built new, and the same for the 2012 typical SE house. The results from this analysis are shown in Figure 114. The embodied energy $\left(\mathrm{GJ} / \mathrm{m}^{2}\right)$ of the 1928, 1969 and 2012 SE snap shot houses is shown in Figure 115. 


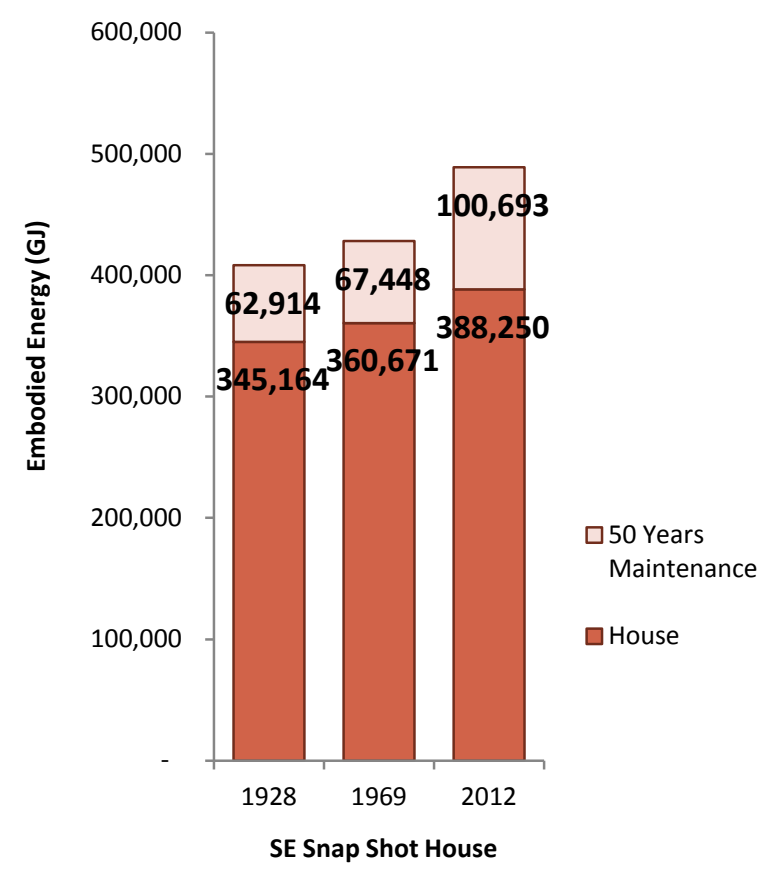

Figure 114: Total Embodied Energy (GJ) of the 1928, 1969 and 2012 SE Snap Shot Houses

The embodied energy of the materials in the 1928 snap shot house was $408,078 \mathrm{GJ}$ or $5,101 \mathrm{GJ} / \mathrm{m}^{2}$. This is approximately $83 \%$ of the 2012 snap shot house $(488,942 \mathrm{GJ}$ or $6,112 \mathrm{GJ} / \mathrm{m}^{2}$ ). Reasons for the difference include the introduction of modern fittings, fixtures and appliances, and the higher levels of comfort desired by present inhabitants leading to the installation of central heating, insulation and carpets. 


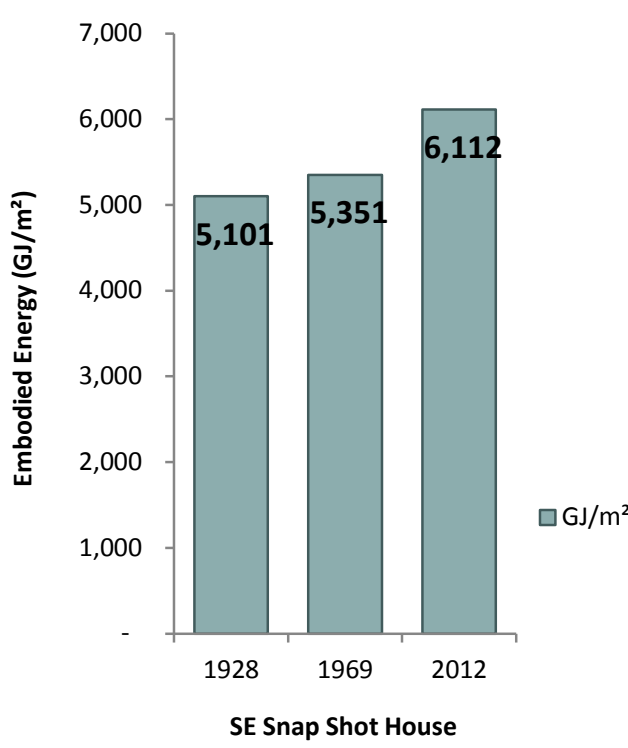

Figure 115: Embodied Energy $\left(\mathrm{GJ} / \mathrm{m}^{2}\right)$ of the 1928, 1969 and 2012 SE Snap Shot Houses

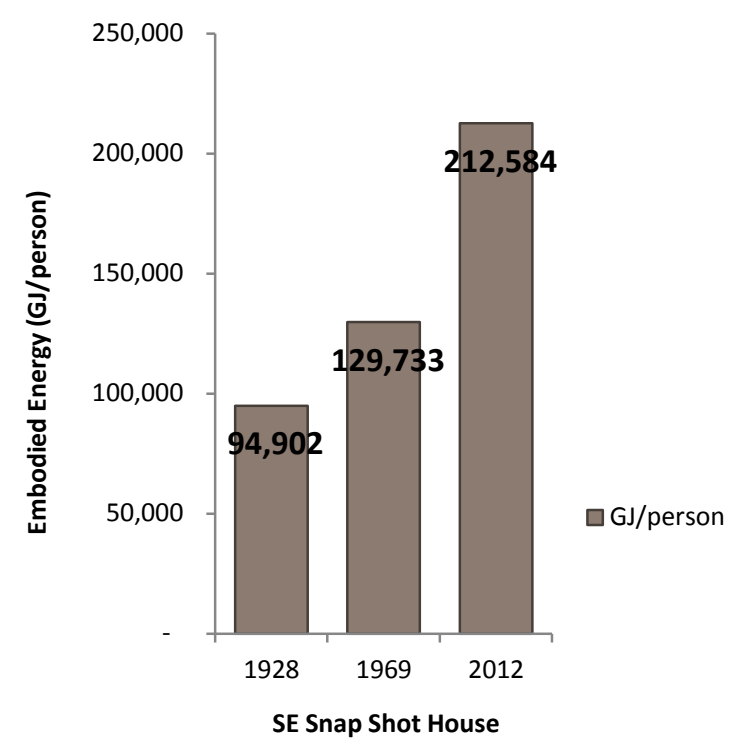

Figure 116: Embodied Energy (GJ/person) of the 1928, 1969 and 2012 SE Snap Shot Houses

To investigate the significance of household occupancy, the embodied energy per person of the snap shot houses was calculated (Figure 116). The average occupancy based on census data was used making the embodied energy of the 1928 snap shot house $94,902 \mathrm{GJ} /$ person, $45 \%$ of the 2012 house (212,584 GJ/person). The embodied energy of the 1969 snap shot house was 129,182 GJ/person, 61\% of the 2012 snap shot house. As a result of the decrease in household occupancy and the increase in embodied energy, the environmental impact of the snap shot houses is now much greater than when first constructed and these results confirm that the occupancy levels are as important for embodied energy as the materials used in the construction of the house.

\subsection{Summary}

The case study houses are no longer predominantly inhabited by families, with single person households common. During the 1930s and 1940s, inhabitants of the village worked together and therefore people knew one another, as one elderly SE interviewee recalls:

"...people say...you could always leave your doors open and that, you know, you could, but nobody had anything did they you see...you went next door, and 
they'd got the same on their table as you had on yours...you all trotted off to work at the same time and you'd come home at the same time, everybody had an allotment and...you just done the things you did... and so consequently, when you grew up, you grew up and you ended up working with people you started school with, you know, when you was three and a half..." [SE_05, 0:03:29].

In strong contrast, inhabitants of the SE houses today do not work together or travel to work together and none of the SE interviewees mentioned spending time with neighbours. In all of the volunteer households women of working age are in paid employment, and many of the houses are uninhabited for long periods of time. One elderly SE interviewee recalled:
"...our children...they loved the village...played football and everything else...Crittalls had all the teams...you knew everybody you see... unfortunately now... a house to a lot of the people...it's just somewhere to sleep, they're not here...there's a lady over the road, she goes out...long while before we get up, and she come back the next day...'cause she works somewhere in London..." [SE_05, 0:22:01].

This same interviewee mentioned that many of the houses on Silver Street are privately owned by landlords who let them to the housing association, "...because they go for cheap you see...even with all that I've done for here, if I get a hundred and fifty thousand, I'd be lucky..." [SE_05, 0:23:06].

Cars prohibit children from playing in the street and most interviewees owned at least one. Interviewees tend to use cars for travel to and from clubs or activities and to spend time with friends and relatives that live in different areas of the country. Clubs no longer need to be local. During the 1930 s and 1940s, the street would have been full of activity (section 4.2.1) but today cars are used for shopping and the street is a transportation zone, primarily for the car.

Interviewees do not have the shared in and out of work interests that characterised the area when owned by Crittalls, and this has changed the sense of community spirit and friendships between the inhabitants of Silver End. Today the houses remain 
affordable for those on low incomes, but present inhabitants often lack the disposable income to maintain them. Many of the SE interviewees stated one reason for buying the house was financial, being all that they could afford (section 4.3.1.4). This is problematic, as many of these home-owners cannot afford to modernise and upgrade their houses, or keep on top of the maintenance requirements. One of the case study houses is in urgent need of structural repair, but the owners do not have funds to carry this out [SE_07, 0:13:35]. One SE interviewee said:

"...my big kind of negative is I've...come to realise that...structurally these houses are pretty rubbish...there tends to be a thing in the village amongst, I guess, particularly older people about, you know, how great the village is and...wasn't Crittall a wonderful bloke for...building these houses...nobody wants to hear, you know, well actually they're rubbish..." [SE_02, 0:32:38].

Many of the interviewees appreciate living in Silver End, however many are unhappy with their house because of the windows, condensation and damp, or the cost of heating.

Interviewee's gardens no longer need to be productive and many do not spend a lot of time gardening because of work commitments and the other forms of recreation available. Garden function has changed enormously, whereas the change to the house function is less, but still recognisable.

Changing lifestyles over the past 85 years have greatly impacted the use of the public and private areas of the settlement. The changing needs, aspirations, and priorities of the different inhabitants have not only affected the use but also the appearance of these areas. This is not unique to Silver End, but is a reflection of what has happened in housing developments throughout England.

"Silver End is a love hate. You either really like it here, or you do not, and I don't think there's a happy medium in that...a friend of mine, she wouldn't move, but she feels it's deteriorated, not the same, and yet we can't exactly say to somebody why, or what it is...it seemed to be utopia when we were children I suppose..." [SE_01, 0:44:56]. 
Over time, the houses have been altered to meet the requirements of owners with different sets of values, requirements and expectations from previous inhabitants. However, many SE interviewees feel that the houses are difficult and expensive to modernize and in this respect the houses might be described as being unmalleable. One SE interviewee described the work to the house as both enjoyable and hard, "...I wasn't expecting it to be as much work as it has been...so I would say that that's been a bit of a negative thing...it's took a lot of time, effort and money..." [SE_04, 0:29:00]. Another SE interviewee mentioned that the houses are difficult to work on, “...you can't chase the walls very easily... [and] because you've got no loft, you can't get everything up and across the loft space..." [SE_01, 0:42:29].

One strong commonality shared by the SE interviewees was the desire to conserve energy and bring their houses up-to-date. Two factors seen as preventing this were cost and the conservation area rules which are discussed further in chapter 6 . 


\section{Chapter 5 - Comparative Study: The Original Houses}

This chapter is a comparison of the experiences of the two groups of elderly interviewees who shared memories of their housing and lifestyle during the 1930s and 1940s (NZ and ENG). The purpose is to explore the differences and similarities in order to understand the impact of the original houses.

As well as data from the interviews, this chapter further develops the embodied energy analysis.

\subsection{Time Use}

\subsubsection{House}

Interviewees living at the time of the original occupants of the TS and SE houses had similar lifestyles in both New Zealand and England, with the fathers typically in fulltime paid employment and the mothers usually home-based and responsible for household work. This was true for 16 (94\%) of the 17 NZ 1930s and 1940s interviewees. In 11 (92\%) of the 12 ENG interviewees' households, father was in fulltime work, and of these, mother not in paid work in 7 (58\%) and employed part-time in 4 (33\%).

The number of persons per household in full-time paid employment differs between NZ and ENG (Figure 117), although the number of adults per household is similar (Figure 118). This is because the additional adults in the NZ households were mostly relatives, like a grandmother, who did not work full-time, whilst in the ENG households they were live-in maids in 2 (17\%) and lodgers in 3 (25\%) households. As such, in 5 (41\%) of the ENG households adults apart from father and mother were in full-time work. Because the sample is small and there was no control over the type of household recruited, these findings only apply to the interviews in this research. However, some patterns, such as father working and mother at home or in part time work appear more significant at 27 of 29 total households (93\%). 


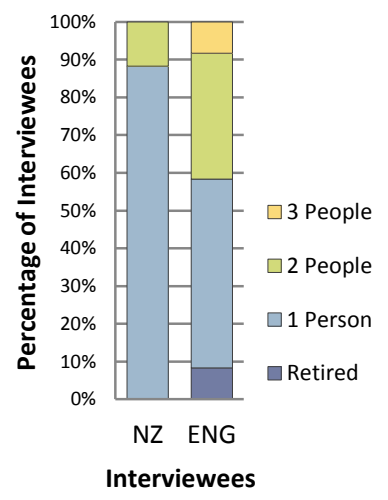

Figure 117: Persons per

household engaged in full-time paid employment (NZ ENG)

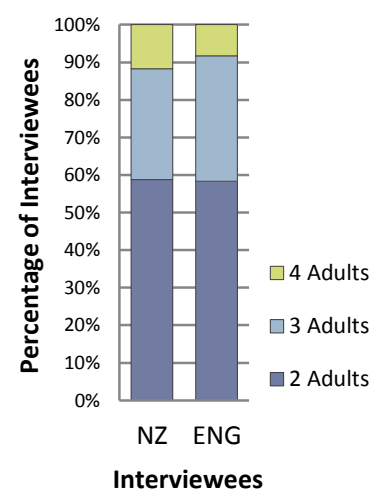

Figure 118: Number of adults per household (NZ ENG)

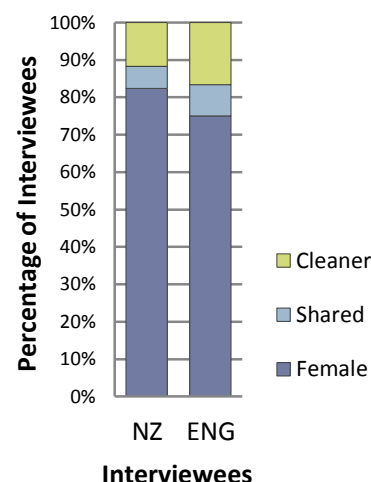

Figure 119: Person responsible for household work (NZ ENG)

Of the 29 1930s and 1940s interviewees, 23 (79\%) recalled household work was only done by mother (Figure 119). Such work was labour intensive then in both NZ and ENG, and tasks such as cooking and washing clothes were done the 'hard way':

...she [mother] would have a dolly tub...and a dolly to sort of push it round and she would have buckets... with clothes on the fire... a big mangle... a great big thing with great big wooden rollers... with a big spring at the top that you slackened off for thicker things...that would stand outside and she would have to ring out there whether it was winter or whatever..." [ENG_02, 0:08:17].

Of the 17 NZ 1930s and 1940s interviewees, 10 (59\%) mentioned a dolly/mangle/copper used for washing clothes, the same proportion as the ENG interviewees (59\%). Interviewees from both groups recalled clothes washing taking place once a week, usually on a Monday [NZ_13, 0:22:02; NZ_10, 0:22:45; NZ_15, 0:07:00; ENG_01, 0:17:27; ENG_04, 0:23:22; ENG_07, 0:13:04; ENG_12, 0:22:44].

The TS and SE houses were constructed with a bathroom containing a cast iron bath with a hot and cold water supply. Of the 17 1930s and 1940s NZ interviewees, only 1 (6\%) mentioned bathing once a week, compared to 5 (29\%) of the 121930 s and 1940 s ENG interviewees. Both NZ and ENG interviewees remembered sharing bath water with other members of the household [NZ_02, 0:07:06; ENG_01, 0:07:43]. 
During the 1930s and 1940s food preparation was similar in both NZ and ENG households, with basic ingredients such as flour, sugar, butter, milk and eggs being purchased. There were no fridges or freezers. Of the $17 \mathrm{NZ}$ interviewees, 12 (71\%) recalled a food safe, and 5 (41\%) of the 12 ENG interviewees recalled a pantry, with fresh food often purchased daily.

For $3(18 \%)$ of the $17 \mathrm{NZ}$ interviewees, breakfast was typically porridge or Weet-bix and toast, lunch was soup or a sandwich, and dinner was meat and two or three vegetables followed by a home-made pudding. For 4 (34\%) of the 12 ENG interviewees a typical breakfast was cereal and toast, lunch (dinner) was meat and two or three vegetables, and tea (evening meal) was bread and butter or jam. There is a difference here, not in terms of what was eaten but its order. Some ENG interviewees recalled their fathers came home at lunch time and this would have been true for the Crittall workers based in the Silver End factory. However, this was not the case for all of the Crittall workers, as those who worked in Braintree or Witham travelled to work by bus and took a packed lunch [SE_01, 1:08:43].

Mother was responsible for preparing food in 25 (86\%) of the 291930 s and 1940s interviewees' households (Figure 120). One NZ interviewee indicated that his mother spent a similar amount of time cooking each day:

“...she would start preparing around about four o'clock in the afternoon...she'd have a cup of tea in the afternoon and then start preparing the vegetables...as children, we ate very early, five o'clock...Sunday lunch was always roast, either beef or lamb, seldom pork, because pork was very expensive... and that would always be followed by hot scones with raspberry jam and cream...Saturday morning was cake and biscuit baking..." [NZ_13, 0:34:10].

Routine and planning appear to have been extremely important in the lives of women at this time in both NZ and ENG, with home baking mentioned by $5(29 \%)$ of the NZ and 4 (33\%) of the ENG interviewees even though this was not included in the recorded oral interview guide. Only 2 (7\%) of the 291930 s and 1940s interviewees mentioned that bread was baked at home, and in both cases, these were ENG 
interviewees [ENG_03, 0:09:33; ENG_04, 0:23:22]. One NZ interviewee was a member of a relatively affluent family, where father was a lawyer and mother had a live-in maid, but routine was still important, as was growing vegetables and the preservation of fruit which the children helped to do [ENG_05, 0:10:49].

None of the NZ interviewees recalled eating out (Figure 121), compared to 4 (33\%) of the ENG interviewees who did this occasionally, although in 2 of these instances, this was buying chips from a fish and chip shop [ENG_06, 0:49:05; ENG_08, 0:17:41]. Although fish and chips have been available in the UK for 150 years and were mentioned by Dickens in Oliver Twist, it is not known when takeaway fish and chip shops became common in New Zealand (I. Stuart, 2010).

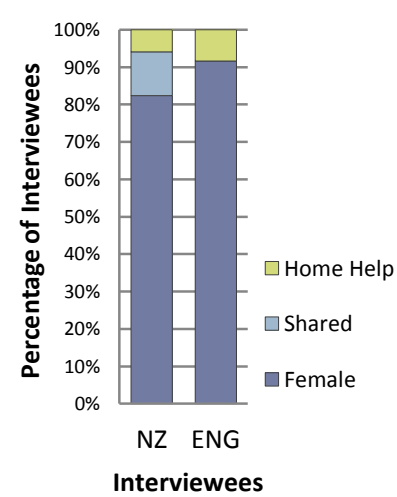

Figure 120: Person responsible for food preparation (NZ ENG)

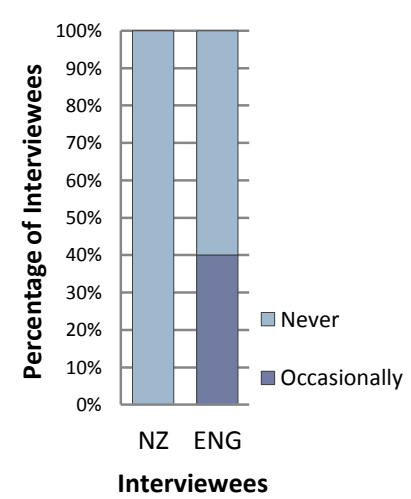

Figure 121: Frequency of eating out (NZ ENG)

4 (24\%) of the 17 NZ 1930s and 1940s lifestyle interviewees mentioned food preservation activities [NZ_02, 0:22:27; NZ_06, 0:48:54; NZ_07, 0:23:02; NZ_08, 0:17:46], as did 2 (17\%) of the ENG interviewees [ENG_04, 0:30:45; ENG_05, 0:10:49] even though this was not included in the recorded oral interview guide.

Food deliveries were common during the 1930s and 1940s and $12(71 \%)$ of the NZ and 11 (92\%) of the ENG interviewees recalled daily deliveries of milk and/or weekly deliveries of groceries and other household wares. Time spent shopping was probably minimal as apart from it being delivered, shops were local. 
During the 1930s and 1940s, the house was a place of production, and $11(65 \%)$ of the $N Z$, and $8(67 \%)$ of the ENG interviewees recalled their mothers sewing, knitting or mending.

\subsubsection{Outdoor Space}

The TS and SE houses had front and rear gardens and the small number of early inhabitants interviewed for this research recalled flowers in the front garden, with a large plot for vegetables at the rear. Father was wholly responsible for garden maintenance in 7 (41\%) of the NZ interviewees' households, the exceptions being fathers not in good health, one interviewee whose mother was widowed and two whose parents employed a gardener (Figure 122). A typical NZ recollection was, "...there was a bit of a pattern...that the wife would look after the front garden and the flowers, and the husband would look after the vegetable garden, but there were lots of exceptions to that..." [NZ_13, 0:01:43]. For 13 (77\%) NZ interviewees, over 11\% of vegetables came from the garden, and several recalled that during the depression this was an essential means of providing food for the table (Figure 123).

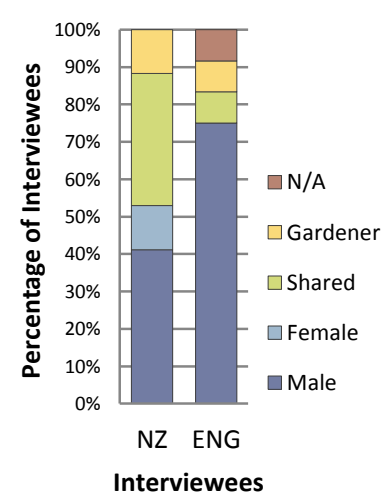

Figure 122: Person responsible for garden maintenance (NZ ENG)

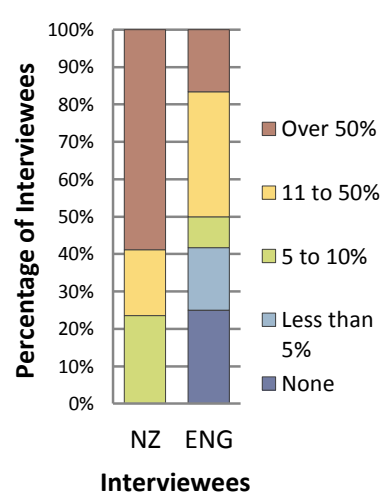

Figure 123: Percentage of consumed vegetables grown at home (NZ ENG)

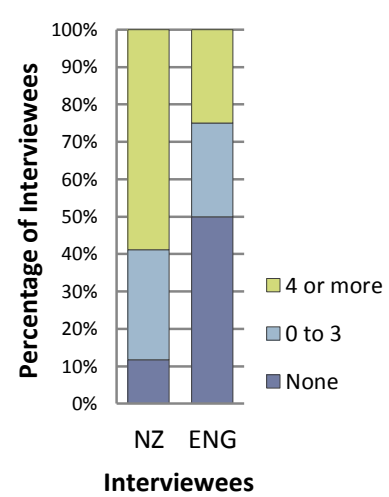

Figure 124: Number of different types of fruit grown at home (NZ ENG)

Of the 12 ENG interviewees, $9(75 \%)$ recalled their fathers alone looked after the garden, however, 5 (42\%) of the ENG interviewees' gardens were small, so possibly did not require as much maintenance as the large SE gardens. The elderly SE interviewees recalled growing vegetables was common in SE gardens during the 1930s and 1940s 
(section 4.2.2), and one remembered that when the SE houses were first built growing vegetables was encouraged and allotments were available for anyone who wanted one [SE_05, 0:42:31]. Less than $11 \%$ of household vegetables came from the garden for 5 (42\%) of the ENG interviewees, compared to the NZ figure of 4 (24\%) possibly due to the smaller gardens.

Fruit was grown in 15 (88\%) of the NZ interviewees' gardens, with 10 (59\%) producing four or more different varieties (Figure 124). Fruit was not grown in 6 (50\%) of the ENG interviewees' households, compared to only 2 (12\%) of the NZ households, again possibly because of the smaller gardens but also because of the climate.

Chickens were kept by 7 (41\%) NZ interviewees (Figure 125) compared to 6 (50\%) of the ENG group. The latter also recalled other animals being kept for meat, with 2 (17\%) households keeping rabbits [ENG_07; ENG_12], and 1 (8\%) ducks [ENG_09].

NZ and ENG 1930s and 1940s lifestyle interviewees generally recalled their father had enjoyed looking after the garden, although there were exceptions to this [NZ_16, 0:07:39; ENG_03, 0:14:52]. Gardening was more labour intensive and time consuming during this period, without the powered garden equipment now common. The necessary productive nature of gardens during this period meant it was essential to spend time outside looking after them.

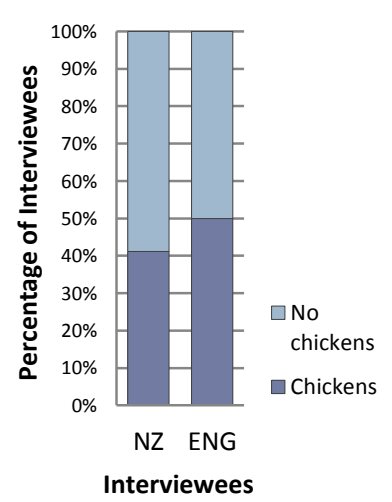

Figure 125: Number of interviewees keeping chickens at home (NZ ENG)

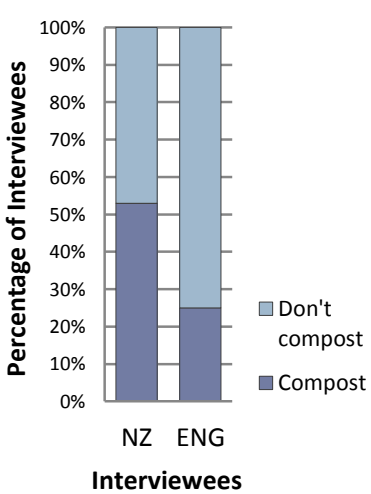

Figure 126: Number of interviewees composting household waste (NZ ENG)

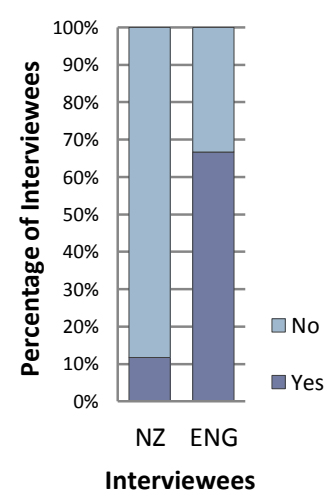

Figure 127: Number of interviewees burning household waste (NZ ENG) 
The 1930s and 1940s NZ and ENG lifestyle interviewees generally struggled to recall what had happened to house and garden wastes, presumably because the households did not produce excessive amounts of these. Of the $17 \mathrm{NZ}$ interviewees, 9 (53\%) mentioned composting, compared to 3 (25\%) of the ENG interviewees (Figure 126). Possibly there was more composting amongst the NZ interviewees due to their larger and more productive gardens. Burning waste was mentioned by $8(67 \%)$ of the ENG interviewees (Figure 127) and 4 (33\%) mentioned there would have been very little waste.

Only $3(18 \%)$ of the 1930s and 1940s NZ interviewees (and none of the ENG group) recalled construction work to the garden, in 2 cases this being the erection of a timber shed.

Of the 17 1930s and 1940s NZ interviewees, 8 (48\%) specifically recalled spending a lot of time outside as children. Similarly, $6(50 \%)$ of the ENG interviewees indicated that they spent lots of time playing outside, and in some cases were encouraged to play somewhere other than in the garden:

"...he [father] was pretty strict about us not playing on his gardens, you know we got into trouble if we paddled all over everything... we had a little bit of a lawn just outside the back windows and we were allowed to play on that...but we really were not encouraged to play in the garden... we backed right onto the playing field and we walked through the garden onto the playing field and we played on the playing field..." [ENG_09, 0:08:14].

Both groups of interviewees also remembered spending a lot of time outside, and children's activities appear to have been less structured, with more free play, usually in the street or a nearby playing field or park (sections 3.2.1 and 4.2.1). Many interviewees recalled with fondness the freedom they experienced as children and the community spirit they felt. During the 1930 s and 1940s, it would seem that people spent more time with neighbours and inhabitants of the street, possibly because of the lack of private transport and other alternatives. 


\section{$5.2 \quad$ Space Use}

\subsubsection{House}

In 9 (54\%) of the 1930s and 1940s NZ interviewees' households there were between 3 and 5 persons per dwelling, and in 6 (35\%) there were 6 inhabitants (Figure 128). Average occupancy was 5.10 for this group, higher than the average 1921 census occupancy of 4.43 persons per dwelling in the Wellington urban area (Census and Statistics Office, 1921, p. 15). There were 3 or more adults residing in 7 (41\%) of households (Figure 129). Home ownership was common amongst the NZ interviewees, 13 (76\%) stated their parents owned or had a mortgage for the house, and the remaining 4 (24\%) rented (Figure 130).

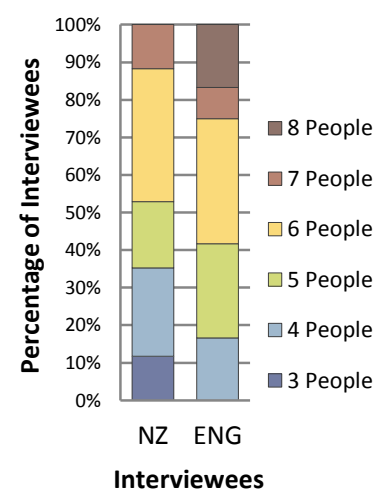

Figure 128: Number of persons per dwelling (NZ ENG)

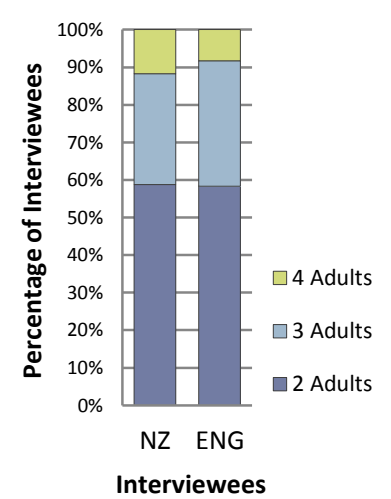

Figure 129: Number of adults per household (NZ ENG)

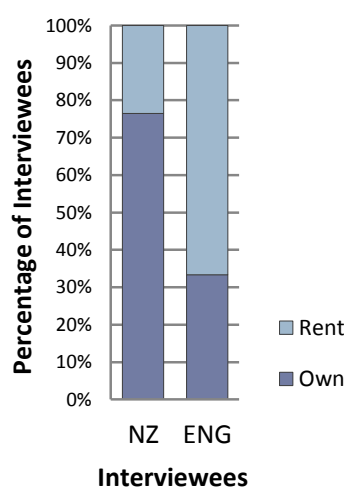

Figure 130: Home ownership (NZ ENG)

The 1911 GB Census gave the average occupancy as 4.3 persons per dwelling (Office for National Statistics, 2013), however the average number of persons/dwelling in the 1930s and 1940s ENG interviewees' households was 5.8 (Figure 128). This figure is higher than the NZ figure despite a similar number of adults per household (Figure 129). The difference is due to the number of children in the ENG households (Figure $131)$ with $3(25 \%)$ containing more than 4 children, compared to none with this number in the NZ interviewees' households. 


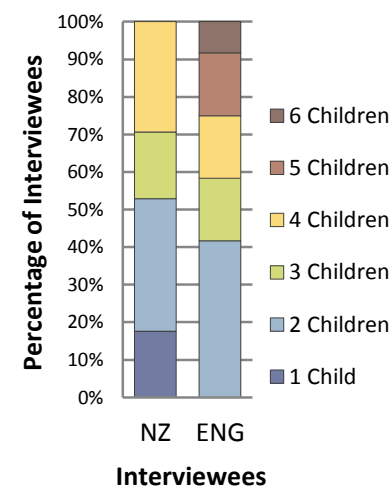

Figure 131: Number of children per dwelling (NZ ENG)

Of the 12 ENG interviewees, 7 (58\%) lived in a household of 6 or more people, and noone where there were fewer than 4 people. In 5 (42\%) households someone outside the nuclear family (a relative or a lodger) lived with the interviewee's family (Figure 129).

Renting was much more common amongst the ENG 1930s and 1940s lifestyle interviewees, and $8(67 \%)$ stated their parents rented the house, compared to only 4 (24\%) of the NZ group (Figure 130). Of the 12 ENG interviewees, 5 (42\%) lived in council owned properties. Original inhabitants of both the TS and SE houses rented the houses from their employers, but the Crittall workers were also given the opportunity to purchase their house through a rent and purchase scheme (section 4.1).

The original TS house $\left(87.5 \mathrm{~m}^{2}\right)$ was slightly larger than the SE house $\left(80 \mathrm{~m}^{2}\right)$, although both contained three bedrooms. The accommodation was similar, and in both houses there was a parlour (TS) or sitting room (SE) containing an open fire, a kitchen (TS) or living room (SE) containing a coal range, a kitchenette (TS) or scullery (SE) containing a sink, and a bathroom (Figure 24, Figure 74 and Figure 75). Although named differently, these spaces fulfilled similar functions. The main difference was that the TS house had a detached timber outhouse containing the coal store, toilet and clothes washing facilities, whereas in the SE house the clothes washing facilities were located in the scullery, with a toilet on the first floor and an internal coal store. 
Of the 17 NZ 1930s and 1940s lifestyle interviewees, 5 (29\%) mentioned having a sitting room or a parlour that was only used very occasionally, "We had another best room, or something or other, which we never went into..." [NZ_04, 0:11:28]. Similarly, $4(33 \%)$ of the ENG interviewees' also recalled a seldom used sitting room or parlour, "We had a front room, in which we had a piano...so we had musical evenings about every other month...otherwise it was hardly used..." [ENG_11, 0:07:43]. In contrast, 3 (25\%) of the 12 ENG interviewees mentioned the small size of their house and recalled that all of the spaces were used. One elderly SE interviewee described living with her mother, father, grandmother and aunt in a SE house during the 1940s, with the sitting room inhabited by her mother and father, and the living room used by her grandmother and aunt [SE_01, 0:03:37] clearly indicating that not all interviewees experienced the luxury of underused space.

Of the 29 1930s and 1940s lifestyle interviewees, 24 (83\%) recalled every bedroom being used as a bedroom, and in many cases bedrooms were used for more than one child of the same sex. Only $3(18 \%)$ of the $17 \mathrm{NZ}$ interviewees recalled a spare bedroom, compared to $2(17 \%)$ of the ENG interviewees.

For the majority of the 1930s and 1940s interviewees the kitchen was the room most frequently inhabited and the centre of activity, with the coal range providing heat for warmth and cooking. For $3(18 \%)$ of the NZ interviewees and $6(50 \%)$ of the ENG interviewees, the coal range was the primary form of heating.

Of the $17 \mathrm{NZ}$ 1930s and 1940s lifestyle interviewees, 11 (65\%) did not recall any alterations being made to their house whilst they lived there. This is similar to the ENG interviewees, 7 (58\%) of whom did not recall any house alterations. Alterations to verandas were mentioned by $3(18 \%)$ of the NZ interviewees and improvements to services, for example the introduction of piped or heated water, were mentioned by 5 (30\%). Within the NZ interview group, only 3 (18\%) stated their house was extended. Of the 5 (42\%) ENG interviewees who recalled house alterations, $3(27 \%)$ mentioned improving the space and water heating, and in 2 of the 3 cases, fathers undertook the work. Only 1 (8\%) ENG interviewee recalled helping his uncle build a timber addition to the rear of the house [ENG_06, 0:24:18]. The fact that TS and SE houses were not 
altered at this time was presumably because the inhabitants were renting the houses and were not allowed to undertake alterations or improvements themselves.

However, the 1930s and 1940s lifestyle interviews would suggest that work to houses was not common during this period with 11 (38\%) of the 29 interviewees not able to recall any alterations being undertaken, and $8(28 \%)$ of the remaining recalling only essential improvements to space and water heating.

Of the 29 1930s and 1940s lifestyle interviewees, 15 (52\%) stated their family did not lock their doors and most recalled feeling safe in their houses. One NZ interviewee mentioned that they never locked their door, not having anything worth stealing [NZ_09, 0:52:14] as did one ENG interviewee [ENG_06, 1:14:18]. During the 1930s and 1940s, people did not appear to have many possessions making storage space within houses less important than today, which is a possible reason for the lack of storage space in both the TS and SE houses.

\subsubsection{Outdoor Space}

Typical TS houses had a front garden of approximately $71 \mathrm{~m}^{2}$ and a rear garden of approximately $385 \mathrm{~m}^{2}$ (a total of $456 \mathrm{~m}^{2}$ ). The front garden of the SE Stuart houses was approximately $126 \mathrm{~m}^{2}$ and the rear garden approximately $252 \mathrm{~m}^{2}$ (a total of $378 \mathrm{~m}^{2}$ ). In addition, because the inhabitants of the SE houses were encouraged to grow vegetables, anyone who lived in Silver End and wanted an allotment could have one [SE_05, 0:42:31].

As previously discussed (sections 3.2.2 and 4.2.2), during the 1930s and 1940s in most cases part of the garden was set aside for growing vegetables. One NZ interviewee recalled how at one stage the entire garden was given over to potatoes [NZ_05, 0:10:16] a memory also shared by an elderly SE interviewee [SE_01, 0:21:21].

Of the 17 NZ 1930s and 1940s lifestyle interviewees, 12 (71\%) recalled flowers in the front garden and vegetables in the rear, contrasting with the ENG interviewees, only 3 (25\%) of whom mentioned this arrangement. However, one elderly SE interviewee said her father loved gardening, growing vegetables in the rear garden and in the 
allotment beyond [SE_08, 0:11:00], and it would appear that the TS and SE houses were generally similar in terms of outdoor space use.

The original TS houses had a detached timber outhouse, containing coal store, toilet and clothes washing facilities. The SE Stuart houses do not appear to have been designed with any outbuildings, although one elderly SE interviewee recalls a coal box outside her house [SE_01, 0:16:35]. Outside facilities in the TS houses occurred at a time when these were coming into the house in NZ in response to a rising interest in hygiene (Schrader, 2014). This was part of the movement for improved health through large windows to let sunlight into houses, flat roofs for exercise, and sanitary facilities that made it easy to keep houses and their occupants clean (Overy, 2007). Thus it is not surprising that the modernist houses at Silver End brought these facilities inside the house.

During the 1930s and 1940s, car ownership was uncommon in both New Zealand and England. Of the $17 \mathrm{NZ}$ interviewees' families, 9 (53\%) had no car, 7 (41\%) had one and $1(6 \%)$ had two. These figures are slightly different in the ENG group where 9 (75\%) of the interviewees households had no car, $2(17 \%)$ had one and $1(8 \%)$ had two (Figure 132). This is comparable with general figures for the UK where by $193820 \%$ of families had access to a private car (O'Connell, 1995).

The TS workers mainly went to work by train (section 3.3.2.3) and the SE workers used buses provided by Crittalls (section 4.3.2.3). Of the 17 NZ 1930s and 1940s lifestyle interviewees', 7 (41\%) recalled their household used public transport regularly, and 6 (35\%) that it was used occasionally. These figures are similar to the ENG group, where $5(42 \%)$ households used public transport regularly and 7 (58\%) occasionally. 


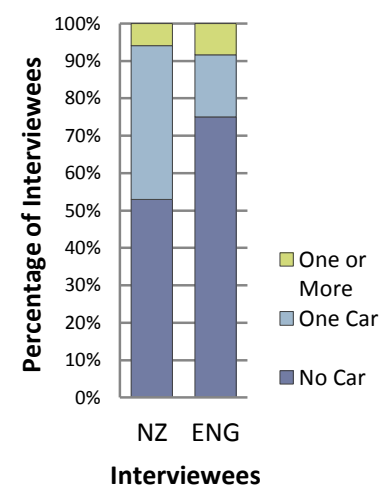

Figure 132: Number of cars per household (NZ ENG)

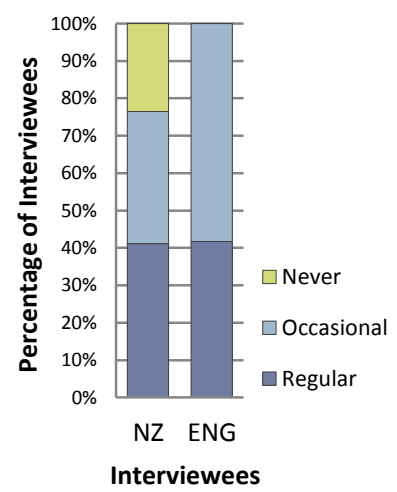

Figure 133: Use of public transportation (NZ ENG)

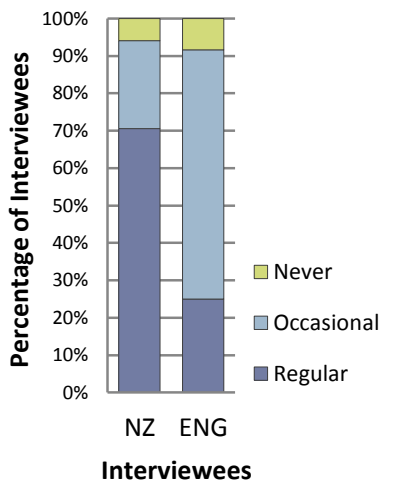

Figure 134: Number of households where bicycles were used regularly (NZ ENG)

Bicycles were used regularly in $12(71 \%)$ of the NZ interviewees' households and occasionally in 4 (24\%). Bicycles were just as common in the ENG interview group, but used regularly in only 3 (25\%) households and occasionally in 8 (67\%) (Figure 134).

\subsection{Energy Use}

\subsubsection{House and Outdoor Space}

Both original TS and SE houses had mains water, the TS had mains electricity and the original SE houses had electricity supplied by a local power plant [SE_01, 0:03:37]. Of the 17 NZ 1930s and 1940s lifestyle interviewees, 3 (18\%) were without a mains water supply (Figure 135) and 1 (6\%) had no mains electricity (Figure 136). Similarly, of the 12 ENG interviewees, 1 (8\%) household had no mains water supply (Figure 135) and 3 (25\%) no mains electricity (Figure 136). One person in this group recalled an outside cold water tap in the yard but no running water inside [ENG_02, 0:08:17].

Gas was supplied to $6(35 \%)$ of the NZ interviewees' houses, all of which were in towns, and 4 (33\%) of the ENG interviewees' houses (Figure 137). One ENG interviewee who did not have electricity remembered two gas mantles for lighting and taking a candle to bed [ENG_02, 0:12:34]. 


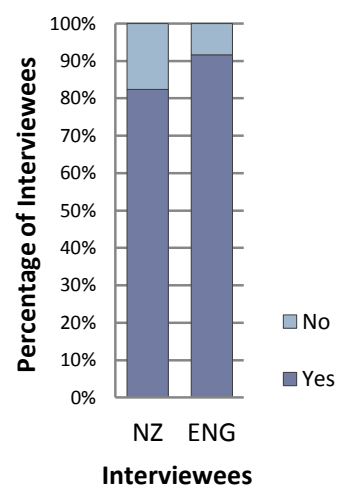

Figure 135: Households with a

mains water supply (NZ ENG)

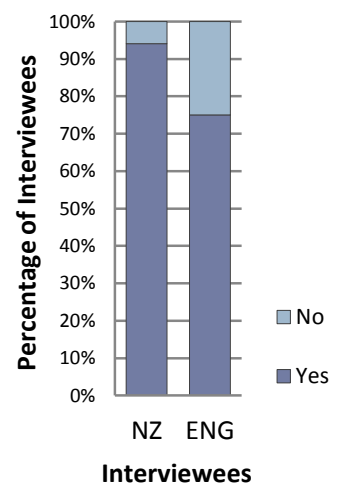

Figure 136: Households with a mains electricity supply (NZ ENG)

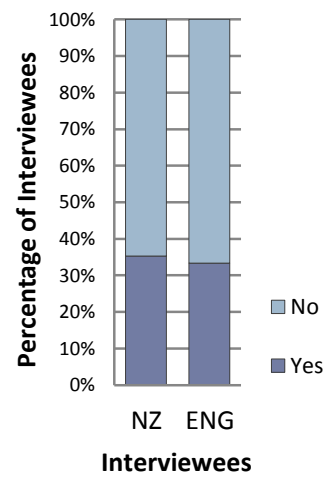

Figure 137: Households with a mains gas supply (NZ ENG)

The original TS houses had a single drop light in each room with a two light pendant in the parlour and a single electric socket in the kitchen. The TS outhouse had no electricity. The original SE Stuart houses had a single drop light in each room, and two single electric sockets, one in the scullery and one in the kitchen.

In the original TS and SE houses energy for space heating the kitchen was a by-product the coal range which did the cooking and provided hot water. One NZ interviewee recalled her mother found their railway workers house too hot in the summer, due to having the coal range lit in order to cook and heat water [NZ_17, 0:03:17]. Similarly, an elderly SE interviewee said it was a relief when they got an immersion heater, as this meant there was no need to light the fire in the summer. Of the 291930 s and 1940s interviewees 17 (59\%) remembered keeping food cool in a food safe (NZ) or pantry (ENG) (sections 3.2.1 and 4.2.1).

The TS houses had a coal range in the kitchen and an open fire in the parlour. The SE houses were better provided with a coal range in the living room, an open fire in the sitting room and open fires in two of the three upstairs bedrooms. Of the $17 \mathrm{NZ} 1930 \mathrm{~s}$ and 1940s lifestyle interviewees, 12 (71\%) recalled open fires as the primary means of heating the house and $3(18 \%)$ a coal range, with only $2(12 \%)$ remembering heating with electricity in the form of a plug in electric fire (Figure 138). Solid fuel was used to heat the house in $15(88 \%)$ cases (Figure 139) and only $3(18 \%)$ interviewees 
mentioned an additional form of space heating. Fewer of the 12 ENG 1930s and 1940s lifestyle interviewees recalled their house primarily being heated by an open fire $(50 \%$ compared to $71 \%$ ) but more by a coal range at (50\% compared to $18 \%$ ) (Figure 138). In common with the NZ interviewees, only $3(25 \%)$ of the ENG interviewees mentioned an additional form of space heating. Of the 29 1930s and 1940s lifestyle interviewees' houses, 27 (93\%) were heated by solid fuel (Figure 139).

Of the $17 \mathrm{NZ}$ interviewees, 4 (27\%) mentioned that cold had been the worst thing about their house. Of the 12 ENG interviewees, 9 (75\%) were unable to think of something they disliked about their house and of the remaining 3 , only 1 (8\%) mentioned the house with its limited facilities, no-one seeing being cold as a problem.

The Miller houses on Broadway and some of the Stuart houses on Silver Street were not constructed with a cavity wall [SE_03, 0:12:29], which would have made them harder to heat. There is also evidence that because of this, damp was a problem for the SE houses in the past [SE_06, 0:30:49] (section 4.4.1.2).

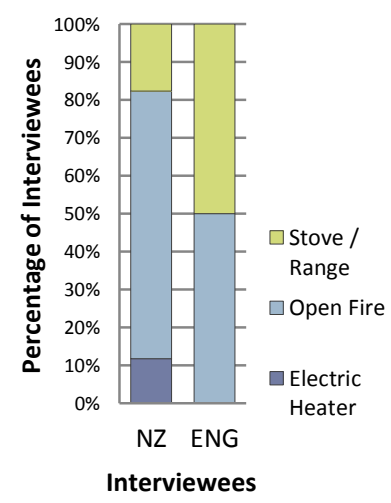

Figure 138: Primary method of space heating (NZ ENG)

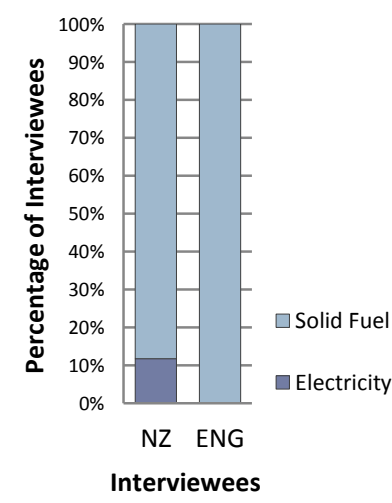

Figure 139: Fuel type in the primary method of space heating (NZ ENG)

In the original TS houses, the coal range was for cooking and a supplementary water heating coil in the firebox (locally called a 'wet back') provided hot water. Cold water was supplied to the wet back, bathroom, kitchenette and outhouse. Hot water circulated through galvanised iron pipes from the wet back to the bathroom and kitchenette. The set up was similar in the original SE houses, with a coal range for 
cooking with a back boiler for hot water. Cold water was supplied to the wet back, the bathroom and the scullery. Hot water circulated through galvanised iron pipes from the back boiler to the upstairs bathroom and scullery.

Water heating for the NZ 1930s and 1940s lifestyle interviewees was varied, with 6 (35\%) recalling a wet back and 6 (35\%) an electric hot water cylinder. A further 3 (18\%) heated water in the copper, or in kettles on the range, with $2(12 \%)$ having a gas califont (instantaneous water heater) (Figure 140). Fuel for water heating was solid fuel in $9(53 \%)$ households, electricity in 6 (35\%) and gas in 2 (12\%) (Figure 141).

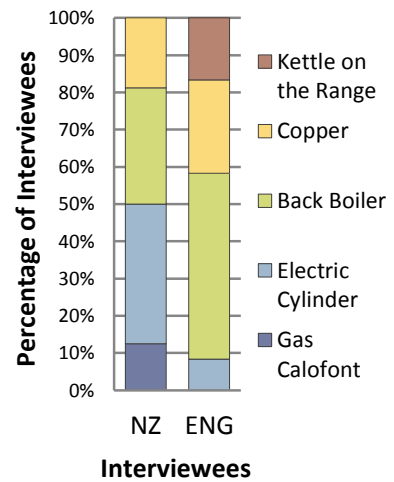

Figure 140: Primary method of water heating (NZ ENG)

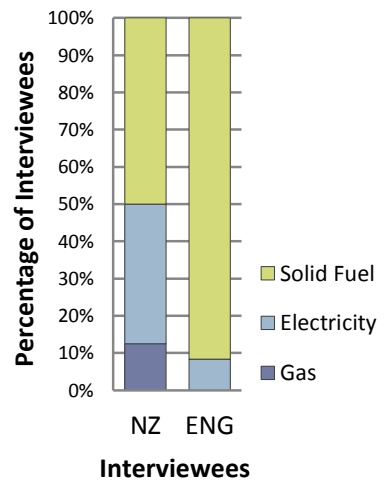

Figure 141: Fuel used in the primary method of water heating (NZ ENG)

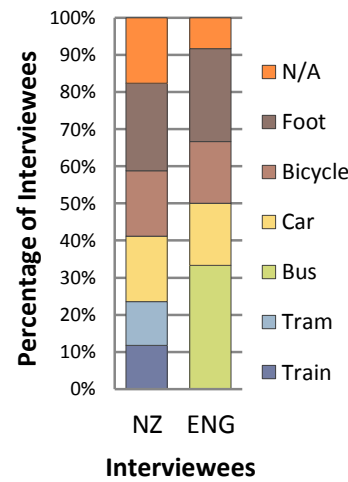

Figure 142: Mode of transportation to and from work (NZ ENG)

Water heating also varied among the ENG 1930s and 1940s lifestyle interviewees, as 6 (50\%) mentioned a back boiler, 3 (25\%) a copper, 2 (17\%) kettles on the range and 1 (8\%) an electric hot water cylinder (Figure 140). Solid fuel was used for water heating in 11 (92\%) households and electricity in 1 (8\%) (Figure 141).

Many of the 29 1930s and 1940s lifestyle interviewees recalled water was heated once a week for washing clothes or for bathing (sections 3.4.1 and 4.4.1), and this would certainly have been the case for the $8(28 \%)$ households whose water was heated by the copper or kettle. 


\subsubsection{Transport}

As previously discussed (sections 3.3.2.3 and 4.3.2.3) the TS workers mainly commuted by train and the SE workers either walked to work or used the buses provided by Crittalls. The mode of transportation to and from work for the fathers of the $291930 \mathrm{~s}$ and 1940s interviewees varied, but only a small number from each group used a private car (3 (18\%) of the NZ fathers and 2 (17\%) of the ENG) (Figure 142). A similar number of NZ and ENG interviewees' fathers travelled to and from work by bicycle (3 (18\%) and $2(17 \%)$ respectively) and on foot (4 (24\%) and $3(25 \%))$. Buses were used by $4(33 \%)$ of the ENG fathers, and $2(12 \%)$ of the NZ fathers used the train and $2(12 \%)$ the tram. Overall, public transport was used for commuting by $8(28 \%)$ fathers of the 29 1930s and 1940s lifestyle interviewees.

As discussed in sections 3.2.1 and 4.2.1, the 1930s and 1940s lifestyle interviewees recalled food being delivered to the house or street which was a place bustling with activity. Due to the absence of cars, friendship circles were generally restricted to those within the local community.

As discussed in sections 3.2.2 and 4.2.2, the 1930s and 1940s lifestyle interviewees often recalled one of their parents, most commonly father, spending considerable time outside maintaining the vegetable garden. The TS and SE gardens were productive and garden maintenance was labour intensive and done by hand.

\subsubsection{Embodied Energy Comparison}

The embodied energy (GJ) in the building elements of both the TS and SE houses as built in 1928 is shown in Figure 143, and the embodied energy in the building elements expressed as a \% of the 1928 totals in Figure 144. The embodied energy calculations are comparable in that they relate to the provision of a 3 bedroom house for a family. 


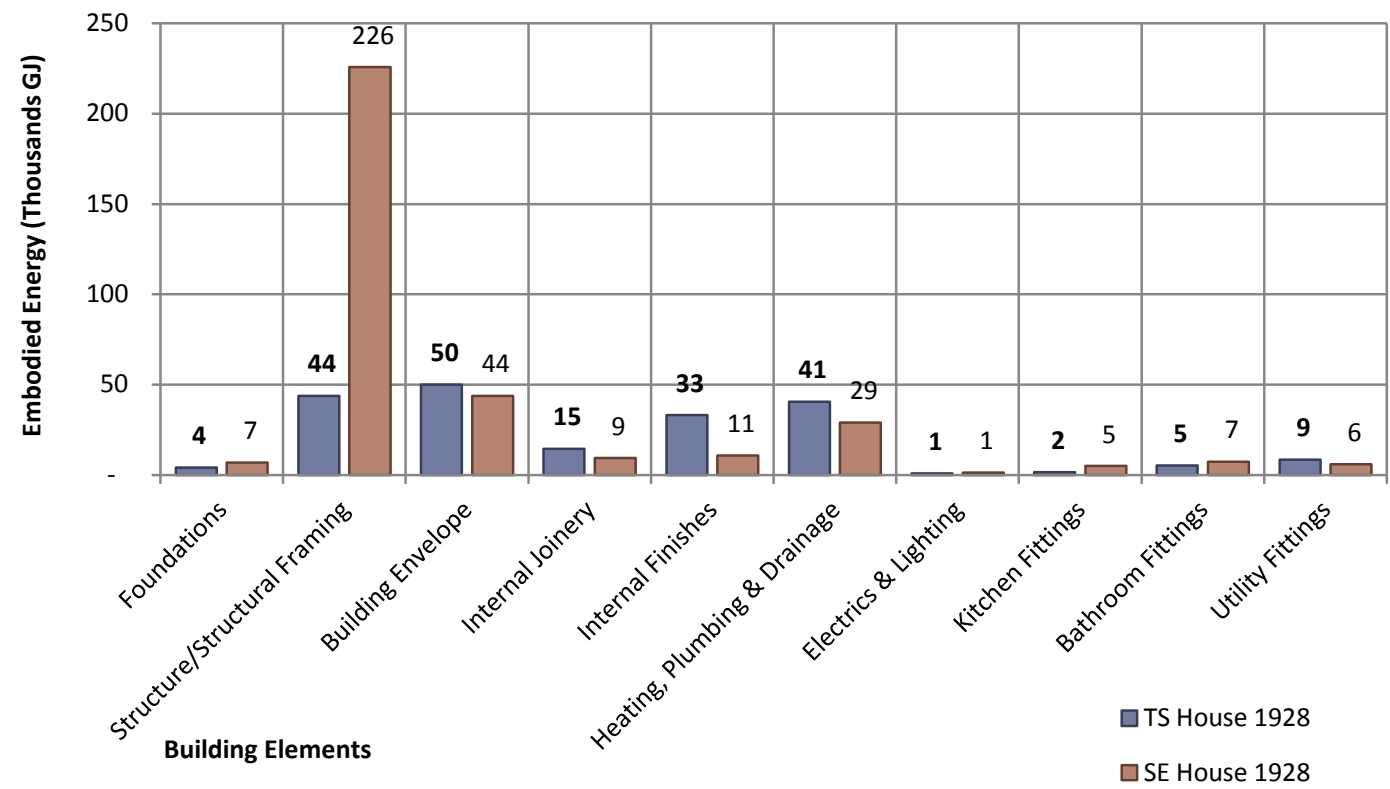

Figure 143: Embodied Energy (GJ) in the Building Elements of the TS House and the SE House in 1928

The original TS house had 50,112 GJ (25\%) of embodied energy in the building envelope (external timber and paintwork, windows and roof covering). There was less embodied energy in the structure/structural framing (walls, brick chimney stack, floor and roof structure) at $43,866 \mathrm{GJ}(22 \%)$ of the total. Heating, plumbing \& drainage accounted for 40,607 GJ (20\%) and internal finishes were 33,147 GJ (16\%).

In contrast, as might be expected in a load bearing brick house, the original SE house had 225,862 GJ (65\%) of embodied energy in the structure/structural framing (loadbearing external and internal walls, floor and roof structure).

The embodied energy of the building envelope (external render and paintwork, windows and roof covering) was less than the TS house at 43,848 GJ (13\%). The SE houses had a rendered and painted finish, compared to the timber boarding, iron roof and paint finish of the TS house. The embodied energy of the heating, plumbing \& drainage was significantly lower than the TS house at $28,909 \mathrm{GJ}(8 \%)$, due to the embodied energy co-efficient of the materials being different in NZ and the UK (see spreadsheet on the attached CD-ROM). The total embodied energy of the original TS house was $202,500 \mathrm{GJ}$, compared to the original SE house at 345,164 GJ. This cannot be a direct comparison, as the TS houses are approximately $7.5 \mathrm{~m}^{2}$ larger and single 
storey rather than two storey, which would affect the embodied energy of the foundations. However, these two facts could point to a lower embodied energy for the SE houses, so the materials used are having an effect.

The total embodied energy of the original TS house is $59 \%$ of the original SE house. This is due to the use of timber as the primary building material with its low embodied energy. Brick is the primary building material in the original SE house and thus the structure accounts for $65 \%$ of the total embodied energy. The foundations in the original TS house were totara piles, again giving a lower embodied energy than the strip concrete foundations of the original SE house. Internal finishes in the original TS house contain more embodied energy than those in the original SE house, as timber was used to line walls and a plaster finish was applied, in contrast to the SE house in which the fair face brick walls were painted.
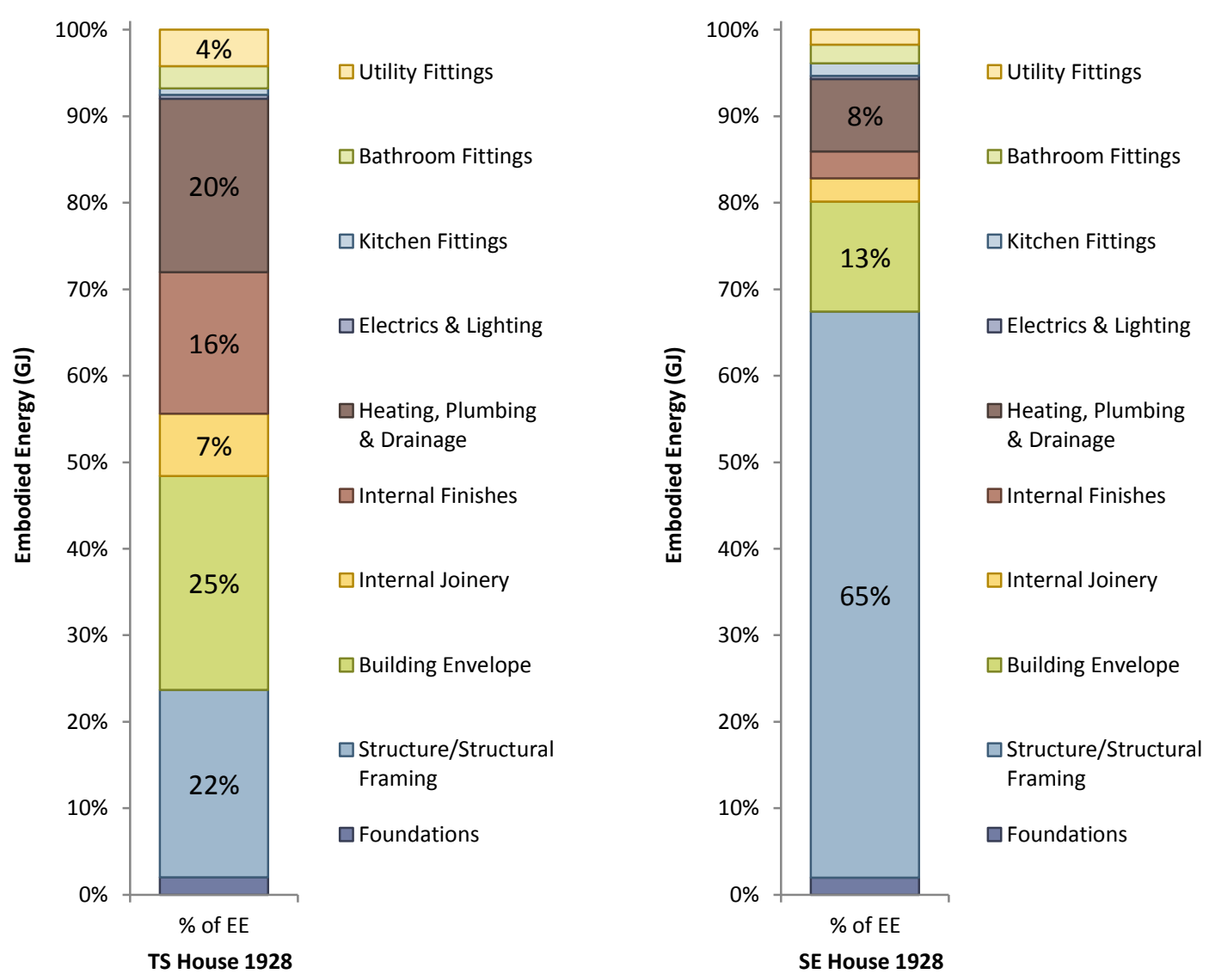

Figure 144: Embodied Energy (GJ) in the Building Elements of the TS House and the SE House in 1928 expressed as \% 
The embodied energy (GJ) in the building materials of the TS and SE houses in 1928, expressed as a \% of the total, is shown in Figure 145. In the 1928 TS house, iron accounted for $30 \%$ of the total, followed by timber (23\%), bricks for the chimney (13\%), copper (10\%) and wallpaper (10\%). The remaining $14 \%$ consisted of 10 other building materials including plaster (6\%), concrete (3\%) and paint (2\%). In contrast, bricks formed $42 \%$ of the total embodied energy in the 1928 SE house, followed by cement mortar (21\%), iron (8\%), timber (6\%) and steel (6\%). The remaining $17 \%$ consisted of 13 other building materials including copper (4\%), concrete (3\%) and paint (3\%).

The use of building materials in the SE house with higher levels of embodied energy, particularly fired clay bricks and cement mortar, account for the difference in the total embodied energy of the houses.
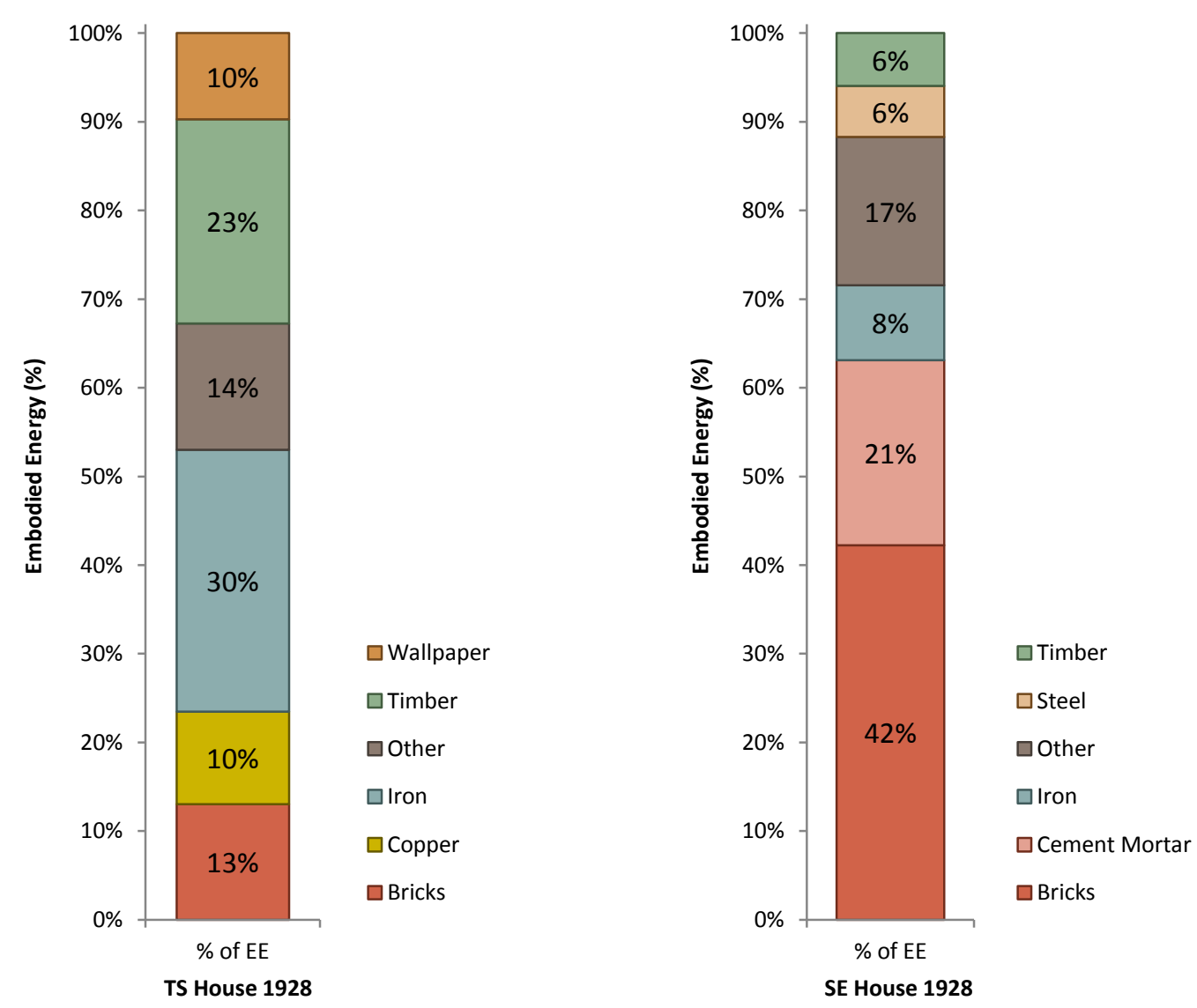

Figure 145: Embodied Energy (GJ) in the Building Materials of the TS House and SE House in 1928 expressed as \% 


\subsubsection{Embodied Energy per $\mathrm{m}^{2}$ and per Person}

As previously explained (section 3.4.1.6), the embodied energy of the 1928 TS and SE houses was calculated and the embodied energy of materials involved in the maintenance of the house over 50 years was then added.

The embodied energy (GJ) of the TS house including the 50 years of maintenance was $280,591 \mathrm{GJ}$ or $3,207 \mathrm{GJ} / \mathrm{m}^{2}$ and the embodied energy (GJ) of the SE house including the 50 years maintenance was 408,078 GJ or 5,101 GJ/m² (Figure 146 and Figure 147), even though the energy embodied in the materials for maintenance of the TS house $(78,092 \mathrm{GJ})$ was greater than for the SE house $(62,914 \mathrm{GJ})$.

The main reason for the difference in maintenance is the need to paint the corrugated iron roof covering of the TS house regularly and the embodied energy involved in its replacement once during this period. The embodied energy of the TS corrugated iron roof is 15,372 GJ, compared to the asphalt roof covering of the SE house at 1,502 GJ. The corrugated iron roof will need to be replaced once in a 50 year maintenance period (A Alcorn, 2010) compared to the asphalt roof covering which requires replacement every 15 years ( 3 times during a 50 year maintenance period) so the maintenance of the TS roof is 15,372 GJ compared to the 4,506 GJ SE roof, which is a significant difference. This also excludes the embodied energy of the paint finish to the corrugated iron roof every 8 years (1,184 GJ) (A Alcorn, 2010). When considering paint, the embodied energy of the maintenance of the TS roof over a 50 year period is $22,476 \mathrm{GJ}$, which is 5 times the embodied energy required in the maintenance of the SE roof. 


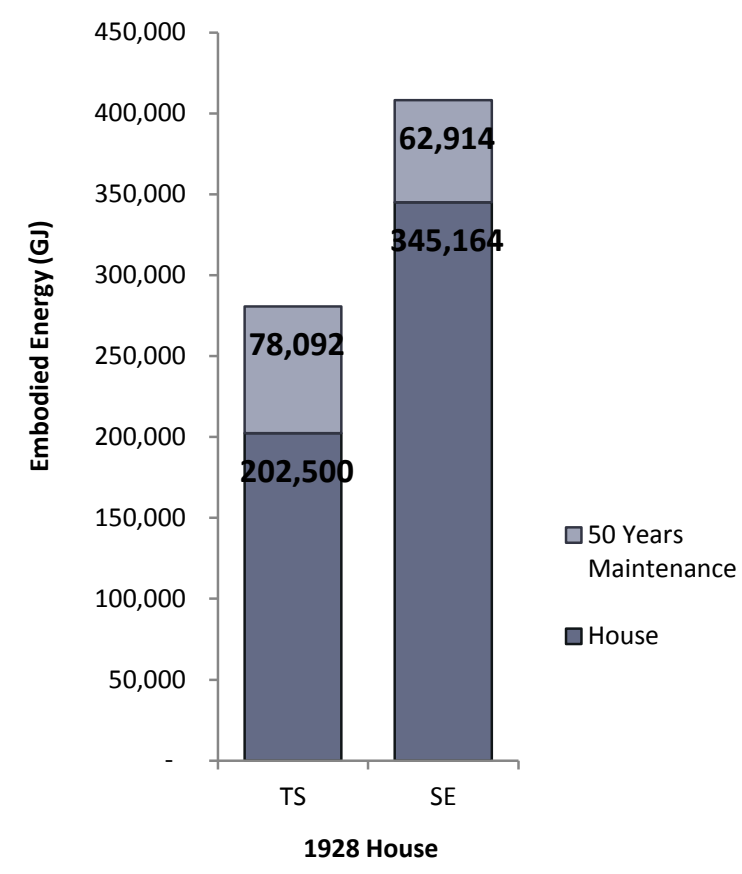

Figure 146: Embodied Energy (GJ) of the 1928 TS House and SE House plus 50 Years Maintenance

The average occupancy based on Census data was used to calculate the embodied energy per person of each of the houses in 1928. The embodied energy of the 1928 TS house was 59,828 GJ/person, and the embodied energy of the 1928 SE house 94,902 GJ/person (Figure 148).

In terms of the impact of each house on the natural environment, the TS house when constructed contained far less embodied energy than the SE house. This was despite each house containing a similar amount of accommodation and similar basic facilities. However the SE house could be prone to rain penetration due to the solid wall construction (section 4.4.1.2). 


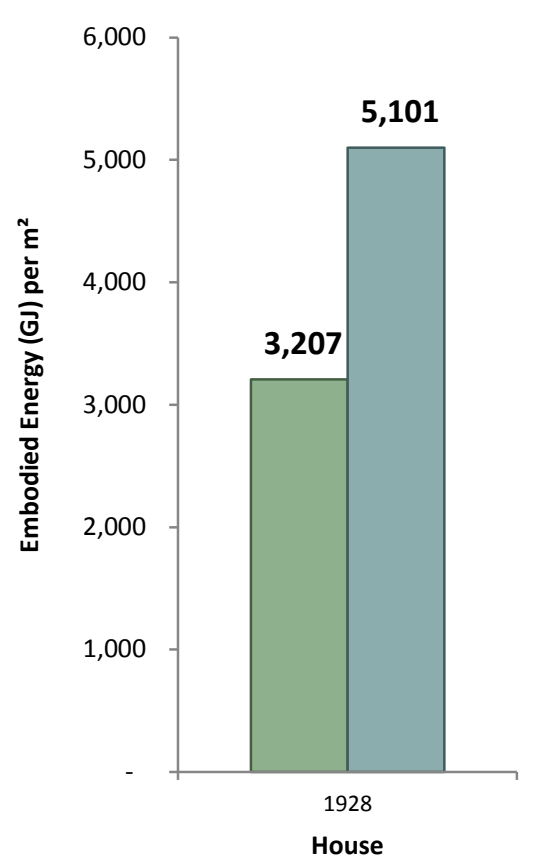

Figure 147: Embodied Energy $\left(\mathrm{GJ} / \mathrm{m}^{2}\right)$ of the 1928 TS House and SE House plus 50 Years Maintenance

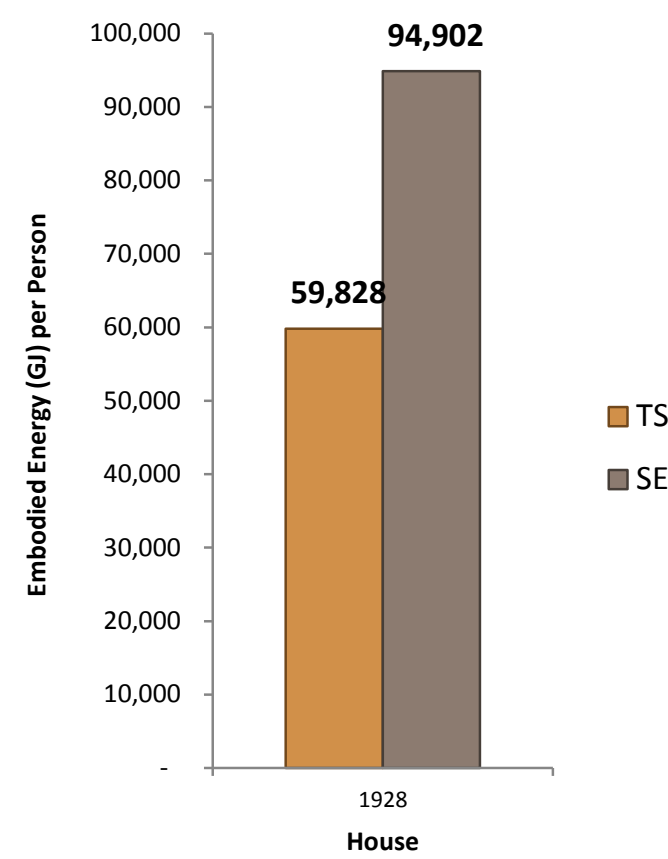

Figure 148: Embodied Energy (GJ/person) of the 1928 TS House and SE House plus 50 Years Maintenance

\subsection{Summary}

Lifestyles in 1930s and 1940s, when the TS and SE houses were new, were similar in New Zealand and England, even though the settlements were at opposite ends of the earth. Typically father worked full-time (27 (93\%) of the 29 interviewees' households) and mother was at home doing all the household tasks, as happened in 23 (79\%) households.

Life was centred on the home and the locality, with food delivered or from local shops (23 (79\%) of the interviewees recalled daily deliveries of milk and/or weekly deliveries of groceries and other household wares). The house was productive (19 interviewees (66\%) recalled their mothers sewing) with meals prepared at home from basic ingredients and the garden providing fresh vegetables and sometimes home grown fruit. The garden was generally looked after by the father in the family (16 (55\%) of interviewees' households). Children were expected to play outside (remembered by 14 (48\%) of the 29 interviewees) and away from the productive garden. 
The same lifestyles also had fewer possessions and fewer modern facilities. Of the 29 1930s and 1940s lifestyle interviewees, 15 (52\%) stated the family did not lock their doors, usually with the comment that there was nothing worth stealing.

Although the pre-cut TS house looks like a small traditional NZ villa, the SE houses were modern in their use of larger windows with horizontal glazing bars and flat roofs. Internally, the plans (TS house $87.5 \mathrm{~m}^{2}$ and SE house $80 \mathrm{~m}^{2}$ ) were similar in terms of the number and types of rooms provided and how these were typically used.

However, the materials of the houses made a difference to the embodied energy when constructed. The two storey load bearing brick house had a higher initial embodied energy $(345,164$ GJ compared to 202,500 GJ). Adding 50 years of maintenance brought the TS house to $280,591 \mathrm{GJ}$ or $3,207 \mathrm{GJ} / \mathrm{m}^{2}$ and the SE house to $408,078 \mathrm{GJ}$ or $5,101 \mathrm{GJ} / \mathrm{m}^{2}$, even though the energy embodied in the materials for maintenance of the TS house $(78,092 \mathrm{GJ})$ was greater than for the SE house $(62,914 \mathrm{GJ})$.

Chapter 6 considers the houses as they exist today and analyses the alterations which have taken place since they were constructed in 1928. The embodied energy of these alterations and maintenance are investigated and compared. 


\section{Chapter 6 - Comparative Study: The Houses Today}

This chapter explores the use of both the TS and SE houses by their present inhabitants. The embodied energy of the building materials invested in the houses since their construction is investigated and finally the impact of the different heritage requirements applying to each set of houses are discussed and compared.

\section{$6.1 \quad$ Time Use}

The TS interviewees were generally middle aged (70\% in their 30 s and 40 s), whereas the SE interviewees were both older and younger (33\% over 60 and 33\% under 30) (Figure 149). This is important as while some SE interviewees have lived in their house for many years, the comparatively low purchase cost in UK terms has meant that recently the houses have attracted young, first time buyers, "Silver End, with an overall average price of $£ 171,697$ was cheaper than nearby Cressing $(£ 247,476)$, Black Notley $(£ 248,980)$ and Kelvedon $(£ 260,122) "$ (Rightmove, 2014).

The TS household size is larger at 2.4 persons/household compared to $1.89 \mathrm{in} \mathrm{SE}$, but this is skewed by the larger number of old people living alone in the latter ( $29 \%$ of TS households are single person, compared to $44 \%$ at SE) (Figure 150).

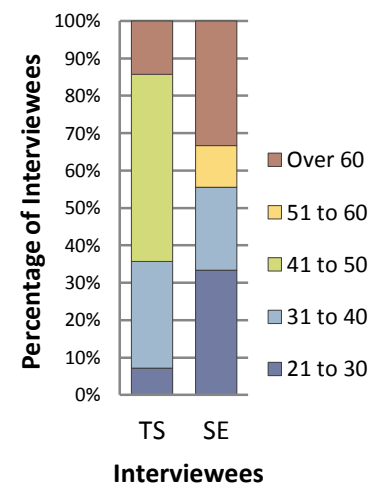

Figure 149: Age of interviewees (TS SE)

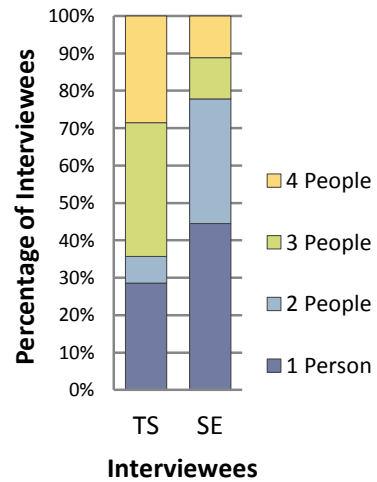

Figure 150: Number of persons per household (TS SE)

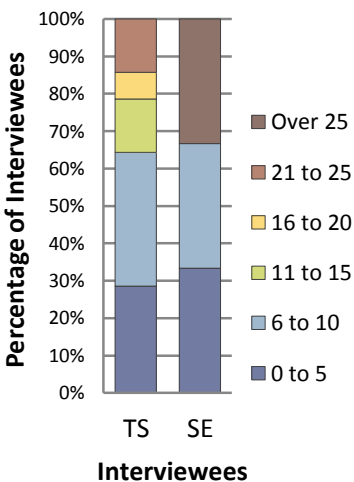

Figure 151: Number of years at this address (TS SE)

Of the 14 TS volunteer households, 9 (64\%) are families with one or two children, compared to only $2(22 \%)$ at SE (Figure 150 ). Approximately $65 \%$ of all interviewees in 
each group have lived in their houses for less than 10 years (Figure 151). Of the 9 SE volunteers, 3 (33\%) have lived in their house for over 25 years (all are aged over 60), whereas none of the TS interviewees have done the same. Only $1(8 \%)$ of the 14 TS volunteers is retired compared to $3(33 \%)$ at SE (Figure 152 ).

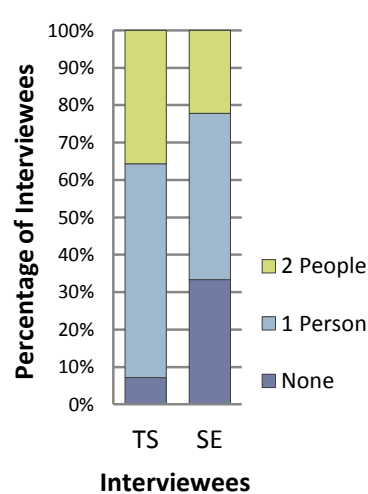

Figure 152: Persons per household engaged in full-time paid employment (TS SE)

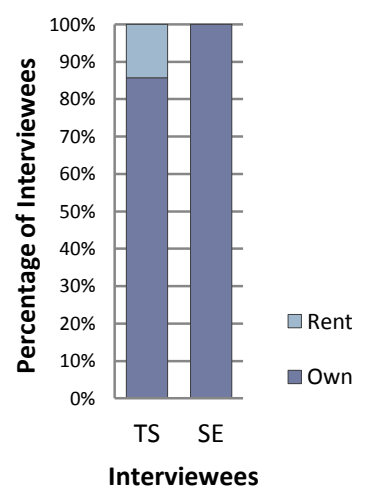

Figure 153: Home ownership (TS SE)

Home ownership is common in both groups with 12 (86\%) TS interviewees owning their houses, compared to all 9 (100\%) in SE (Figure 153). Of the first reasons given for choosing the house, location is common to both groups, however 6 (43\%) TS interviewees also mentioned the house (layout, style, appearance, condition), whereas none of the SE interviewees did (Figure 154). When all the given reasons are considered, location remains important for both groups but the house is more important for TS interviewees (56\% of all given reasons) (Figure 155).

Significantly, 8 (89\%) SE interviewees were born locally or regionally, compared to only $8(57 \%)$ of the 14 TS interviewees (Figure 156). The SE interviewees commonly mentioned wanting to live in the area and the modernist houses being considerably cheaper than houses in other local settlements. This is further illustrated by the fact that $26 \%$ of all SE reasons for buying the house were linked to available finances (Figure 155):

"...only place I could afford unfortunately...at the time it was about fifty thousand pound cheaper to buy a three bedroom flat roofed house in Silver End 
than what it was to buy a two bedroom house in another village..." [SE_06, $0: 02: 23]$

Inhabitants of the TS and SE case study houses were different. Typically, TS volunteers were young career professionals, with young families, and in some cases aspiring to move on to another house. The SE volunteers were retired people who had lived in SE for over 25 years, single professional people, or young couples who were living there because it was all they could afford.

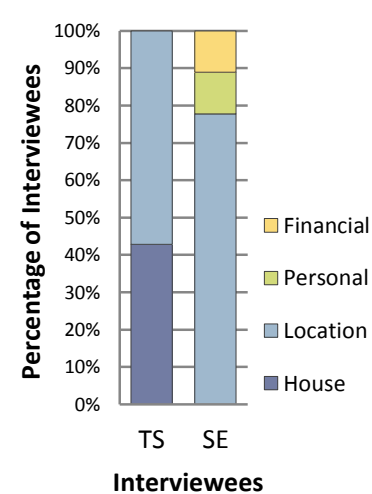

Figure 154: Reasons for choosing to buy or rent the house (first answer) (TS SE)

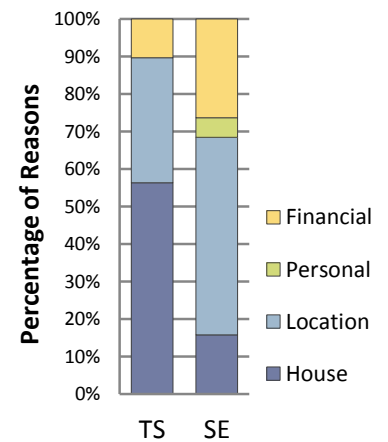

Interviewees

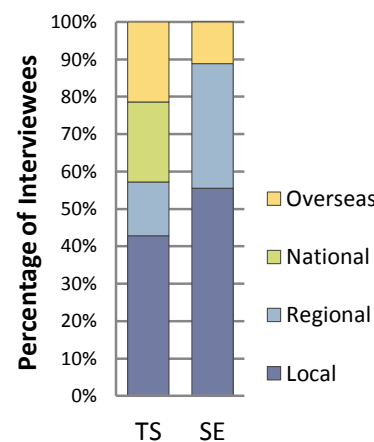

Interviewees
Figure 155: Reasons for choosing to buy or rent the house (all answers) (TS SE)
Figure 156: Birth zone of interviewees (TS SE)

\subsubsection{House}

Adults in all but $2(14 \%)$ of the volunteer TS households were in some form of paid employment. The exceptions were a retired person and a stay-at-home mother. In 5 (36\%) TS households, father worked full-time and mother part-time, and in the remainder all adults worked full-time. Similarly, in 6 (66\%) of the volunteer SE households, all adults were in full or part-time work, with the remaining 3 (33\%) households being retired people, with no stay-at-home wives or mothers.

The occupations of TS householders included accountants, solicitors, lecturers, teachers, ICT and other professionals. SE householders' occupations included an electrician, lecturer, government worker, ICT professional and members of the police. The SE interviewees appeared to spend more time at work than the TS interviewees 
(sections 3.2.1 and 4.2.1). This is reflected in answers to the question regarding the balance between work, family and recreation time (Figure 158), where $84 \%$ of the nonretired SE interviewees said they were doing too much work, whereas only $31 \%$ of the non-retired TS interviewees shared this opinion. Apart from the 4 retired households, the TS and SE case study houses were usually only occupied during weekday evenings/nights and for part of the weekend, with a number of houses left unoccupied for considerable periods of time.

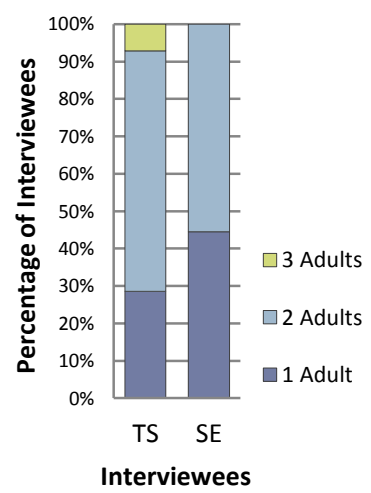

Figure 157: Number of adults per household (TS SE)

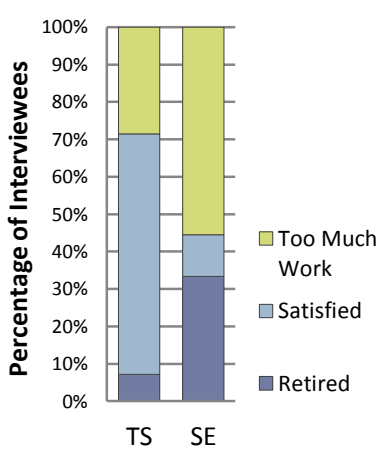

Interviewees

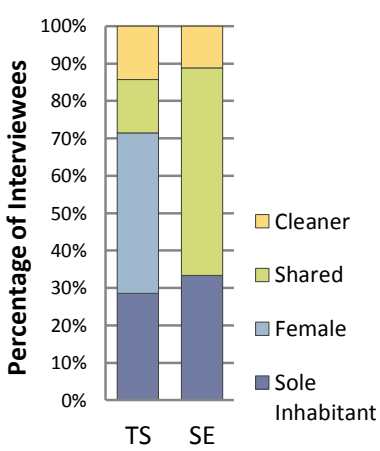

Interviewees
Figure 158: Balance between work, family and recreation time (TS SE)

For the TS interviewees, household work was solely done by the female member in $43 \%$ of the households, but was in the responsibility of the sole inhabitant in 4 (29\%) households, both female and male in $2(14 \%)$, and a cleaner in $2(14 \%)$. In the SE households, housework was the responsibility of the sole inhabitant in 3 (33\%) households, both male and female household members in 5 (56\%), and a cleaner in 1 (11\%) (Figure 159). In most of the volunteer households, all adults were engaged in some form of paid employment and as such, household work was often shared. This accords with a recent study that showed the ratio between the time all women and all men spend on all housework in America dropped from 6.1:1 in 1965 to 1.6:1 in 2009/10 (Bianchi, Sayer, Milkie, \& Robinson, 2012).

The time spent undertaking domestic chores varied between the TS and SE households (sections 3.2.1 and 4.2.1). TS interviewees often struggled to estimate the weekly time 
spent on household work, as much of it is automated [TS_01, 0:20:38; TS_03, 0:45:58]. One SE interviewee estimated spending four hours per week on housework [SE_03, 0:58:51], and another described not spending much time, only undertaking chores as and when required [SE_02, 0:36:12].

Similarly, the time spent in food preparation varies, depending upon household priorities. One TS volunteer stated they could take anywhere between 10 and 60 minutes to prepare dinner [TS_06, 0:49:45], while two others spent approximately 30 minutes a day on this [TS_03, 1:00:07; TS_10, 0:48:25]. One SE household spent as little time as possible cooking [SE_02, 0:38:54] whilst another did not want to spend lots of time cooking for one [SE_0:39:07]. A further SE interviewee said they either prepared a meal very quickly or would spend hours, depending upon what they were cooking and the time available [SE_06, 1:02:30].

The female in the household was not always responsible for food preparation, although this happened more in the TS volunteer households (Figure 160). In 3 (33\%) SE households males and females shared the cooking and the male was responsible in $1(11 \%)$, but noting a further $3(33 \%)$ households were single inhabitants. Interviewees from both groups mentioned eating a variety of dishes from different cultural backgrounds each week, involving rice, pasta and potatoes. Eating out was common for both TS and SE interviewees (Figure 161), echoing UK statistics that show in 2011 over a third of the total UK food budget, excluding alcohol, went on 'catering' (Defra, 2012, p. 16). 


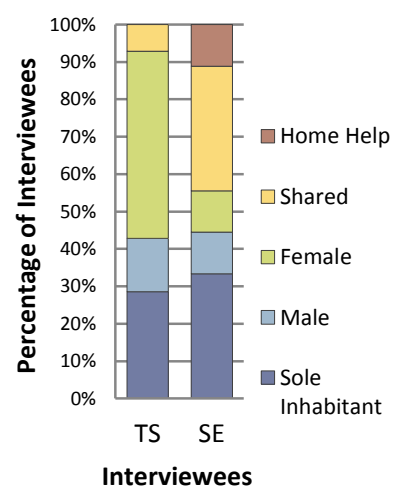

Figure 160: Person responsible for food preparation (TS SE)

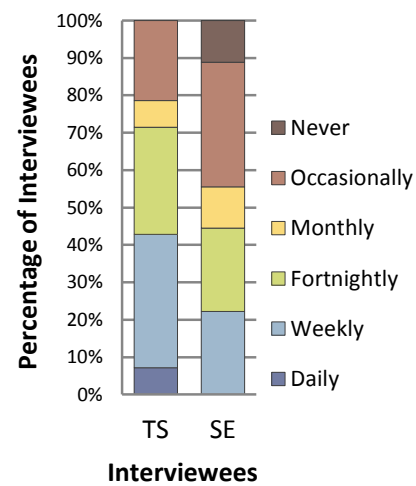

Figure 161: Frequency of eating out (TS SE)

Labour saving devices are common in many volunteer households, making housework easier, and allowing inhabitants to spend time on other activities. Every volunteer household had a washing machine, apart from one elderly person SE household whose clothes were washed by a family member. Dishwashers were more common in the TS households, with 13 (93\%) owning one, compared to 5 (56\%) of the SE households (Figure 162). Tumble dryers were also more common in the TS households, with 11 (79\%) owning one (Figure 163), 3 of which were used regularly (Figure 164). Of the 9 SE households, 5 (56\%) owned a tumble dryer and all were used occasionally when it was not possible to dry clothes outside or inside on a clothes horse (Figure 163 and Figure 164). Of the 23 TS and SE case study houses, 21 (92\%) had been fitted with showers, either over the bath, or in a separate shower cubicle. Water heating was in most cases instantaneous and daily showers appeared to be more popular than taking a weekly bath. A recent UK study showed the average Briton takes 4.4 showers/week and 1.3 baths/week (Smithers, 2013). 


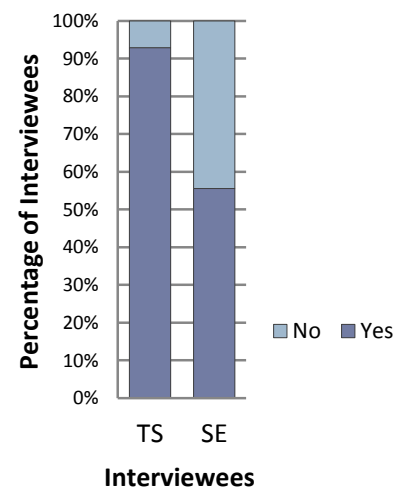

Figure 162: Households with a dishwasher (TS SE)

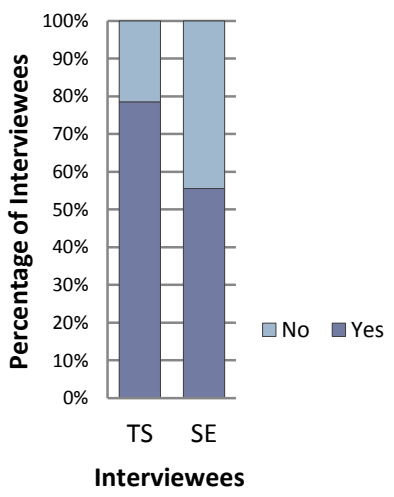

Figure 163: Households with a tumble dryer (TS SE)

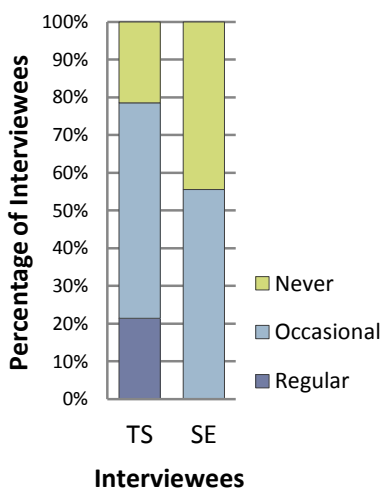

Figure 164: Frequency of use of a tumble dryer (TS SE)

Nearly all interviewees used the car for a weekly supermarket shop, often on the way to or from work. The exceptions were one TS interviewee whose weekly shopping was delivered, having been ordered online, and one SE elderly person household where a family member did the shopping. Similarly, the car was often used for travel to and from out-of-work or out-of-school activities.

TS and SE interviewees both stated a typical evening during the week was spending time at home with their immediate household members. Typical activities were cooking and eating dinner, bathing children, watching television and working. It was more common for interviewees from both groups to spend time with extended family or friends at the weekend than during the week.

Of the 14 TS interviewees, 11 (78\%) mentioned recent holidays abroad and 11 (78\%) had regular holidays in NZ. The TS volunteers appeared to holiday frequently, except for one couple who had spent the last few years investing time and money in renovating their house, and another family whose only holiday was visiting family. Of the 9 SE interviewees, 4 (44\%) mentioned recent holidays abroad and 3 (33\%) had regular holidays visiting family. The SE volunteers did not holiday as often as the TS volunteers possibly due to the lack of available time and/or funds. 


\subsubsection{Outdoor Space}

Vegetable gardening was popular amongst the TS interviewees, with 10 (71\%) of the 14 households growing vegetables. Of these, 6 (43\%) estimated growing less than $5 \%$ of all their consumed vegetables and 4 (29\%) between 5 and 10\% (Figure 165). In sharp contrast, only $1(11 \%)$ retired SE interviewee currently grew vegetables with 2 (22\%) others blaming the lack of free time for not doing this [SE_04, 0:36:00; SE_06, 0:45:20]. Fruit was grown in 11 (79\%) of the TS and $6(67 \%)$ of the SE gardens (Figure 166). In the TS gardens, apples, lemons, feijoas, plums and strawberries were mentioned more than once, whilst the SE gardens commonly contained apple trees and gooseberry bushes which, in many cases, were not planted by the current inhabitants.

In the TS households, garden maintenance was either undertaken by the sole inhabitant (14\%), the male member of the household (21\%), or was shared $(29 \%)$. In 5 (36\%) households a gardener was employed, or someone outside the household helped, commonly a family member (Figure 167). In 4 of these 5 households all adults were working full or part-time. The person responsible for garden maintenance in the SE households also varied, in $3(33 \%)$ it was the male, in $1(11 \%)$ the female and in another 1 (11\%) the task was shared. One elderly-person household received assistance with the garden as she was no longer physically able to care for it. More of the TS households employed gardeners than the SE households, possibly indicating higher levels of disposable income.

In both interview groups, 1 (7\% TS, 11\% SE) household kept chickens (Figure 168). This reflects a rise in poultry keeping in gardens, at least in the UK (Wallop, 2009). 


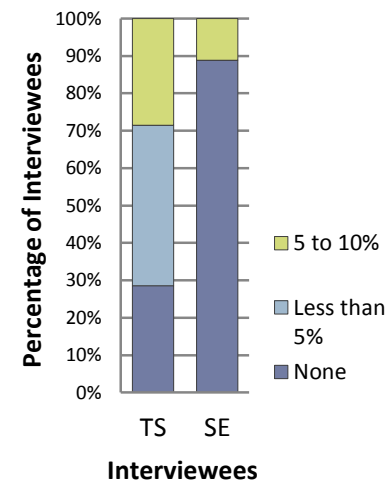

Figure 165: Percentage of

consumed vegetables grown at home (TS SE)

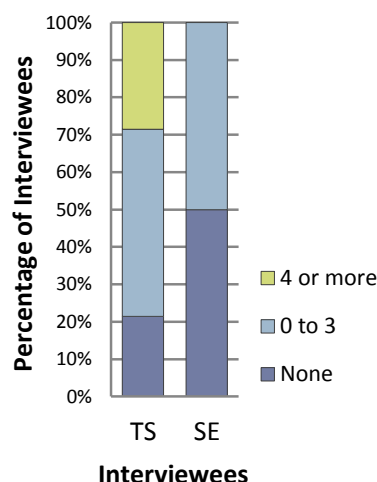

Figure 166: Number of different types of fruit grown at home (TS $\mathrm{SE})$

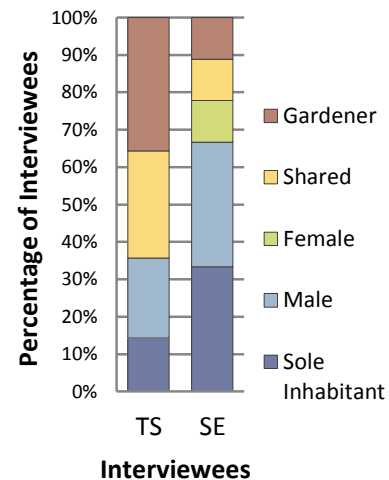

Figure 167: Person responsible for garden maintenance (TS SE)

Typically little time was spent gardening by inhabitants of the TS and SE houses, even though it is still considered pleasurable (sections 3.2.2 and 4.2.2). As previously discussed (sections 3.2.1 and 4.2.1), most adults in the TS and SE households work for money, and many of the SE adults work very long hours, which is a possible justification for not gardening much, although the preference for other types of recreational activity could also be a reason. However, this lack of time does not stop the ownership of gardening equipment, such as electric lawnmowers (Figure 170). Electric lawnmowers were common in both the TS and SE households and the 4 (29\%) TS households who did not own a lawnmower paid a gardener to mow their lawn.

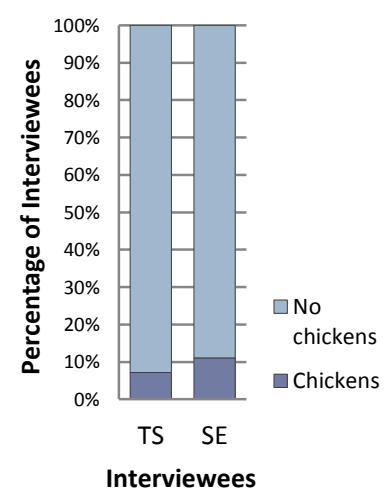

Figure 168: Percentage of interviewees keeping chickens at home (TS SE)

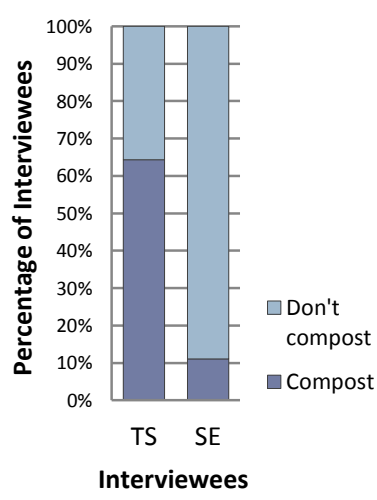

Figure 169: Number of

interviewees composting household waste (TS SE)

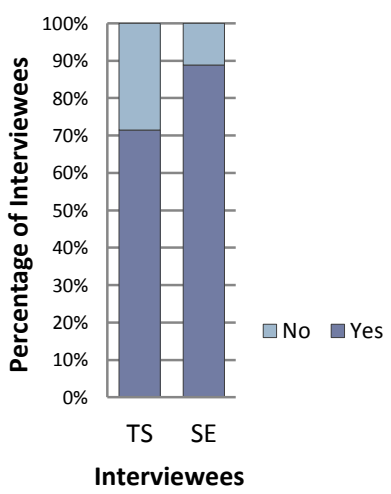

Figure 170: Households with an electric lawnmower (TS SE) 
Kitchen waste was composted by 9 (64\%) of the TS volunteer households, most commonly in a compost bin, but only by $1(11 \%)$ of the SE interviewees (the same interviewee also grew vegetables), although the remaining 8 (89\%) interviewees used the food recycling bin provided by the council (Figure 169). If the SE households do not have productive gardens, there is no particular need for compost.

As previously discussed (section 3.2.2), weather was the reason given by TS interviewees for not spending a lot of time outside [TS_06, 0:25:45; TS_10, 0:26:18], although one interviewee spent as much time as possible outside, normally amounting to one day a week [TS_12, 0:11:34]. Similarly, one retired SE interviewee preferred to be outdoors weather permitting and spent as much time as possible in the garden [SE_01, 0:25:01], whilst another retired SE interviewee spent about half an hour a day maintaining the garden [SE_05, 0:43:11]. Weather was mentioned by several SE interviewees as deterring them spending time outside, with 4 (44\%) being outside much more during the summer months. Of the SE interviewees who worked full-time, only $1(11 \%)$ spent a significant amount of time outside whatever the weather [SE_03, $0: 17: 29]$, and another mentioned spending about half a day a week during the summer maintaining the garden [SE_09, 0:07:24].

Of the 14 TS interviewees, 13 (93\%) mentioned making changes to their garden, with several having invested considerable time and money in landscaping work. In one TS household, the garden had been redesigned with the intention of making it low maintenance [TS_11, 0:23:25]. In contrast, only 6 (67\%) of SE interviewees mentioned changing their garden. One reason for this difference might be the topography of the gardens. The TS houses are on sloping sites and benefit from the introduction of retaining walls and steps, whereas the SE gardens are flat. When asked about planned future alterations, 4 (44\%) SE interviewees mentioned wanting to undertake work to their garden.

The garden was the main reason for choosing to buy the house for 2 (14\%) TS interviewees, and $2(14 \%)$ gave the deck and indoor/outdoor flow as the best thing about the house. Only 1 (11\%) SE interviewee mentioned the garden as a reason for choosing to buy the house, and $1(11 \%)$ gave the garden as one the best things about 
their house, suggesting the garden was not the main attractor for either volunteer group.

Double doors to the rear, installed since the house was built, were present in 11 (79\%) of the TS houses, commonly opening onto a deck or area of hard landscaping, and many interviewees mentioned these doors were open in good weather. Similarly, there were double doors to the rear in $8(89 \%)$ of the 9 SE houses and in $7(77 \%)$ a rear ground floor addition had been constructed, most commonly a conservatory or sun room, reflecting a desire for connection with the rear garden and outside world. One elderly SE interviewee mentioned installing patio doors in the main room at the rear of the house, "...it was always light enough, it was just a fashion thing I think, something that we fancied doing, so that you could walk from here into the garden and feel part of the garden..." [SE_01, 0:27:35].

Play equipment such as trampolines, sand pits, tree houses and rope swings are a feature in many TS gardens. Today, cars make it dangerous for children to play in the street and this public space is dominated by the car in both interview groups. None of the TS interviewees mentioned their children playing in the street.

Most TS and SE interviewees appeared to appreciate having a good sized garden, although few spent much time outside (apart from the retired interviewees and those undertaking DIY landscaping work). The garden today seems to be a desirable, although not often used asset, but the view of it from inside the house is important to many. This highlights the modern preference for different types of recreational activity, but is also indicative of the lack of free time for gardening, as expressed by several SE interviewees (section 4.2.1).

\subsection{Space Use}

\subsubsection{House}

Average occupancy in the 1996 NZ Census was 2.77 persons per dwelling (Statistics New Zealand, 1998, p. 45) and 2.64 in this survey of 14 households, none of which contained more than 4 inhabitants (Figure 171). Similarly, in the 2011 UK Census the 
average occupancy was 2.3 persons per dwelling (Office for National Statistics, 2013), and 1.9 in this survey. The TS and SE houses, although originally designed to be inhabited by families, are no longer solely occupied by these, with 4 (29\%) of the TS volunteer households being single persons along with 4 (44\%) of the SE households and only 2 (22\%) of the latter having over 2 people.

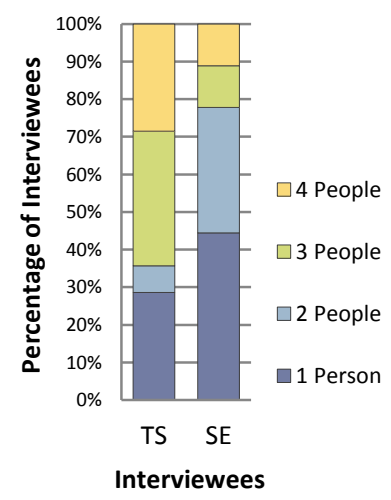

Figure 171: Number of persons per household (TS SE)

In $13(93 \%)$ of the 14 TS houses, the original parlour is now the master bedroom and in all these cases the original bedroom 3 has another function, such as a dining area, television room or study. In only 1 (7\%) of the TS houses, inhabited by a single person, did this front room bear any resemblance to the original parlour. In most TS houses, what were originally bedrooms 1 and 2 were still bedrooms, but now have only one occupant. It would appear that in the TS households, a 'best' sitting room separate from the living area is no longer needed, or that having a larger bedroom is more important for those living there. The two storey SE houses remained unchanged in that the ground floor rooms function as the public rooms (living room, kitchen and dining room), with the bedrooms located on the more private first floor. This division in the planning is less clear in the single storey TS houses where room functions are more flexible.

The spare room was a feature of several TS houses, primarily those occupied by single people and couples with one or no children (section 3.3.1.3). Because of the low occupancy levels, only one of the three original bedrooms was used for sleeping on a 
regular basis in 7 (78\%) of the SE houses (section 4.3.1.5). Some of the latter had a spare bedroom as a space for overnight visitors and also an upstairs study [SE_02, 0:12:50; SE_09, 0:02:44]. Today, the computer is an important method of communication, and all of the TS households owned a desktop computer, a laptop, or another portable device, compared to $7(77 \%)$ of the 9 SE households.

Only 3 (21\%) of the TS houses have retained the original floor plan ( 2 of which are rented), and in the remaining $11(79 \%)$ the back of the house has been remodelled to incorporate a larger kitchen area accommodating cooking, food storage and washing facilities (section 3.3.1.4). In these houses, the kitchen zone is where cooking takes place as part of an open-plan kitchen/dining/lounge area. In the SE houses, the original kitchen/living room is typically a dining area, and the scullery has been remodelled as a fitted kitchen incorporating cooking, food storage and clothes washing facilities (section 4.3.1.6).

In $6(66 \%)$ of the SE houses, the small rooms which were once the larder and fuel store have been removed to make the kitchen area larger. Unlike the TS houses which have been remodelled with one large zoned open-plan living space, the SE houses commonly have three separate downstairs rooms used as a kitchen, dining and living room. Of the 9 SE houses, 7 (77\%) have a ground floor addition to the rear of the house, and in most cases, this is a conservatory or sun room, reflecting both the desire for more space and connection with the rear garden.

Bathrooms in most TS houses studied have been remodelled as part of the creation of the open plan living area. In 4 (29\%) cases the bathroom was now in the original bedroom 2, bringing it into the centre of the house (section 3.3.1.5). In 11 (78\%) TS houses, the toilet was in the bathroom, and in 12 (85\%) a shower had been fitted, either over the bath (in 6 cases) or in a separate cubicle. Recessed lights and modern fittings and fixtures were a common feature in 9 (64\%) of the TS remodelled bathrooms. Similarly, 8 (89\%) SE houses have remodelled bathrooms, and in 7 (77\%) the original bathroom and toilet have been knocked into one room, creating more space and allowing a shower cubicle to be installed in some cases. 
The original TS houses were designed with a detached outhouse containing the coal store, toilet and clothes washing facilities (section 3.3.1.6). Original outhouses remained in 10 (71\%) of the interviewees' gardens, but their function had changed to become a storage space for bicycles, household and gardening tools. In the original SE Stuart houses, the copper was located in the corner of the scullery (J. Stuart, 1928) and has since been replaced by the washing machine and tumble dryer, which in all cases are located in the kitchen.

It would appear from the TS interviews that the house is perceived as being malleable (section 3.3.1.7). In contrast, one SE interviewee said, "...I've got to say, these houses...they're not easy to work on, you can't chase the walls very easily... because you've got no loft, you can't get everything up and across the loft space..." [SE_01, 0:42:29]. Only 1 (11\%) of the SE houses had been significantly altered (to create a large downstairs bathroom and new kitchen within in a ground floor extension), with the remaining 8 (89\%) keeping the original internal walls.

When asked about significant moments in recent years, 3 (21\%) TS and 2 (22\%) SE interviewees mentioned buying or undertaking work to their house. This refurbishing and modernising to suit their functional and aspirational lifestyle would appear to be both enjoyable and rewarding for many interviewees, and 1 (7\%) TS couple and 2 (22\%) SE couples mentioned not going on holiday in recent years, but rather choosing to invest time and money in their houses.

Of the 14 TS interviewees, 6 (43\%) felt the small size of the house was one of the worst things about it, and $3(21 \%)$ mentioned the lack of storage space. Storage space has been increased through fitted wardrobes in bedrooms of $3(21 \%)$ of the TS houses and loft ladders have been installed in often widened loft hatches. Outhouses, as stated, are used for storage and space beneath the houses utilised for the storage of outdoor equipment. One TS interviewee explained that the deck was an attempt to create more space, acting as an additional living space (section 3.3.1.8). Opinions differed about the size of the smaller houses in Silver End, one single person living in an SE Stuart house thought the kitchen was too small [SE_02, 0:04:33], another that their main room downstairs was just the right size for two people [SE_03, 0:04:25], and a 
third felt the house was too small, even for two people [SE_09, 0:14:04]. The lack of storage space within the SE houses was mentioned by several interviewees, although none stated that this was one of the worst things about the house, with the conservation area status, windows and flat roof being the primary dislikes. For one interviewee, Christmas decorations and other possessions were stored by a family member [SE_06, 0:27:20], whilst another had two sheds in the rear garden for storage [SE_09, 0:06:25].

Of the 14 TS interviewees, 13 (93\%) felt safe in their house, and the remaining interviewee felt safe most of the time. All TS interviewees mentioned locking their doors, but only 1 (7\%) had a security system. Similarly, 8 (89\%) of the 9 SE interviewees felt safe in their house, and the remaining interviewee was not happy when her male partner was working a night shift. Similarly, all SE interviewees kept their doors locked, $2(22 \%)$ had a security system, and another $1(11 \%)$ wanted to get one.

The TS and SE houses are today, to a greater or lesser extent, places for eating, resting or sleeping and storage, in many cases being uninhabited for large parts of the day and week (section 3.2.1). When at home inhabitants spend much more time in the house than in the garden (section 3.2.2) and the house seems to be a place for storing consumer goods and using technology such as televisions and computers for recreation and relaxation. Retired occupants in both the TS and SE interview groups appeared to enjoy their gardens the most.

\subsubsection{Outdoor Space}

Many TS and SE interviewees have erected fences around their rear gardens to contain children or animals and make their property more secure. Timber decks and retaining walls are also features of many TS rear gardens to create flat areas and bring order to the original sloping sites. When asked about alterations to the house and outdoor space, 13 (93\%) TS interviewees mentioned work to the garden, the most common answer. Of the 9 SE interviewees, 6 (67\%) also mentioned work to the garden, following internal decoration (78\%) and replacement of bathroom fittings (78\%). 
When asked about planned future alterations, 4 (44\%) SE interviewees would like to undertake work to their garden, in three cases landscaping and planting and erecting new fences in the other (section 4.3.2.1).

Of the 9 SE gardens, none had a vegetable plot, although $1(11 \%)$ interviewee grew vegetables in an adjacent allotment, compared to 12 (71\%) productive TS gardens. However, the area set aside for vegetables in the latter is generally no more than $2 \mathrm{~m}^{2}$. As discussed in section 5.2.2.1, far more time is being spent inside the house than in the garden making it important that gardens are easy to maintain.

As previously mentioned (section 5.2.2.1) the function of the original TS washhouse has moved inside the house, usually in the form of a cupboard in the bathroom containing a washing machine and tumble dryer. Of the 9 SE interviewees, 4 (44\%) have built or altered outbuildings involving the construction of a large concrete shed, and the erection of a summer house (also used as a place to dry clothes during the winter) and a greenhouse. As previously discussed (section 4.3.1.10), in some cases garden structures are used for storage to compensate for the lack of this in the house.

The introduction of double doors to the rear of the TS houses for connection between the internal and external spaces has resulted in areas of hard landscaping (usually a timber deck) at the rear (section 3.2.1). There would appear to be a strong desire amongst TS inhabitants to enjoy the garden, whilst at the same time being sheltered from the elements. The sun room or conservatory at the rear of 7 (77\%) of the SE houses is also often accompanied by an area of hard landscaping. Washing lines are found in most TS and SE gardens.

Of the 14 TS households, 13 (93\%) had one car and none had more. This was similar in the SE households, where $8(89 \%)$ had at least one car, and $3(33 \%)$ had two (Figure 172). In 7 (50\%) TS households, at least one member used public transport regularly, with $2(14 \%)$ never using it and the remainder using it occasionally. In contrast, 7 (78\%) of the SE interviewees never used public transport, and 2 (22\%) used it occasionally (Figure 173). The greater TS use could be attributed to the nearby electric suburban rail link to the $\mathrm{CBD}$, since the original houses were built to be close to the 
railway. However both Silver Street and Broadway are on the local bus route. Many SE interviewees felt public transport was both inconvenient (in terms of timing and frequency) and expensive, and one stated that running a car was cheaper than using public transport, even with the cost of fuel [SE_03, 1:16:55].

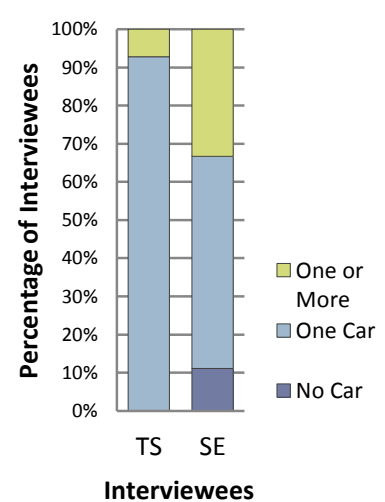

Figure 172: Number of cars per household (TS SE)

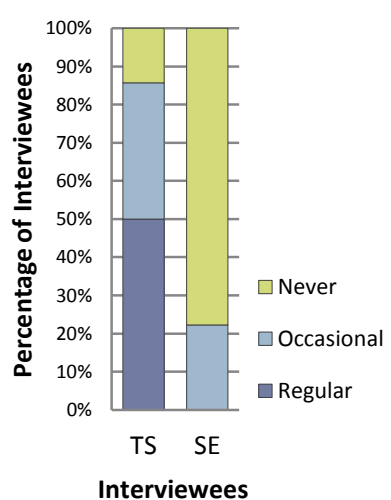

Figure 173: Use of public transportation (TS SE)

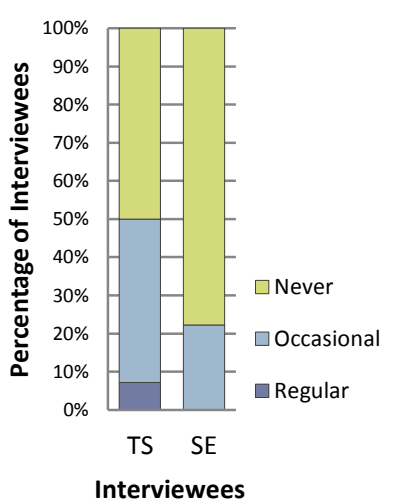

Figure 174: Number of households where bicycles are used regularly (TS SE)

Of the TS households, 7 (50\%) had bicycles for recreational purposes, but only 1 household had a bicycle for regular commuting (Figure 174). In contrast, only 2 (22\%) of the SE volunteer households had bicycles and in both cases these were used occasionally. Driveways to the front of many of the TS and SE houses now occupy space once dedicated to garden area. In both the Tarikaka Settlement and Silver End, cars line both sides of the road outside the houses, and in the latter many are parked upon the grass verges, to the detriment of the visual appearance of the public areas.

\subsection{Energy Use}

\subsubsection{House and Outdoor Space}

The primary method of space heating used solid fuel in 7 (50\%) of the TS houses (57\% of which had access to free wood). However, the solid fuel burner was generally in the living room and may have had limited ability to heat the rest of the house. This contrasts with the potentially thermally more comfortable SE houses where 8 (89\%) had gas fired central heating with radiators in most rooms (Figure 175 and Figure 176). 


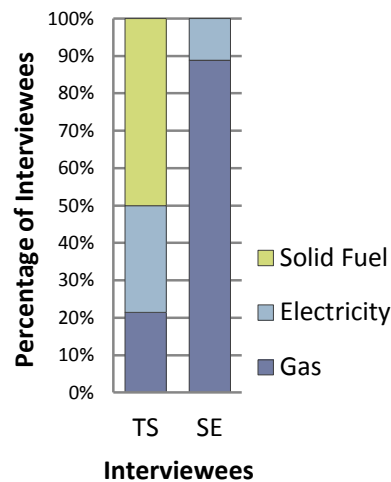

Figure 175: Fuel used in the

primary method of space

heating (TS SE)

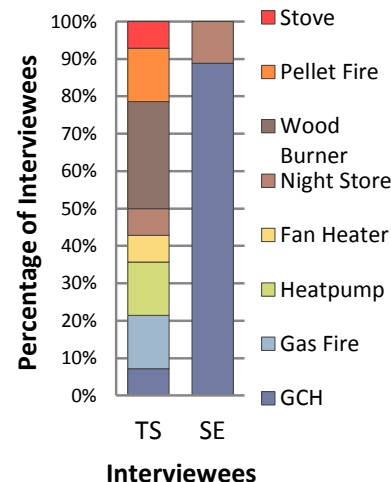

Figure 176: Primary method of space heating (TS SE)

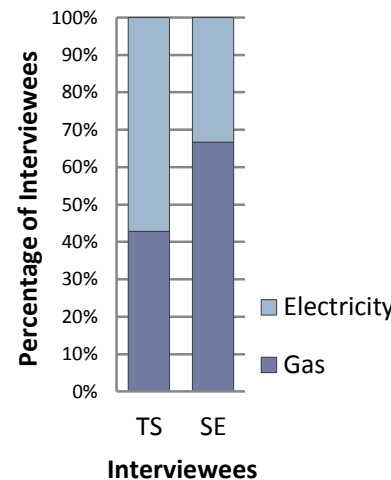

Figure 177: Fuel used in the primary method of water heating (TS SE)

Of the 14 TS households, 11 (79\%) used an additional method of space heating including fan heaters (14\%) and oil filled radiators (64\%), commonly located in bedrooms. In the TS houses, gas played a much smaller role, with $43 \%$ ( 6 households) using gas for water heating, compared to $67 \%$ (6 households) in the SE sample (Figure 177 and Figure 178).

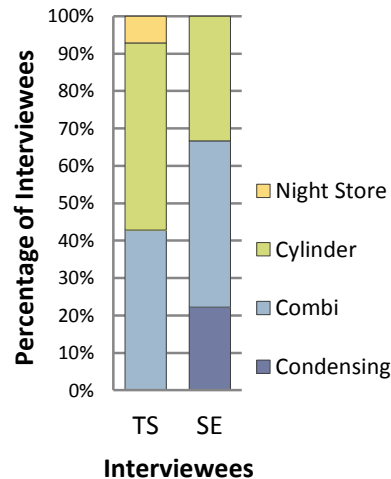

Figure 178: Primary method of water heating (TS SE)

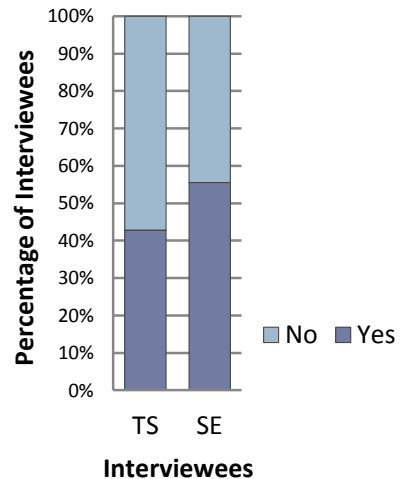

Figure 179: Households with timer controlled space heating (TS SE)

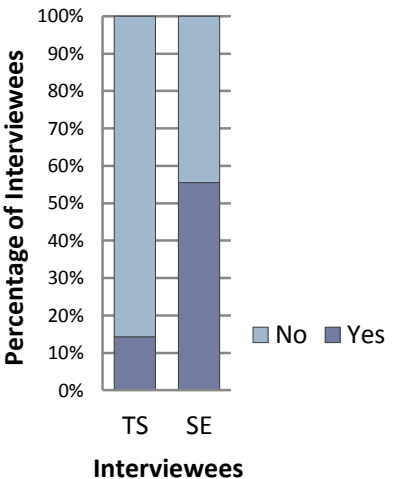

Figure 180: Households with temperature controlled space heating (TS SE)

Timer controlled space heating was slightly more common in the centrally heated SE houses (Figure 179). Typically, in both TS and SE groups, the houses were heated early morning and late afternoon/early evening during the week and during the weekends when people were at home. In 5 (56\%) SE houses the gas fired central heating was 
programmed to switch on if the internal air temperature dropped below a set figure, whereas only $14 \%$ of the TS houses utilised temperature as a means of controlling space heating (Figure 180):

"...because we both work full-time, it [the house] can be empty twelve hours a day...if you get home at say eight o'clock at night, by the time you then try to heat the house up, you're probably going to bed, so we put it on a timer, even if it's on a low temperature...it means there's a bit of warmth in the house..." [SE_03, 0:09:25].

Despite the different climates (TS 1,718 degree days to $18^{\circ} \mathrm{C}$ and SE 2,935 degree days to the same base) (BizEE Software Limited, 2013), the average household fuel costs were similar at $£ 1,082$ /annum in TS houses, despite the free wood, and $£ 1,249$ /annum in SE (Figure 181) (conversion based on 0.51GBP to 1NZD from xe.com on $4^{\text {th }}$ July 2013). This underlines the comparative cheapness of gas as a fuel in the UK, coupled with efficient heating systems based on combination or condensing boilers. However, many interviewees expressed concern about the cost of heating with the majority actively working to reduce costs, "...it does feel cold sometimes...in the winter, we'll make sure the bedroom doors are kept shut, the curtains are shut early to try and keep the heat in, things I suppose you wouldn't do in a more modern house..." [SE_07, 0:09:01].

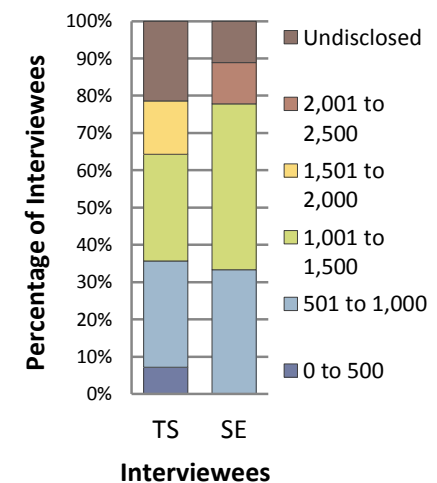

Figure 181: Household fuel cost (GBP per annum) (TS SE)

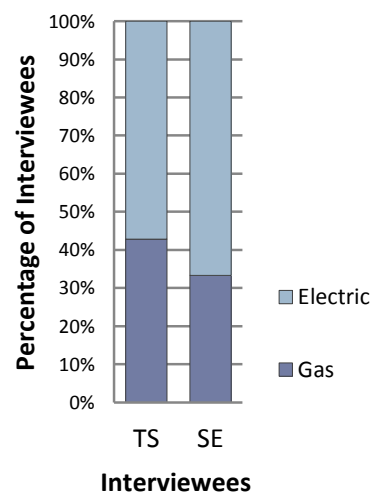

Figure 182: Fuel type for oven (TS SE)

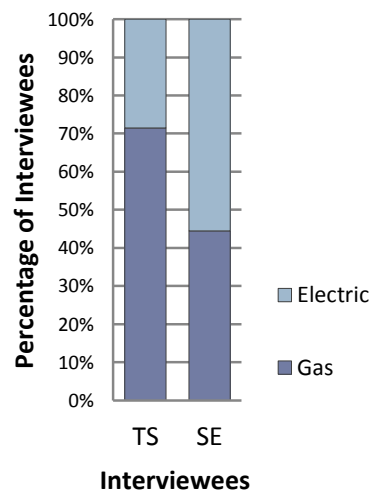

Figure 183: Fuel type for hob (TS SE) 
A huge variation in people's comfort standards emerged, and as such, average household fuel costs varied greatly (Figure 181). Converting all the fuel costs to GBPs, in the TS group, 1 (7\%) interviewee who was a recipient of free solid fuel and only heated one room in the house estimated spending less than 500GBP per annum on fuel, yet 2 (14\%) TS interviewees thought they spent between 1501 and 2000GBP per annum. In the SE group, 3 (33\%) interviewees estimated spending between 501 and 1000GBP per annum on fuel, and 1 (11\%) between 2001 and 2500GBP per annum.

All TS and SE houses contained a range of household appliances such as a fridge, freezer, dishwasher, washing machine and vacuum cleaner. One SE interviewee mentioned investing in energy efficient appliances [SE_06, 0:41:12]. Of the 14 TS households, $6(43 \%)$ had a gas oven and $10(71 \%)$ a gas hob. Fewer SE households used gas for cooking, as 3 (33\%) had a gas oven and 4 (44\%) a gas hob (Figure 182 and Figure 183). Many interviewees, especially those with young children (see quotation below) or work uniforms, washed clothes often, "...I'm pretty sure that I'm washing more than once a day...I try and do it in the morning because then I can hang it out, and it dries during the day, rather than using the dryer..." [TS_06, 0:38:21]. As previously discussed (section 5.2.1.1), 11 (79\%) TS interviewees owned a tumble dryer, compared to 5 (56\%) SE interviewees, but of these, most only used it when necessary. Interviewees with a dishwasher, 13 (93\%) TS households and 5 (56\%) SE, tended to use this daily.

Numerous alterations have been made to the TS houses, the most common being work to the garden (93\%), followed by installation of insulation (79\%) and internal decoration (79\%) (Figure 184). Painting externally and new or altered outbuildings have been undertaken by $64 \%$ of interviewees, and over $50 \%$ have replaced windows and external doors (particularly those to the rear garden), installed additional lighting and/or sockets and made improvements to the space and water heating systems. A further $50 \%$ have replaced kitchen fittings and $50 \%$ have altered the internal layout by reconfiguring internal walls. The SE houses have also been altered by the current inhabitants, but the pattern is different, the most common alteration being replacement of bathroom fittings (78\%), followed by renewal of the roof covering 
(67\%), improvements to space and water heating systems (67\%), installation of additional lighting and/or sockets (67\%) and work to the garden (67\%) (Figure 184). Of the 9 SE interviewees, 5 (56\%) have repaired the external render and/or paintwork, whilst 4 (44\%) have installed insulation and 4 (44\%) have worked on new or altered outbuildings.

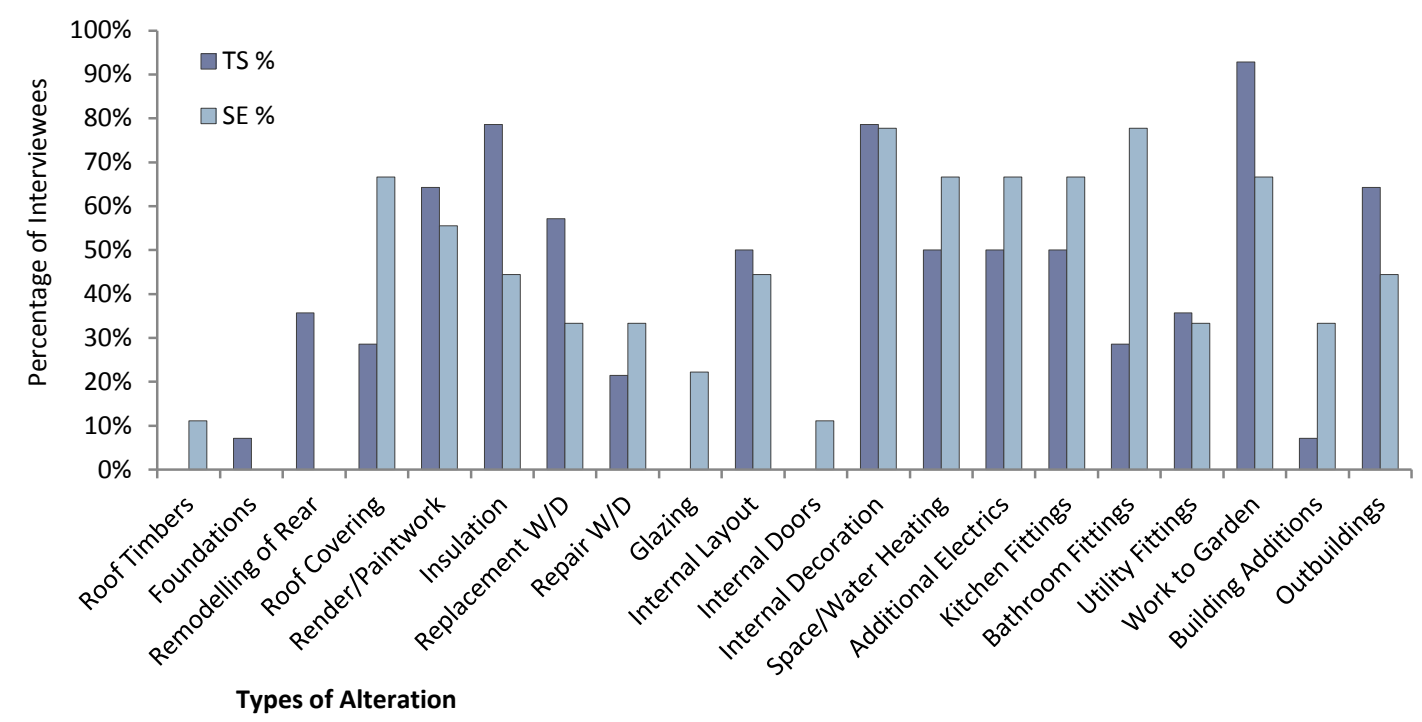

Figure 184: Alterations undertaken by the TS and SE interviewees

In comparing the alterations, the materials and methods used in the construction of the houses become important. Installing insulation in the timber frame TS houses is relatively straightforward given the easy access to the pitched roof and piled foundations, unlike the SE two storey masonry flat roofed houses with no underground floor access except by removing floorboards. As a result, 79\% of TS interviewees have installed insulation, compared to only $44 \%$ of SE (Figure 184). The interviews revealed that installing insulation is of high importance to both groups, but that construction materials, methods and external rules limit the ability of home owners to insulate their houses satisfactorily.

Of the 14 TS interviewees, 4 (29\%) have replaced the corrugated iron roofing, which is expected to have a 50 year life (A Alcorn, 2010, p. 326), whilst 5 (67\%) of the 9 SE interviewees have replaced the built up felt roofing with an expected 15-25 year life (Brinsmead, 2009). Of the 9 SE interviewees, 6 (67\%) would like to replace all their 
single glazed windows and external doors, but only 3 (33\%) have managed to replace any, due to conservation area restrictions and the prohibitive cost of approved window types, "...we're trialling some techniques, methods to try and help with damp and mould, 'cause unfortunately, changing the windows is...very expensive...so we're seeing if we can work our way around it..." [SE_03, 0:14:15], "...we'd love double glazing...actually the biggest issue we've got with the house is the windows..." [SE_09, $0: 10: 10]$

Of the 14 TS interviewees, 8 (57\%) have replaced windows and external doors to the rear of their houses as part of remodelling the interior. The original windows and doors to the front and sides have been reasonably well maintained, and 3 (21\%) TS interviewees have repaired windows. As special permission is required to replace original windows to the front and sides with double glazed units (section 3.1.2), none of the TS interviewees have done this.

As previously discussed (section 3.4.1.5), 7 (50\%) TS interviewees had remodelled the internal layout by changing the rear of the house and creating an open plan living/kitchen/dining area. Only 1 (11\%) SE interviewee had significantly altered the internal layout of their house, with the timber frame, single storey TS houses appearing more malleable in this respect. Of the 14 TS interviewees, 11 (79\%) had decorated their houses internally, as had a similar percentage of SE interviewees (78\%). Improvements to the space and water heating systems and the installation of additional lighting and/or electric sockets, had been undertaken by significant numbers in both groups.

The findings illustrate that energy renovations (installation of insulation, replacement of single glazed windows and external doors, and upgrading of space and water heating systems) are important to both sets of interviewees, although the ability to undertake this work is dependent upon available finances and the heritage or conservation status requirements. These types of alteration, together with essential maintenance, such as repair or replacement of the roof covering or external render, are found commonly in the two groups. 
Alterations to the internal layout and decoration are more common in the TS houses, as are work to the garden and new or altered outbuildings, perhaps indicating not only differing levels of disposable income, but also the amount of free time to undertake such work. Only $31 \%$ of non-retired TS interviewees felt that they were working too much, compared to $83 \%$ of non-retired SE interviewees, which may explain why TS inhabitants have more time to work on their houses. Similarly, 10 (71\%) TS interviewees grew vegetables, compared to only 1 (11\%) SE interviewee, the latter interviewee group often stating it was lack of time rather than desire that prevented them from doing this.

A number of interviewees from both groups have personally undertaken work on their houses or received assistance from skilled family members and friends. One SE interviewee re-wired the house [SE_03, 0:08:10] and another asked his father to fit new radiators [SE_06, 0:11:42]. At least 2 (14\%) TS interviewees installed insulation themselves [TS_04 0:06:12 and TS_11 0:18:00], whilst none of the SE interviewees have been able to insulate the flat roof or under floor area without employing a trades person, indicating the TS houses are easier to work on.

Sections 3.3.2.1 and 4.3.2.1 discussed the alterations carried out to rear gardens by the TS and SE interviewees. However, the energy implications of these are not investigated further in this research.

\subsubsection{Embodied Energy Comparison}

Figure 185 illustrates the increase in the embodied energy of the typical TS house from its construction in 1928 to 2012 and Figure 186 illustrates the same data for the typical SE house. 


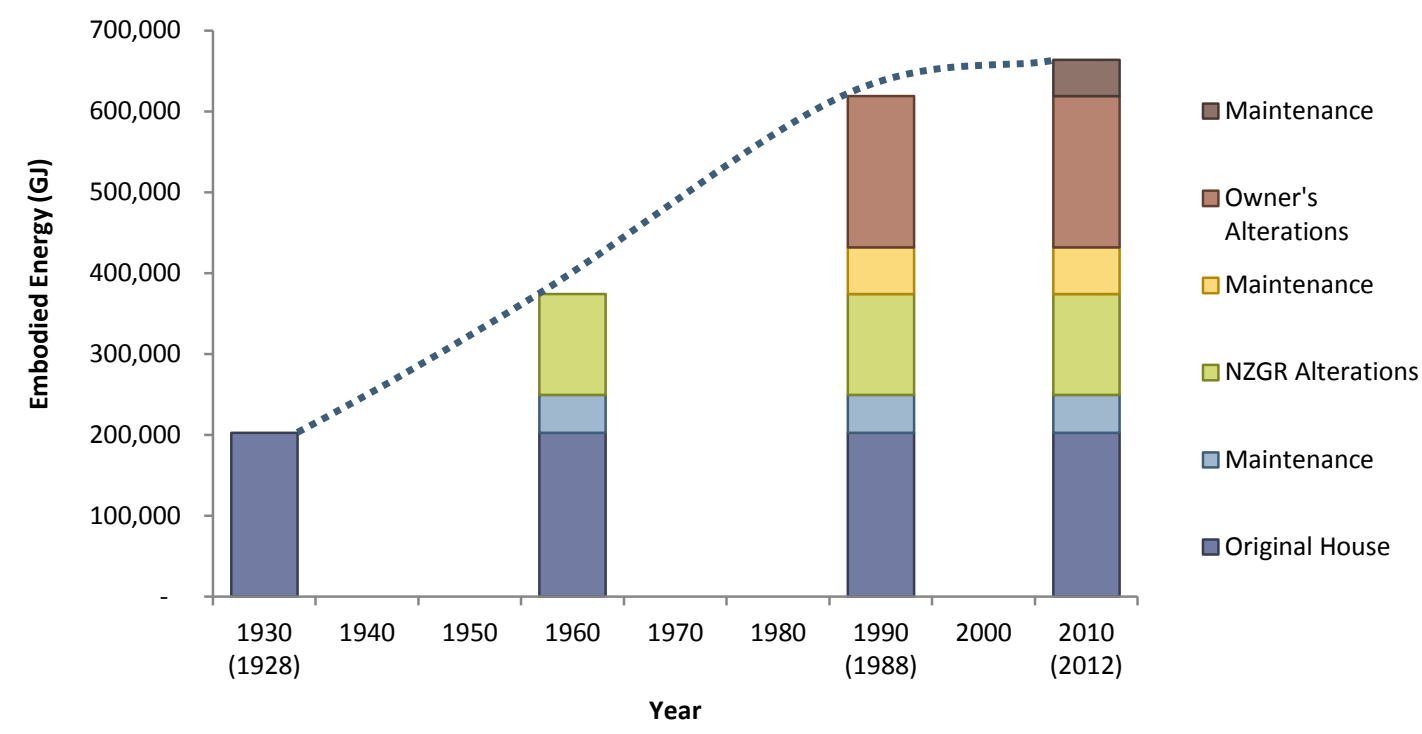

Figure 185: Increase in Embodied Energy (GJ) of the TS House from 1928 to 2012

The building materials of the original 1928 TS house are $31 \%$ of the total cumulative embodied energy. NZGR alterations in 1960 represent 19\% and owner's alterations post-1988 a further $28 \%$. Although maintenance seems significant, amounting to $23 \%$ of the total cumulative embodied energy, this is spread over the approximate 80 year life of the house.

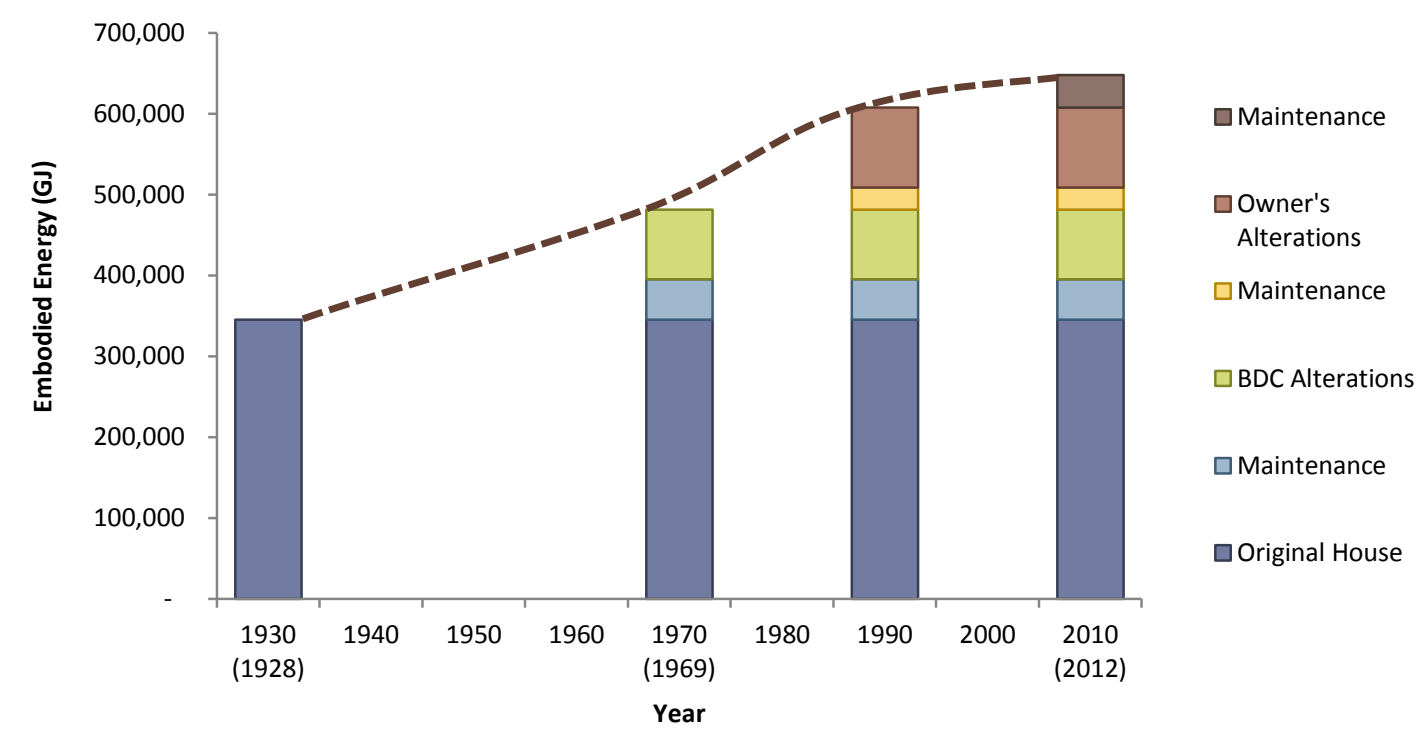

Figure 186: Increase in Embodied Energy (GJ) of the SE House from 1928 to 2012

In contrast, the building materials of the original 1928 SE house are $53 \%$ of the total cumulative embodied energy, much greater than the TS house. BDC alterations in 
1969 represent $13 \%$ and owner's alterations post-1990 a further $15 \%$ which are both less than the alterations to the TS houses undertaken at a similar time. The embodied energy of maintenance is less than the TS house, with less exterior painting (walls but not roof), but is still significant amounting to $18 \%$ of the total cumulative embodied energy over the 80 year period.

Figure 187 shows the embodied energy (GJ) in the building materials of the TS and SE houses from construction in 1928 to 2012.

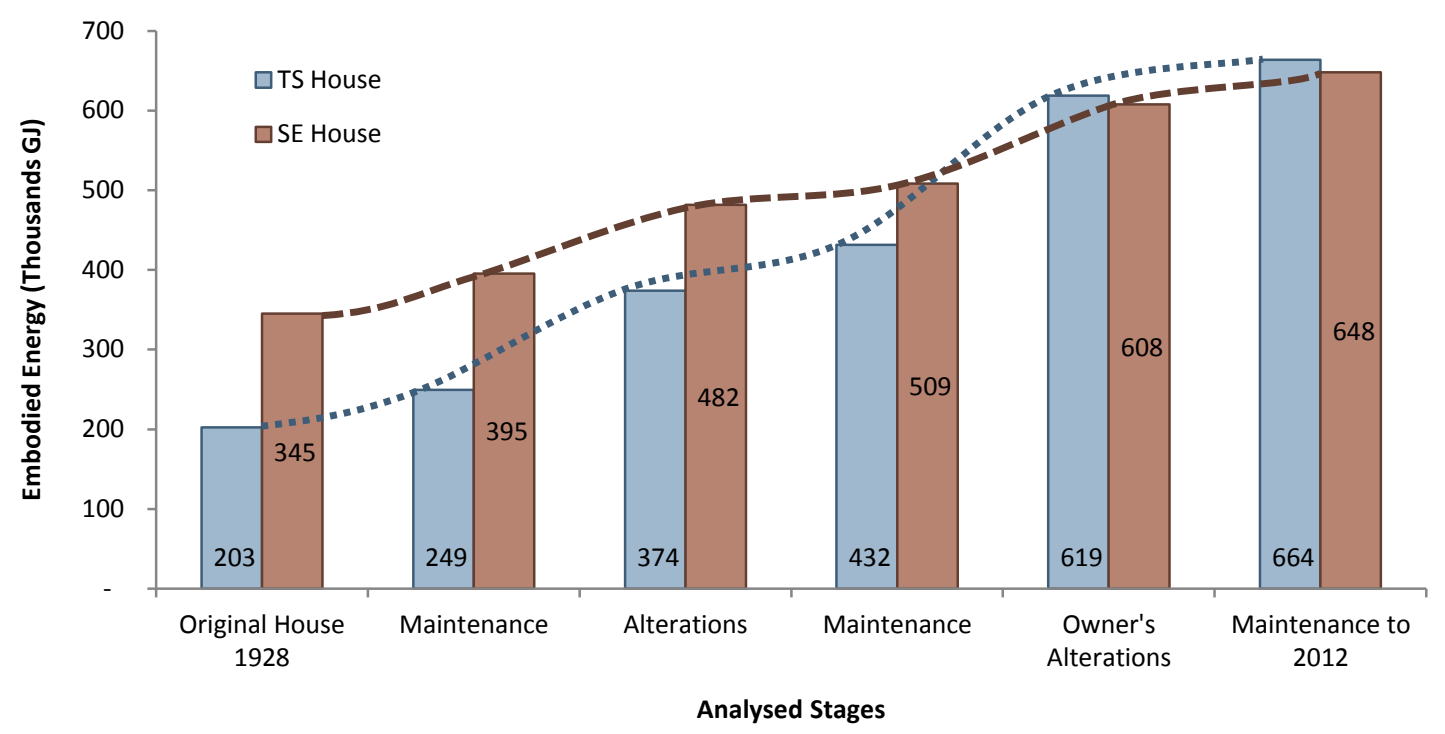

Figure 187: Embodied Energy (GJ) of the Building Materials invested in the TS House and SE House from construction in 1928 to 2012

Although the TS house as constructed had much lower levels of embodied energy than the SE house (202,500 GJ compared to 345,164 GJ), the results of the LCA show that over time, the alterations and improvements made to the house combined with the necessary maintenance mean that the cumulative embodied energy of the TS house in 2012 is higher than the SE house $(663,637$ GJ compared to $647,851 \mathrm{GJ})$. The cumulative embodied energy of the TS house and SE house in 2012 is shown in Figure 188. 


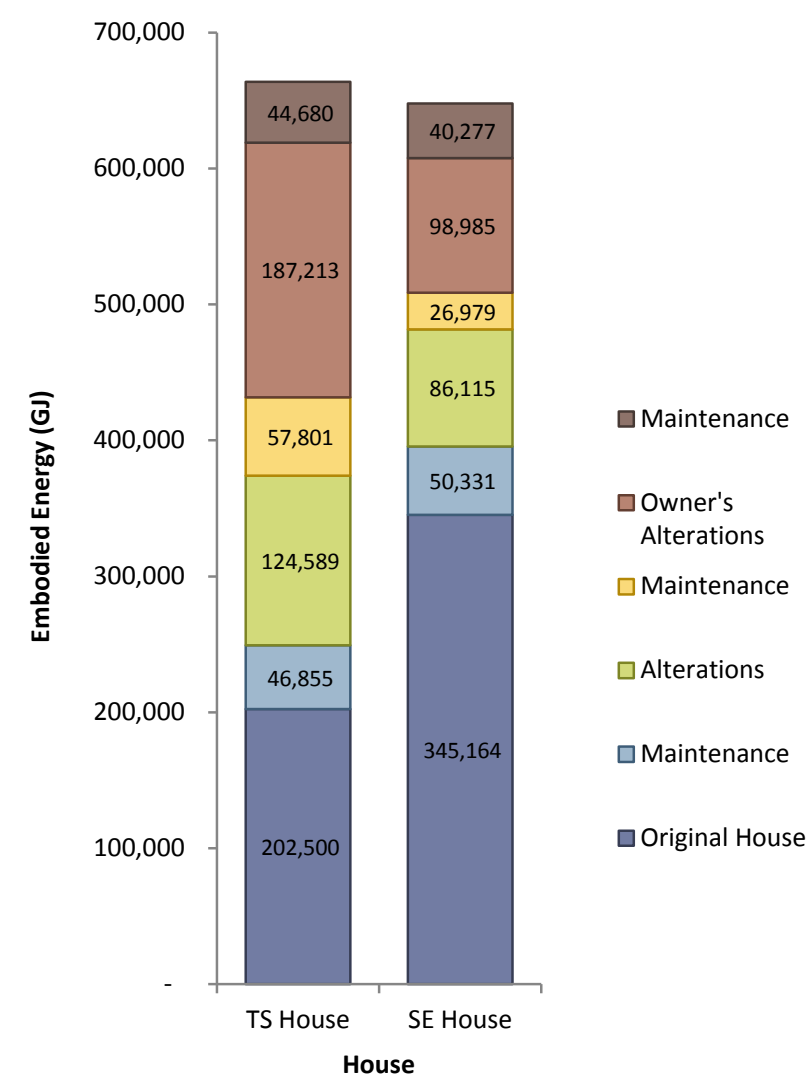

Figure 188: Cumulative Embodied Energy (GJ) of the TS House and SE House in 2012

As previously discussed (section 5.1.3) the embodied energy of the original TS house was $59 \%$ that of the original SE house. This is because timber was the primary structural building material, compared to brick in the SE house. Additionally there were timber foundations in the TS house compared to strip concrete foundations in the SE house, and timber wall linings and a plaster finish internally in the TS house in contrast to the SE house in which the fair face brick walls were painted.

Alterations carried out in 1960 by NZGR increased the cumulative embodied energy of the TS house by $124,589 \mathrm{GJ}$, which is significantly higher that the increase of $86,115 \mathrm{GJ}$ from the 1969 alterations by BDC to the SE house. The type of work carried out in each case was different (sections 3.4.1.5 and 4.4.1.5), with the NZGR alterations having the greater energy implications, through renewal of the timber house piles in concrete, construction of an adjoining utility and toilet, and renewal of the iron roof to the house and outhouse. Alterations common to both TS and SE houses included the replacement of the original hot and cold water pipework, installation of a new hot 
water cylinder, new kitchen and bathroom fittings and new floor coverings in these areas. The alterations carried out by BDC also included installation of partial central heating, 1 radiator for each room on the ground floor and 1 radiator on the first floor landing, and the necessary boiler.

The embodied energy (GJ) of alterations carried out by house owners in 1988/1990 were much higher in the TS than the SE house $(187,213 \mathrm{GJ}$ compared to $98,985 \mathrm{GJ})$. One reason for this might be the higher disposable income of TS interviewees (section 5.2) or the fact the house was easier to alter. Again, the type of work in each case was different (sections 3.4.1.5 and 4.4.1.5), with the alterations by TS owners having greater energy implications, through creation of an open plan living/kitchen/dining area, renewal of the iron roof to the house and outhouse, insulation to the roof, walls and floor, and the replacement of the internal wall and ceiling linings.

Alterations common to both TS and SE houses included the construction of built in wardrobes and cupboards, fitting of carpet throughout, replacement of floor coverings in the kitchen and bathroom and ceramic tiling to walls in these areas, a full re-wire with additional light fittings and sockets and new kitchen and bathroom fittings including a separate shower cubicle and heated towel rail.

The alterations carried out by SE house owners also included upgrading the central heating system, the replacement of steel Crittall windows with UPVC windows to the rear elevation, re-rendering and re-painting of the external surfaces and installation of a small amount of insulation to the roof and part of the ground floor. The TS houses have been remodelled internally, whereas the SE houses have not. This is partly to do with the TS houses being single storey, but also due to the timber framing which facilitates change, compared to the brick loadbearing walls in the SE houses, which are harder to move. Bathrooms are much easier to relocate in the TS houses, as underfloor areas are accessible for running pipework and drainage, again something much more difficult in the SE houses with the loadbearing walls and solid floor construction. As such, DIY in NZ will alter the fabric of the house whereas DIY in the UK is more to do with changing the interior look. 
As previously discussed (section 5.1.3.2), the embodied energy (GJ) of maintenance in both houses is significant, but higher in the TS house, due to the need to paint the corrugated iron roof covering regularly as well as the embodied energy involved in its replacement. Painting of external surfaces is required for both groups of houses.

The embodied energy (GJ) of each of the building elements in the TS and SE houses in 2012 is shown in Figure 189, and the embodied energy of the building elements in each of these houses expressed as a \% of the 2012 totals in Figure 190.

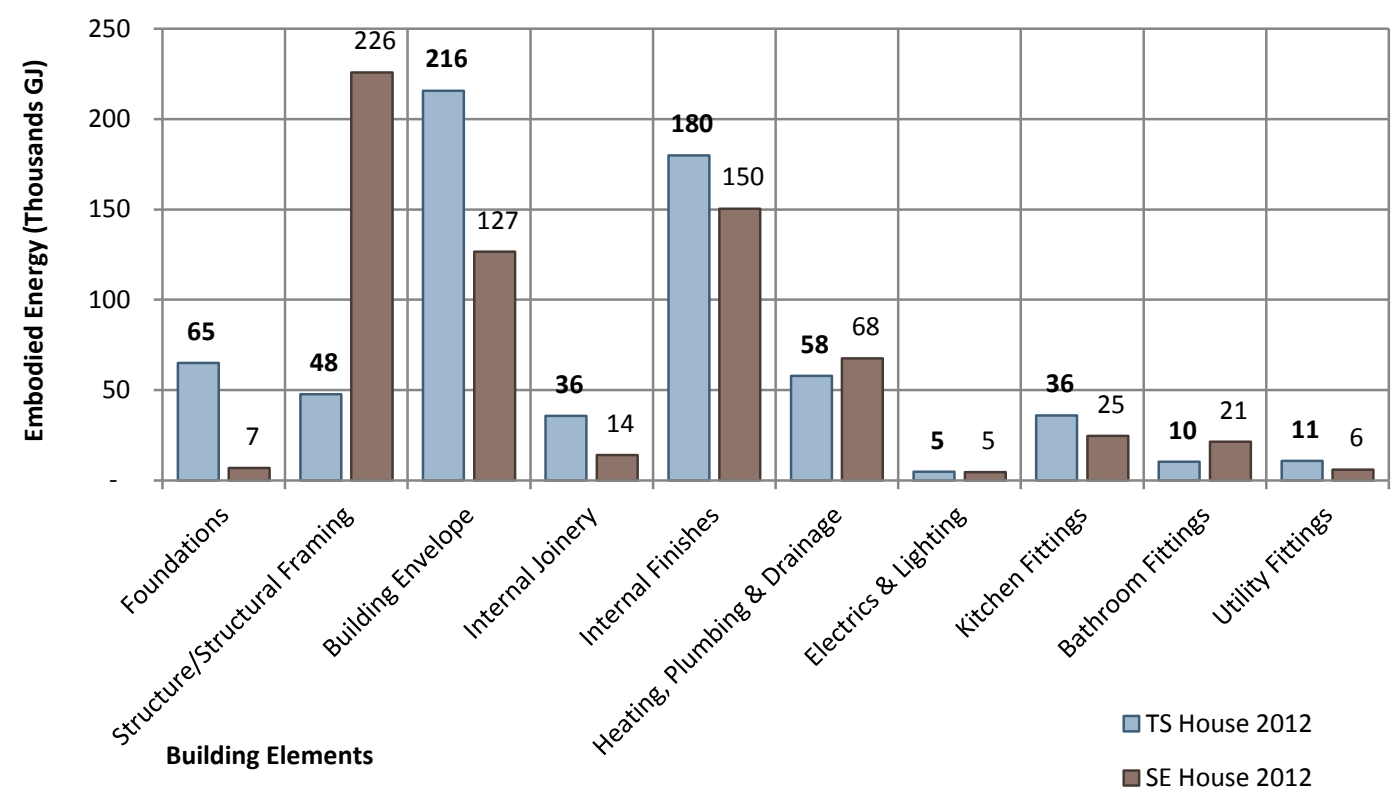

Figure 189: Embodied Energy (GJ) in the Building Elements of the TS House and the SE House in 2012

The 2012 TS house had 215,776 GJ (33\%) of embodied energy in the building envelope (external timber and paintwork, windows and roof covering), while the internal finishes were $179,936 \mathrm{GJ}(27 \%)$. The foundations accounted for $64,928 \mathrm{GJ}(10 \%)$ and heating, plumbing \& drainage for 57,948 GJ (9\%). The structure/structural framing (loadbearing external and internal walls, floor and roof structure) were 47,617 GJ (7\%) and kitchen fittings were $36,011 \mathrm{GJ}(5 \%)$.

In contrast, the 2012 SE house had 225,862 GJ (35\%) of embodied energy in its structure (loadbearing external and internal walls, floor and roof structure), while the internal finishes were 150,451 GJ (23\%). The building envelope (external render and 
paintwork, windows and roof covering) accounted for 126,557 GJ (20\%), heating, plumbing \& drainage for $67,587 \mathrm{GJ}(10 \%)$, and kitchen fittings for $24,522 \mathrm{GJ}(4 \%)$.
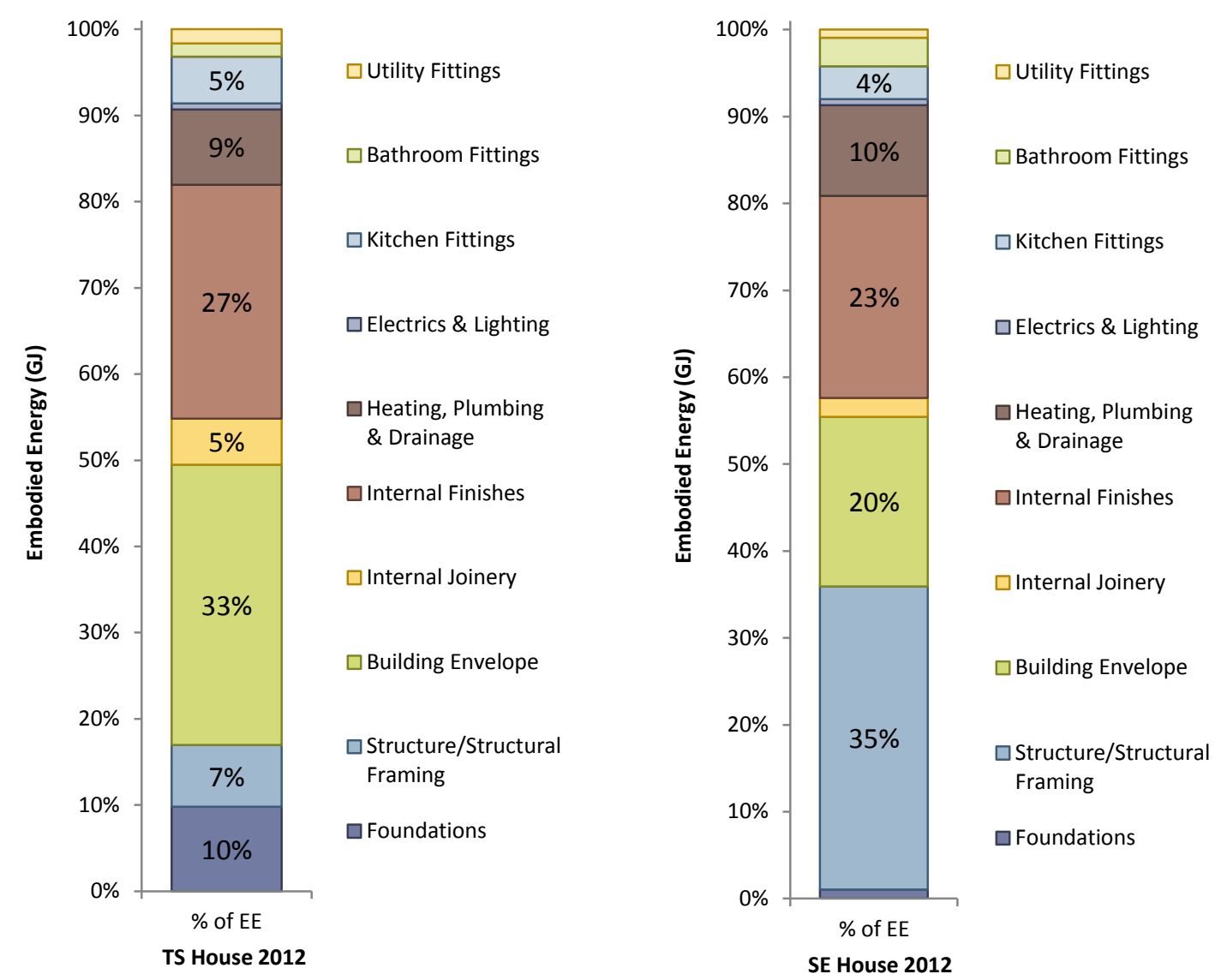

Figure 190: Embodied Energy (GJ) in the Building Elements of the TS House and the SE House in 2012 expressed as \%

The embodied energy (GJ) of each of the building materials in the TS and SE houses in 2012, expressed as a \% of the total is shown in Figure 191.

In the TS house, iron accounted for $15 \%$ of the total embodied energy, followed by timber (13\%), wallpaper (12\%), concrete (10\%) and paint (9\%). The remaining $40 \%$ ('Other') consisted of 16 other building materials including insulation (8\%), plaster (5\%), steel (5\%), vinyl (5\%) and copper (4\%). The 6 new materials introduced to the TS house since 1928 are aluminium, carpet, insulation, PVC, stone and vinyl.

In the SE house in 2012, bricks accounted for $23 \%$ of the total embodied energy, followed by steel (12\%), paint (12\%), cement mortar (11\%) and carpet (6\%). The remaining $36 \%$ consisted of 20 other building materials including wallpaper (5\%), iron 
(5\%), timber (4\%), cement render (3\%) and copper (3\%). The 7 new materials introduced to the SE house since 1928 include aluminium, carpet, insulation and wallpaper. The basic structure of the SE house has remained the same, but the materials introduced internally have contributed to the increase in its embodied energy.
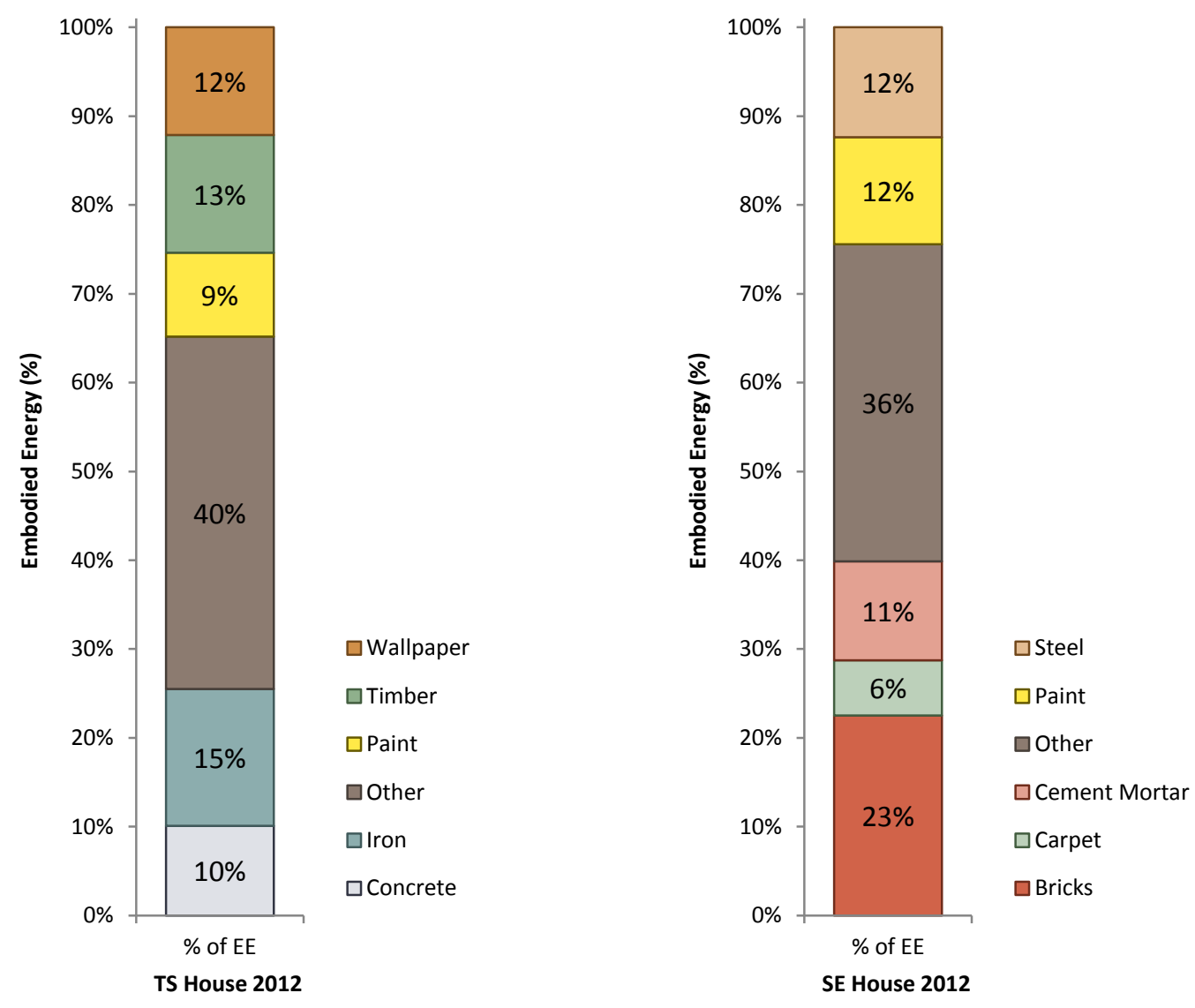

Figure 191: Embodied Energy (GJ) in the Building Materials of the TS House and the SE House in 2012 expressed as \%

As previously discussed (section 5.2.3.1), the TS houses are easier to work on and as such, good levels of insulation have been installed, increasing the cumulative embodied energy of the houses. SE houses cannot be insulated as easily and do not have a roof space in which to run pipework and cables, making it more difficult for certain types of alteration to be carried out.

The cumulative embodied energy of the TS house in 2012 was $663,637 \mathrm{GJ}$, having increased $328 \%$ since it was constructed, compared to $647,851 \mathrm{GJ}$ in the $2012 \mathrm{SE}$ 
house, with a much lower increase of $188 \%$ since first constructed. Timber is often promoted as being a more sustainable building material than brick, but unlike brick, it has a tendency to rot unless treated. Although far more energy is embodied in the structure of the SE house initially, it is more durable than the structure of the TS house, highlighting that investing in materials that have high embodied energy might be a useful approach in creating more sustainable buildings.

\subsubsection{Embodied Energy per $\mathrm{m}^{2}$ and per Person}

As previously discussed (section 3.4.1.6), in order to investigate the significance of design decisions, the houses were analyzed at three points in time and the embodied energy involved in a maintenance period of 50 years was calculated. The house was analyzed as constructed in 1928, as if the 1960/1969 version (immediately following the NZGR or BDC renovations) was built new, and the same for a 2012 typical TS and SE house. For the purpose of this analysis, these houses were called the snap shot houses and the results are shown with the maintenance highlighted in Figure 192 and alongside one another in Figure 193. The embodied energy $\left(\mathrm{GJ} / \mathrm{m}^{2}\right)$ of the 1928, 1960/1969 and 2012 snap shot houses is shown in Figure 194.
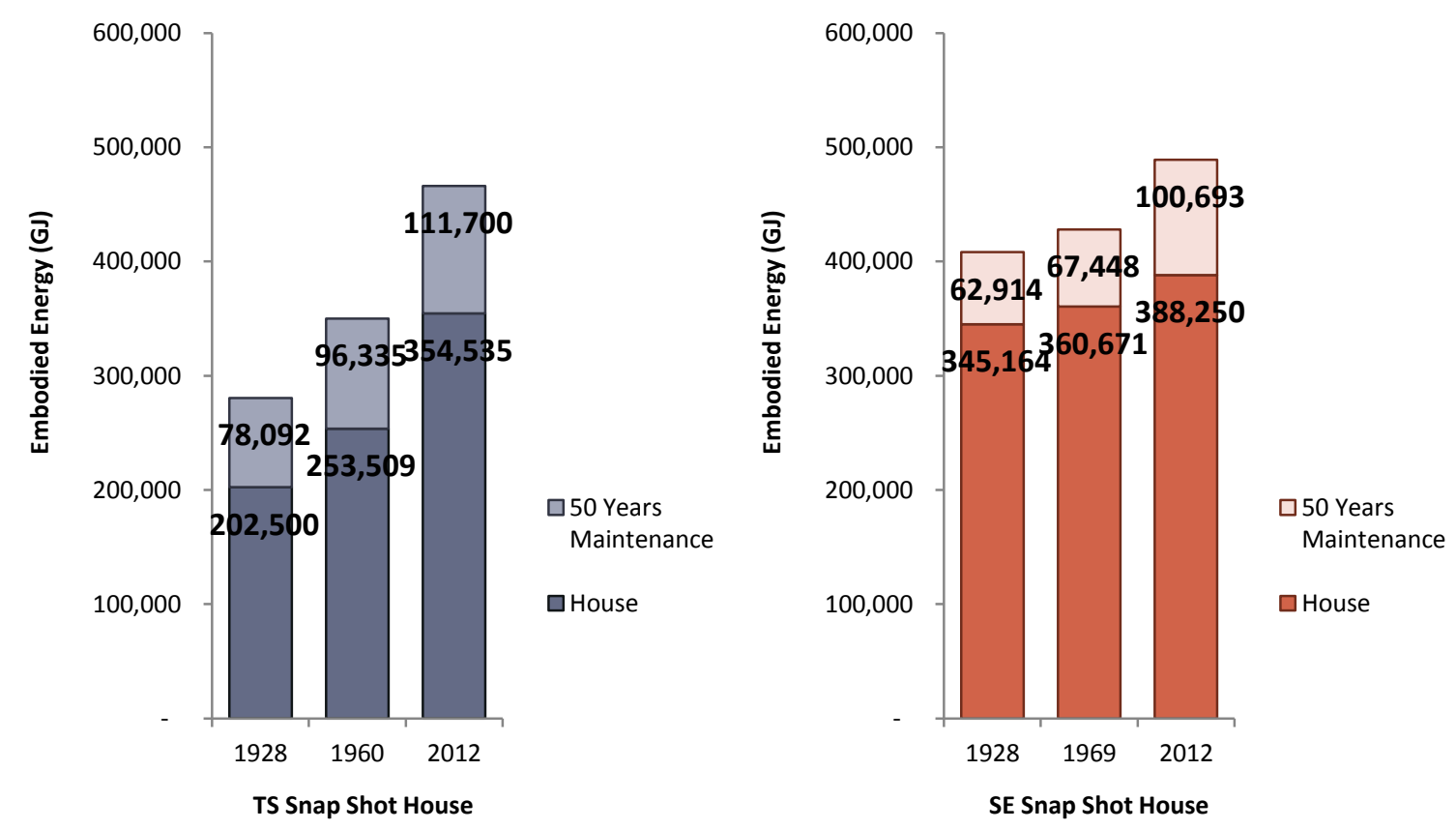

Figure 192: Embodied Energy (GJ) of the 1928, 1960/1969 and 2012 TS and SE Snap Shot Houses highlighting the 50 Years Maintenance 
The embodied energy of each snap shot house increases as expected, but the increase of the TS house is much more dramatic than that of the SE house. This is because the 2012 SE snap shot house is very like the 1928 SE snap shot house in terms of structure and materials, with the addition of central heating, a small amount of insulation, double glazing to the rear, a more modern (but still small) kitchen, a modern bathroom and fitted carpets. In contrast, the 2012 TS snap shot house is very different from that of 1928 , as it has concrete foundations, large levels of insulation and a larger modern kitchen and bathroom.

Maintenance for the 2012 snap shot houses is higher than for the 1928 and 1960/1969 houses, as it includes the replacement of carpets and wallpapering, both introduced since 1928.

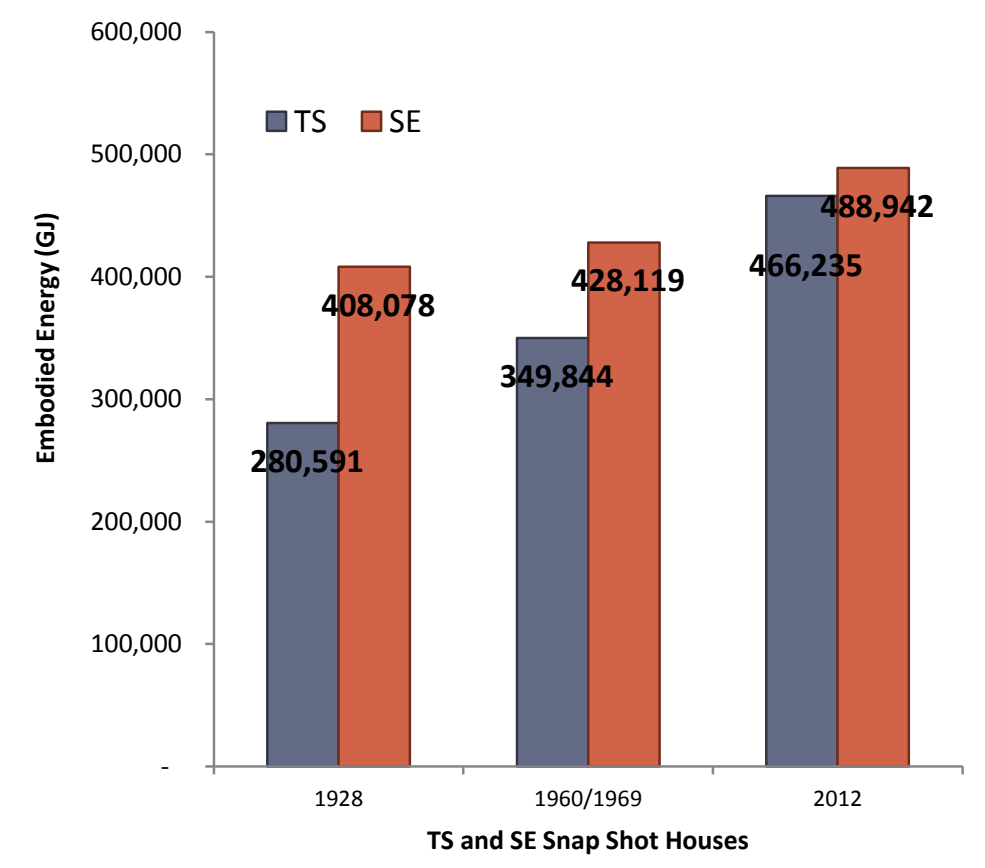

Figure 193: Embodied Energy (GJ) of the 1928, 1960/1969 and 2012 Snap Shot Houses

The embodied energy of the materials in the 1928 TS snap shot house was $280,591 \mathrm{GJ}$ or $3,207 \mathrm{GJ} / \mathrm{m}^{2}$. This is approximately $60 \%$ of the 2012 TS snap shot house $(466,235 \mathrm{GJ}$ or $5,328 \mathrm{GJ} / \mathrm{m}^{2}$ ). The embodied energy of the materials in the $1928 \mathrm{SE}$ snap shot house was $408,078 \mathrm{GJ}$ or $5,101 \mathrm{GJ} / \mathrm{m}^{2}$, which is approximately $83 \%$ of the $2012 \mathrm{SE}$ house $\left(488,942 \mathrm{GJ}\right.$ or $\left.6,112 \mathrm{GJ} / \mathrm{m}^{2}\right)$. 
The newly constructed TS house $(280,591 \mathrm{GJ})$ contained far less embodied energy than that of the SE house $(408,078 \mathrm{GJ})$ due to its timber frame compared to the masonry construction of the latter. However, the difference in the embodied energy of the 2012 snap shot houses is much smaller $(466,235 \mathrm{GJ}$ in the TS house, compared to $488,942 \mathrm{GJ}$ in the SE house), as the TS house in 2012 contains large amounts of insulation and larger kitchens. If these two snap shot houses were to be constructed exactly as they existed in 2012, then the embodied energy invested in them (including that of the 50 year maintenance period) would be similar, highlighting that two houses with different layouts, construction materials and methods, also differing in terms of style, can have similar levels of embodied energy.

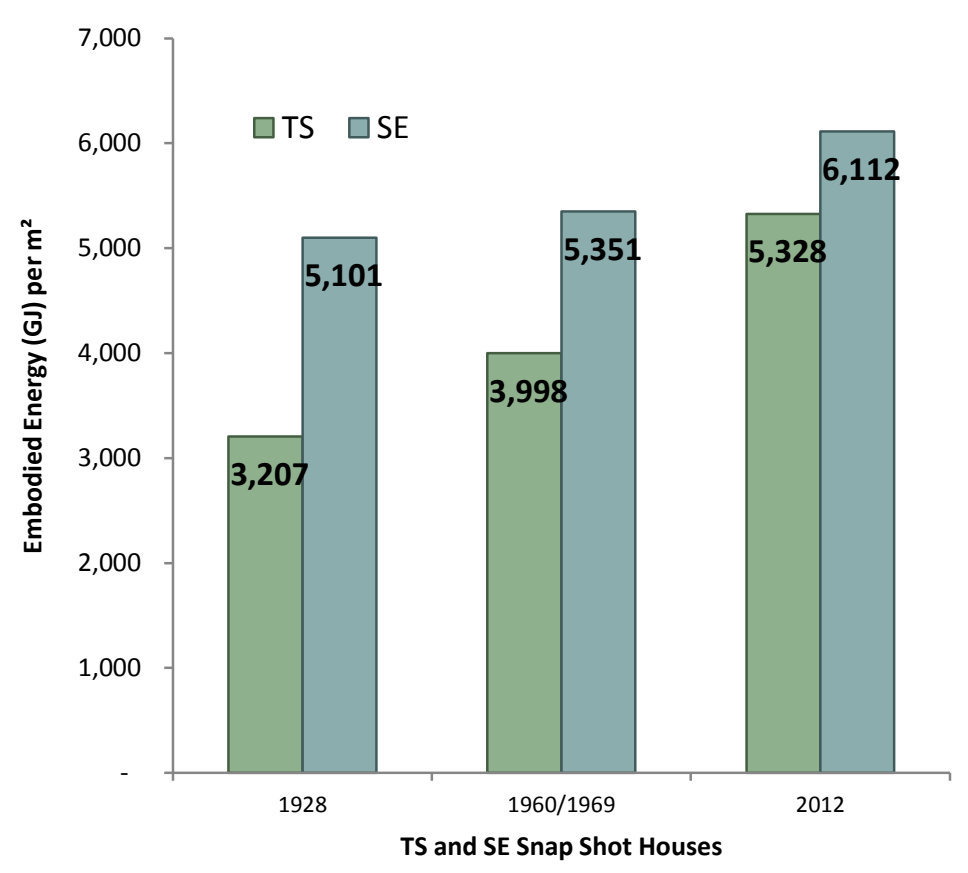

Figure 194: Embodied Energy (GJ/m²) of the 1928, 1960/1969 and 2012 Snap Shot Houses

As previously explained (section 3.4.1.6) in order to investigate the significance of household occupancy, the embodied energy per person of the snap shot houses was also calculated using the average occupancy based on Census data (Figure 195). The embodied energy of the 1928 TS snap shot house was $59,828 \mathrm{GJ} /$ person, compared to $94,902 \mathrm{GJ} /$ person for the 1928 SE house. The embodied energy of the 2012 TS snap shot house was $168,316 \mathrm{GJ} /$ person, compared to $212,584 \mathrm{GJ} /$ person for the $2012 \mathrm{SE}$ house. 
Figure 194 shows the impact of the new materials in each of the snap shot houses, whereas Figure 195 highlights the impact of occupancy.

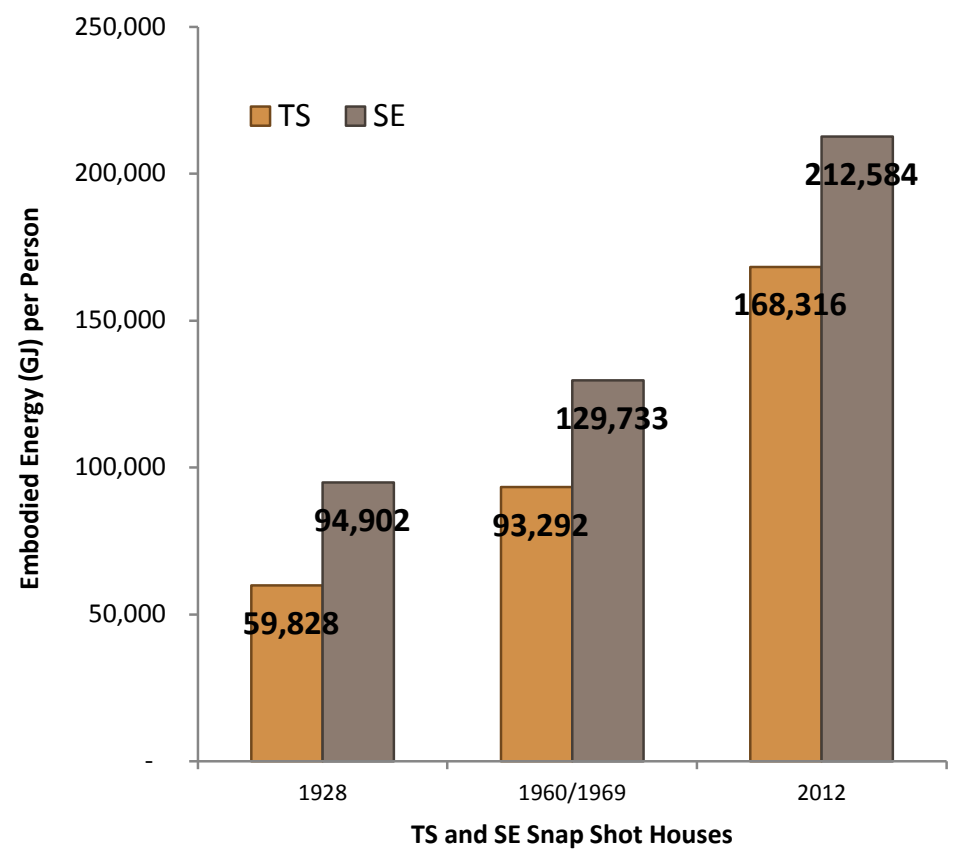

Figure 195: Embodied Energy (GJ/person) of the 1928, 1960/1969 and 2012 Snap Shot Houses

Occupancy levels are extremely important in the consideration of environmental impact, with lower occupancy levels increasing the impact of a house on the natural environment. In both New Zealand and England, household size has decreased since 1928, and consequently, the embodied energy per person of both the TS and SE houses has significantly increased. The TS and SE case study houses once provided accommodation for families of 4 or more people, but now accommodate far less. This shows that in the design of new housing, household occupancy is important, as a house with low levels of embodied energy per $\mathrm{m}^{2}$ could have high levels of embodied energy per person. 


\subsection{Heritage Implications}

All TS and SE interviewees were asked what they felt were the best and worst things about their house and its location. Most interviewees responded with multiple answers, all of which have been documented, but to begin with first answers are considered separately.

Interestingly, TS first answers regarding the best things were more varied than those of the SE volunteers. Of the 14 TS interviewees, 2 (14\%) felt that the best thing about their house was the deck and another $2(14 \%)$ the location. The remaining 10 (72\%) all gave different answers including the history of the area, the orientation of the house to the sun, the size of the house, and its character and condition.

In contrast, the first response of $3(33 \%)$ of the SE interviewees was the location close to the city and transport links, 2 (22\%) felt that their house was a home, 2 (22\%) mentioned the village environment, $1(11 \%)$ the size of the house, and $1(11 \%)$ the high ceilings.

Of the first responses given by the TS interviewees, 8 (57\%) were in connection with the house and 5 (36\%) the suburb. Of the 9 SE interviewees, 5 (56\%) first responded with something in the connection with the village and the remaining 4 (44\%) with the house (Figure 196).

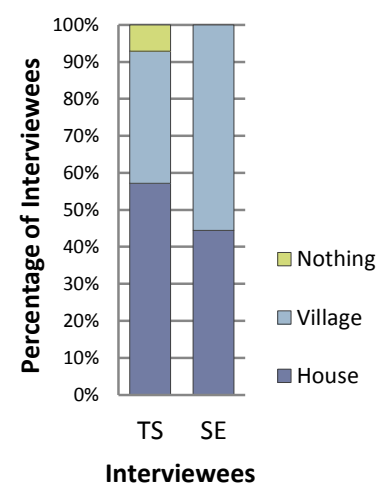

Figure 196: Best thing about the house and place where you live (first answer) (TS and SE)

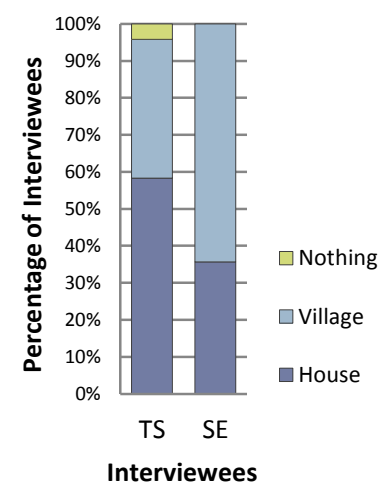

Figure 197: Best thing about the house and place where you live (all answers) (TS SE) 
When considering all answers given, $36 \%$ of all SE responses were the village environment and $29 \%$ the location of the house close to good road networks. When considering all responses, $58 \%$ of TS interviewees mentioned something in connection with the house and $38 \%$ the location, thus following a similar pattern to the first response. However, SE interviewees responded differently, with $64 \%$ mentioning the village and $36 \%$ the house (Figure 197).

In response to the question on the worst things about their house and where they lived, the first response of 5 (36\%) TS interviewees was the size of the house, 2 (14\%) that it was cold, and the remaining 7 (50\%) gave 7 different answers which included the exposure to the elements, the extent of maintenance required and the design of the kitchen. For $1(7 \%)$ interviewee the worst thing about the house was its orientation to the sun, which was the best thing for another TS interviewee, highlighting the problem of using the same house plan on opposite sides of the road.

Of the 9 SE interviewees, 2 (22\%) first said the worst thing about the house and Silver End was the conservation area status, and the remaining 7 (77\%) gave 7 different answers which included the external doors, the cost of renovation work, the flat roof and the windows. When considering all answers, $19 \%$ of TS responses were that the house was cold, $19 \%$ were to do with the size of the house, $11 \%$ indicated the lack of storage space, together with 14 other varied answers. For the SE interviewees, $18 \%$ of all answers were to do with the conservation area status, $12 \%$ the flat roof, $12 \%$ the windows, $12 \%$ mould/condensation, together with 8 other answers which included lack of insulation and cost of heating. 


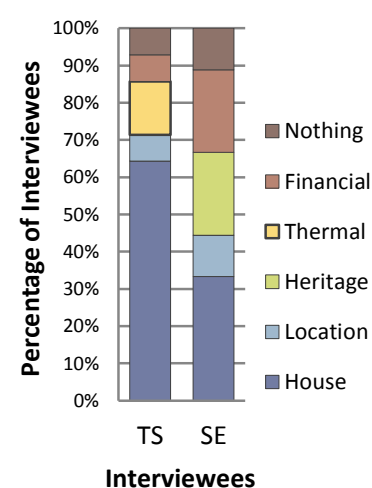

Figure 198: Worst thing about the house and place where you live (first answer) (TS and SE)

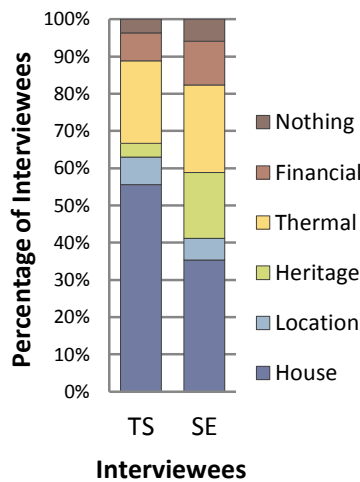

Figure 199: Worst thing about the house and place where you live (all answers) (TS SE)

The first responses of TS and SE interviewees to the question on the worst things about their house and place where they lived were different (Figure 198), as 9 (64\%) TS interviewees mentioned something in connection with the house, compared to only 3 (33\%) of the SE group. Of the 14 TS interviewees, 2 (14\%) mentioned thermal comfort, whereas 2 (22\%) SE interviewees mentioned the conservation area status and a further $2(22 \%)$ the financial implications of living there. When considering all responses to this question, the TS answers followed the same pattern as that of the first answer given (Figure 199), but the thermal comfort of the house now featured in the SE responses.

Heritage status (TS) or conservation area status (SE) affect the ability to make alterations to the houses, but seemed to be more of a problem for SE interviewees. For the worst things about their house and where they lived, interviewees from both groups complained about cold, draughts, lack of insulation, condensation, mould and the cost of renovations in approximately equal number ( $22 \%$ of TS and $24 \%$ of SE responses), "...we are used to UK dwellings where you've got central heating and a bit of thermal mass... we do miss that..." [TS_04, 0:12:55], "...because it's a solid brick property, there's no insulation, there's limited ventilation because... we've got secondary glazing... and it's not like you can say, well, l'll just open the windows for an hour, 'cos you...get...Atlantic air coming in, you know..." [SE_03, 0:12:29]. None of the SE interviewees gave the size of the smaller SE house as one of the worst things about 
it, although it was an issue for 6 (43\%) TS interviewees, "...so everything we have done when it comes to renovation has been to find more space, we are often thinking about how we can get another cubic foot of space here and there...so for me the house just isn't big enough..." [TS_03, 0:37:18]. As previously discussed (section 5.2.2.1), 7 (77\%) of the SE houses had a ground floor addition to the rear of the house, which might be one reason why size was not an issue for the interviewees. Another reason might be the higher space standards expected by the TS interviewees, as NZ houses tend to be larger than those in the UK (Quotable Value, 2011; Roberts-Hughes, 2011).

As noted, both groups of houses are in areas protected because of their heritage value. However, only Wellington City Council offer heritage grants. Since March 2009, eight TS households have received these for conservation of windows and baseboards, renovation of interior walls, repair and replacement of weatherboards, and repair and reinstatement of roof, gutters and downpipes. These grants, although not substantial (maximum \$15,000NZD per household), acknowledge the additional costs associated with owning a house in a heritage area (Strategy and Policy Committee, 2012).

There are no such grants available for owners of the SE houses, which has led to a problem with replacement windows. The SE interviewees were almost unanimously unhappy because they could not replace the old single glazed steel Crittall windows with modern double glazed units to improve thermal comfort and lessen maintenance, "... those windows are well past their sell buy date and don't fit with how people live now ..." [SE_02, 0:04:33].

The Silver End Conservation Guide emphasizes that original features should be replaced with modern copies, using the original materials, but noting modern Crittall metal windows are galvanised, powder-coated and draught-stripped, so not like the original. The guide suggests double glazing is normally unacceptable because window sections have to be thicker which alters original proportions (Braintree District Council, 1999, p. 9). However in 2009, Crittall double glazed units were approved by BDC for numerous non-listed modernist houses in the Conservation Area managed by Greenfield Community Housing (Planning Application No. 09/1272/FUL). Many SE interviewees shared that they had investigated the double glazed windows that would 
gain BDC approval, but complained that they were more expensive than standard UPVC double glazing.

The Conservation Guide notes that secondary glazing is a more efficient way of reducing heat-loss and is acceptable if the design matches that of the external window (Braintree District Council, 1999, p. 9). However, both the Energy Saving Trust and English Heritage acknowledge that secondary glazing is not as well sealed as a double glazed unit (the former will save $£ 105$ a year on energy bills, whereas the latter will save f170) (Energy Saving Trust, 2013)), but state it is cheaper to fit and still saves energy (English Heritage, 2010, p. 8). Secondary glazing to all, or part of their house, has been installed by 2 (22\%) SE interviewees despite the inconvenience of cleaning twice as much glass [SE_05 0:09:38].

Many interviewees showed a strong commitment to reducing their energy consumption which is reflected in the types of alterations they had carried out (15 (65\%) of all interviewees had installed insulation and $13(57 \%)$ had improved their space and water heating). However, many SE interviewees saw conservation and construction issues as hindering the thermal upgrading of their houses because these raise the cost. The modernist houses at Silver End are cheaper to purchase than traditional houses of a similar size in the surrounding areas. As a result they attract young, first-time buyers but in many cases these people do not have the disposable income to put into their houses and are consequently living in cold and damp conditions. Crittall's original intention was to improve living conditions for workers (Braintree and Witham Times, 1930), but 85 years later wage earners are battling issues of condensation and mould, unable financially to make the necessary improvements. For a man who wanted to be modern and give his workers decent houses it seems a pity that these same houses cannot be brought up to decent modern standards, as the owners wish. An elderly interviewee summed up the general feeling:

"I am unhappy with Crittall windows actually, because you have to paint them and...it peels off, chips off, and we're not allowed to have the plastic, although...I don't think they look very good, they're a lot better than they were, 
and they could certainly provide something that was fine here... let's move with the times...Mr Crittall would have done so..." [SE_01, 0:35:26].

In contrast, the TS houses appear more adaptable and easier to upgrade thermally, partly because they are made of timber, but also because they are no longer inhabited by workers on low incomes and many owners can afford to do work to their houses. This work is also easier to do because heritage rules appear to be less strict than at SE and because small grants are available to maintain key features, such as main façade windows, that keep the heritage character of the area.

English Heritage state that listing is not meant to 'freeze' a building, but is a way of balancing the historic interest of the site with its modern uses, so it remains viable (English Heritage, 2013a). This raises the question of whether a house is functional if the internal thermal environment is poor and problems of condensation and mould mean that clothing and linen are continuously damp. It also seems a paradox that the low income workers for whom Silver End was originally designed can now not afford to insulate or heat their homes to a reasonable level. At present the cost of heritage at SE is being borne by those who like their houses but cannot afford to live in them comfortably.

"I wasn't expecting it to be as much work as it has been...it's took a lot of time, effort and money...the worst thing is not being able to change the windows, because I think that the Council, Heritage, whatever are cutting their nose off to spite their face. They want to keep these houses alive...for future generations, which I totally understand, but if they don't do something about it...they're gonna go to wreck and ruin, which a lot of the houses are, 'cos people have just given up, because... why decorate the house, and then the roof leaks and the windows leak..." [SE_04, 0:29:00]. 


\subsection{Summary}

In 2012, the TS and SE houses were no longer solely inhabited by families as was the case originally. The two groups of volunteer households were different in terms of their size and average age. The TS houses no longer appear affordable to those on a low income, contrasting with the SE houses which are cheaper than houses in other nearby settlements.

Adults in all but 5 (22\%) of the 23 volunteer households were in some form of paid employment, and many of the case study houses were usually only occupied during weekday evenings/nights and for part of the weekend. Housework was often shared between the male and female members of the household, as was the cooking, although the latter was usually done by the female in the TS households. Vegetable gardening was much more popular amongst the TS interviewees and the person responsible for garden maintenance varied between the two groups. Of the 23 case study houses, 19 (83\%) had double doors to the rear reflecting a common desire for connection with the rear garden and outside world, even though the garden was generally not used much.

Space use has changed in $13(93 \%)$ of the 14 TS houses, with the original parlour now functioning as the master bedroom. The SE houses remain unchanged with public rooms on the ground floor and private on the first floor. Today's low occupancy levels mean many case study houses have a spare room. Of the 14 TS houses, 11 (79\%) have been remodelled to form a rear open-plan kitchen/dining/lounge area, whereas the SE houses tend to have three separate downstairs rooms, a kitchen, dining and living room. However, 7 (77\%) of the 9 SE houses have a ground floor addition to the rear of the house, compared to none of the TS houses. The original floor plan, single storey nature and timber framed TS house seem easier to adapt than the masonry SE house.

Of the 14 TS interviewees, 6 (43\%) felt the small size of the house was one of the worst things about it, and $3(21 \%)$ mentioned the lack of storage space. The latter was mentioned by several SE interviewees, although none stated that this was one of the worst things about the house, with the conservation area status, windows and flat roof 
being the primary dislikes. This is interesting when considering that the TS house has a slightly larger (9\%) floor area than the SE house $\left(87.5 \mathrm{~m}^{2}\right.$ compared to $\left.80 \mathrm{~m}^{2}\right)$, with less circulation space and a pitched roof for storage, highlighting the higher demand for space of the TS interviewees.

Other than the retired households, inhabitants spend much more time in the house than in the garden, and technology is important for recreation and relaxation. Refurbishing and modernising their house appeared to be both enjoyable and rewarding for the interviewees with the means to do this. Heritage status (TS) or conservation area status (SE) affected the ability of owners to make alterations to the houses, but seemed to be more of a problem for SE interviewees.

Although the TS house as constructed had much lower levels of embodied energy than the SE house (202,500 GJ compared to $345,164 \mathrm{GJ})$, the alterations and improvements made to it combined with the necessary maintenance mean that the cumulative embodied energy of the TS house in 2012 is higher than the SE house $(663,637$ GJ compared to $647,851 \mathrm{GJ})$. The TS houses appear more adaptable and easier to upgrade thermally, partly because they are made of timber, but also because they are no longer inhabited by workers on low incomes and many owners can afford to do work to them. 


\section{Chapter 7 - Reflections and Conclusions}

This chapter contains reflections on the research carried out and discusses changes and improvements to the HAMH for both the qualitative and quantitative data. The research questions are answered and conclusions are drawn regarding the success of the HAMH. Finally, the limitations of the $\mathrm{HAMH}$ and opportunities for further research are discussed.

\subsection{Qualitative Data: Recorded Oral Interviews}

Recorded oral interviews are a rich source of data offering many opportunities for further analysis. They facilitate the collection of a large amount of data in a comparatively short space of time, as it is much quicker for a respondent to speak an answer than write one. In this study, interviews undertaken with two interviewees at the same time ( 9 of the 52 interviews) were very successful in terms of the quantity and quality of data collected. Occasionally, these interviewees would discuss the question between themselves and often two, sometimes different, opinions were offered. It was not uncommon for interviewees to correct one another and also trigger one another's memories. One disadvantage of interviewing two people simultaneously was that interviews often took longer and, occasionally, the interviewees would 'talk over' one another.

A disadvantage of the recorded oral interview was the time involved in processing the recorded oral data. Unlike a questionnaire, where answers are written down and can be easily transferred into a chart or table, a process that is automatic with on-line questionnaires, the first step with recorded oral interviews is to listen to them and then abstract into note format. In this study, the time for this activity was between 3 and 4 times the length of the interview, depending upon the clarity of the interviewee. A one hour interviewee could, therefore, take up to four hours to abstract, and was often followed by another four hours of work in taking data from the notes and inputting it into the relevant tables and spreadsheets to allow for further analysis and comparison. However, on reflection, for this research recorded oral interviews proved to be the appropriate method of data collection, due to the amount, quality and depth 
of information gained through them, from which strong patterns emerged and findings were confirmed through repeatedly being shared by different interviewees.

The value of the oral interview approach was perhaps summed up by the response of one elderly lady who towards the end of the interview exclaimed, "... what boring questions!". Much of the data that is critical to understanding change is about the everyday and the mundane or ordinary. The personal approach of the interviewer created an acceptable environment for the interviewees, and as a result they were mostly happy to talk and share memories and information without feeling under pressure to provide a 'correct' answer.

The recorded oral interviews were carried out by four different interviewers, all of whom were female, two aged in their late 30 s and two in their late 60s. All of the interview data was abstracted by one person, ensuring consistency of analysis, and the content and quality of the interviews was similar, despite the data collection being undertaken by different interviewers. Each interviewer attempted to get answers to all interview questions, thus consistent data emerged.

Although the interview guide was distributed prior to the interview, it was unclear from many of the interviews whether it had been read beforehand. It is possible that the provision of an interview guide could be an unnecessary step. Interviewees often took the discussion in a different, but sometimes relevant, direction and were encouraged to do so before being guided back to the topic by the interviewer. The role of the interviewer was to ensure that all topics were discussed, whilst allowing space for the interviewees to reflect and share their thoughts, feelings and opinions.

In one interview undertaken in connection with the Silver End group of case study houses, an interviewee talked about his house and village for 28 minutes before the interviewer asked a question. Many topics were covered during these 28 minutes and the interviewer was able to interject with short questions where additional information was required, or pick up missing information when working through the interview guide following these first 28 minutes. 
The questions asked in the recorded oral interview were specific and in many cases generated very detailed responses. For example, whilst recalling the number of rooms in the house, many elderly interviewees would recall significant events that had once taken place in these rooms and the people that had been associated with them. Often a response to a question would contain several layers of information, and interviewees would answer a number of questions simultaneously. One ENG interviewee, when asked about typical meals, responded by talking about food received from his grandfather during the war-time, "...my grandfather used to send my mother rabbits, two rabbits in the post, and I have seen my mother skinning them and making a stew, which was quite often that we had these, he helped my mother with the rations..." [ENG_10, 0:03:09]. In response to a question about the main reasons for choosing to buy the house, one TS interviewee responded, "...because we loved the area, loved the location, we loved the houses, we rented up the road, two doors down... and we weren't very good at saving, so we thought well if we buy the house then at least we'll have some money..." [TS_08, 0:02:04]. Another TS interviewee, when asked how they felt about the place where they lived, responded in the single short answer below by sharing some of their past (having moved often), something that they liked about the house (size), things that they consider would make the house better (a fourth bedroom, a bigger living area and a separate toilet), and something about the management of the house (responsibility for housework):

"I love it, I don't want to move, I have moved so many times...I like the size...having a fourth bedroom would be nice and a slightly bigger living area, but you know I clean the house, I do all the housework, I work, so it's manageable...it would be nice to have a separate toilet..." [TS_06, 0:06:02].

Similarly, in response to the same question, one elderly NZ interviewee recalled that they liked the house, but went on to explain a negative aspect of it, describing its orientation, the temperature of some of the internal spaces and the strategy for keeping warm at night (hot water bottles):

"We quite liked it, but it was incredibly cold in the winter time, especially the bedrooms, because the bedrooms faced east, and at night time, in the winter, 
going from a warm kitchen or living room we used to take hot water bottles to bed, but those houses were incredibly cold, and you'd wake up in the morning and there'd be ice on the inside of the windows..." [NZ_13, 0:10:24].

In response to a question regarding the alterations and improvements which have been undertaken, one interviewee responded by describing how they had replaced the corrugated iron roof, including details of how they were able to pay for it:

“...we didn't get a builder's report when we bought this place...and so we weren't aware of the fact that the roof was basically crumbling...so we had to put a new roof on, and to do that...we had to go to the bank to borrow some money..." [TS_05, 0:16:41].

Similarly, one elderly ENG interviewee recalled an extension to the house and described the materials from which it was constructed:

"...it was built up against the house, of course, and it was just a lean-to...there was one door and a window, and it was made of timber and a lot of the timber was scrounged from wherever we could, it had a felt roof, when I say a felt roof, that maybe sounds strange to some people, it was like a tarpaulin roof... and that was it, it was pretty primitive I must admit, but...it served the purpose and it was still there when I left..." [ENG_06, 0:24:18].

During the elderly person interviews, information would often be offered in a different order from that of the oral interview guide, as questions would often trigger memories of activities or events which the interviewees were encouraged to share. Often interviewees would reflect whilst sharing memories, "...l don't know how she managed..." [NZ_09, 0:16:05], and, "...it was a good environment to grow up in..." [NZ_10, 0:18:19]. Elderly interviewees in particular, seemed to enjoy sharing their opinions and occasionally reflected upon how they had raised their own children.

A number of topics not included in the interview guide were mentioned by interviewees. Several elderly NZ and ENG interviewees described the preservation and bottling of fruit and home-baking. This highlighted activities common during the 1930s 
and 1940s and which required a type of storage space within the house. Similarly, several modern TS and SE interviewees talked about wanting to conserve fuel and energy and their strategies for doing this, highlighting this as an area of concern for them, despite this not being included in the recorded oral interview guide.

A survey by questionnaire would not facilitate the collection of data of this depth or breadth, suggesting that interviews should be carefully designed for each target group, even within the same study. Analysis of the interview data highlighted where questions could be revised to facilitate ease of remembering, for example, moving the question about cooking to the section about the kitchen space. Also, other topics could be included in the recorded oral interview guide, being appropriate to the period of investigation, for example, home baking and preservation during the 1930s and 1940s, and fuel conservation present day.

This research involved interviewing 29 elderly persons and 23 present day inhabitants of the case study houses. The sample was small and there was no control over the type of household recruited, thus the findings outlined in this research only apply to these interviews. However, this research shows that the use of a standard set of questions in a one-to-one (and sometimes one-to-two) interview setting can result in the collection of valuable knowledge about the historic and current use of houses.

For this project, the recorded oral interviews provided extra information as well as confirming findings through repetition. A sample size of less than 15 interviewees was found to be viable for a reasonably homogenous interview group. The present inhabitants of the case study houses were interviewed before the house was surveyed making the survey easier, and data from the recorded oral interviews was filtered through the single abstractor which ensured consistency. As a method of recording architectural history, particularly when used in conjunction with photographic and measured surveys, the recorded oral interviews proved extremely valuable. This approach is recommended for other researchers interested in the mundane and trivial information which is critical to understanding the many ways in which houses were used in the past and in the present. 
The interviews with the present inhabitants of the case study houses, if archived for use by future researchers, could prove to be a rich source of primary data, and a 'snapshot' of life in the Tarikaka Settlement and Silver End in 2012/2013. Although the VUW Ethics approval for this study requires the individual interview data to be destroyed at the end of the research, the tabulations and summaries provide a rich data for future use and could be used by researchers with an interest in the history of cooking, gardening, recreation and work in NZ and England.

Analysis of the interview data revealed many similar answers to questions from interviewees in NZ and England as they recounted similar memories. The lifestyles of current inhabitants of the two groups of case study houses were also similar. This amount of repetition was not anticipated and further research could investigate these patterns in more detail.

\subsection{Quantitative Data: Embodied Energy Analysis}

As previously described (section 2.3) the case study houses were surveyed on the day of the interview. Surveys took between 2 and 3 hours to complete but in several cases had to be undertaken much more quickly due to the availability of the interviewees.

TS houses were quicker to survey, as the original house plan was the same for each house measured, whereas the SE case study houses took more time, being a mix of several different house types. The SE houses also did not have the same quantity or quality of historical data available as the TS houses, so the survey was important in constructing a history of the houses.

From each group of case study houses, one house was selected for more thorough analysis, which represented a layout typical of most of the houses surveyed. It was easier to identify a typical TS house due to the original standard plan, but more difficult to select a typical SE house. The final decision was based upon the quality and accuracy of the original drawings, which were best in the case of the SE Stuart house. Because the 9 SE houses were different in terms of their original plan, the house 
measured for the embodied energy analysis was also a house incorporating the most common alterations undertaken by the SE volunteers.

This selection of a typical house for analysis is a potential problem of the HAMH method. In this case where the houses for both sets of workers were basically similar, finding a typical house was possible. This would hold true of modern speculative UK houses, which do tend to have repetitions, but might be harder for modern NZ houses which in any one street tend to be different.

Floor plans, sections and elevations of the selected houses were created in AutoCAD, which was also used to record the current mechanical and electrical layouts and services information.

The environmental impact of the case study houses was measured and calculated in terms of material resources consumption. Embodied energy coefficients for the TS house were taken from four sources (A Alcorn, 2003, 2010; A. Alcorn \& Wood, 1998; Hammond \& Jones, 2008). The first three are specifically for NZ and the other is from a UK meta study which was also the source of the coefficients for the SE house. Ideally all coefficients should come from their country of origin but the situation is complicated as building materials are also imported both NZ and the UK. The origins of all the materials proved to be impossible to track down during the house surveys.

Coefficients for the same building materials differed in the NZ and UK sources due to the different fuels and processes used, and this was the main reason for the difference in the embodied energy of the heating, plumbing and drainage in the two groups of case study houses (section 5.3.2).

It is likely that historic embodied energy coefficients would be different from the modern ones used in this analysis. Ideally the coefficients appropriate to the houses when first built should have been used for analysis. This is of potential importance, as more electricity was produced from coal in the UK in the 1930s than is now the case, as the UK modern electricity mix also contains gas, atomic and wind as well as coal power, which will lower the environmental impact of the electricity (Figure 200). However, historic coefficients were not available for this study, so the decision was 
made to use modern coefficients consistently so that the results could be compared. The aim in this research was always to compare houses past and present rather than calculate absolute values of EE.

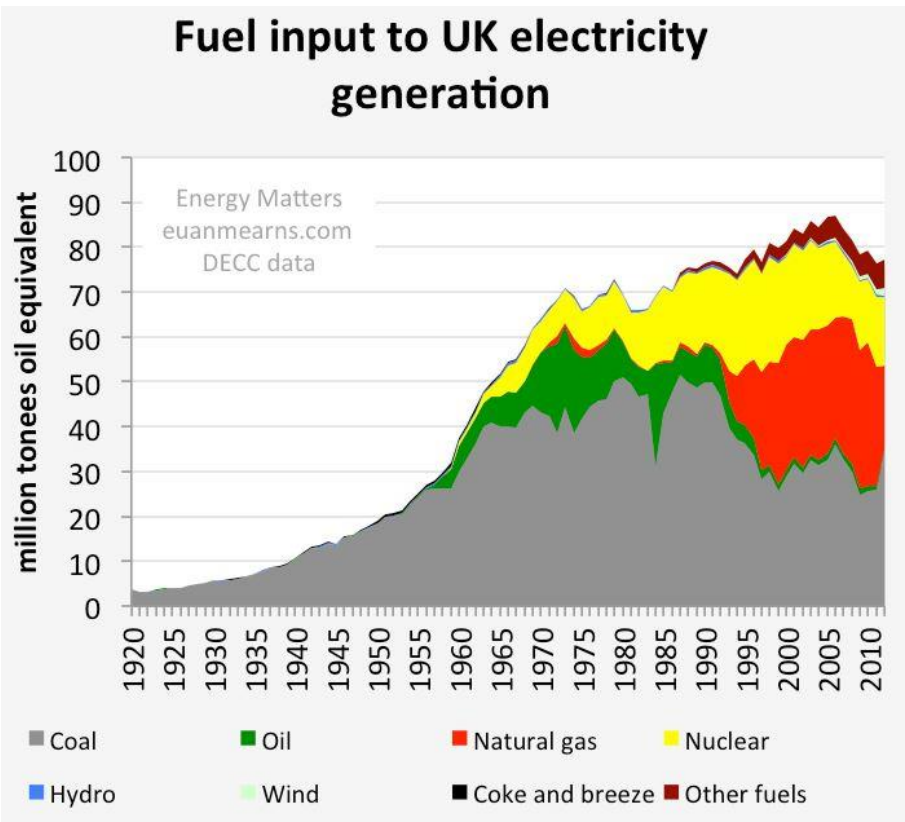

Figure 200: Historic fuels used for UK electricity (http://euanmearns.com/uk-electricity-generationstatistics-1920-2012/)

Measurement of quantities of materials from the house plans was time consuming and this process would have benefitted from a set of standardised documentation for calculating the embodied energy of a house (including alterations and maintenance) with systematic methods of measurement to help ensure accuracy. The spreadsheets produced for this research are basic, but could provide a platform for the development of a standard set of forms designed specifically for this purpose to support future research. It often proved difficult and time consuming to find the weight of a specific material, fixture or fitting, and a database containing this information would be of benefit to others attempting to undertake the same or a similar task.

Similarly, an agreed database needs to be developed containing the embodied energy coefficients of building materials in different countries which would ensure consistency and accuracy for researchers undertaking similar work elsewhere. Nevertheless, it may still be difficult to track the sources of imported materials in the changes and maintenance over the life of a house. Such information would be available if houses 
had to have logs books and records of service in the way of some cars. This could be associated with some form of 'house operation manual', providing the knowledge from the builder and early occupants on the operational and maintenance requirements.

The embodied energy $\left(\mathrm{GJ} / \mathrm{m}^{2}\right)$ of the original house was calculated from the detailed analysis of the materials used in the original construction of the house and because of the detailed drawings this was straightforward, given the caveat about the lack of historic embodied energy coefficients. Maintenance embodied energy in this analysis had to be based on data about average replacement cycles rather than house history. Again, a log book of what happened to a house would provide an interesting comparison with these assumed average cycles. Consideration of the changes to the embodied energy $\left(\mathrm{GJ} / \mathrm{m}^{2}\right)$ of each of the case study houses from alterations to the building fabric proved valuable in comparing the two groups of case study houses. However, it was the calculation of embodied energy per person that revealed most about the link between lifestyle and household energy, highlighting the importance of occupancy in the environmental impact of a house (Tran, 2014; R. Vale \& Vale, 2009).

\subsection{Research Questions}

This section discusses the answers to the three research questions set out in section 1.6.

\subsubsection{Time Use}

The first research question was: How has time use changed in the house and outdoor space?

The oral interview part of the HAMH proved critical in identifying the changes in time use that had occurred since the case study houses were constructed. The recorded oral interviews were essential in answering this question, and although the sample size was small, strong patterns emerged on which the following conclusions are based. 
The amount of time spent inside the case study houses has reduced since the 1930s and 1940s, when many women did not work and the house was usually occupied for large parts of every weekday and during the weekends. Today, it is usual for the case study houses to be occupied for only part of each weekday, most commonly the evening and/or night, and for part of the weekend. An estimate would be a drop in occupancy from 22 out of 24 hours in 1930s and 1940s to 16 out of 24 hours for a modern weekday. However, further research is needed to investigate these patterns in more detail.

It also seems several inhabitants of the SE houses are working longer hours than those who first occupied the houses, and longer hours than the present inhabitants of the TS houses. This could reflect the different income levels of the modern occupants and the relative cost of houses in NZ and the UK. A simple cost of living calculator shows comparing 2014 living in Chelmsford, Essex and Wellington shows monthly disposal income after tax is $5.3 \%$ higher in Wellington whilst the price per square metre of an apartment outside the city centre is $62.7 \%$ lower (Numbeo, 2014). This is an area for further research.

The HAMH interviews also revealed the changes in lifestyle that affect how the house is occupied. For example, less time is spent on housework today than in the past, due to the introduction of labour saving devices. The time involved in the preparation of meals can also be less, due to the greater variety of food now available and the ability to purchase pre-prepared food. To an extent, food preparation time has shifted from the house to industry, as has the time once involved in the preservation of food, a lost activity due to the availability of fridges and freezers and year round imports of fruit and vegetables. Shopping patterns have also changed from deliveries to the street to a weekly shop at the supermarket by car (The British Library Board, 2014). Many of the TS and SE volunteers, apart from those who are retired, spend a far greater amount of time inside the house, as opposed to spending time in the garden, which has in most cases shifted from being a place of production to being more ornamental.

The answer to the research question is that time use has changed with people spending less time in the house. This matched with a change in expectations 
associated with an increased desire, or possibly need, to earn money outside the house. At the same time higher disposable incomes mean people travel further from home for social relationships. In the past when people had less money and fewer possessions the house and the immediate neighbourhood were the centre of most people's lives. The change in transport requirements and associated energy use since the case study houses were constructed would be worth exploring through further research.

\subsubsection{Space Use}

The second research question was: How has space use changed in the house and outdoor space?

In answering this question, both the recorded oral interviews and house surveys proved useful. The big change is that fewer people are living in the houses, and when at home, more time is spent inside than outside.

The big change is in household occupancy which is considerably lower today than during the 1930s and 1940s, and this has impacted on space use. Whereas bedrooms were for sleeping in the 1930s and 40s, and were often shared, today the spare room/guest bedroom/study space has become a feature of many of the houses studied here. In contrast, the best 'parlour' or front room which was seldom used has virtually disappeared and the space in many TS houses has been remodelled to create an open-plan living/kitchen/dining area. The SE houses did not follow this pattern, but today all downstairs rooms were used (living room, dining room and kitchen). In both groups of houses connection of the house to garden has become important as the garden is for leisure rather than for growing food.

Apart from the remodelling and upgrading of the bathroom and the relocation of laundry facilities, the big spatial change has been creating more storage. At Silver End where there is no loft to access, storage has in some cases been built as a separate space in the garden. 
Storage is important today because people appear to have more possessions. When it comes to spaces, internal remodelling has occurred in the TS houses and many of the harder to change SE houses have had a rear extension added such as a sunroom or conservatory. This creates a sense of being outside in all weathers, and this despite the fact that people are spending more time in their houses than outside, again different from the 1930s and 1940s.

\subsubsection{Energy Use}

The third research question was: How has energy use changed in the house and outdoor space?

The energy use patterns are different in NZ and the UK. In the latter energy for space and water heating and cooking has in most cases shifted from solid fuel to electricity or gas, as has energy for cooking. The whole house is now heated and temperature controlled via a thermostat. In NZ there has been a shift from coal, but solid fuel in the form of wood is still used for space heating, along with gas and electricity. In addition, normally only one room is heated although portable heaters may be used in bedrooms. Houses in NZ are not automatically temperature controlled. Multiple light fittings and additional electrical sockets are found in many of the case study houses in both countries, which will tend to increase energy consumption. During the 1930 s and 1940s, water was usually heated once a week for washing clothes and for bathing, whereas today water heating is usually continuous and hot water is supplied to multiple locations within the house. However, despite all these changes, houses in both TS and SE interview groups were described as cold and uncomfortable. This is partly because of financial constraints but also because the houses, especially those in Silver End, are expensive to heat adequately because they are difficult to insulate. This situation is exacerbated by the heritage regulations in place at Silver End, compared the freer grant-supported heritage regulations at the Tarikaka Settlement.

What are the embodied energy implications of alterations to the fabric of the house?

When it comes to the energy embodied in the house, the two storey load bearing brick SE house had a higher initial embodied energy than the TS house $(345,164 \mathrm{GJ}$ 
compared to $202,500 \mathrm{GJ})$. However, because the TS houses are easier to alter and thermally upgrade through the introduction of large quantities of insulation, and because of their maintenance requirements, the cumulative embodied energy of the timber TS house in 2012 is higher $(663,637 \mathrm{GJ}$ and a $328 \%$ increase since it was constructed) than the brick SE house $(647,851 \mathrm{GJ}$ and only a $188 \%$ increase). This is an important finding, since timber framed housing is seen to be the less environmentally damaging as timber is considered to be a more sustainable material than brick (Khatib, 2009).

The difference is due to the maintenance and investment in refurbishment, including the addition of thermal insulation to create a more energy efficient building. The consequences of similar improvements to the thermal performance of the SE houses was not investigated, as the changes were not made due to the more restrictive heritage (conservation) rules applying in Silver End than in the Tarikaka Settlement.

It was not possible to undertake a detailed embodied energy analysis of the changes to the outdoor space. This was mainly due to the largely undocumented change that had taken place over time, good quality data was not readily available either on the date at which the changes were made or the extent of work required. A detailed study of the outdoor area would have been required, and this was not within the time scope of this research.

The HAMH was able to highlight the importance of occupancy levels in the environmental impact of houses. The embodied energy of the 1928 TS snap shot (see section 6.3.2.1) house was $59,828 \mathrm{GJ} /$ person, compared to $94,902 \mathrm{GJ} /$ person for the 1928 SE house. The embodied energy of the 2012 TS snap shot house was 168,316 GJ/person, compared to $212,584 \mathrm{GJ} /$ person for the 2012 SE house. The trend to lower occupancy may change with time, so this topic would benefit from further research. 


\subsection{Research Aim Evaluation}

The primary aim of this research was to develop and apply a Hybrid Analysis Method for Housing $(\mathrm{HAMH})$ as a vehicle for the investigation of the relationship between the environmental impact of the building materials in a house and the lifestyle of its inhabitants, both immediately after construction and in the present day (section 1.3).

The research was conducted in the four phases as described in section 1.5. The method has shown that useful data can be extracted by combining qualitative and quantitative approaches. The results have identified new understanding of the ways in which houses and their use have changed over approximately 80 years that would not have been possible with other research methods.

\subsection{Lifestyle and Embodied Energy}

For the purpose of this research, lifestyle was defined as changes in time use, space use and energy use of the house occupants (section 1.6). These changes were then related to the embodied energy of the house.

The results imply it is the changes in technology that have affected lifestyle and which have contributed most to the change in the embodied energy of the house. For example, dishwashers and ovens in kitchens both enable people to wash and cook more quickly and have an impact on embodied energy. The requirement for houses to be more thermally comfortable and able to be heated effectively for certain parts of the day, due to more people being in paid work, means that new forms of heating have been introduced, which also affects the embodied energy

Other factors which affect embodied energy include the country in which the house is located and the materials available, the choice of materials used for alterations, and the wealth of the owners. The case study houses were originally designed and constructed for workers and therefore building costs would be comparable to income and hence material choices. One aim of this research was to see what had happened to these workers' houses since. 
None of the current inhabitants of the case study houses mentioned embodied energy (although many discussed operating energy) and it is unlikely that any of the interviewees are aware of the need to minimise it. Without financial incentives, it is doubtful whether householders would invest in more expensive products to reduce embodied energy, although this is a subject for further research.

\subsection{Limitations of the HAMH}

One disadvantage of the choice of case study houses was the practicality and complexity of comparing houses in two different nations, which meant that two distinct people groups were investigated. However, this research shows that there was value in comparing the two groups. The single storey timber houses are easier to alter, but require more maintenance, and conversely the two storey masonry houses are harder to alter and require less maintenance, which is interesting since timber is promoted as being the more 'sustainable' building material. Another disadvantage of the choice of case study houses was the need to apply different coefficients to the embodied energy calculations. If a second group of houses had been identified in NZ, the same coefficients could have been used, making the outcome more robust.

One limitation of the HAMH is the inability to make a comparison between the results of the embodied energy analysis with the work of other researchers. In NZ, embodied energy calculations have been carried out on a theoretical house, rather than a real one (A Alcorn, 2010). The modelled house had a timber frame and steel roof, and floors were either concrete slab or suspended timber. Numerous variations of this model were produced, substituting different components/materials and re-calculating the embodied energy. The shell of the large $200 \mathrm{~m}^{2}$ house (light weight, year 2000 construction, suspended timber floor) had an initial embodied energy of 354,723GJ $\left(1,774 \mathrm{GJ} / \mathrm{m}^{2}\right)$ discounting internal fixtures and fittings. This is not far from the initial EE of the 1928 TS house including all fixtures and fittings, which was calculated as 249,355 GJ $\left(2,771 \mathrm{GJ} / \mathrm{m}^{2}\right)$, the fixtures and fittings and the smaller footprint (or ratio of corners to floor area) accounting for the difference. 
As mentioned in section 1.2.4, reasons for the relatively few publications about residential POE compared with other sectors, include the difficulty of gaining access to people's private homes, and the challenge of securing a representative benchmark sample (Stevenson \& Leaman, 2010). One genuine concern at the outset of this research was whether or not a suitable number of willing participants could be identified. However, finding the 23 case study house volunteers did not prove difficult, although letters to the 67 TS houses produced 14 volunteers (21\%), while letters to the 102 SE houses on Silver Street and Broadway produced only 9 volunteers (9\%). One reason for this difference might be that many of the TS volunteers have undertaken considerable work to their houses, have a genuine love for them and want to 'share' this with others. However, this was not always the case as $2(14 \%)$ of the TS houses were rented and unaltered by the present inhabitants. Another reason might be the significant number of SE houses that are owned and managed by a local housing association, none of which were volunteered for study by the current tenants. A more likely reason is that the TS houses are located in Wellington, with Victoria University of Wellington being known to residents, whereas for the inhabitants of Silver End, receiving a letter from someone on the other side of the world, requesting the opportunity to visit them and study their house might seem implausible. However, 9 SE inhabitants responded to this request and contributed the valuable data that made this research possible.

When asked why they had volunteered to be part of the study, many of the TS interviewees talked about their interest in the history of the Tarikaka Settlement and several expressed empathy for researchers, having been involved with research themselves. Similarly, the SE volunteers were people who were interested in the history of Silver End and the houses, but also included people frustrated by the conservation rules who were eager to express their opinions about the houses and the local area. One commonality between all volunteers was their generosity in terms of the gift of their time to participate in the study and the openness of their sharing of information about themselves and their home. It is possible that an attempt to recruit volunteers face-to-face might have been more successful, but it was decided that in a study of this nature, which is intrusive and involves a volunteer allowing a complete 
stranger into their home, that it would be better to engage with people who were interested and excited about the research, participating for genuine reasons, without feeling under pressure to do so. However, recruiting larger and more statistically robust samples could remain a challenge if the HAMH was applied more widely. It is thus important to remember that the findings outlined in this research only apply to the households who volunteered and the houses which were studied.

The HAMH approach is time consuming, so to collect a larger sample in order to provide more certainty for the findings would take considerable resources. One way around this would be to locate and make more use of existing oral history resources to cut the interview and interview analysis time.

The environmental impact of the case study houses in this research was only assessed through the embodied energy in the materials of the house from its construction in 1928 to 2012. Further research would benefit from the development of a suitable method to quantify changes in embodied energy of the materials in the outdoor spaces associated with the house. This would include changes in landscaping, planting and construction of specialist structures including retaining walls, paths and sheds.

For a true LCA measuring or modelling, the operating energy of the house over its life is also necessary. Another investigation area would be the energy in the transport used by inhabitants past and present. If these investigations were to be carried out and considered together with changes in lifestyle, the link between household total energy consumption and lifestyle would be more complete.

\subsubsection{Improving the HAMH}

As previously mentioned (section 7.1) the recorded oral interview guide could be improved through the re-organisation of questions to facilitate ease of remembering, for example, relocating the questions connected with housework and household appliances to the section on the house and kitchen, and the introduction of other topics appropriate to the period of study, such as food preservation during the 1930s and 1940s and energy saving present day. In addition, a standard set of forms for recording and comparing data obtained through the recorded oral interview with 
answers in part pre-loaded into an Excel document could speed up the data handling and processing. These are largely changes of detail, rather than major changes to the basic approach. The interview technique was found to be successful and to have created a valuable resource of knowledge as to the way people lived in the case study houses, in both the past and present.

A recent paper suggests that the variation and incomparability of embodied energy databases and current day interpretations of embodied energy makes its calculation and comparison difficult (Dixit, Fernandez-Soliz, Lavy, \& Culp, 2010). A standardised set of documentation for calculating the embodied energy of a house, with systematic methods of measurement and reliable embodied energy coefficients for different countries and for different times would also improve the accuracy of estimating the overall impact of housing (section 7.2).

\subsection{Further Research}

Some additional suggested avenues for further research are linked directly to the $\mathrm{HAMH}$ and the methods described in this thesis, whereas others are more general, and prompted by issues raised from the findings of the thesis.

\subsubsection{Household Energy Use}

The HAMH identified changes in energy use primarily through the data obtained from the recorded oral interviews. The house surveys were important in corroborating the information gained from the interviews, and details of the mechanical and electrical items were noted as part of these.

A detailed analysis of energy use in the houses based on an understanding of the major end-uses (notably space heating, water heating, refrigeration and light) would help fill out a life cycle energy analysis. This may help better quantify the value of energy efficiency improvements, such as additional thermal insulation. 


\subsubsection{Longitudinal Comparisons}

On reflection, the real value of the HAMH seems to be its use as a vehicle for comparison and as such, it needs to be applied to other groups of houses, constructed in different time periods and in other locations. This should enable meaningful comparison between houses designed differently, using varied methods of construction in a variety of materials that are inhabited by different people with differing lifestyles, with the overall aim being to see how lifestyle and environmental impact relate to each other. The success, adaptability and affordability of the different groups of case study houses, relative to one another, could be explored.

This research already suggests that one key to housing affordability is a change in values that will accept more occupants per house. This simple move would not only lessen environmental impact but also make housing more affordable both to own and to run. However, a larger sample is needed to explore these ideas further. Further research in this area is likely to contribute more valuable insights into the link between the environmental impact of the house and the lifestyle of its inhabitants, both past and present.

In the application of the HAMH in other settings, an attempt should be made to interview original inhabitants of the case study houses, and not only those living in similar houses at the same point in time. Due to the age of the case study houses selected for this research, it was extremely difficult to identify original inhabitants who were willing to be interviewed, but this might be possible in houses constructed more recently, say 40 years ago rather than 80 years ago.

This research has shown that the purpose of housing seems to have changed over the past 85 years. During the 1930s and 1940s, the house was very much a place of production and the adjacent public spaces were places for social interaction. Present day uses appear to be for eating and sleeping, relaxing, and engaging with technology, with the adjacent public spaces being dominated by the car. This raises the question of whether modern house design is reflective of this change in purpose, and also sufficiently flexible to accommodate future change in lifestyles. In addition, what is 
the role and responsibility of the developer/house builder? This is another area for further research.

Another issue raised by this research is the treatment of houses that have heritage status. The differing rules between NZ and the UK are worthy of further exploration, in terms of the affect they have on the occupants and the appearance of the houses.

Other areas for future research include investigations into modern houses, specifically house size and space usage, householders' decision making in terms of material choice, and the role of the garden.

This research highlights the importance of material choice in terms of lifetime performance and maintenance requirements. It also makes a contribution to the argument for embodied energy to form part of the Building Code and Building Regulations requirements in NZ and the UK respectively.

\subsection{Final Thoughts}

This research has highlighted a change in the purpose and function of housing over an 80 year period. The comparative studies highlighted the sense of community which once existed within two 1920s housing developments, the Tarikaka Settlement in New Zealand and Silver End in England. In both areas today, the community spirit is not strong, with inhabitants tending to know only adjoining neighbours. This can be attributed in part to the fact that the present inhabitants do not work alongside one another, also the lack of private transport (notably cars) during the 1930s and 1940s, meant that inhabitants spent a lot of time together in social situations.

On the basis of these findings, it is the use of the $\mathrm{HAMH}$ as a vehicle for comparison of different groups of case study houses which is its main strength.

“...we've got all sorts of advantages [today] that we didn't have then, we didn't even think of then...we've got a car, we can trip around the countryside...but you weren't conscious of... restrictions because you weren't conscious of the other possibilities...television came along, so everybody had to have television, 
and you can't imagine living without it, but we did live without it...I think this is just generally true of all people, all times, everywhere, you actually settle into an environment...you make it fit you the best you can and then you accept that...as time goes on, things will change..." [NZ_14, 1:03:47].

Change is inevitable, so the design of housing should acknowledge this. This research has shown that the use of a Hybrid Analysis Method for Housing which considers a house and its inhabitants, both past and present, is able to produce findings that should help inform the way in which houses are designed in the future.

This thesis has provided useful information not only for the researcher, but also to help to make inhabitants aware of the impact of both their house and lifestyle on the natural environment. It challenges the idea of what a sustainable house is by showing it is the people, their values and what they do that really matter, not just the materials of which the house is made. 
Page $\mathbf{2 8 0}$ of $\mathbf{3 3 2}$ 
Appendices

Page $\mathbf{2 8 1}$ of $\mathbf{3 3 2}$ 
Page $\mathbf{2 8 2}$ of $\mathbf{3 3 2}$ 


\section{Appendix A: Recorded Oral Interview Guide for use with Present}

Day Inhabitants of the Case Study Houses

\section{Categories and Questions}

\section{FAMILY}

1

Where were you born and in which year?

Who are the members of your immediate family? Do they live with you?

2 Do you have any relatives living nearby? Where do they live? In the same street, same suburb, same town, etc.

Does anyone else live with you, other than the members of your immediate family described previously? Lodger, friend, etc.

\section{HOUSING}

4

Do you rent or own the house?

5

What were the main reasons for choosing to rent/buy this house? Location, cost, size/number of rooms, external appearance, internal fittings, outdoor space, etc. How do you and your family feel about the place where you live? Do you know how your house/house type is perceived by the wider community? Can you name the rooms in the house and describe how they are used? Sleeping

7 areas, living areas, washing/storage areas, etc.

8 Which services are connected to your house?

9 How often and by what means is the house heated?

10 How often and by what means is water heated? For bathing, washing clothes, etc.

11 How does this amount differ during the summer months? Gas, Electricity, Coal, Wood, etc.

What types of waste are generated in the house and outdoor space? How is waste disposed of? Have your family made any alterations or improvements to the house whilst you have lived here? If so, please could you describe these.

14 Can you describe the outdoor space which is associated with the house. What are the main activities that take place in the outdoor space? How much

15 time do you and your family spend in the outdoor space? Who is responsible for maintenance of the outdoor space? What do you consider are the best and worst things about the house and place where you live? How much time do you and your family spend in and around the house and outdoor space, compared with your time spent elsewhere?

Do your family regularly rent or own any other houses at the same time as this house? If so, where are these located and how often are they used?

19 Do you feel that housing and its associated costs are perceived to be expensive or affordable? 


\section{EDUCATION AND WORK}

20

Where do your children (if applicable) go to school? Did you choose where they go to school? How do they travel to school?

What are the occupations of all adults residing in the house? What number of

21 hours do they spend working each day? Do they appear to be happy in their work?

Who is responsible for household work? Do any other members of the

22 household help with any housework? What are the main tasks undertaken daily and weekly, and how much time do these tasks take to complete?

Do your family own any of the following household items (if applicable)? If so,

23 how often are they used? Fridge, oven, washing machine, vacuum, lawn mower etc.

24

How satisfied do you feel that you and your family are with the balance between work, family and recreation time?

FOOD

\section{Home Grown Food}

Do you grow vegetables at home? Which types? Potatoes, pumpkins, corn,

25 carrots, peas, lettuce/salad crops, tomatoes, etc. If and when do you buy vegetables?

26

Do you grow fruit at home? Which types? Apples, plums, pears, lemons, strawberries, oranges, grapes, etc. If and when do you buy fruit?

27 Do you produce any other types of food at home? Eggs, milk, meat products, etc.

28 Approximately what percentage of consumed food is grown at home?

29 Do you receive home grown food from relatives and neighbours? If so, what type and how often?

\section{Bought Food}

30

Who is responsible for purchasing food? Where is food purchased? Dairy, local shops, market, supermarket, etc.

31 How often do your family buy food?

32 What is a typical breakfast, lunch and dinner?

33

Who is responsible for the preparation of each meal? How long does it take to prepare each meal?

34 Do you and your family eat out? If so, how often and what would the meal be?

35 Do you feel that bought food is perceived to be expensive or affordable?

TRANSPORTATION

36

What forms of private transport do you have at home? How often are these used and for what purposes? Car, bicycle, etc

37 What forms of public transport do you and your family use? How often are these used and for what purposes? Bus, train, ferry, etc.

38 Do you feel that transportation (both private and public) is perceived to be expensive or affordable?

\section{RECREATION}

39

How do you and your family spend time in the evenings? Please could you describe a typical evening.

40

How do you and your family spend time on the weekends? Please could you describe a typical Saturday and Sunday. 
Do your family own any of the following items (if applicable)? How often do you

41 watch or listen to them as a family? Television, radio, gramophone, telephone, etc.

Are your children (if applicable) involved in any organised out-of-school

42 activities?

Girl Guides, Boy Scouts, music, sport, etc.

43

What toys do your children own (if applicable)? X-Box or similar, construction toys, toy trains, Dolls House etc.

44

What are the recreational activities of your immediate family? Sewing, gardening, DIY, sports, amateur dramatics, etc.

In a typical year, how often and where do you go during holiday periods? How

45 do you get there? Please could you describe a recent holiday that you particularly enjoyed.

46 How often do you spend time with your extended family? Where do they live and how do you get there?

47 By what means and how often do you communicate with significant friends and family? Letter, phone call, visit, etc.

48 What social groups or networks are you a part of? Church, sports clubs, hobby groups, etc.

\section{SIGNIFICANT MOMENTS}

49 In recent years, what are your most significant or memorable moments?

\section{QUALITY OF LIFE}

50 Do you feel safe in your house?

51 What methods do you use to keep your house and possessions secure?

52 How would you rate you and your family's overall quality of life? 
Page 286 of $\mathbf{3 3 2}$ 


\section{Appendix B: Recorded Oral Interview Guide for use with 1930s and 1940s Housing and Lifestyle Interviewees}

\section{Categories and Questions}

\section{FAMILY}

1

Where were you born and in which year?

Who lived with you? Were there any members of your immediate family that did

2 not live with you? Did you have any relatives living nearby? Where did they live? In the same street, same suburb, same town, etc.

Did anyone else live with you, other than the members of your immediate family

3 described previously? Lodger, friend, etc. Did you have any pets? Dog, cat, bird, goldfish etc.

\section{HOUSING}

4 What type of house did you live in and where was it located?

5 From what materials was the house constructed? Walls, floor, roof, etc.

6 Did your parents rent or own the house?

What do you think were the main reasons for your parents choosing to rent/buy

7 this house? Location, cost, size/number of rooms, external appearance, internal fittings, outdoor space, etc.

Can you describe each of the rooms in the house? What were they like and how

8 were they were used? Sleeping areas, living areas, kitchen, washing/storage areas, etc.

9

Which services were connected to your house? Can you recall the number of lights and sockets in each room (if applicable)?

10 By what means was the house heated and how often?

11

12

13

14

15

16

17

18

19

By what means was water heated, how often and for what purposes? For bathing, washing clothes, etc.

Do you ever recall your parents worrying about the cost of fuel or the cost of heating the house during the winter months?

Do you recall what types of waste were generated in the house and garden? How was waste disposed of?

4 Did you have a garden? If so, please could you describe this.

What were the main activities that took place in the garden? How much time did you and your family spend in the garden?

Who was responsible for garden maintenance? Approximately how much time

was spent per week on garden maintenance? Did you or your siblings (if relevant) help with taking care of the garden?

Did your family make any alterations or improvements to the house whilst you lived there? If so, please describe these.

How much time do you recall you and your family spending in and around the house, compared with your time spent elsewhere?

How did you and your family feel about the place where you lived? Do you recall how your house/house type was perceived by the wider community?

What do you consider were the best and worst things about the house and place where you lived? 
Did your family regularly rent or own any other houses at the same time as your main house? If so, where were these located and how often were they used?

22 Do you ever recall your parents worrying about paying the rent/mortgage? EDUCATION AND WORK

23

Where did you go to school? Did you choose where you went to school? How did you travel to school?

24 Did you and your siblings (if relevant) enjoy going to school? What types of activities did you do at school?

25 What were your parents' occupations? Do you recall the number of hours that they spent working each day? Did they appear to be happy in their work? Who was responsible for household work? Did you or your siblings (if relevant)

26 help with any housework? What were the main tasks undertaken daily and weekly, and how much time did these tasks take to complete?

Did your family own any of the following household items? Fridge, freezer, oven,

27 washing machine, vacuum cleaner, lawn mower etc. How often were the following activities undertaken? Bathing, washing clothes, vacuuming, etc.

\section{FOOD}

\section{Home Grown Food}

Did you grow vegetables at home? Do you recall which types? Potatoes,

28 cabbages, parsnips, carrots, peas, lettuce/salad crops, tomatoes, etc. If and when did you buy vegetables?

29 Did you grow fruit at home? Do you recall which types? Apples, plums, pears, lemons, oranges, strawberries, raspberries etc. If and when did you buy fruit?

30 Did you produce any other types of food at home? Eggs, milk, chicken etc.

31 Do you recall approximately what percentage of consumed food was grown at home?

Did you receive home grown food from relatives and neighbours? If so, what type and how often?

\section{Bought Food}

33

Who was responsible for purchasing food? Where was food purchased? Dairy, local shops, market, supermarket, etc.

34 Do you recall how often your family bought food?

35 What would a typical breakfast, lunch and dinner be?

36

Who was responsible for the preparation of each meal? Do you recall how long it took to prepare each meal?

37

Did you and your family eat out? If so, how often and what would be the meal be?

38

\section{TRANSPORTATION}

39

What forms of private transport did you have at home? How often were these used and for what purposes? Car, bicycle, etc.

What forms of public transport did you and your family use? How often were these used and for what purposes? Bus, train, ferry, etc.

41

Do you ever recall your parents worrying about the cost of petrol, or the cost of public transport?

\section{RECREATION}

42 Did your family own any of the following items? How often did you watch or 
listen to them as a family? Television, wireless, gramophone etc.

Did your family own books? How much time did you and your family spend reading? How often (if at all) did you or your family visit a public library? How do you recall you and your family spending time in the evenings? Please describe a typical evening.

How do you recall you and your family spending time at the weekends? Please describe a typical Saturday and Sunday.

Were you involved in any organised out-of-school activities? Girl Guides, Boy Scouts, music, sport, etc.

47 What toys did you own? Construction toys, toy trains, Dolls House etc.

48 What were the recreational activities of you and your immediate family? Sewing, reading, gardening, DIY, sports, amateur dramatics, etc.

What social groups or networks were you a part of (if any)? Church, sports clubs, hobby groups, etc.

In a typical year, how often and where did you go during holiday periods? How

50 did you get there? Please could you describe the holiday that you recall with most clarity, or the holiday that you remember enjoying the most.

How often did you spend time with your extended family? Where did they live

51 and how did you get there?

52

By what means and how often did you communicate with significant friends and family? Letter, phone call, visit, etc.

\section{SIGNIFICANT MOMENTS}

As you recall your early years, what are the significant or most memorable moments? Please describe the memories of people or places which are particularly important to you.

\section{QUALITY OF LIFE}

How satisfied do you feel that you and your family were with the balance between work, family and recreation time during this period?

55 What do you consider was better about life in your early years than life today?

56 What do you consider is better about life today than it was in your early years?

57 Did you feel safe in your house?

What methods did your family use to keep their house and possessions secure (if any)?

59

How would you rate you and your family's overall quality of life during your early years? How does this compare to today? 
Page $\mathbf{2 9 0}$ of $\mathbf{3 3 2}$ 


\section{Appendix C: Ethics Approval Number 19031}

TE WHARE WĀNANGA O TE ŪPOKO O TE IKA A MĀUI

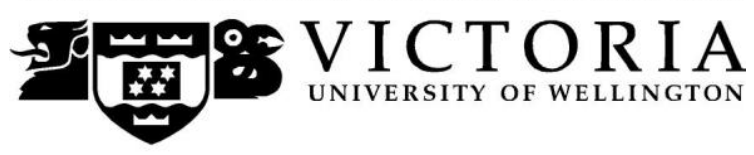

Phone 0-4-463 5676

MEMORANDUM

Fax $\quad 0-4-4635209$

\begin{tabular}{l|l}
\hline TO & Adele Leah \\
\hline COPY TO & $\begin{array}{l}\text { Brenda Vale } \\
\text { Nigel Isaacs }\end{array}$ \\
\hline FROM & Dr Allison Kirkman, Convener, Human Ethics Committee \\
\hline
\end{tabular}

\begin{tabular}{l|l}
\hline DATE & 16 December 2011 \\
\hline PAGES & 1 \\
\hline
\end{tabular}

SUBJECT

Ethics Approval: 19031

Times Change, Seasons Change, Houses Adapt

Thank you for your application for ethical approval, which has now been considered by the Standing Committee of the Human Ethics Committee.

Your application has been approved from the above date and this approval continues until 1 June 2014. If your data collection is not completed by this date you should apply to the Human Ethics Committee for an extension to this approval.

Best wishes with the research.

Allison Kirkman

Human Ethics Committee 
Page 292 of $\mathbf{3 3 2}$ 


\section{Appendix D: Notes from a Recorded Oral Interview with a Present}

Day Inhabitant of a Case Study House

\section{Ngaio, Wellington}

Interview Number:

Interviewee:

Date:

Recorded at:

Interviewer:

Abstracter:

Recording Equipment:

Recording Format:
TS_11

$22^{\text {nd }}$ May 2012

, Ngaio, Wellington 6035

Adele Leah

Adele Leah

TASCAM Linear PCM Recorder DR-40

AKG C417 PP Vocal Condenser Microphones

.wav file, 24bit at $96 \mathrm{kHz}$, with interviewer and interviewee on

separate channels

Time-

code

Ref.

0:00:00 Recording identification and permission granted. FAMILY

$0: 00: 45$

Born in DUNEDIN in 1978.

0:00:53 MIRAMAR before they bought the house. MOTHER and FATHER live in KHANDALLAH. Describes FATHER'S WORK.

$0: 01: 55$ One DOG.

\section{HOUSING}

$0: 02: 03$

Owns the house, bought in late 2009. Explains that the BANK owns the house really.

Describes that they lived with MOTHER a long time whilst saving up a deposit. They were determined not to buy a house until they had saved a twenty per cent deposit. Details. Explains that prior to that, she had moved about twenty four times and had lived in "disgusting" places. "...so we had quite a strict criteria for what we wanted and a lot of it was based around afternoon sun and, you know, good water pressure, and, you know, all those sort of practical things that you don't really find often in the same place in Wellington. But eventually we saw this place and we thought, oh yes, it meets our criteria..." Explains that they didn't like the colour of the external paint and the house seemed overpriced. Describes the purchasing process which took six months. Details.

Explains that it was more the bones of the house that they liked, rather than the external appearance. Details. 
purchased it have made it better to live in. Describes that the first thing they did after they bought the house was to sort out all of the INSULATION. Describes fitting the UNDER FLOOR insulation herself, spending four or five months underneath the house, cutting each piece of insulation to size. Details. "...but for us, that made the biggest difference because if muffled the noise inside, it was like a big drum, sort of echoing, and it stopped the wind blowing through and up...come winter, all of a sudden, it retained its heat from the day and it felt lovely, and it was, you know, it just felt cosy." Details. Reflects on the cost of the houses in the street.

KITCHEN, "I use it a lot and I hate it...the owners before us must have put in like a flat pack type kitchen setup...I think they've tried to keep it in keeping with the style of the house, but it's just really thoughtless..." Details the numerous problems in terms of the 0:07:45 layout, which include the recess for the FRIDGE being too small, items not lining through, water pooling in the corner of the SINK, and the WORKTOP being three inches too high. However, enjoys COOKING, the room gets the morning SUN and is a nice space to be in.

LOUNGE with the BOX FIREPLACE, explains that they spend most of their time in this room. When it is sunny, they will open the FRONT DOOR and spend time on the PORCH. "....and in winter, that little box pumps out so much heat that we always end up on the far side of the room...it's too hot." Explains that they haven't figured out a way to get the heat to the other rooms in the house yet, but that 0:09:49 idea will come. JUNK ROOM, which will be the SPARE BEDROOM or the BABY'S ROOM on day. Explains that this room has been relined, and they have employed a JOINER to make RIMU surrounds for the WINDOWS and the BASE BOARDS. STUDY, which has also been re-lined, contains a bed and some more "junk". Explains that they have purchased the CARPET, but it is being stored whilst they finish the PAINTING.

MASTER BEDROOM ... the largest room. SUN ROOM ... used to be the TOOL ROOM, but explains that they have reconditioned and relined the SHED and so the TOOLS have gone back out there. Explains that eventually, it would be nice to have the SUN ROOM as the SUMMER DINING ROOM. Details. BATHROOM and the SHED for storing TOOLS and BIKES.

0:12:59 GAS, ELECTRICITY and BROADBAND.

Explains that they would light a FIRE most days in the WINTER, when

0:13:07 the temperature drops below thirteen degrees. Explains that they have lit less than ten FIRES this year.

Used to be a GAS powered HOT WATER CALIFONT system in the house. Explains that they took that out quite quickly and installed the most efficient BOSCH INSTANT GAS powered WATER HEATER. "...it's like the most eco-friendly system you can buy..." WOOD is free. Describes how they scavenge WOOD. Explains that they have been burning the SARKING that they have ripped out of 0:14:39 the house, they have about eighteen boxes. SUMMER ... ELECTRICITY $\$ 30$ per month, GAS $\$ 35$ per month. Last month they had the most expensive bill that they have had, which was $\$ 140$ for 
both. Attributes this to the use of POWER TOOLS. Details. Explains that they keep SHOWERS to a minimum length and describes how they are replacing the HALOGEN LIGHTS for LED's. "So really it's just the fridge, the TV which we turn off at the wall most days, and charging computers and stuff."

WASTE ... have two COMPOST bins, RECYCLE PLASTICS and PAPER, burn NEWSPAPERS for the FIRE. One full yellow bag every two weeks for general WASTE.

RE-ROOFED, installed UNDER FLOOR INSULATION, RE-GIBBED and INSULATED the walls in the two small middle BEDROOMS. Installed a CEILING LADDER in the HALLWAY for good access to the ROOF . Topped up the CEILING INSULATION. Removed the GAS CALIFONT system and installed BOSCH system. Explains that there used to be a WCC sewerage main at the front of the house which overflowed. WCC repaired this and installed a new junction, which

0:18:00 enabled them the get the whole front garden LANDSCAPED. Built a wood box to store WOOD, cleaned out underneath the house, removed 64 cubic metres of JUNK and GREEN WASTE off the section in eight, 8 cubic metre skips. LEVELLED and flattened the whole back LAWN which took a lot of cubic metres of TOPSOIL. RETAINED the back section, CONCRETED behind the SHED, RE-LINED and REROOFED the SHED. RE-CONDITIONED the front WINDOW, in the KITCHEN. Replaced the FRONT DOOR.

"Every tree that we pulled out we have replaced with a native..."

0:21:03 Explains that they have spent the last six months working on the FENCING.

TO DO LIST ... finish PAINTING the middle two rooms, get the

0:21:27 CARPET down, PAINT the SUN ROOM at the back, PAINT the exterior WINDOW SILLS, then look at the BATHROOM and the KITCHEN.

OUTSIDE ... DIY, does all of the big jobs, mows the LAWNS,

0:22:17 "...he is the instigator for most of the DIY stuff that we do..." Details. Explains that every weekend is spent outside.

Explains that the GARDEN was a "jungle" when they purchased the house, and they are trying to get it to a point where it is low maintenance. Details.

BEST THING ... WARMTH of the house when you arrive home, great NEIGHBOURS. WORST THING ... not really anything.

Most of the time they are at home. Details.

Do not regularly rent or own any other houses.

"I'd say expensive, I think we're pretty lucky to be able to do what we do, but even the way that we do things, we have to be pretty creative, in order to make it affordable... we make smart decisions I think." Explains.

EDUCATION AND WORK
is an ACCOUNT MANAGER in the per day);
hours per day).
happy in his work.
is mainly responsible for HOUSEHOLD WORK. Explains that
she is in charge of the INSIDE and is in charge of the OUTSIDE.


WASHING CLOTHES ... as and when required. Explains that allocating a specific amount of time is difficult, as she spends a lot of time MULTI-TASKING. Estimates one or two hours a day, which includes COOKING.

FRIDGE/FREEZER, ELECTRIC OVEN, GAS HOB, WASHING MACHINE, nO TUMBLE DRYER, VACUUM CLEANER, LAWN MOWER, POWER TOOLS including an ELECTRIC CHAINSAW for cutting WOOD.

"It's reasonably balanced, there's not much time for doing nothing..."

\section{FOOD}

No VEGETABLES are being grown at home currently, but the intention is to grow vegetables at home in the future.

Purchase VEGETABLES as and when required. Undertakes one big shop every one to two weeks, and then does top up shopping in between, when she is passing a shop. BUTCHER for fresh meat, occasionally goes to the VEGETABLE MARKET.

Described FRUIT tree. Explains that when they plant VEGETABLES, SALAD. Details.

Explains that they did consider chooks, but deciding against them as they would ruin the grass.

A bag of FEIJOA'S every year from a NEIGHBOUR'S PARENT'S. Two bags of FEIJOA'S a year from parents. MARMALADE from mother. BREAKFAST ... muesli, fruit, LUNCH ... varies, bought lunches,

0:36:58 DINNER ... meat and vegetables, don't often eat too much carbohydrate, casseroles, curry. an hour to an hour in food preparation each day.

Eat out once a week, for a cheap meal, sometimes a CURRY. Also might eat out on special occasions. Details.

"I'd say expensive, I try and stay away from big packaged and processed food...going to eat out is more expensive than it should be, for what you get."

\section{TRANSPORTATION}

has a COMPANY CAR, used extensively for work. Explains that in the last month, they have bought a CAR for $\square$ is

0:39:18 travelling to WORK and back every day in the CAR, but prior to this was catching the TRAIN and the BUS. BICYCLES ... two each, used for recreation.

Do not use PUBLIC TRANSPORT. "...I think if Wellington wasn't quite

0:40:12 so hilly, and my shops weren't so spread around, I'd like to think that I could bike between them all, but it's just not feasible..."

0:40:42 "I think it is expensive..." Details. 
0:43:02 they rely on their CELL PHONES. Communicate via. TEXT or EMAIL. TELEVISION ... evenings. I PAD for listening to MUSIC.

$0: 44: 08$

Explains that CYCLING is a big part of their lives, but since they bought the house, they haven't done as much as they would like to. HOLIDAYS ... they went to MELBOURNE this Christmas for ten days,

0:44:30 but since purchasing the house in 2009, their holidays have primarily been spent at home doing DIY. Details.

0:45:55 Not involved with any SOCIAL GROUPS and NETWORKS.

\section{SIGNIFICANT MOMENTS}

0:46:19 Buying the house.

QUALITY OF LIFE

$0: 46: 39$

SAFE ... yes.

SECURITY ... COMMUNITY, “...I think it's more important to know your neighbours necessarily than to lock your door..."

$0: 46: 51$

$0: 47: 30$ "It's hard to complain..."

Describes how they, together with NEIGHBOURS applied to Wellington City Council for some plants for the roadside. A group of residents all helped to plant the native plants in the SPRING, there were about 150 plants in total. These RESIDENTS are helping to maintain the roadside areas of planting adjacent to their houses, which are ordinarily the responsibility of WCC. Thank you for the interview.

$0: 49: 32$ [Interview ends] 
Page 298 of $\mathbf{3 3 2}$ 


\section{Appendix E: Notes from a Recorded Oral Interview with a 1930s and 1940s Housing and Lifestyle Interviewee}

\section{[Wellington 1937]}

Interview Number:

Interviewee:

Date:

Recorded at:

Interviewer:

Abstracter:

Recording Equipment:

Recording Format:
NZ_03

$28^{\text {th }}$ May 2012

Wellington, 6011

Adele Leah

Adele Leah

TASCAM Linear PCM Recorder DR-40

AKG C417 PP Vocal Condenser Microphones

.wav file, 24bit at $96 \mathrm{kHz}$, with interviewer and interviewee on

separate channels

Time-

code

Ref.

0:00:00 Recording identification and permission granted.

\section{FAMILY}

$0: 00: 44$

Born in LOWER HUTT, WELLINGTON in 1937.

IMMEDIATE FAMILY ... BROTHER and three younger SISTERS.

MOTHER and FATHER. Details. RELATIVES ... Describes a large

0:00:58 FAMILY on his mother's side living in EASTBOURNE. His father's SISTER and MOTHER ( GRANDMOTHER) also lived with them. Mentions that his GRANDFATHER had died in 1926. Details.

$0: 02: 28$

No other RELATIVES or LODGERS lived with them. Mentions that his GRANDMOTHER lived with them until she died. Details.

\section{HOUSING}

Explains that the house that he remembers the best was the house that they moved to in HAWKES BAY. was nearly seven years old when they moved there. TYPE of house ..."It was a very large wooden house, originally two storey, it was built in 1876 I think, but the top storey fell off during the 1931 earthquake, and they made a huge roof over the top of it, it had verandas round the three sides."

0:03:29 PARENTS OWNED the house.

REASONS for CHOOSING to BUY, "...they actually moved to Hawkes Bay when I was about five, because I was very ill with bronchitis and pneumonia in Lower Hutt...the doctor apparently told them that if they didn't take me to a warmer place, they'd probably lose me. So Dad was a horticulturist in Lower Hutt and they moved up to Napier for a sort of piece work job with a local council...then Dad bought a poultry killing business... and that's why we moved there." Mentions that his FATHER wanted a better JOB, but that he wasn't, "...really 
cut out for business..." Explains that after a few years, his FATHER got ill from quill infections from the CHICKENS and had to give that up.

FAMILY ... "Oh we loved the area, there was only twelve hundred people there, and it was a small borough ..." Explains that they had quite a lot of land, and they grew PEAS and TOMATOES and FRUIT which they SOLD. "It was like a small farm let really, Dad...used to 0:05:04 bring home wild pigs and we put them in a pen...but for my mother it was quite a lonely life because she left all her brothers and sisters down in Eastbourne... and I know she missed them. She was a very meek sort of person and didn't form friendships easily...and I don't think my father was intellectually stimulated there."

ROOMS in the HOUSE ... "There were four very large rooms, with a very wide corridor down the middle and stairs leading off the corridor up to... what was originally... four rooms upstairs, but what 0:06:02 now was a very large attic...One end of the veranda had been turned into a kitchen, and there was another room which was the bathroom and the washhouse, and a small room near the stairs where my grandmother lived until she died."

Describes the four large rooms ... a DINING ROOM with a COAL RANGE, a LOUNGE/LIVING ROOM with a huge fire that was four feet wide. Other side of the corridor, a large room that his PARENTS lived in and another room that his SIBLINGS slept in, "... and I slept

0:06:51 out on the veranda in the open...the fantails used to come in a poop on my bed in the morning and I did get very wet one time I remember. My father, at the other end of the veranda to where I was sleeping, put up a small wall for my older sister to sleep in as she got older..." Reflects.

Mentions that they did not have HOT WATER when they first arrived at the house, "... we had a tap on the side of the coal range, and after a year or two I think my Dad put a big cylinder behind there, we got a different coal range which heated our water..."

0:09:00 LIGHTS and SOCKETS ... "There was a central light, and that was about it."

SERVICES ... Explains that they had several WATER BORES on the property, "...it was artesian water and we had a tank on the side of the house, and the water was sufficient pressure, natural pressure, to fill the tank...I don't think we had mains water while we lived there... I left there when I was nineteen to go to university." ELECTRICITY SUPPLY. No GAS. "We had a telephone service which was a party line and you had to ring it; two, four, two, $K$ was our number...and often it was very slow."

0:10:00 MATERIALS ... all TIMBER and an IRON ROOF.

SPACE HEATING ...OPEN FIRE in the LOUNGE and the STOVE for COOKING. Mentions that it was one of his JOBS, to cut the WOOD for the FIRE. "I didn't wear shoes 'til I went to high school...even

0:10:12 through high school I just had roman sandals, I didn't have any shoes...quite a few of us only had bare feet to school, primary school, we used to run to school...it was how it was...in summer time it was hot weather and your feet got used to the gravel..." 
in, his father installed a WOOD BURNING STOVE and the WATER was heated in a BOILER beside the STOVE. Mentions that afterwards they piped the WATER to the BATHROOM. Prior to this, they would HEAT WATER in the COPPER and bail the water into the BATH.

COST of FUEL ... Does not recall the cost of ELECTRICITY, but mentions that they only used it for LIGHTING. Explains that Dad 0:12:04 used to bring home WOOD, which was FREE. Mentions that, because they had a killing farm, his FATHER put in a large FREEZER that you could walk in to. Details.

WASTE ..."I don't think it was an issue really, 'cause we didn't have tinned things, we just bought bread...I don't recall us having any problems with waste..." Explains that there was no WASTE COLLECTION other than for HUMAN WASTE, the NIGHT CART used to come and collect the waste from the OUTSIDE TOILET, which was located behind the WOOD SHED. Explains that the NIGHT CART operated for quite a long time, his father eventually put in a SEPTIC TANK.

ALTERATIONS and IMPROVEMENTS ... WATER HEATING, SEPTIC TANK, TOILET relocated from outside into the BATHROOM. Explains that when he was a TEENAGER, he did a lot of WORK on the house himself. Describes how he lifted the ROOF of the main section and built a huge BEDROOM for himself upstairs. FATHER GLAZED in the

0:14:19 PORCH that slept on. Details. Explains that no-one taught him any building skills, but that he simply learned by doing it. Mentions that his FATHER had a NEW KITCHEN built, just before left home. Details. Explains that prior to this, water had used to pour down the kitchen wall, behind the dresser. Reflects.

GARDEN ... "We had a huge garden; we grew everything that we needed." Mentions that, as a TEENAGER, he would grow PLANTS himself and sell them for some POCKET MONEY ... recalls selling ONION PLANTS. Explains that he used to CYCLE to HIGH SCHOOL, which was seven miles away and in the morning, before $\mathrm{SCHOOL}$, he would go to sell his plants at a nearby NURSERY. Mentions that Dad sold the business, but even after that, they still had a lot of CHOOKS. GARDEN ACTIVITIES ... Describes the GARDEN as being a part of their lives. Explains that in the late 1940s, the GOVERNMENT forced the SALE of a lot of their property for HOUSING, which ended the marketing of PEAS and TOMATOES.

GARDEN MAINTENANCE ... "We all did a bit..." Explains that his Dad, by this time, had worked for a NURSERYMAN, several miles away, he used to BIKE there and back. Mentions that they were generally self-sufficient.

BEST THING ... "I don't think I ever had a bad thought about it...we had a freedom then, we used to roam in the hills... we used play in

0:18:34 the hay... we used to collect mushrooms and sell those... we had a very happy childhood really." Explains that he had a different sort of life experience to his SISTER, who was born thirteen years later. TIME spent at HOME ... "We didn't travel much, of course. In the 0:19:39 early days, when my Dad had the poultry business, we used to go out with him occasionally...to pick up chooks, especially turkeys at 
Christmastime, on the truck, we had a truck by then. But we played in the river, which was very close by, we spent a lot of time in the river, my parent's never worried about where we were..." Mentions that he PLAYED MUSIC a lot when he was young and his Dad was very MUSICAL. DAD supplemented his INCOME by playing at NIGHT CLUBS, "...he was a very good trumpet player...and the man across the road who was actually a builder, played the piano, he could even do it when he was very drunk...so my Dad and he often had parties at home..." Explains that his youngest SISTER was MUSICAL and his MOTHER played the PIANO. Details of his PARENTS moving to AUCKLAND. COST of HOUSING ... mentions that he thinks that it was quite hard financially for his parents. Details.

SCHOOL ... Explains that there was no choice of primary school, describes it as being a good school. Details. Recalls the TOILETS being outside in the school PLAYGROUND. WALKED to school which was only about a mile away.

Enjoyed school. SCHOOL ACTIVITIES ... played in the PLAYGROUND,

0:23:11 MARBLES. Explains that he was two years older than everyone else, due to his ILLNESS. Details.

PARENTS' OCCUPATIONS ... FATHER ... Explains that later in life, he managed gardens of a large estate in Auckland and became quite well known. He had originally trained as an accountant, but didn't enjoy it. Reflects on the difficulty of life during the 1930s, "...certainly, they were very poor." Mentions that his GRANDMOTHER had no income and they supported her until she died.

"...he worked very long hours...and he'd often work on a Saturday..."

0:24:41 Don thinks that his FATHER was HAPPY in his work. Recalls playing SPORT on a SATURDAY and his FATHER watching him. Details. MOTHER ... Explains that she had lots of PREGNANCIES, lost two CHILDREN, and was often quite ILL. Details. At one point his MOTHER had to have a helper to assist with HOUSEKEEPING, "...because she was just worn out basically." HOUSEHOLD WORK ... MOTHER, "... because Dad worked outside, it was a natural division of things..." Explains that SIBLINGS did not help with housework, because there was so much to do outside, "...just even keeping up the firewood was quite a task."

HOUSEHOLD WORK ... "It would have been mostly her life, I think, 0:27:02 cooking especially, she did go bowls and made some friends...I remember my nana coming to stay a few times from Eastbourne..." HOUSEHOLD ITEMS ... Bought their first WASHING MACHINE in the 1950s. A square AIDA, "... prior to that everything was done from the copper..." Mentions that they never had an ELECTRIC COOKER

0:27:39 and used a lot of WOOD. Does not remember having a VACUUM CLEANER. Recalls his FATHER doing a lot of SCYTHING. After his FATHER sold the SECTIONS, he developed a LAWN where the SEPTIC TANK was, and he used a hand MOWER. 
Explains that they didn't have a FRIDGE until later when the KITCHEN was relocated. Mentions that they had a PLASTER OF

0:29:18 PARIS type SAFE by the WELL, with SACK over it. This would soak up the WATER and keep things COOL. Mentions that they had a COW, and for a while made their own BUTTER.

BALANCE between WORK, FAMILY and RECREATION time ... Explains that his BROTHER took an APPRENTICESHIP and was very gifted in TOOL MAKING, good at fixing things. Reflects. Mentions playing a lot of TENNIS. Describes his middle SISTER contracting POLIO in the

0:30:10 epidemic and not being able to walk for a long time. Describes having a COT in the DINING ROOM and helping her. During the EPIDEMIC, Mum schooled the CHILDREN on the VERANDA where slept. Reflects on having regular hours each day set aside for school work.

Explains that his FATHER worked long hours, but he enjoyed meeting his FRIENDS in the PUB.

\section{FOOD}

\section{HOME GROWN FOOD}

VEGETABLES ... TOMATOES, KUMARA ... at one point in time there was a potato problem and Dad made quite a lot of money from

0:31:58 selling kumara, PUMPKIN. Explains that HAWKES BAY has got a fantastic CLIMATE for growing VEGETABLES, "...I would doubt that we bought vegetables."

FRUIT ... PEARS, APPLES, FIGS, PLUMS, and APRICOTS ... which they sold down south. Mentions that they grew several types of plums, some of which are not marketed anymore and were delicious. Does not recall ever purchasing FRUIT.

FOOD PRODUCED at home ... EGGS, MILK from the COW was more of a HOBBY, BUTTER. "It was a fairly narrow diet we had, but it was good stuff...had a lot of roasts and during duck shooting season Dad used to bring home lots of ducks."

PERCENTAGE of consumed food GROWN at HOME ... purchased

0:33:45 FLOUR, BUTTER, BREAD and the basic items. Recalls MOTHER cooking lots of SCONES.

NO HOME GROWN FOOD from RELATIVES or NEIGHBOURS. "I had

my own veggie garden; I used to sell veggies, even to my mother."

\section{BOUGHT FOOD}

FOOD PURCHASED at the VILLAGE. Recalls a good BUTCHER, a HABERDASHERY, BAKER, "...a trough outside for watering the horse." Does not recall buying food in bulk, MOTHER purchased the FOOD. Recalls CYCLING in early in the morning, to get the BREAD.

TYPICAL BREAKFAST ... "We always had porridge for breakfast..." LUNCH ... BREAD. DINNER ... ROAST MEAT meals. Reflects.

FOOD PREPARATION ... MOTHER. Does not recall how long his MOTHER spent COOKING each day. GRANDMOTHER did not help much, "...she didn't believe men should go into the kitchen actually,

0:36:18 it was quite a difficult issue with my mother..." Recalls his FATHER later COOKING two FRIED EGGS for BREAKFAST every day. Mentions that GRANDMOTHER also didn't believe in CHILDREN talking much, so they weren't allowed to talk whilst seated at the 
$0: 37: 24$

$0: 37: 30$

$0: 37: 42$

$0: 38: 43$

$0: 40: 41$

$0: 41: 26$

$0: 42: 05$

0:43:06

$0: 44: 57$

$0: 45: 35$

table, during the time when she was alive.

FAMILY never ate out.

BOUGHT FOOD... mentions that they didn't buy any pre-prepared FOOD.

\section{TRANSPORTATION}

PRIVATE TRANSPORTATION ..."In the early days Dad had a truck with the poultry business, and then he got a old Chrysler car, which was the only car that I can remember them ever having... I learned to drive in it." Explains that there were BUSES, his GRANDMOTHER used to produce beautiful KNITTING and would WALK down the road to catch the BUS into NAPIER to sell the KNITTING. All FAMILY members had BICYCLES. Recalls saving up his POCKET MONEY to purchase his own BICYCLE. TRUCK was purely for BUSINESS use. PUBLIC TRANSPORTATION ... used by MOTHER to get to NAPIER. Reflects on mother's FRIENDSHIP with NEIGHBOUR. used to CYCLE or catch the SCHOOL BUS to high school.

TRANSPORTATION ... doesn't recall whether or not this was perceived to be EXPENSIVE or AFFORDABLE ... SCHOOL TRANSPORT was FREE. Recalls going on one FAMILY HOLIDAY to TAUPO in the Chrysler ... FATHER caught and they SMOKED FISH. "The car broke down on the way home and we had to...park up on the side of the road ..."

\section{RECREATION}

TYPICAL EVENING ... Explains that there wasn't much RADIO, they played the GRAMOPHONE, played CARD GAMES. Explains that he enjoyed doing HOMEWORK when he was at HIGH SCHOOL. "...I think we just hung out and did things..."

TYPICAL WEEKEND ... SATURDAY and SUNDAY ... they always had a big ROAST LUNCH. Played FOOTBALL and his SISTER played BASKETBALL. Details. Explains that the WEEKEND was generally, OUTDOOR, FREE TIME, down by the RIVER.

Purchased his first TELEVISION in 1968. GRAMOPHONE ... yes. RADIO ... occasionally listened to at five o'clock. TELEPHONE ... used mostly by PARENTS, but not used often.

ORGANISED OUT-OF-SCHOOL ACTIVITIES ... CUBS and BOYS BRIGADE on FRIDAY NIGHT'S. Details. SCOUTS ... used to BIKE quite a way to get there. SISTER went to GUIDES. Recalls working for BADGES and remembers it being quite an activity. was in the LOCAL FOOTBALL TEAM for a while. Played SOFTBALL at SCHOOL. TENNIS ... recalls that the local ANGLICAN CHURCH had a free COURT, and that playing TENNIS was quite a sociable time. Participated in BIBLE CLASS and CHURCH activities. TOYS ... remembers that they had a MECCANO set at one point. "We didn't really need toys, because of all the outdoor things...there weren't that many children's books then...I don't recall many toys." RECREATIONAL ACTIVITIES ... MOTHER was good at SEWING and made a lot of their CLOTHES, especially his SISTERS' CLOTHES. MOTHER was also good at CROCHET, joined BOWLING with FATHER. FATHER'S recreation was going to the PUB and having some DRINKS with the GUYS ... every night at six o'clock. Details. 
TIME with extended FAMILY ... Recalls travelling on the TRAIN to visit FAMILY in LOWER HUTT once or twice. Details of GRANDMOTHER in EASTBOURNE. Recalls the very sociable years

0:47:26 that his PARENTS spent in EASTBOURNE before moving to HAWKES

BAY, has old photographs of his FAMILY playing CRICKET. Reflects. Explains that his GRANDMOTHER in EASTBOURNE FLEW up to NAPIER to visit them twice in an old AC3. a while.

\section{SIGNIFICANT MOMENTS}

"...the Queen's visit of 1953, it was made a huge thing actually... another time was when my grandmother disappeared,

0:50:39 she'd died in the night...I wasn't allowed to go to the funeral and I was very upset...it was quite nice talking to her, but she never said much about her background."

\section{QUALITY OF LIFE}

SAFE ..."Yes, completely." Explains that there was a burglary once, someone tried to steal their chickens. The burglar had kicked his

0:51:47 FATHER and broken his ribs, he knew who the burglar was, but wouldn't report him as he would have made trouble for his FAMILY. Reflects.

Explains that he still feels safe in his house, "...probably

0:52:41 unrealistically so." Mentions that they never LOCKED their doors and explains that today he always has to think about it. Reflects. SECURITY ... Doesn't even know if his FATHER'S FREEZER was locked, "...you never thought about being robbed."

BETTER in the PAST ... FREEDOM that they had as CHILDREN.

Reflects, "...I don't like the idea of driving to school to pick them up, I think it's good for kids to be able to, with their friends, walk to and from, but always to have a parent at home, when they arrive home is really good I think..." Reflects. Explains that he thinks that there is a lot more interaction now between PARENTS and their CHILDREN, and more involvement from FATHERS in the FAMILY, which is good.

Mentions that he enjoys the opportunity for CONCERTS due to living in the CITY and not in the COUNTRY and the fact that there are more BOOKS. Mentions that his FATHER worked as a CLEANER in the TOWN HALL for a while, because they didn't have much money. Also, his FATHER had looked after the CEMETERY and dug holes for many years, "...he was a hard worker my Dad..."

QUALITY of LIFE ... Explains that it was a simple life and that for that there is today. Reflects. Mentions the death of his WIFE. 
0:58:29 [Interview ends]

Page $\mathbf{3 0 6}$ of $\mathbf{3 3 2}$ 


\section{Appendix F: Original Floor Plan of a Tarikaka Settlement House}

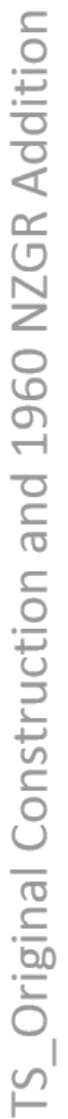
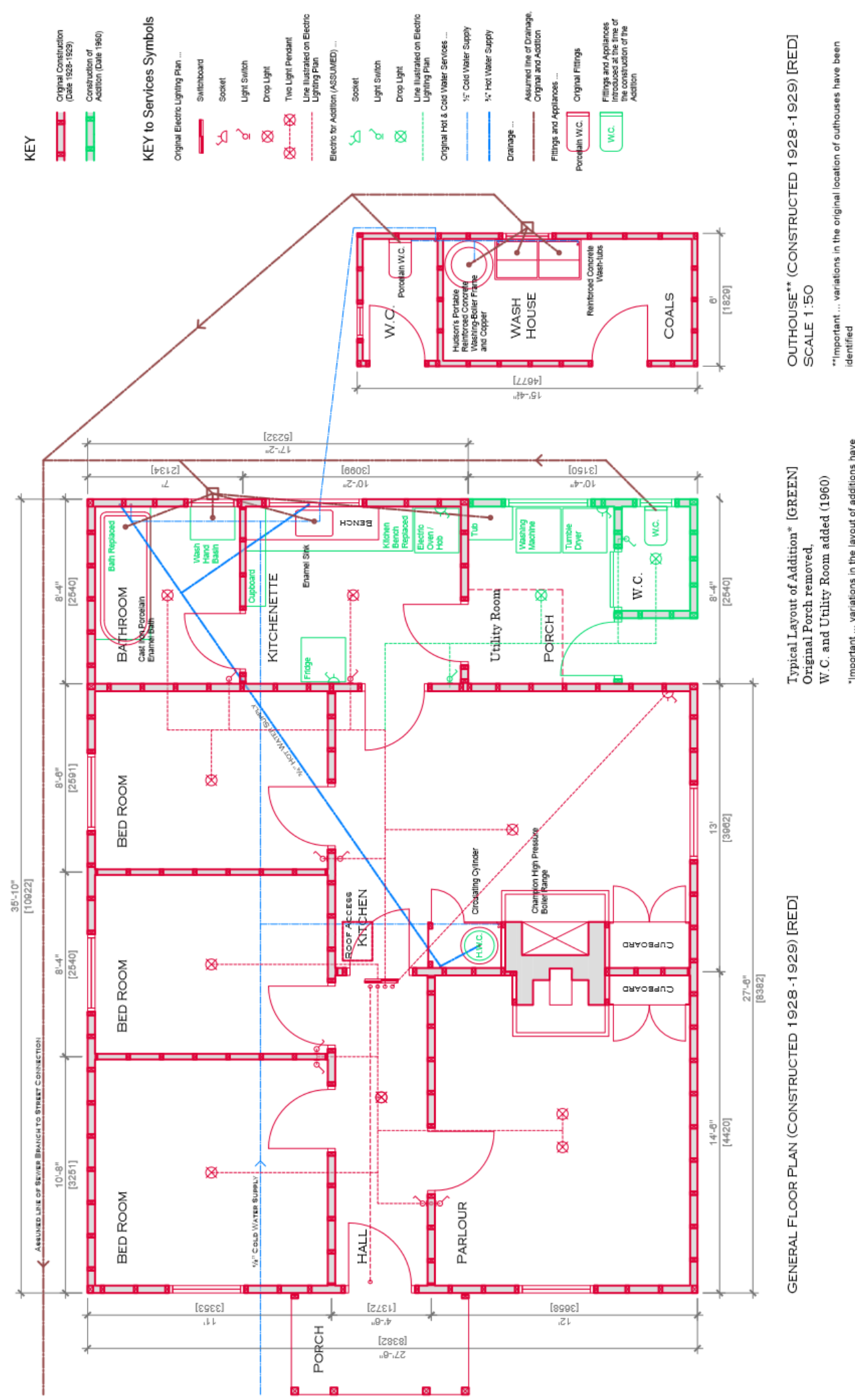

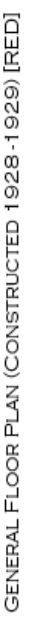


Page 308 of $\mathbf{3 3 2}$ 


\section{Appendix G: Present Day Floor Plan of a Tarikaka Settlement}

\section{House}
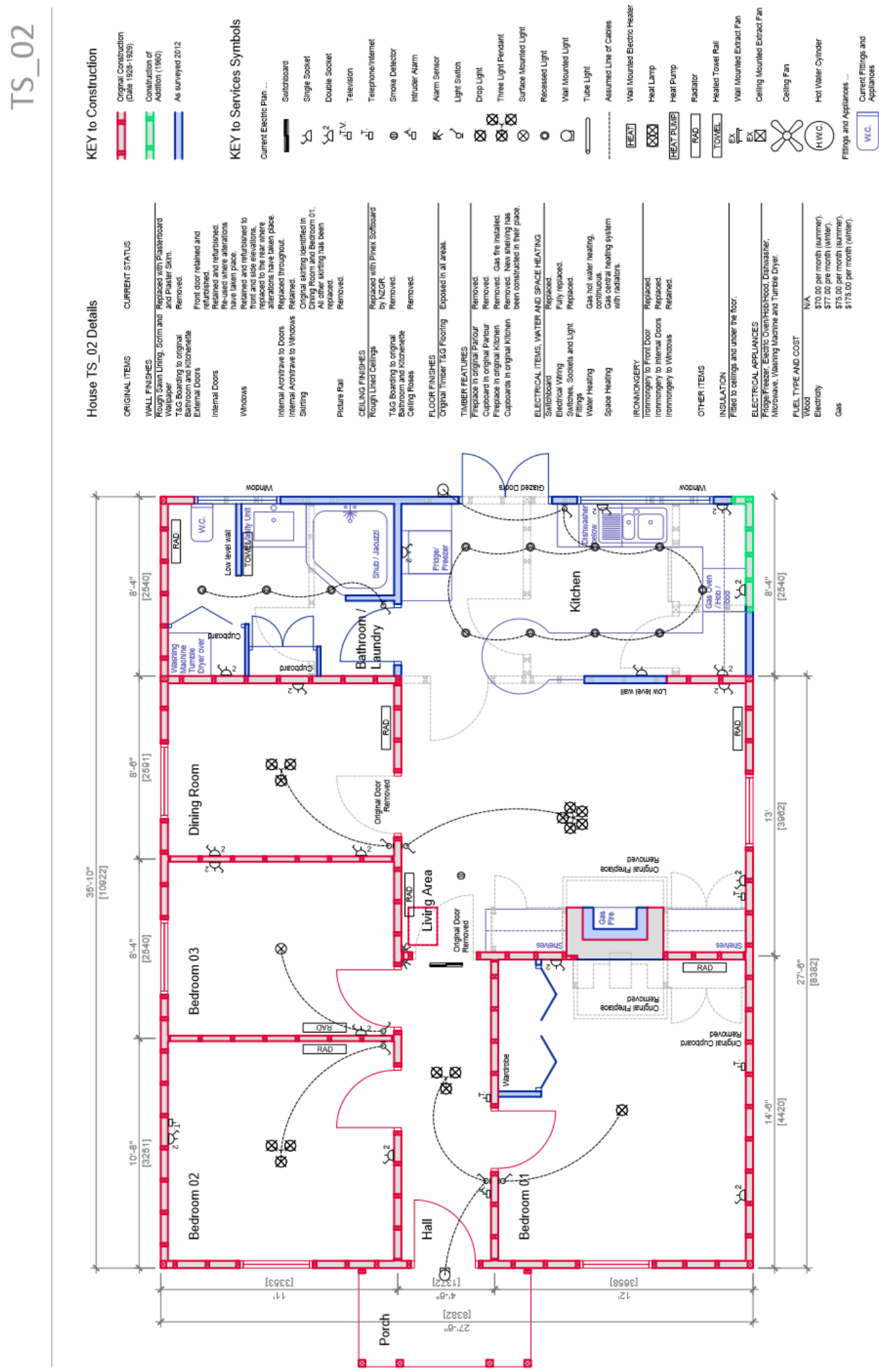
Page $\mathbf{3 1 0}$ of $\mathbf{3 3 2}$ 
Appendix H: Original Floor Plan of a Silver End Stuart House

高
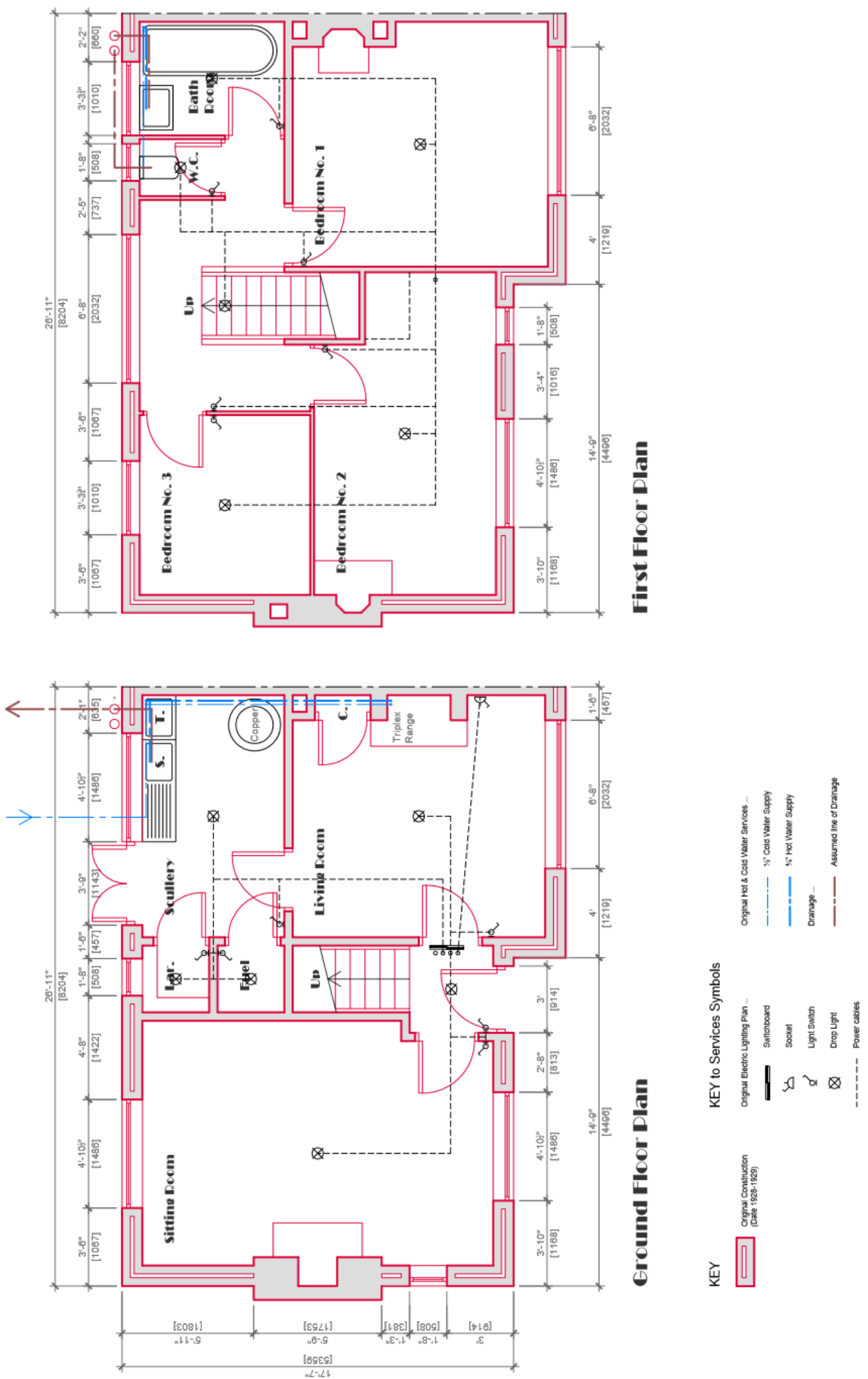
Page 312 of 332 


\section{Appendix I: Present Day Floor Plan of a Silver End Stuart House}

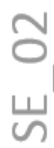
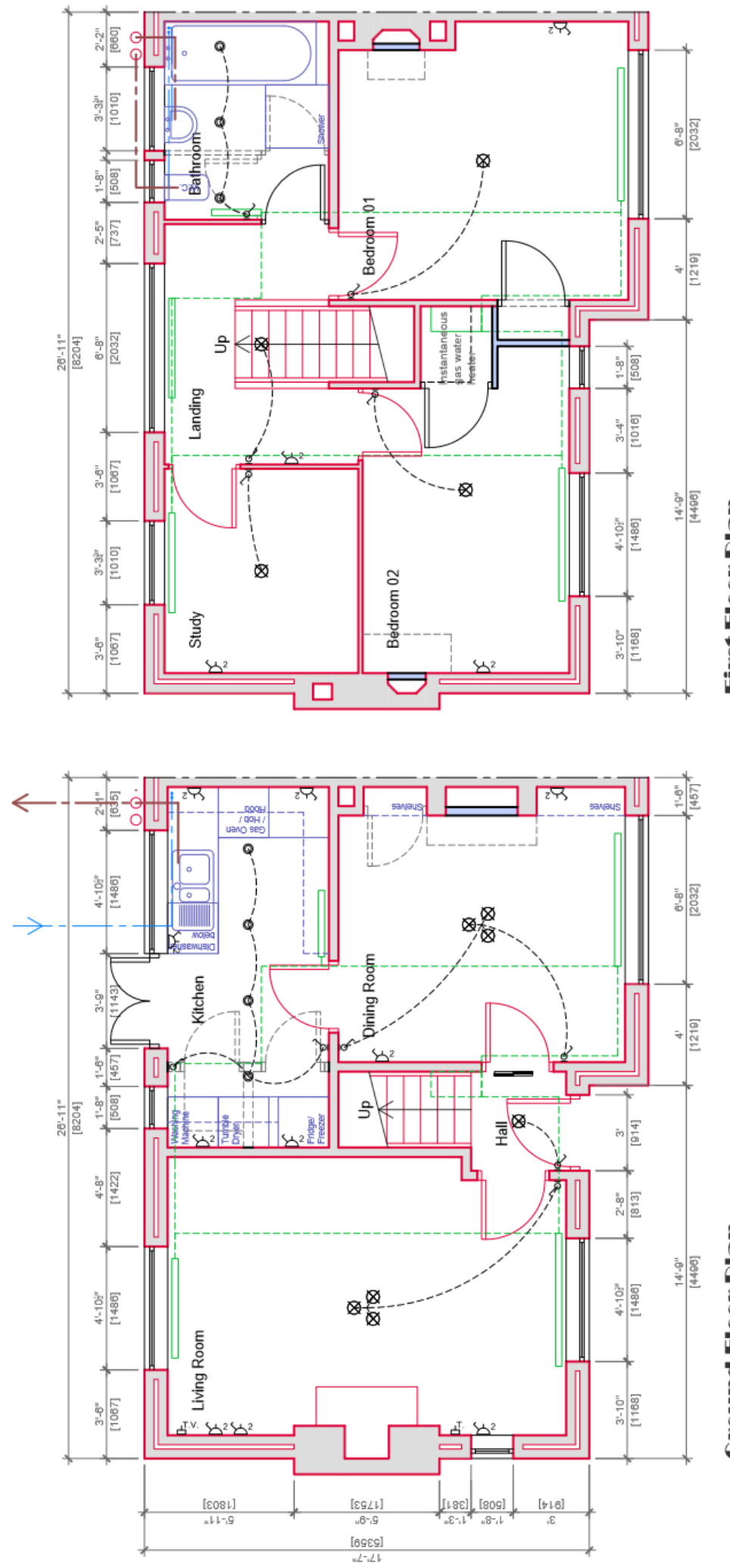

를
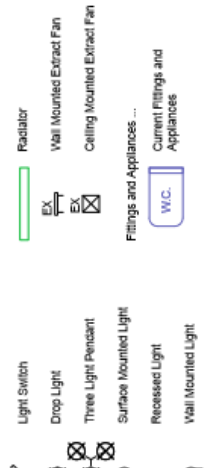

० $\otimes \otimes \circ 0$

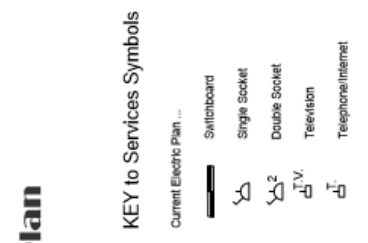

흘

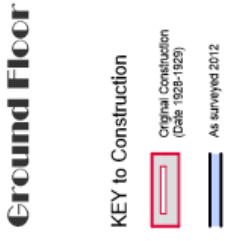


Page 314 of 332 
Appendix J: Results of the Embodied Energy Analysis for the Tarikaka Settlement House

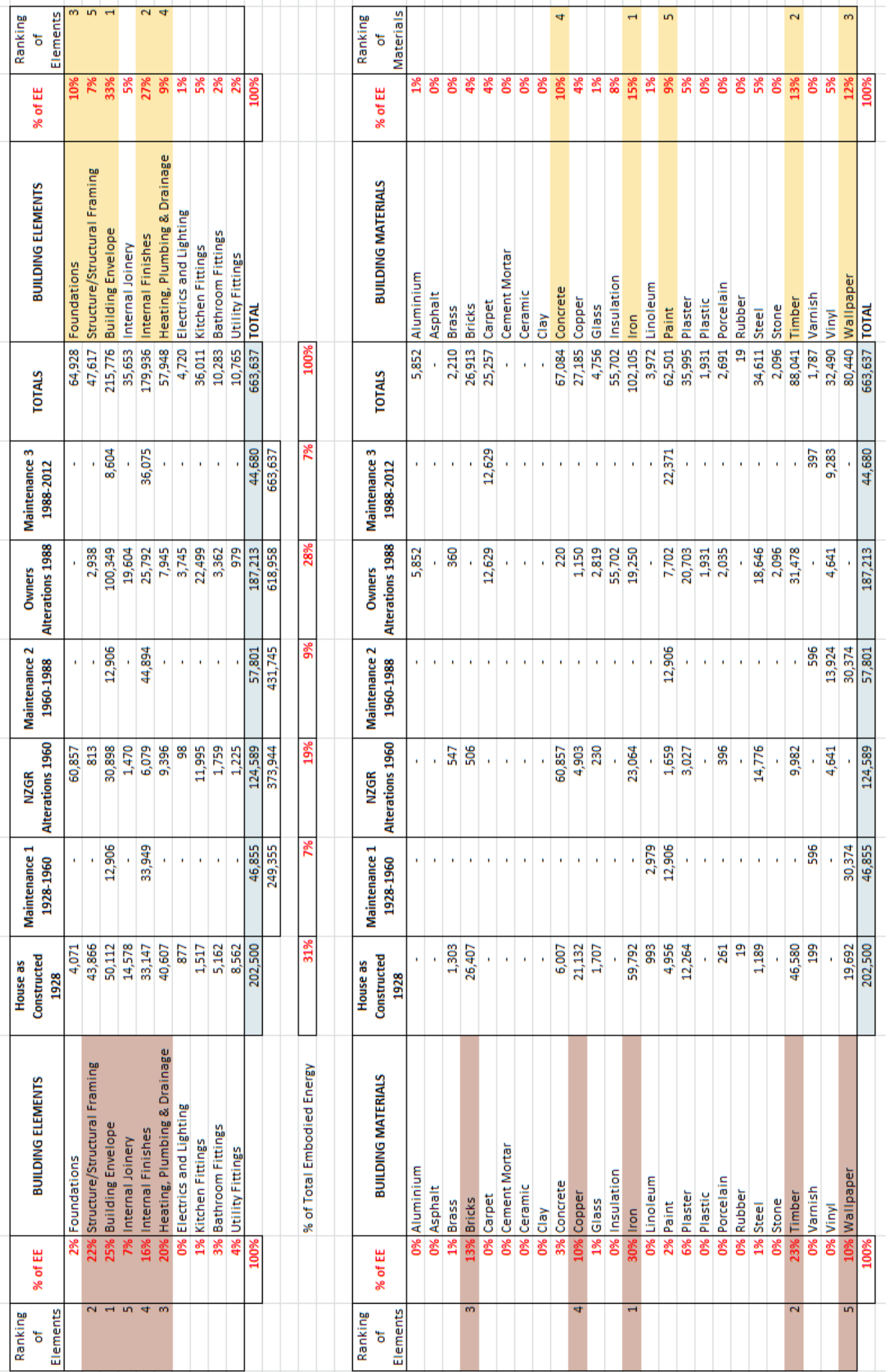


Page $\mathbf{3 1 6}$ of $\mathbf{3 3 2}$ 
Appendix K: Results of the Embodied Energy Analysis for the Silver End House

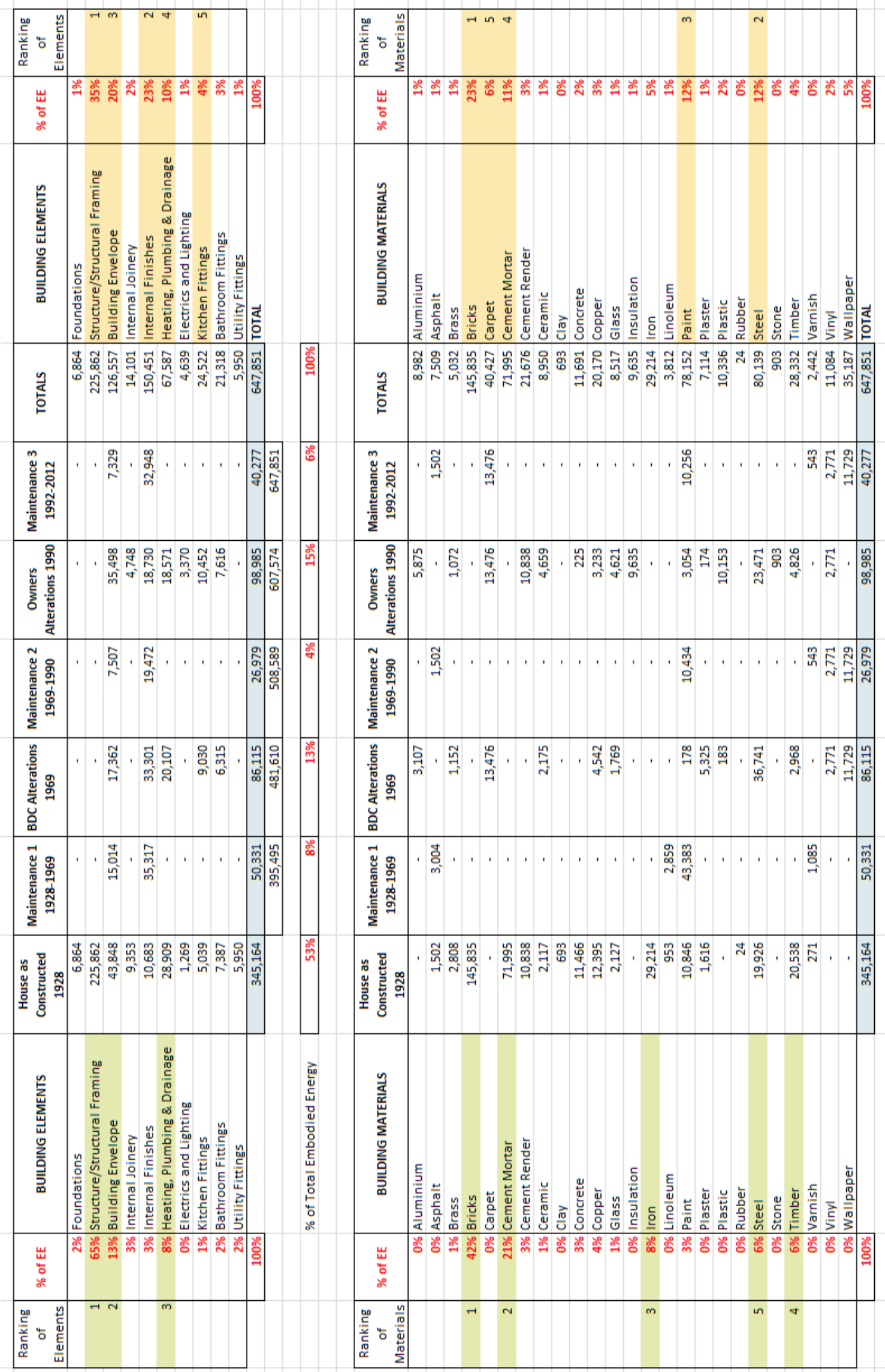


Page 318 of $\mathbf{3 3 2}$ 


\section{Bibliography}

Alcorn, A. (2003). Embodied Energy and $\mathrm{CO}_{2}$ Coefficients for NZ Building Materials. Wellington: Centre for Building Performance Research, Victoria University of Wellington.

Alcorn, A. (2010). Global sustainability and the New Zealand house. (PhD in Architecture), Victoria University of Wellington, Wellington.

Alcorn, A., \& Wood, P. (1998). New Zealand Building Materials Embodied Energy Coefficients Database, Volume II - Coefficients. Wellington: Centre for Building Performance Research, Victoria University of Wellington.

Architectural Branch. (1927). Plan of Housing Scheme for Railway Dept. Ngaio. Department of Railways. Located at Wellington City Archives, in file ref. 00001:1375:36/164 Pt 1, Subdivision (original): 7-27 Bombay Street (extension), Carroll Street, 8-40 Khandallah Road, Ngata Street (all), Pomare Street (all) and Tarikaka Street (all), A Aplin, New Zealand Railways, Ngaio Railways and Housing Development.

Aslet, C. (2010). Villages of Britain: The Five Hundred Villages that Made the Countryside. London: Bloomsbury Publishing PIc.

Auckland Star. (1923). Housing Railwaymen, The Government's Example. Auckland Star, 26th September 1923.

Beddoe, D. (1989). Back to home and duty: Women between the wars 1918-1939. London: Pandora.

Bianchi, S., Sayer, L., Milkie, M., \& Robinson, J. (2012). Housework: Who Did, Does or Will Do it, and How Much Does it matter? Social Forces, 91(1), 55-63.

BizEE Software Limited. (2013). Calculating Degree Days. Retrieved 14th July, 2013, from www.degreedays.net/calculation.

Bradbury, D., \& Powers, R. (2011). New natural home. New York: Thames \& Hudson.

Braintree and Witham Times. (1930). Special Supplement. Braintree and Witham Times, Friday August 1st, p. 2.

Braintree District Council. (1999). Supplementary Planning Guidance, Silver End Conservation Guide, January 1999. Braintree District Council.

Braintree District Council. (2013). Restrictions that Apply in a Conservation Area. Braintree District Council. Retrieved from www.braintree.gov.uk/info/200221/planning/205/do i live in a conservation area/ $\underline{2}$ on 10th July 2013.

Brinsmead, N. (2009). Flat Roof Repair. Retrieved 22nd July, 2013, from www.homebuilding.co.uk/advice/key-choices/roofing/flat-roof-repair.

Brookes, B. (Ed.). (2000). At home in New Zealand. Wellington: Bridget Williams Books. 
Brookes, B., Macdonald, C., \& Tennant, M. (Eds.). (1992). Women in history 2. Wellington, NZ: Bridget Williams Books.

Burnett, J. (1980). A social history of housing, 1815-1985 (Second ed.). London and New York: Methuen \& Co. Ltd.

Carpenter, R. (2007). Mister Pink: The Architectural Legacy of Walter Francis Crittall (18871956). Essex: Essex County Council.

Census and Statistics Office. (1921). Results of a Census of the Dominion of New Zealand, taken for the night of the 17th April 1921. Part XV. Dwellings. Wellington: New Zealand Government. Located at the National Library of New Zealand, Wellington.

Chiras, D. (2000). The natural house: A complete guide to healthy, energy-efficient, environmental homes. White River Junction: Chelsea Green.

Clark, C. (1962). Memorandum from C. Clark, Chief Civil Engineer, to the General Manager, New Zealand Government Railways, 30th March 1962. Wellington: New Zealand Government. Located at Archives New Zealand, Wellington Office, in file "Alterations and Improvements to Railway Houses " [1914-1966], Archives Reference No. AAEB W3199 Box 238, Record No. 14/2043, accessed on 20th September 2012.

Clarke, K. V. (1980). Memorandum for the Town Clerk, Report to the Historic Places SubCommittee, Railway Housing Settlement, Tarikaka Street, 18th July 1980. Wellington: City Planner, Wellington City Council. Located at Wellington City Archives, in file ref. 00277:327:28/6/72, Tarikaka Street, New Zealand Railways (NZR) Houses, accessed on 24th April 2012.

Clarke, K. V. (1988). Report to Town Planning Committee, Railway Houses in Tarikaka, Ngata and Pomare Streets, 27th June 1988. Wellington: City Planner, Town Planning Department.

Clarke, K. V. (1989). Report for Housing and Urban Renewal and Community Services Committee, 2nd March 1989. Wellington: City Planner, Town Planning Department.

Cleaver, P., \& Sarich, J. (2009). Turongo: The North Island Main Trunk Railway and the Rohe Potae, 1870-2008. A Report Commissioned by the Waitangi Tribunal for the Te Rohe Potae district Enquiry (Wai 898), November 2009.

Cleveland, C. J., \& Morris, C. (Eds.). (2009). Dictionary of Energy (1st Edition ed.): Elsevier Science.

Coates, J. G. (1923). Railways Statement by the Minister of Railways, Hon. J. G. Coates. Appendix to the Journals of the House of Representatives, 1923 Session I-II, D-02. Accessed from AJHR Online on 28th February 2013.

Coates, J. G. (1924). Railways Statement by the Minister of Railways, Hon. J. G. Coates. Appendix to the Journals of the House of Representatives, 1924 Session I, D-02. Accessed from AJHR Online on 28th February 2013. 
Cochran, C., \& Murray, R. (2010). Tarikaka Street Settlement Heritage Area Design Guide. Wellington: Wellington City Council.

Commission for Architecture and the Built Environment. (2005). What it's like to live there: the views of residents on the design of new housing. London: Commission for Architecture and the Built Environment Retrieved from www.webarchive.nationalarchives.gov.uk/20110118095356/http://www.cabe.org.uk/ files/what-its-like-to-live-there.pdf.

Construction Industry Research and Information Association (CIRIA). (1995). Environmental Impact of Materials: Volume A/Summary. London: CIRIA.

Crittall, F. H. (1934). Fifty Years of Work and Play. London: Constable \& Co. Limited.

Crittall Magazine. (1926). The Silver End Ceremony. Crittall Manufacturing Company, The Crittall Magazine, Volume 2, Number 5, June 1926, p. 104.

Crittall Magazine. (1928). Silver End, 1928. Crittall Manufactuing Company, The Crittall Magazine, Volume 4, Number 6, June 1928, p. 130.

Crocombe, A. (2007). A lighter footprint: a practical guide to minimising your impact on the planet. Carlton North: Scribe Publications.

Cwerner, S., \& Metcalfe, A. (2003). Storage and Clutter: Discourses and Practices of Order in the Domestic World Journal of Design History, 16(3).

Daniels, J. R. S. (1986). Letter to the Chief Planner, Town Planning Department from the Director of the New Zealand Historic Places Trust, 7th March 1986. Wellington: New Zealand Historic Places Trust. Located at Wellington City Archives, in file ref. 00277:327:28/6/72, Tarikaka Street, New Zealand Railways (NZR) Houses, accessed on 24th April 2012.

Defra. (2012). Food Statistics Pocketbook 2012. UK Government Retrieved from http://webarchive.nationalarchives.gov.uk/20130123162956/http:/www.defra.gov.uk Lstatistics/files/defra-stats-foodfarm-food-pocketbook-2012-130104.pdf.

Department for Communitites and Local Government. (2014). Improving the energy efficiency of buildings and using planning to protect the environment. Retrieved 3rd August, 2014, from https://www.gov.uk/government/policies/improving-the-energyefficiency-of-buildings-and-using-planning-to-protect-the-environment/supportingpages/code-for-sustainable-homes

Department of Building and Housing (DBH). (2011). Compliance Document for New Zealand Building Code Clause H1 Energy Efficiency. Third Edition. Retrieved 16th December, 2014, from www.dbh.govt.nz/UserFiles/File/Publications/Building/Compliancedocuments/H1-energy-efficiency-3rd-edition-amendment-2.pdf

Department of Communities and Local Government. (2010). English Housing Survey Housing Stock Report 2008. United Kingdom Government Retrieved from www.gov.uk/government/uploads/system/uploads/attachment data/file/6703/17507 54.pdf. 
Department of Energy \& Climate Change. (2013). Domestic Energy Consumption in the UK between 1970 and 2012. Retrieved 9th June 2014, from www.gov.uk/government/collections/energy-consumption-in-the-uk

Director of Parks and Recreation. (1983). Memorandum to City Planner, Railway Housing: Tarikaka Street, 28th November 1983. Wellington: Wellington City Council. Located at Wellington City Archives, in file ref. 00001:1375:36/164 Pt 1, Subdivision (original): 727 Bombay Street (extension), Carroll Street, 8-40 Khandallah Road, Ngata Street (all), Pomare Street (all) and Tarikaka Street (all), A Aplin, New Zealand Railways, Ngaio Railways and Housing Development, accessed on 27th April 2012.

Dixit, M., Fernandez-Soliz, J., Lavy, S., \& Culp, C. (2010). Identification of parameters for embodied energy measurement: A literature review. Energy and Buildings, 42(8), 1238-1247.

Dudding, M. (2008). Abstracting oral histories (a how-to guide) [electronic resource]. Retrieved from http://www.oralhistory.org.nz/documents/duddingabstractingguide2008.pdf

Dyer, P. (2010). The Great Railway House Bazaar. North and South, Issue Number 297, 1st December 2010.

EECA. (2009). Make Your Home Warmer and Healthier. Retrieved 9th June 2014, from www.energywise.govt.nz/sites/all/files/action-sheet-2-warm-healthy-home-10-09.pdf

EECA. (2014). Funding Available. Retrieved 9th June 2014, from www.energywise.govt.nz/funding-available

Energy Saving Trust. (2011). Cut your energy costs: A homeowner's guide to energy performance improvements refurbishing living spaces. Retrieved 2014, from http://www.energysavingtrust.org.uk/Publications2/Housingprofessionals/Refurbishment/Refurbishing-living-spaces-homeowner

Energy Saving Trust. (2013). Windows. Retrieved 22nd July, 2013, from www.energysavingtrust.org.uk/Insulation/Windows.

English Heritage. (2010). Energy Efficiency and Historic Buildings: Secondary Glazing for Windows. English Heritage. Retrieved from www.english-heritage.org.uk on 22nd July 2013.

English Heritage. (2013a). Listed Buildings. English Heritage. Retrieved from www.englishheritage.org.uk/caring/listing/listed-buildings/ on 10th July 2013.

English Heritage. (2013b). The National Heritage List for England. English Heritage. Retrieved from www.english-heritage.org.uk/professional/protection/process/national-heritagelist-for-england/ on 10th July 2013.

Evans, L. (1989). Post occupancy evaluation case study: Married quarters housing at ADFA. In B. Judd \& P. Bycroft (Eds.), Evaluating housing standards and performance. Red Hill, ACT: RAIA National Education Division. 
Evening Post. (1905). The Housing Problem, through a Health Officer's eyes, some recommendations. Evening Post, 23rd September 1905, p. 5.

Evening Post. (1906). Workers' Homes. Evening Post, 3rd October 1906, Volume LXXII, Issue 81, p. 2.

Evening Post. (1920). Housing Railwaymen, Real Progress made, North Island Programme, Town Planning in Practice. Evening Post, 4th November 1920, p. 5.

Evening Post. (1927). Railway Houses, New Workers'Scheme, Settlement at Ngaio, 20-acre purchase. Evening Post, 21st June 1927, p. 10.

Fanning, J. (1986). Letter to the Chairman of the Town Planning Committee from the Ngaio Progressive Association, 28th March 1986. Wellington: The Ngaio Progressive Association.

Federal Facilities Council. (2001). Learning from our buildings: A state-of-the-practice summary of post-occupancy evaluation. Washington DC: National Academy Press.

Ferguson, G. (1994). Building the New Zealand dream. Palmerston North: The Dunmore Press Limited.

Ferguson, W. (1919). Memorandum for C. J. Drake, Esq., Secretary, Board of Health, Wellington, 24th March 1919. Wellington: New Zealand Government. Located at Archives New Zealand, Wellington Office, in file "Sanitation - Housing Question" [19181935], Archives Reference No. H1 Box 1981, Record No. 177/2, accessed on 16th February 2012.

Ferguson, W., Elliott, J. S., \& Newton, G. P. (1919). Board of Health, Report of the Committee on Housing, 10th July 1919. Wellington: New Zealand Government. Located at Archives New Zealand, Wellington Office, in file "Sanitation - Housing Question" [19181935], Archives Reference No. H1 Box 1981, Record No. 177/2, accessed on 16th February 2012.

Field, C. (2011). The ecological footprint of Wellingtonians in the 1950s. (Masters of Building Science), Victoria University of Wellington, Wellington.

Forty, A. (1986). Objects of desire: Design and society, 1750-1980. London: Thames and Hudson.

Fraser, M. (1919). Table showing for all Private Houses and Tenements in each Metropolitan Area the Number of Persons to a Room at the Census of October, 1916. Census \& Statistics Office, Wellington, 19th February 1919. Wellington: New Zealand Government. Located at Archives New Zealand, Wellington Office, in file "Sanitation Housing Question" [1918-1935], Archives Reference No. H1 Box 1981, Record No. 177/2, accessed on 16th February 2012.

Gram-Hanssen, K. (2010). Residential heat comfort practices: Understanding users. Building Research \& Information 38(2). 
Grand Designs. (2014). Great British Refurb Campaign. Retrieved 9th June 2014, from www.greatbritishrefurb.co.uk

Greater Wellington Regional Council. (2014). Composting cuts rubbish by 45\%. Retrieved 12th June, 2014, from www.gw.govt.nz/composting-cuts-rubbish-by-4/

Gunn, E. (1932). Economy in house design. London: The Architectural Press Ltd.

Hammond, G., \& Jones, C. (2008). Inventory of Carbon and Energy (ICE), Version 1.6a, Sustainable Energy Research Team (SERT). Bath: Department of Mechanical Engineering, University of Bath.

Harding, L. S., [Director]. (1983). Letter to the Town Clerk. Wellington: New Zealand Railways. Located at Wellington City Archives, in file ref. 00001:1375:36/164 Pt 1, Subdivision (original): 7-27 Bombay Street (extension), Carroll Street, 8-40 Khandallah Road, Ngata Street (all), Pomare Street (all) and Tarikaka Street (all), A Aplin, New Zealand Railways, Ngaio Railways and Housing Development, accessed on 27th April 2012.

Henretty, N. (2013). Household Energy Consumption in England and Wales, 2005-11. London: Office for National Statistics.

Heritage New Zealand. (2014). Search the List. Retrieved 3rd August, 2014, from http://www.heritage.org.nz/the-list

HM Government. (2010). Conservation of Fuel and Power Approved Document L1A. 2013 Edition. Retrieved 16th December, 2014, from www.planningportal.gov.uk/uploads/br/BR PDF AD L1A 2013.pdf

Humble, N. (Ed.). (2000). Mrs Beeton's book of household management. New York: Oxford University Press.

Hume, L. (1989). Memorandum to Derek Fry, Parks and Recreation Department, Tarikaka Street, Ngaio, Community Improvement Area, 11th October 1989. Wellington: Renovation Advice Office. Located at Wellington City Archives, in file ref. 000444:110:4/57/18 Pt 1, Ngaio Community Improvement Area, Tarikaka Street Railway Settlement, accessed on 24th April 2012.

Humphris, A., \& Mew, G. (2009). Ring around the city: Wellington's new suburbs, 1900-1930. Wellington: Steele Roberts Publishers.

Institution of Civil Engineers (ICE). (2014). Energy Briefing Sheet: Embodied Energy and Carbon. Retrieved 14th December, 2014, from www.ice.org.uk/Informationresources/Document-Library/Energy-Briefing-Sheet---Embodied-Energy

Isaacs, N., (Ed.), Camilleri, M., French, L., Pollard, A., Saville-Smith, K., Fraser, R., . . Jowett, J. (2010). Energy use in New Zealand households: Final report on the Household Energy End-use Project (HEEP), BRANZ study report 221. Judgeford, NZ: BRANZ Ltd.

Jackson, A. (1973). Semi-detached London; suburban development, life and transport, 1900-39. London: Allen \& Unwin. 
Jensen, F. (2012). Modernist Semis and Terraces in England. Surrey: Ashgate Publishing Limited.

Jeremiah, D. (2000). Architecture and design for the family in Britain, 1900-70. Manchester: Manchester University Press.

Judd, B., \& Bycroft, P. (Eds.). (1989). Evaluating housing standards and performance. Red Hill, ACT: RAIA National Education Division.

Khatib, J. (Ed.). (2009). Sustainability of Construction Materials. Cambridge: Woodhead Publishing Limited.

Koones, S. (2014). Prefabulous world: energy-efficient and sustainable homes around the globe. New York: Abrams.

Lawton, E. (2013). Footprinting New Zealand urban form and lifestyles. (PhD in Architecture), Victoria University of Wellington, Wellington. Unpublished, submitted for examination in January 2013.

Lewis, J. (1986). Labour and love: Women's experience of home and family 1850-1940. Oxford: Basil Blackwell Ltd.

Lewis, P. (2011). House: British domestic architecture. Munich and New York: Prestel.

Mackay, C. (2011). A century of adaption: A study of alteration patterns in sixteen timber villas in Wellington, New Zealand. School of Architecture. Victoria University of Wellington. Wellington.

Mass Observation. (1943). An Enquiry into People's Homes. London: Advertising Service Guild.

May, H. (1992). Minding children, managing men: Conflict and compromise in the lives of postwar pakeha women. Wellington, NZ: Bridget Williams Books.

McArthur, J. (1986a). Qualified support for Tarikaka Street. The Independent Herald, 3rd March 1986.

McArthur, J. (1986b). Tarikaka Street could be tourist attraction. The Independent Herald, 27th January 1986.

McCarthy, C., \& Dudding, M. (2008, 3rd-6th November 2008). Happy delirium and irrational urges: The heritage values of preservationists, modernists and home owners. Paper presented at the Responsibilities \& Opportunities in Architectural Conservation: Theory, Education, and Practice Petra University, Amman, Jordon.

McCutcheon, I. A. (1983). Memorandum to the District Engineer, New Zealand Railways on 9th December 1983. Wellington: Wellington City Council. Located at Wellington City Archives, in file ref. 00001:1375:36/164 Pt 1, Subdivision (original): 7-27 Bombay Street (extension), Carroll Street, 8-40 Khandallah Road, Ngata Street (all), Pomare Street (all) and Tarikaka Street (all), A Aplin, New Zealand Railways, Ngaio Railways and Housing Development, accessed on 27th April 2012. 
McQueen, A. E. (1986). Letter to City Planner, Wellington City Corporation from Assistant General Manager, New Zealand Railways, 21st April 1986. Wellington: General Manager's Office, New Zealand Railways.

Miller, J. (1929). Silver End Garden Village, Non-Parlour House B Type. James Miller A.R.S.A. Architect, 15 Blythswood Square, Glasgow, 21st February 1929. Located at Braintree District Council Planning Department.

Ministry for the Environment. (2013). Resource Efficiency. Retrieved 9th June 2014, from www.mfe.govt.nz/issues/resource-efficiency

Ministry of Business Innovation and Employment (MBIE). (2007). Building Controls Update No.

67. Retrieved 14th December, 2014, from www.dbh.govt.nz/bcupdate-article-67

Ministry of Housing and Local Government. (1963). Space in the Home. Her Majesty's Stationery Office.

Mithraratne, N., Vale, B., \& Vale, R. (2007). Sustainable living: The role of whole life costs and values. Oxford: Butterworth-Heinemann.

Mobbs, M. (2010). Sustainable house (2nd ed.). Sydney: UNSW.

Moroney, V. J. (2004). Life in the Ngaio Railway Settlement 1930-1940. The Onslow Historian, Official Journal of the Onslow Historial Society Inc., Volume 34 Nos 1 \& 2, 2004.

Muthesius, S. (1982). The English terraced house. New Haven and London: Yale University Press.

New Zealand Government. (1905). Workers' Dwellings Act, 30th October 1905. 5 EDW. VII. 1905, No.42, pp. 439-443. New Zealand Government. Retrieved from http://www.nzlii.org/ on 13th December 2011.

Numbeo. (2014). Cost of Living Comparison Between Chelmsford and Wellington. Retrieved 3rd August, 2014, from http://www.numbeo.com/cost-ofliving/compare cities.jsp?country1=United+Kingdom\&country2=New+Zealand\&city1= Chelmsford\&city2=Wellington

O'Connell, S. (1995). The Social and Cultural Impact of the Car in Interwar Britain. (PhD), University of Warwick. Retrieved from http://wrap.warwick.ac.uk/36384/1/WRAP THESIS O'Connell 1995.pdf

Office for National Statistics. (2013). 2011 Census, Population and Household Estimates for the United Kingdom, March 2011. Retrieved 21st July, 2013, from www.ons.gov/uk/ons/rel/census/2011-census.

Overy, P. (2007). Light, air and openness: modern Architecture between the wars. London: Thames \& Hudson.

Oxford English Dictionary. "house, n.1": Oxford University Press.

Oxford English Dictionary. "hybrid, n. and adj.": Oxford University Press. 
Oxford English Dictionary. "malleable, adj.": Oxford University Press.

Oxford English Dictionary. "'working 'class, n.": Oxford University Press.

Page, I. (2012). Housing - then and now. Retrieved 3rd August, 2014, from http://www.buildmagazine.org.nz/articles/show/housing-then-and-now/

Page, I., \& Ryan, V. (2010). It Takes All Types - A Typology of New Zealand Housing Stock. Retrieved 26th January, 2015, from www.branz.co.nz/cms show download.php?id=753d59ddda364f574508eb6f11bd18d $\underline{0 \mathrm{c} 3 \mathrm{ffc} 5 \mathrm{~b} 5}$

Paul, J. T., [Chairman]. (1919). The Report of the Committee of the Town Planning Conference appointed to deal with The Housing Problem, 23rd May 1919. Wellington: New Zealand Government. Located at the National Library of New Zealand, Wellington, in AJHR 1919, Vol. II [F-I], H22-A Town Planning Conference, 1919. [Reports of Committees].

Pennington, S., \& Westover, B. (1989). A hidden workforce: Homeworkers in England, 18501985. Basingstoke: Macmillan Education.

Perkins, H., \& Thorns, D. (1999). House and Home and their Interaction with Changes in New Zealand's Urban System, Households and Family Structures. Housing, Theory and Society(16), 124-135.

Planning Portal. (2014a). Energy Saving. Retrieved 9th June 2014, from www.planningportal.gov.uk/planning/greenerhomes/energysaving

Planning Portal. (2014b). Greener Buildings. Retrieved 9th June 2014, from www.planningportal.gov.uk/buildingregulations/greenerbuildings

Platts-Mills, D. E., [Chairwoman], Crawford, A. D., \& Watt, P. C. (1920). Emergency Report on Housing by the Women's Committee of the Town Planning Association. Wellington: New Zealand Government. Located at Archives New Zealand, Wellington Office, in file "Railway Departments House Building Programme" [1895-1921], Archives Reference No. R3W2278 232, Record No. 1911/1981/1, accessed on 27th February 2012.

Preiser, W., Rabinowitz, H., \& White, E. (1988). Post-occupancy evaluation. New York: Van Nostrand Reinhold.

Quotable Value. (2011). Average house size by age. Retrieved 28th July, 2014, from http://www.qv.co.nz/resources/news/article?blogld=62

Ravetz, A., \& Turkington, R. (1995). The place of home: English domestic environments, 19142000. London: E \& FN Spon, an imprint of Chapman \& Hall.

Renovation Advice Office. (1990). Works Operations Committee, 5th February 1990. Wellington: Wellington City Council. Located at Wellington City Archives, in file ref. 000444:110:4/57/18 Pt 1, Ngaio Community Improvement Area, Tarikaka Street Railway Settlement, accessed on 24th April 2012. 
Rightmove. (2014). House Prices in Silver End, Witham, Essex, last updated on 30 June 2014. Retrieved 28th July, 2014, from http://www.rightmove.co.uk/house-prices/SilverEnd.html

Roaf, S., Fuentes, M., \& Thomas, S. (2001). Ecohouse: A design guide. Boston: MA: Architectural Press.

Roberts-Hughes, R. (2011). The Case for Space: the size of England's new homes. Retrieved 28th July, 2014, from http://www.architecture.com/Files/RIBAHoldings/PolicyAndInternationalRelations/Ho $\underline{\text { meWise/CaseforSpace.pdf }}$

Roberts, E. (1984). A woman's place: An oral history of working-class women, 1890-1940. Oxford [Oxfordshire] and New York: B. Blackwell.

Rosenfeld, M. (1956). The New Zealand House. Auckland: House Design Publications.

Salmond, J. (1986). Old New Zealand houses, 1800-1940. Auckland: Reed Methuen.

Schrader, B. (2005). We call it home: A history of state housing in New Zealand. Auckland: Reed.

Schrader, B. (2014). Housing - Interior planning and living. Retrieved 28th July, 2014, from www.TeAra.govt.nz/en/interactive/38650/housing-floor-plans

Simons, G. E. (1986). Tarikaka Street Ngaio Railway Settlement, Preservation and Restoration Scheme. Wellington.

Sir John Burnet and Partners Architects. (1927). Silver End Garden Village Essex, Cowmans' and Pigmans' Cottages. Sir John Burnet and Partners Architects, Drawing Number 3/5/1, Date 3.5.27. Located at Braintree District Council Planning Department.

Smith, P. F. (2004). Eco-refurbishment: A practical guide to creating an energy efficient home. Oxford: Architectural Press.

Smithers, R. (2013). Daily showers account for biggest water use in UK homes. Retrieved 2014, 28th July, from http://www.theguardian.com/environment/2013/jul/04/dailyshowers-water-use-uk-homes

Society for Research on Women in New Zealand. (1982). In Those Days: A Study of Older Women in Wellington. Wellington: Wellington Branch, Society for Research on Women in New Zealand.

Stang, A., \& Hawthorne, C. (2005). The green house: New directions in sustainable architecture (1st ed.). New York: Princeton Architectural Press, Washington, D.C. National Building Museum.

Statistics New Zealand. (1998). New Zealand Now: Housing. Wellington.

Stevenson, F., \& Leaman, A. (2010). Evaluating housing performance in relation to human behaviour: New challenges. Building Research \& Information, 38(5). 
Stevenson, F., \& Rijal, H. (2010). Developing occupancy feedback from a prototype to improve housing production. Building Research \& Information 38(5).

Strategy and Policy Committee. (2012). Report 2 (1215/52/IM) Heritage Grants, 7th June 2012. Strategy and Policy Committee, Wellington City Council.

Stuart, I. (2010). 150 Years of Fish and Chips, New Zealand Herald. Retrieved from www.nzherald.co.nz/lifestyle/news/article.cfm?c id=6\&objectid=10685334

Stuart, J. (1928). Silver End Garden Village Essex, Parlour Houses Type 1A to be erected in Silver Street. Building Department, Silver End, June 1928. Located at Braintree District Council Planning Department.

Te Whare, B. (1986). Leave our Ngaio railway houses alone. The Independent Herald, 24th February 1986.

The British Library Board. (2014). Learning Food Stories: Retail Experience. Retrieved 2nd August, 2014, from http://www.bl.uk/learning/citizenship/foodstories/Accessible/retailingexperience/reta ilexperienceintro.html

Thomas, L. (2009). The energy we use in New Zealand homes. Wellington: Royal Society of New Zealand.

Thormark, C. (2006). The effect of material choice on the total energy need and recycling potential of a building. Building and Environment, 41(8), 1019-1026.

Thorne, R., \& Canter, D. (1970). Attitudes to housing; a cross cultural comparison. Sydney: Architectural Research Foundation, Department of Architecture, University of Sydney.

Tippett, H., \& Runeson, G. (1985). Research Paper 85/1: Quality evaluation of residential buildings. Wellington: National Housing Commission.

Toynbee, C. (1995). Her work and his: Family, kin and community in New Zealand 1900-1930. Wellington, NZ: Victoria University Press.

Tran, T. (2014). Sustainable patterns of living based on an investigation of footprint in HanoiVietnam, Wellington-New Zealand and Oulu-Finland. PhD Thesis., Victoria University of Wellington.

Truebridge Callender Beach Limited. (1985). Letter to the Town Clerk, Proposed Subdivision of PT Section 6 Kaiwarra Dist. being PT Plan B/148 - Tarikaka Street, New Zealand Railways, 3rd October 1985. Wellington: Truebridge Callender Beach Limited. Located at Wellington City Archives, in file ref. 00001:1375:36/164 Pt 1, Subdivision (original): 7-27 Bombay Street (extension), Carroll Street, 8-40 Khandallah Road, Ngata Street (all), Pomare Street (all) and Tarikaka Street (all), A Aplin, New Zealand Railways, Ngaio Railways and Housing Development, accessed on 27th April 2012.

Uffelen, C. V. (2012). Passive Houses: Energy Efficient Homes. London: Braun Publishing. 
United Kingdom Government. (1980). Housing Act 1980. United Kingdom Government. Retrieved from www.legislation.gov.uk/ukpga/1980/51 on 18th July 2013.

Unknown. (1986). Photograph of Tarikaka Settlement. Wellington City Council. Located at Wellington City Archives, in file ref. 00277:327:28/6/72, Tarikaka Street, New Zealand Railways (NZR) Houses.

Unknown, [Architectural Branch]. (1927a). Letter to the Town Clerk from the Officer in Charge of the Architectural Branch, New Zealand Government Railways. Wellington: New Zealand Government Railways. Located at Wellington City Archives, in file ref. 00001:1375:36/164 Pt 1, Subdivision (original): 7-27 Bombay Street (extension), Carroll Street, 8-40 Khandallah Road, Ngata Street (all), Pomare Street (all) and Tarikaka Street (all), A Aplin, New Zealand Railways, Ngaio Railways and Housing Development, accessed on 27th April 2012.

Unknown, [Architectural Branch]. (1927b). Plan of Housing Scheme for Railway Department, Ngaio, A.B. 1089, c.1927. Wellington: New Zealand Government Railways. Located at Wellington City Archives, in file ref. 00001:1375:36/164 Pt 1, Subdivision (original): 727 Bombay Street (extension), Carroll Street, 8-40 Khandallah Road, Ngata Street (all), Pomare Street (all) and Tarikaka Street (all), A Aplin, New Zealand Railways, Ngaio Railways and Housing Development, viewed on 27th April 2012.

Unknown, [Architectural Branch]. (1929). Record of the handover of houses at Ngaio from the Architectural Branch to the District Engineer, 19th February 1929. Wellington: New Zealand Government. Located at Archives New Zealand, Wellington Office, in file "Houses built by the Architectural Branch" [1927-1936], Archives Reference No. R-W3 37, Record No. 11328, accessed on 28th September 2012.

Unknown, [Board of Health]. (1919). Board of Health Report on Housing, 8th August 1919. Wellington: New Zealand Government. Located at Archives New Zealand, Wellington Office, in file "Sanitation - Housing Question" [1918-1935], Archives Reference No. H1 Box 1981, Record No. 177/2, accessed on 16th February 2012.

Unknown, [Chief Engineer's Office]. (1895). Memorandum for the General Manager from Chief Engineer's Office, Working Railways Department, Wellington, 20th June 1895, Accommodation for Station Masters etc. Wellington: New Zealand Government. Located at Archives New Zealand, Wellington Office, in file "Railway Department's House Building Programme" [1895-1921], Archives Reference No. R3W2278 232, Record No. 1911/1981/1, accessed on 27th February 2012.

Unknown, [N.Z.R. Architectural Branch]. (Unknown). Standard House, Plan AB/1123. Factory Cut. Plan Book. Wellington.

Unknown, [New Zealand Building Progress]. (1920). Railway Department's Housing Schemes. New Zealand Building Progress, pp. 77-82. Located at Archives New Zealand, Wellington Office, in file "Railway Department's House Building Programme" [18951921], Archives Reference No. R1893W2278 1232, Record No. 1911/1981/1891, accessed on 1827th February 2012.

Utley, J., \& Shorrock, L. (2012). Ninety years of housing, 1921-2011: Trends relating to living standards, energy use and carbon emissions. BRE Press. 
Vale, B., \& Vale, R. (2010). Domestic energy use, lifestyles and POE: Past lessons for current problems. Building Research \& Information 38(5).

Vale, B., \& Vale, R. (Eds.). (2013). The Hockerton housing project, England. London: Earthscan.

Vale, R., \& Vale, B. (2009). Time to eat the dog : the real guide to sustainable living. London: Thames \& Hudson.

Wackernagel, M., \& Rees, W. (1996). Our ecological footprint: Reducing human impact on the earth. Gabriola Island, BC; Philadelphia, PA New Society Publishers.

Wallop, H. (2009). Back to the Good Life: thousands take up chicken ownership. Retrieved 28th July, 2014, from http://www.telegraph.co.uk/foodanddrink/foodanddrinknews/5406430/Back-to-theGood-Life-thousands-take-up-chicken-ownership.html

Watkins, J. T. (1919). Memorandum for C. J. Drake, Esq., Secretary, Board of Health, Wellington, 28th March 1919. Wellington: New Zealand Government. Located at Archives New Zealand, Wellington Office, in file "Sanitation - Housing Question" [19181935], Archives Reference No. H1 Box 1981, Record No. 177/2, accessed on 16th February 2012.

Wellington City Council. (2013). Chapter 21 Heritage Rules, Wellington City District Plan. Wellington: Wellington City Council. Retrieved from http://wellington.govt.nz/ /media/your-council/plans-policies-and-bylaws/districtplan/volume01/files/v1chap21.pdf on 1st August 2013.

Wellington City Council. (2014a). Housing Upgrade Background. Retrieved 9th June 2014, from www.wellington.govt.nz/services/community-and-culture/housing/housingupgrade/background

Wellington City Council. (2014b). Towards 2040: Smart Capital. Retrieved 9th June 2014, from www.wellington.govt.nz/your-council/structure-and-vision/vision-2040/towards-2040smart-capital

West, J., Atkinson, C., \& Howard, N. (1994). Embodied Energy and Carbon Dioxide Emissions for Building Materials. Paper presented at the First International Conference on Buildings and the Environment, Watford.

Wilkinson, C. A., [Chairman]. (1919). New Zealand Industries Committee (Report of the), 27th August 1919. Wellington: New Zealand Government. Located at Archives New Zealand, Wellington Office, in file "16 January 1919 - Minister of Agriculture - Enquiry by House of Representatives Industries Committee regarding establishment of new Industries [Organisation of Department]" [1918-1920], Archives Reference No. AAFZ W5703 412 Box 2, Record No. Ag. 11/221/26, accessed on 7th February 2012.

WWF Cymru, \& Stockholm Environment Institute. (2005). Reducing Cardiff's Ecological Footprint: a resource accounting tool for sustainable consumption. WWF Cymru. 
Page 332 of $\mathbf{3 3 2}$ 